\title{
The impact of changes in financial reporting regulation on financial accounting method choice
}

Citation for published version (APA):

Mertens, G. M. H. (1997). The impact of changes in financial reporting regulation on financial accounting method choice. [Doctoral Thesis, Maastricht University]. Universiteit Maastricht. https://doi.org/10.26481/dis.19970306gm

Document status and date:

Published: 01/01/1997

DOI:

10.26481/dis.19970306gm

Document Version:

Publisher's PDF, also known as Version of record

\section{Please check the document version of this publication:}

- A submitted manuscript is the version of the article upon submission and before peer-review. There can be important differences between the submitted version and the official published version of record.

People interested in the research are advised to contact the author for the final version of the publication, or visit the DOI to the publisher's website.

- The final author version and the galley proof are versions of the publication after peer review.

- The final published version features the final layout of the paper including the volume, issue and page numbers.

Link to publication

\footnotetext{
General rights rights.

- You may freely distribute the URL identifying the publication in the public portal. please follow below link for the End User Agreement:

www.umlib.nl/taverne-license

Take down policy

If you believe that this document breaches copyright please contact us at:

repository@maastrichtuniversity.nl

providing details and we will investigate your claim.
}

Copyright and moral rights for the publications made accessible in the public portal are retained by the authors and/or other copyright owners and it is a condition of accessing publications that users recognise and abide by the legal requirements associated with these

- Users may download and print one copy of any publication from the public portal for the purpose of private study or research.

- You may not further distribute the material or use it for any profit-making activity or commercial gain

If the publication is distributed under the terms of Article $25 \mathrm{fa}$ of the Dutch Copyright Act, indicated by the "Taverne" license above, 


\title{
The Impact of Changes in
}

\section{Financial Reporting Regulation on}

\author{
Financial Accounting Method Choice
}





\section{The Impact of Changes in}

\section{Financial Reporting Regulation on}

\section{Financial Accounting Method Choice}

\section{PROEFSCHRIFT}

ter verkrijging van de graad van doctor aan de Universiteit Maastricht, op gezag van de Rector Magnificus, Prof. Mr. M.J. Cohen, volgens het besluit van het College van Decanen, in het openbaar te verdedigen op donderdag 6 maart 1997 om 16.00 uur

door

Gerardus Maria Hubertus Mertens 


\section{Promotor:}

Prof. dr. W.F.J. Buijink

Beoordelingscommissie:

Prof. dr. S.J. Maijoor (voorzitter)

Prof. dr. J.Gr. Backhaus

Prof. H.L. Brink RA

Prof. dr. M.N. Hoogendoorn RA (Universiteit van Amsterdam) 


\section{Acknowledgements}

This book is concerned with the impact of financial accounting regulation on financial reporting practice. The research of this dissertation was performed at the accounting department of the faculty of economics, Maastricht University. Here I would like to express great appreciation to the many people that contributed to vital discussions, criticisms, and moral support which were inevitable for finishing this study.

The initiators of my academic career, Jan van de Poel and Willem Buijink, guided me in my first steps into the area of financial accounting as a Ph.D student. I owe a lot to Willem, who taught me the ins and outs of (positive) financial accounting research and helped me to improve my skills and attitude as a researcher.

I would like to thank Jürgen Backhaus, Henk Brink, Martin Hoogendoorn and Steven Maijoor for judging the final version of the manuscript and for providing useful comments. Editorial comments by Sen McGlinn are also acknowledged.

This dissertation is based on several datasets. I would like to thank Frits Bonger and Jan Daamen of the Central Bureau of Statistics in Heerlen in obtaining the financial information necessary for one of the datasets. Further thanks go to Martin Hoogendoorn who provided his dataset on accounting changes, as well as Ms. A. Stichova and Dr. J. Brezet of the Economic Historical Archives of the Erasmus University Rotterdam.

I want to thank my former Maastricht University colleagues Bram Beek, Roger Dassen, Tom Groot, Marc Gulikers, Gunter Lemmen, Roger Meuwissen, Luc Quadackers, Ton van Reeken, Markus Schaen, Arnold Schilder and Eddy Vaassen, Frans Volmer, Sonja Passau, Els van Aernsbergen, Ilse Gronenschild and Miranda van den Boorn for creating a very pleasant working atmosphere. Thanks also to all my new colleagues at Tilburg University and the Limperg Institute, whom I have enjoyed working with since 1996 and hope to continue to do so.

I am especially grateful to Laury Bollen, Frank Hartmann, Jos and Tjeu Blommaert, and Stephen Zeff (Rice University) who provided valuable assistence and commented in detail on the present version of the dissertation. Last but certainly not least I thank Harold Hassink for being my (accruals) partner in crime and providing me with many useful comments until the finish. We shared many things: a common research method as well as the problems related thereto, one office, very good discussions about research and 'other things', but most important many good times.

Most of all, I want to thank those who contributed in a way not directly related to the contents of this dissertation, especially my parents, Maud, family and friends.

Gerard Mertens

January 1997, Stevensweert. 
Chapter I

Financial accounting method choice and financial reporting regulation $\ldots \ldots \ldots \ldots \ldots \ldots \ldots \ldots \ldots$

1.1 Introduction . . . . . . . . . . . . . . . . . . . .

1.2 Voluntary financial reporting: economic theory ........... 4

1.2.1 Non-regulated public disclosure of financial statements . . . . . . . . 4

1.2.2 Non-regulated choice of financial accounting methods . . . . . . . 6

1.3 The effect of government financial reporting regulation on financial accounting methods $\ldots \ldots \ldots \ldots \ldots \ldots \ldots \ldots$

1.4 The motivation of this dissertation $\ldots \ldots \ldots \ldots \ldots \ldots \ldots \ldots$

1.5 Outline ........................... 17

Chapter 2

The effects of two major financial reporting regulation changes in the Netherlands on accounting method choice:

description and development of hypotheses $\ldots \ldots \ldots \ldots \ldots \ldots$ I 8

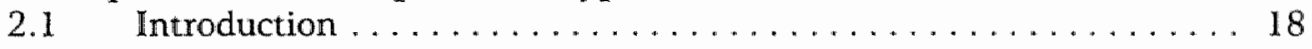

2.2 Analyses of the contents of two major Acts: WJO and Title $8 \ldots \ldots 20$

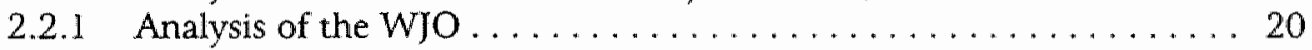

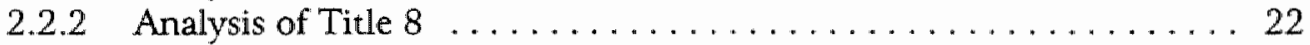

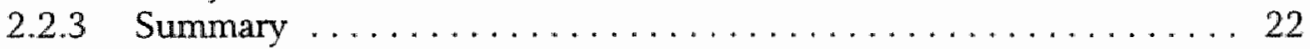

2.3 Development of the research questions . . . . . . . . . . 23

2.3.1 Observation of the changes in the frequency of item disclosure . . . . 23

2.3.2 Observation of changes in accounting policy (accounting method changes) . . . . . . . . . . . . . 24

2.3.2.1 Additional explanatory variables of financial accounting method choice: size, leverage, and industry effects . . . . . . . . 28

2.3 .2 .2 Size . . . . . . . . . . . . . . . . . . . . . 30

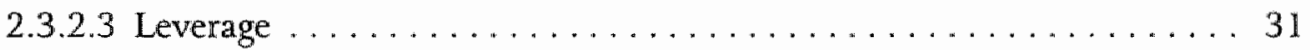

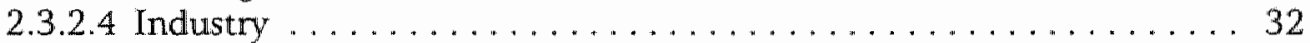

2.3.3 Observation of changes in accounting accruals ........... 32

2.3.3.1 Additional explanatory variables of financial accounting method choice: size, leverage, and industry effects . . . . . . . . 38

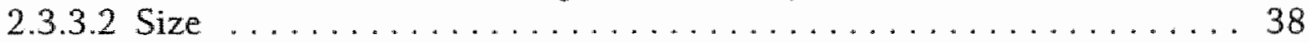

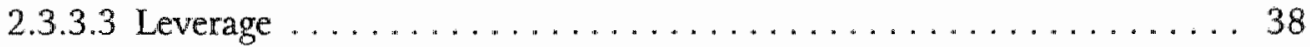

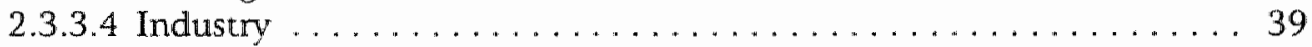

$2.4 \quad$ Data . . . . . . . . . . . . . . . . . . . . . 39

2.4.1 Method I: Accounting method changes . . . . . . . . . . . 40

2.4.2 Method II: Accounting accruals . . . . . . . . . . . . . . 40

2.5 Summary ........................... 41 
Wiii

Chapter 3

Empirical evidence on the effects of the implementation of the WJO in 1971 and Title 8 in 1984 :

an analysis of accounting method changes $\ldots \ldots \ldots \ldots \ldots \ldots$

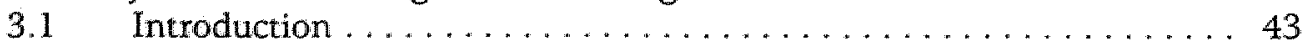

3.2 Method and data selection ...................... 44

3.2 .1 Introduction . . . . . . . . . . . . . . . . . . . . . . . 44

3.2 .2 Method ................................ 46

3.2 .3 Sample selection and test-period . . . . . . . . . . . . . . . . . 50

3.3 Hypotheses and results of the empirical analysis of accounting method changes (1): introduction of the first major accounting

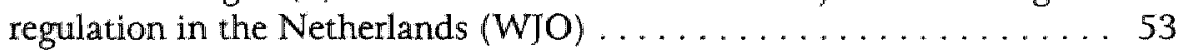

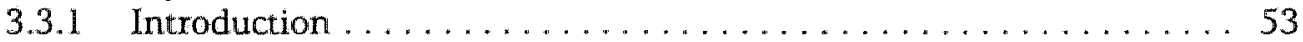

3.3 .2 Hypotheses . . . . . . . . . . . . . . . . . . . . . 53

3.3.3 Results: distribution of accounting method changes between 1966 and $1976 \ldots \ldots \ldots \ldots \ldots$

3.3.4 Magnitude of accounting changes method with an effect on earnings and/or equity . ..................... 59

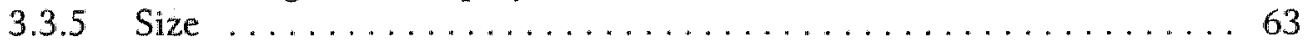

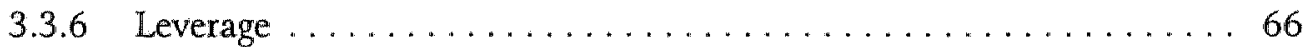

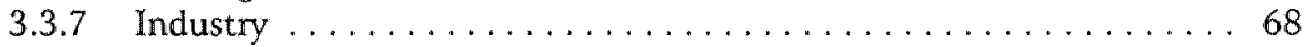

3.4 Hypotheses and results of the empirical analysis on accounting method changes (2): introduction of the second major accounting regulation in the Netherlands (Title 8$) \ldots \ldots \ldots \ldots \ldots \ldots$

3.4. I Introduction $\ldots \ldots \ldots \ldots \ldots \ldots \ldots \ldots \ldots \ldots \ldots \ldots \ldots$

3.4 .2 Hypotheses ........................... 73

3.4.3 Results: distribution of accounting method changes between 1977 and $1986 \ldots \ldots \ldots \ldots \ldots \ldots \ldots$

3.4.4 Magnitude of accounting method changes with an effect on earnings and/or equity $\ldots \ldots \ldots \ldots \ldots \ldots \ldots \ldots \ldots$

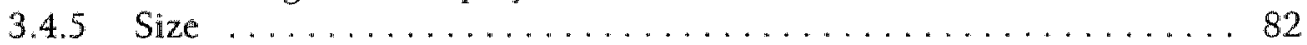

3.4 .6 Leverage ............................... 83

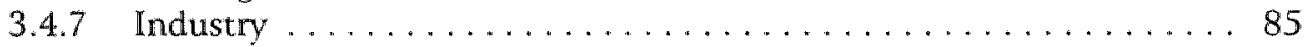

3.5 Summary and conclusions $\ldots \ldots \ldots \ldots \ldots \ldots$

Chapter 4

Empirical evidence on the effects of the implementation of the WJO in 1971 and Title 8 in 1984:

an analysis of accounting accruals $\ldots \ldots \ldots \ldots \ldots \ldots$

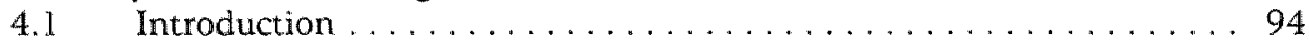

4.2 Method and data selection . . . . . . . . . . . . . . . . . 95

4.2.1 Introduction: some further remarks about accruals measurement . . . 95

4.2 .2 Method . . . . . . . . . . . . . . . . . . . . . 100 
4.2.2.1 Discretionary accruals: method $I \ldots \ldots \ldots \ldots \ldots \ldots \ldots \ldots$

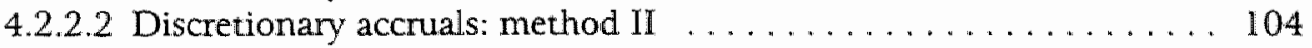

4.2 .3 Sample selection and test-period .................. 106

4.3 Hypotheses and results of the empirical analysis of accruals (1): introduction of the first major accounting regulation in the Netherlands (WJO) $\ldots \ldots \ldots \ldots \ldots \ldots \ldots \ldots \ldots \ldots$

4.3 .1 Introduction . . . . . . . . . . . . . . . . . . . . 108

4.3.2 Hypotheses . . . . . . . . . . . . . . . . . . . . . 108

4.3.3 Results: accruals method $1 \ldots \ldots \ldots \ldots \ldots \ldots \ldots \ldots \ldots \ldots \ldots$

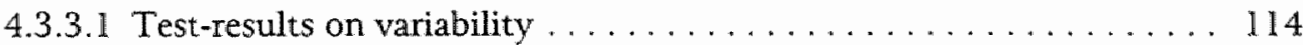

4.3.4 Results: accruals method II .................. 116

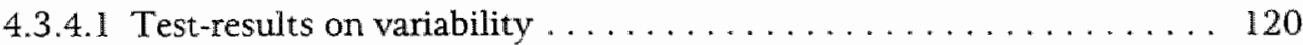

4.3 .5 Size .............................. 121

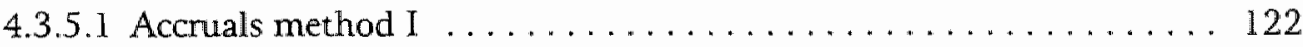

4.3.5.2 Accruals method II . . . . . . . . . . . . . . . . . . . 123

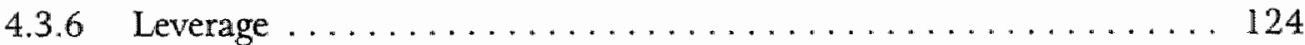

4.3.6.1 Accruals method I . . . . . . . . . . . . . . . . . . 124

4.3.6.2 Accruals method II . . . . . . . . . . . . . . . . . . . . 125

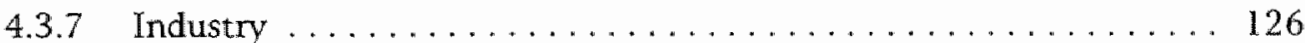

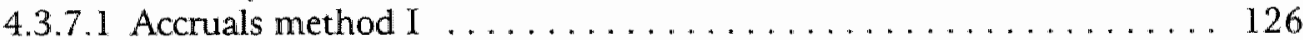

4.3 .7 .2 Accruals method II ........................ 126

4.4 Results of the empirical analysis of accruals (2): introduction of the second major accounting regulation in the Netherlands (Title 8 ) . . . . . . . . . . . . . . . . 130

4.4 .1 Introduction . . . . . . . . . . . . . . . . . . . . . 130

4.4 .2 Hypotheses . . . . . . . . . . . . . . . . . . 130

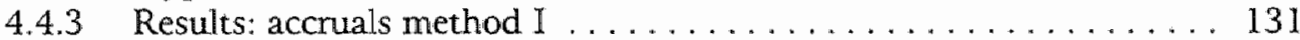

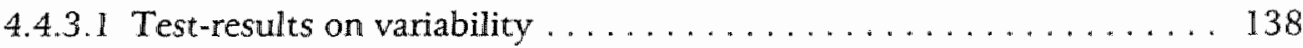

4.4 .4 Results: accruals method II . . . . . . . . . . . . . . . . . 139

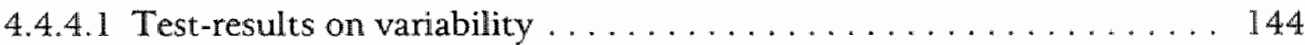

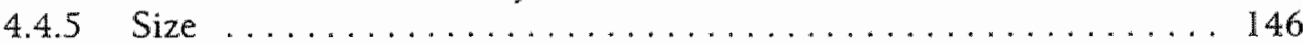

4.4.5.1 Accruals method I . . . . . . . . . . . . . . . . . . . I46

4.4 .5 .2 Accruals method II . . . . . . . . . . . . . . . . . . 147

4.4 .6 Leverage . . . . . . . . . . . . . . . . . . . . . 148

4.4 .6 .1 Accruals method $I \ldots \ldots \ldots \ldots \ldots \ldots \ldots \ldots \ldots \ldots \ldots$

4.4 .6 .2 Accruals method II . . . . . . . . . . . . . . . . . . . . 149

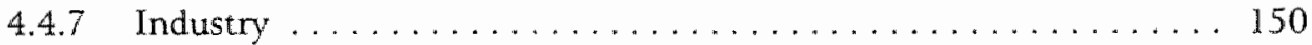

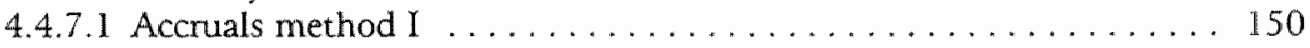

4.4 .7 .2 Accruals method II . . . . . . . . . . . . . . . . . . . . 153

$4.5 \quad$ Summary and conclusions $\ldots \ldots \ldots \ldots \ldots \ldots \ldots \ldots \ldots \ldots \ldots$ 


\section{Chapter 5}

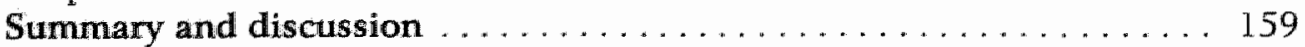

5.1 Introduction . . . . . . . . . . . . . . . . . . . . 159

$5.2 \quad$ Summary ..................................... 159

5.3 Comparison of both methods and results: consistency, limitations and opportunities . . . . . . . . 164

5.3.1 Results and consistency ...................... . 164

5.3 .2 Limitations and opportunities . . . . . . . . . . . . . 166

$5.4 \quad$ Further research opportunities $\ldots \ldots \ldots \ldots \ldots \ldots \ldots \ldots$

\section{Appendices}

Appendix 2A: Assessment of the debates, reports, and articles on Dutch financial accounting practice prior to the WJO .. 171

Appendix 2B.I: Changes in financial reporting requirements as a consequence of the implementation of the Act on Annual Financial Statements (WJO) and an analysis of its contents ................ 182

Appendix 2B.2: Changes in financial reporting requirements as a consequence of the implementation of the Fourth European Economic Community Directive (Title 8) and an analysis of its contents

Appendix 3A.1: Sample firms WJO ... . . . . . . . . . . . . . . . 209

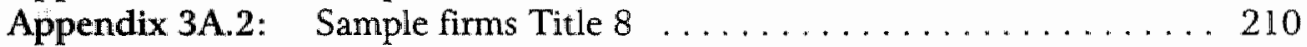

Appendix 3B.1: Distribution of accounting changes per

category for WJO sample firms ............. 212

Appendix 3B.2: Distribution of accounting changes per category for Title 8 sample firms . . . . . . . . . . 213

Appendix 3C.1: Accounting changes per type for WJO sample firms . . . 214 Appendix 3C.2: Accounting changes per type for Title 8 sample firms . . 226

Appendix 4A: The accruals approach: definition, methodology and areas of application . . . . . . 235

Appendix 4B.1: Sample firms WIO ................... 241

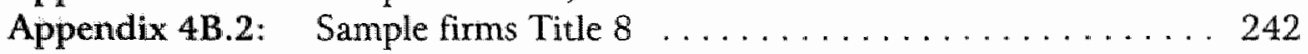

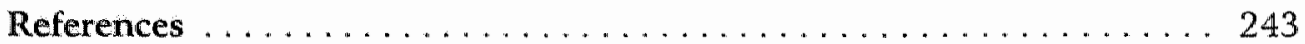

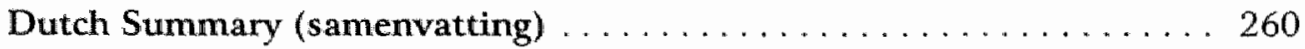

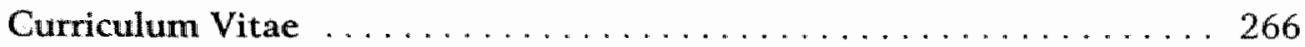


List of abbreviations:

- ASE Amsterdam Stock Exchange

- BV Private limited liability companies

(Besloten Vennootschap)

- CAJ Advisory Committee on Annual Reporting (Commissie van Advies inzake Jaarrekening)

- Coop Cooperative society

(Cooperatie)

- CV Limited partnership

(Commanditaire Vennootschap)

- FECD Fourth European Community Directive

(vierde EEG-richtlijn)

- NIVRA Royal Dutch Institute of Registered Auditors

(Nederlands Instituut van Register Accountants)

- NV Public limited liability companies

(Naamloze Vernootschap)

- OWM Mutual guarantee association

(Onderlinge Waarborg Maatschappij)

- RJ Council on Annual Reporting

(Raad voor de Jaanverslaggeving)

- TO Tripartite Study Group

(Tripartiete Overleg)

- WIO Act on Annual Financial Statements

(Wet op de Jaarrekening van Ondernemingen) 


\section{Chapter 1}

\section{Financial accounting method choice and financial reporting regulation}

\section{I.1 Introduction}

The aim of this dissertation is to investigate the impact of government legislation on financial reporting practice. More specifically, it examines the extent to which the introduction of (additional) financial reporting rules through government regulation affects firms' financial accounting method choices. Financial accounting method choice or financial accounting policy refers to the selection of specific methods, measurement techniques and disclosure techniques, from the total set of alternatives available for financial reporting by a firm. ${ }^{1}$

This dissertation will provide evidence on the effects of two major financial accounting regulations, (1) the Act on Annual Financial Statements (Wet op de Jaarrekening van Ondernemingen; WJO) implemented in 1971 and (2) the Fourth European Economic Community Directive in 1984 (incorporated in Title 8, Book 2 of the Dutch Civil Code), on financial reporting practice in the Netherlands. ${ }^{2}$

The dissertation is intended to contribute to the economics-based financial accounting literature in three respects. First, the results presented contribute to the empirical analysis and evaluation of financial reporting regulation, ${ }^{3}$ an issue that has

\footnotetext{
In a broader sense of course, accounting policy refers to accounting standards, opinions, interpretations, rules and regulations established by regulatory bodies with the authority to establish enforceable policies (Hendriksen and van Breda, 1992, p.235).

${ }^{2}$ In 1990 Title 8 has been replaced by the present Title 9 as a result of the implementation of the Seventh EEC-Directive in the Netherlands. Throughout this dissertation the implementation of the Fourth European Economic Community Directive.into Dutch legislation will be referred to as Title 8 .

${ }^{3}$ Financial reporting regulation includes both financial reporting legislation and financial reporting standards issued either by governmental or private bodies (Lev, 1988, p.I). The
} 
not received much attention in the Dutch academic accounting literature so far. Second, the empirical analysis will be structured around two different theories of firm accounting method choice: the opportunistic behaviour perspective and the efficient (optimal) contracting perspective. The results of the analysis may therefore enhance a positive theory of accounting method choice. Third, two different research techniques are employed in the empirical chapters of the dissertation, which enables both results and methods to be compared. The overall intended effect of this strategy is to strengthen the empirical results.

Within the economics based accounting literature, research on the supply of financial accounting information is concerned with firms' financial reporting activities, including accounting method choices. These choices are the result of (1) demand forces (determined by various users of financial accounting information), (2) the costs of producing the information, and (3) regulatory forces, if present. ${ }^{4}$ The uses to which financial accounting information is put, depending on what kind of information the decision makers (like investors or shareholders) require, determines the demand side of the market for financial accounting information.

This dissertation focuses on the supply side of financial accounting information through an empirical study of the effects of financial reporting regulation. Relevant economic theory studies the role of financial accounting information in economic relationships or contracts between an agent (e.g. management) and his principal (e.g. shareholders). Contracts within a firm are designed to reduce conflicts of interest and financial accounting information is often used in those contracts. Financial reporting is therefore an important part of the firm's contracting process (Watts and Zimmerman, 1987, p.193). The provision of such information is in principle cost effective for all parties related to the firm, and therefore maximizes their wealth.

Financial reporting regulation can affect the contracting process. In this context Watts and Zimmerman (1987, pp.193-194) point out that:

"Externally mandated accounting standards could theoretically facilitate the contracting process. That is, an accounting standard setting board could devise accounting procedures that improve contracts and thereby reduce the conflict of interest among the parties. However, that seems unlikely...."

Indeed, from an economic theory or agency theory perspective it can be argued that

primary source of financial accounting regulation in the Netherlands is legislation.

${ }^{4}$ See Buijink (1992, p.16). 
financial reporting regulations reduce firms' possibilities for minimizing costs (and in such a way impose additional costs on firms). These costs consist of (1) direct costs of making and enforcing these rules by government and the costs born by firms confronted with these rules, and (2) indirect costs arising from their effect on investment, production and financing decisions of firms (Watts and Zimmerman, 1986, p.169).

Yet, financial reporting in most market economies has been subject to a growing number of compulsory standards and government legislation. Financial reporting in the Netherlands is no exception. Until 1970, financial accounting practice remained more or less unregulated. But with the implementation of the WJO in 1971 a shift took place towards a more regulated financial reporting environment. A second major change occurred thirteen years later when Dutch accounting legislation was adapted to the Fourth European Economic Community Directive in 1984.

Financial reporting regulation in the Netherlands, and elsewhere, obviously affects various features of financial accounting practice. For instance, it determines which firms are required to disclose information, the number of items to be disclosed, the measurement of these items, and the frequency of disclosure. The purpose of this dissertation is to investigate empirically the impact of the accounting regulations implemented in $197 \mathbb{1}$ and 1984 on accounting practice. More specifically, it investigates the effect of their specific disclosure and measurement rules on firms' accounting method choice in the Netherlands. Three panels containing financial accounting data of Dutch firms subjected to the new financial reporting requirements of both Acts will be analysed empirically to evaluate the effects of these mandatory changes in financial accounting regulation. ${ }^{5}$

The remainder of this chapter proceeds as follows. Section 1.2 introduces economic theory explaining accounting method choice behaviour. First, this theory explains the rationale for firms to supply financial accounting information voluntarily, in the absence of any government regulation. Second, factors that determine the choice of financial accounting procedures will be considered. Section 1.3 discusses the effects of government financial reporting regulation on financial accounting method choice by firms. In section 1.4 the motivation for this dissertation will be provided and the methods explained. Finally, section 1.5 constitutes an outline of the remaining chapters of the dissertation.

${ }^{5}$ See section 2.4 for a detailed description of the data panels used in this dissertation. 
The topic of this dissertation is the impact of government regulation on firm managements" financial accounting method choice. The set of available financial accounting methods can evidently be affected by government intervention. In practice, government regulation in this area invariably takes the form of a restriction of the set of financial accounting methods available to a firm. ${ }^{6}$ But, before examining the effect of government regulation we first study firms' financial accounting method choice through the theory of non-regulated (voluntary) financial accounting disclosure.

\subsubsection{Non-regulated public disclosure of financial statements}

To discuss theories on accounting method choice by firms and the effect of government regulation, it is appropriate to address the fundamental question: why would firms voluntarily supply publicly available financial accounting information, in the absence of regulatory financial reporting requirements? An economic approach to voluntary financial disclosure is described here to attempt to provide an answer. The economics-based theoretical research in this area has a common element in that it assumes costly contracting. ${ }^{7}$ This concept, originally put forward by Coase (1937), is summarized by Ball and Smith (1992, p.1):

...[Coase observed that] in the absence of contracting costs, firms would be irrelevant: consumers could contract directly with the owners of factors of production; there would be no demand for firms to intermediate between them; all decisions would be based on a complete set of costlessly observable market prices.

A similar argumentation holds for financial accounting information: in a world without contracting costs accounting would be irrelevant since the information relevant to decision-making would be costless. Since (accounting) information is not costless, theoretical attention is focused on the economics of agency relationships. In this literature the main hypothesis about the voluntary production and dissemination of

\footnotetext{
${ }^{6}$ Of course government regulation could also be a source of innovation of financial accounting methods, leading to an enlargement of the set of available methods. But, as Watts and. Zimmerman (1997, p.209) point out, government regulation rather sought to narrow the discretion over accounting procedures.

${ }^{7}$ For an overview of the economic theories on the supply of financial disclosure information see Leftwich et al. (1981), Holthausen and Leftwich (1983), Benston (1984, 1986) and Lev (1988).
} 
financial reporting that can be identified is the agency hypothesis.

According to the agency hypothesis, the firm can be viewed as a set of contracting relationships among the contracting parties, within both capital markets (Jensen and Meckling, 1976, p.217) and markets for managerial labour (Fama, 1980, p.291). Agency theory then views the role of financial accounting information as the monitoring and enforcing of these contracts to reduce the agency costs of certain conflicts of interest, for instance, conflicts of interest between bondholders and stockholders. The financial accounting information to be disclosed, and the choice of financial accounting methods, are selected as a part of a wealth maximizing process, assuming that they lower the costs of monitoring (i.e. agency costs). In fact, in the contracting based models of organization, financial accounting information plays an important role in the overall efficient contracting technology of the firm and the choice of accounting policies depends on the relative magnitude of the various types of contracting costs (Watts and Zimmerman 1990, p.57). Examples of empirical studies concerning voluntary disclosure issues are Leftwich et al. (1981), and Chow and Wong Boren (1987), and Wong (1988). Benefits of voluntary disclosure include reduction in borrowing costs, increase in share prices, reduced labour costs ${ }^{9}$ and a decreasing likelihood of harmful regulation (i.e., political benefits).

Another step in using accounting information as a monitoring device is to have financial reports testified by an independent outside auditor to lower contracting costs, assuming the audit is not mandated already. Chow (1982) and more recently Buijink (1992) provide examples of the extent of voluntary audits as a part of the efficient contracting process. ${ }^{10}$

Lefiwich et al. (1981, p.61) examine the features of firms disclosing voluntary interim reports. More specifically, they investigate the relationship between reporting frequency and the firm's capital and asset structure (size, leverage) and other monitoring devices (number of outside directors, stock exchange listing). The results indicate that differences exist with respect to leverage and stock exchange listing. Chow and Wong Boren (1987) report on voluntary financial disclosure practices of Mexican firms. They found that voluntary disclosure is positively related to firm size, but not to leverage and assets in place. Wong (1988) studied voluntary disclosure of current cost in financial statements to determine underlying economic incentives. He found that voluntary presenters of current cost have higher tax rates, lower leverage ratios, larger market concentration ratios, and are more capital intensive.

\footnotetext{
The idea is that financial accounting information can serve as a cost-efficient internal and external monitoring mechanism for inside and outside markets for managers Fama, 1980 , p.294)
}

${ }^{10}$ Chow (1982) reports on voluntary audit of the financial statements by US firms in 1926 . before the Security and Exchange Commission (SEC) regulation mandated an external audit. 
Hence, agency theory and related empirical research on the public disclosure of nonregulated financial statements provide evidence of the way in which financial statements can reduce agency costs in a non-regulated financial accounting environment."

\subsubsection{Non-regulated choice of financial accounting methods}

In addition to providing explanations of the non-regulated production and dissemination of financial accounting information, economic theory has also concentrated on the firm's or manager's choice of financial accounting methods. The financial accounting information which is provided incorporates specific management choices regarding the accounting numbers and procedures. These accounting numbers are used in agency contracts to reduce costs. ${ }^{12}$ In other words, contracting costs theories also seek determinants of firm accounting policy choices, and the empirical research building on these theories has addressed the determinants of managements' financial accounting choices under a variety of circumstances.

During the last three decades the accounting literature has produced several positive theories regarding the choice of accounting procedures by the firms' management.

(1) In 1964 Gordon put forward a first positive theory of managerial financial accounting method choice. Based on the assumption that managers maximize their wealth, he argued that managements' accounting policy choices will depend on the level and growth rate of reported earnings, as well as the variance of reported earnings (Gordon 1964, p.261)..$^{13}$ A first attempt to test this argument empirically was conducted by Gordon et al. (1966), focusing on management attempts to decrease the

Variables as firm size, leverage, number of debt covenants and ownership structure were associated with the demand for external independent auditing. Buijink (1992, pp.89-114) extended Chow's work, using Dutch data to investigate firm characteristics in association with the demand for external independent auditing.

\footnotetext{
"Watts (1977) and Watts and Zimmermam (1978) provided the basic ideas based on the analysis of Jensen and Meckling (1976), which have been empirically examined in the studies discussed above.
}

\footnotetext{
${ }^{12}$ Accounting numbers are also useful for: (1) equity capital markets, (2) debt capital markets, (3) labour markets, (4) product markets, and (5) political markets areas. Lev's study (1989) evaluates the results of the empirical research on usefulness of accounting earnings.

${ }^{13}$ See also Watts and Zimmerman (1986. pp. 134-136) for a discussion of Gordon's mechanistic hypothesis.
} 
variance of reported eamings, or, put differently, to smooth eamings. ${ }^{14}$ Note that at basic assumption in Gordon's work was that the capital market could be fooled by managements' financial accounting choices. Despite the lack of significant results from this empirical research, it resulted in a substantial number of articles. ${ }^{15}$

(2) Subsequent research was concerned with the (semi-strong form of the) Efficient Market Hypothesis. In 1968, Ball and Brown (1968) and Beaver (1968) initiated a research program "capital markets research in accounting" that examined the relationship between accounting information and the value of the firm. They assumed that financial accounting information can supply information for investment decisions. This type of research, which could be classified under the information perspective of positive accounting research ${ }^{16}$ rendered insight into the use of accounting numbers by the stock market, investigating the relation between accounting numbers and stock prices. Although there is a large body of stock price studies, it could not provide explanations of why managers choose specific accounting procedures. ${ }^{17}$ The reason for this is that accounting changes could not have any effect on stock prices, since accounting changes do not (directly) affect the cash flow of the firm and only these future cash flows determine the firm's stock price. ${ }^{18}$ Watts and Zimmerman (1990, p.138) conclude that stock price tests are probably relatively weak tests of positive accounting theory.

(3) A third perspective, already discussed in the previous section, is the contracting view. The contracting view is used to explain implicit and explicit contracts that rely

\footnotetext{
${ }^{14}$ In addition to Gordon (1964), Healy (1985). Brayshaw and Eldin (1989). Beatty and Verrechia (1989) developed a multi-period model of managerial behaviour that suggests income increasing or income decreasing (big bath) activities. Income will be managed not only as a function of the specific circumstances in one single period, but also in the periods prior to and thereafter.

${ }^{15}$ Copeland (1968), Copeland and Licastro (1968), and Barnea, Ronen and Sadan (1975, $1976)$ for instance, empirically tested the income smoothing hypothesis. Ronen and Sadan (1981) present an overview of this strand of research.

${ }^{16}$ Holthausen (1990) and Watts and Zimmerman (1990) present a theoretical overview on this type of research.

${ }^{17}$ Extensive reviews on this type of studies are provided by Foster (1980), Holthausen and Leftwich (1983), Watts and Zimmerman (1986), Bernard (1989) and Dopuch (1989).

${ }^{18}$ However, there are accounting changes that do have a (direct) impact on cash flows in that they affect firms' taxes (i.e, the effects of switching inventory valuation methods in the case of the United States).
} 
on accounting numbers since these form the basis for the chosen set of accounting methods. The basic theoretical research is Watts (1977), Watts and Zimmerman (1978), Jensen (1983), and Holthausen (1990). Within the contracting literature there is a distinction between opportunism and efficiency as determinants of accounting policy choice (Ball and Smith, 1992, p.4). In both situations contracting can be cost effective and therefore reduces agency costs.

According to Holthausen (1990, p.207) efficient contracting implies that:

"...accounting methods, like the form of organisation chosen or the form of contracts written, will be selected to minimize agengy costs amongst the various parties to the firm".

Indeed, if decisions are driven by wealth maximization, management is said to behave efficiently. This implies that the wealth of all parties related to the firm is maximized, not just that of management itself. Here, ex ante, the set of available accounting methods is "efficiently" restricted to maximize the value of the firm. Managements" $x$ post choices within the set of accepted accounting procedures are rational responses to changing contracting environments and their purpose is to maximize the value of the firm. For instance, changes in economic circumstances might lead to changes in firms" contracts (i.e. accounting policies).

Opportunistic behaviour refers to a situation in which managers act in their own self interest, e.g. where managers' compensation contracts determine their accounting choices. If they use the discretion within the choice of accounting methods ex post to their own advantage and these choices have wealth distributive effects, which causes the wealth of for instance shareholders to decrease and that of managers to increase, managers are said to act opportunistically. Because the contracting parties expect some redistributive effects they will reduce the price they pay. The outcome of the ex post choice of accounting method by management can either increase the wealth of all parties or redistribute wealth among parties.

Holthausen (1990, p.209) concludes that these two explanations are not mutually exclusive, they may be both partial explanations of observed accounting choices. In fact $_{\text {, }}$ it is not always easy to distinguishing between efficient contracting and opportunistic behaviour due to (potential) problems of a theoretical and empirical nature (Ball and Smith 1992, p.4). ${ }^{19}$ One of the problems in empirical research is the difficulty to

\footnotetext{
${ }^{19} \mathrm{Ball}$ and Smith (1992, p.4) conclude that distinguishing between efficient contracting and opportunistic behaviour is theoretically and empirically difficult; theoretically because "...in the presence of positive contracting costs there will be a positive optimal (efficient) amount of
} 
distinguish between $e x$ ante and ex post accounting choices, because contracts are constantly rewritten (Watts and Zimmerman, 1990, p.138). ${ }^{20}$

A review of the empirical literature on accounting method choice by Hasisink and Mertens (1992b) reveals that the contracting perspective, representing either efficient contracting or opportunistic behaviour, has received the most attention. ${ }^{21}$ The studies in this strand of literature investigate how managers' financial accounting choices are related to the existence of firms" contracts which are based explicitiy or implicitly on accounting numbers. The evidence suggests that the financial accounting policy of firms are related to these contracts, implicitly or explicitly.

Christie (1990) has evaluated the evidence presented in fourteen different empirical studies, based on the contracting approach, of firms' accounting policy choice. He reported that several variables included in these studies have explanatory power across studies. These variables are management compensation, size, leverage, risk, constraints on interest coverage, and constraints on dividends. Hence, Christie (1990, p. 15) concludes that positive (i.e., contracting costs based) accounting theory can explain accounting method choice.

In summary, the main literature on accounting method choice is based on the proposition that the choice of these methods affects the wealth of the firm, and thus implicitly the wealth of all parties related to the firm (positive accounting theory). The economic existence of a firm depends on the ability to reduce contracting costs and financial accounting information plays a central role in these contracts. In the

opportunism", while empirical problems arise because the findings are often multi-interpretable, in the sense that a specific accounting method choice can increase the wealth of all contracting parties as well as that of a single party (management).

${ }^{20}$ There is another economic theory that should also be mentioned; signalling theory. Due to information asymmetry, managers have information about their firm which other parties involved do not have. Both managers and the other parties have an incentive to reduce this information asymmetry (the informed party wants to receive the highest price by distinguishing from low quality securities and the less informed parties want to pay the right price), management provides a signal to the less informed parties who now can form an expectation. In this so called signalling theory, the choice of accounting methods reveals manager's expectations about the firm's future performance. For instance, the choice of inventory method might represent a signalling role (Gaeremynk, 1994, p.30).

${ }^{2}$ Hassink and Mertens (1992b) is an overview of the positive accounting literature on the determinants of accounting method choice in the last three decades. Examples of this literature include Liberty and Zimmerman (1986), Lilien et al. (1988), Beatty and Verrechia (1989), Hand (1989), DeAngelo (1990), Jones (1991), Cahan (1992), and Guenther (1994). 
next section the efficient contracting perspective will therefore be used to discuss the effect of government regulation on firms' financial accounting policy choices.

\subsection{The effect of government financial reporting regulation on financial accounting methods}

So far, theory was used to explain the form and contents of financial reporting in an unregulated setting. In this setting, firms and their stakeholders make voluntary arrangements to reduce agency costs, which in turn increases resources available to them. This process leads to different sets of acceptable accounting policies and choices within this accepted set that can vary across firms and industries (Watts and Zimmerman 1987, p.208). The accepted set could be defined as the set of accounting procedures within which managers have discretion given the contractual framework they report in. Given the specific contracts of the firm and its contracting parties, each firm adopts, within the accepted set of accounting procedures, the choice which minimizes contracting costs. Acceptable accounting procedures may therefore vary across firms and industries as the nature of the contracts varies from firm to firm.

If standard setting bodies (e.g. the government) decide to enforce accounting procedures, this could restrict the accepted set, depending on the firm's specific circumstances (i.e., the firm's accepted set). Government regulation may therefore harm firms, by limiting their possibilities to minimize agency costs, which would then lead, seen from an efficient contracting point of view, to suboptimality. ${ }^{22}$

This reasoning obviously contrasts with that of standard setters, who often take the position that the availability of choice of financial accounting methods provides room for the manipulation of the accounting numbers. ${ }^{24}$ This reasoning implicitly assumes

\footnotetext{
${ }^{27}$ Hence, from an efficient contracting perspective, this will not maximize managements' utility. See also Watts and Zimmerman (1990, pp. 135-137) for a more detailed discussion of the firms choices within the accepted set.

${ }^{23}$ Hassink and Mertens (1992a, pp.45-48) illustrate a theoretical situation in which the firm's accepted set of accounting procedures is limited by government regulation. This leads to a suboptimal equilibrium with increased agency costs.

${ }^{24}$ It should be mentioned that there are also alternative arguments for government financial reporting regulation. For a review of these arguments and the economic theories explaining government interference (public and private interest theories) we refer to excellent discussions by (Maijoor, 1994) and Bollen (1996, chapter two). Alternative (non-economic) theories of financial reporting regulation are: (1) a political economy approach, represented by Cooper and
} 
that managers act opportunistically and thus maximize their own welfare at the cost of other contracting parties. Government regulation is then designed and motivated to prevent management's opportunistic behaviour. But, as already mentioned in the introduction to this chapter, it seems doubtful from a contracting cost perspective whether it is possible to reduce agency costs through government financial reporting regulation. To amplify, Watts and Zimmerman (1987, p.208) provide two reasons why government regulations will lead to less efficient sets of accounting contracts.

First, they argue that a (government) standard setting body can only contribute to efficiency if it has cost advantages in designing or enforcing accounting standards and it helps design new accounting procedures that reduce agency costs. The latter is not very likely to occur, since most standards have narrowed the set of accepted financial accounting procedures. ${ }^{25}$ In other words, government regulation will restrict managers' efficient voluntary financial accounting choices, as shown in Figure 1.l. The effect is that the total accepted set of financial accounting procedures available to firms will be restricted. The Venn diagrams illustrate the situation before and after government intervention.

Second, Watts and Zimmerman (1987, p.209) argue that it is more difficult for a centralized standard-setting body to design overall optimal financial accounting procedures, because circumstances vary from firm to firm. Since managers and other contracting parties of the firm have better information on the specific circumstances of the individual firm, the outcome of such a contracting process (including accounting procedures) is likely to be more efficient. Accounting standards therefore limit firms' ability to minimize agency costs.

To sum up based on the theory of contracting the ways in which management can exercise discretion over accounting numbers can be driven by two different motives (Watts and Zimmerman, 1990, pp.136-137). First, from the opportunistic behaviour perspective, management intends to increase it's own welfare through (ex post)

Sherer (1984), and Booth and Cocks (1990), (2) an organisational-cultural approach, represented by Cooke and Wallace (1990), and (3) a social/historical approach as in Puxty et al. (1987).

${ }^{25}$ See footnote 5 . 
Figure 1.1: Effects of government intervention on the available set of accounting procedures.

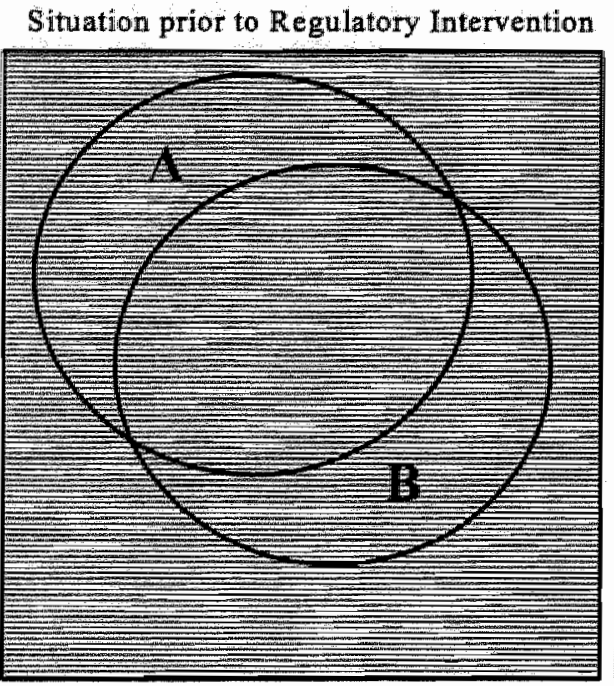

Situation after Regulatory Intervention

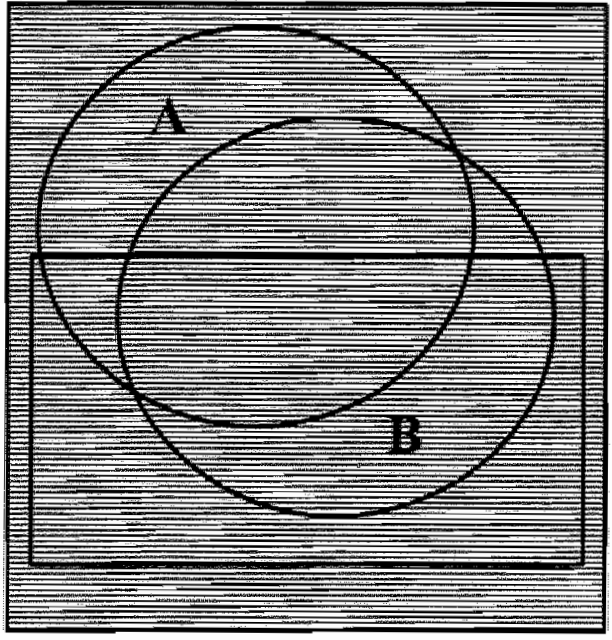

Total set available

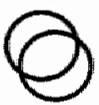

Accepted set firms A and B

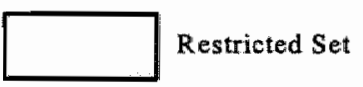

accounting method choices at the cost of the other contracting parties (causing wealth redistributions). Government regulation is then intended to restrict managements' ( $2 x$ post) accounting choices, by reducing the $c x$ ante set of accepted accounting procedures.

It is then assumed that through mandlatory regulation opportunistic behaviour can and will be reduced. If firms indeed act opportunistically government regulation can only be effective, that is reduce agency costs, if financial accounting regulation can restrict managers opportunistic behaviour. On the other hand, if one assumes that managers act efficiently, mandatory accounting regulation imposes costs on firms.

Second, from the efficiency perspective, it can be argued that management will choose accounting procedures that maximize the wealth of all contracting parties, both ex ante and ex post. In that case government intervention will lead to suboptimal choices and increased contracting costs, because the optimal contracting structure (i.e. the accepted set of accounting procedures) of the firm will be affected.

This dissertation examines the possible effects of mandatory financial reporting 
regulation on firms' accounting policies in the light of these perspectives. It is closely linked to the central theme of the contracting costs literature, which attempts to gain insight into the motives and means by which management exercises discretion over financial reporting.

\subsection{The motivation of this dissertation}

The theories on (voluntary) financial reporting and accounting method choice presented in section 1.2.1 and 1.2.2 are formulated in a theoretical world without government intervention. Subsequently, positive theories have also been developed to explain government interference. This dissertation is concerned with the effect of government regulation on financial reporting practice. This is important for several reasons.

First, from a regulatory point of view, it is important to examine the impact of regulations that have been adopted on financial reporting practice (Chow, 1983, p.73). Accounting policy makers, when formulating new requirements, need to know the consequences of newly established standards on (firms') accounting practice in order to formulate an effective policy. ${ }^{26}$

From the late seventies on, the Anglo-Saxon literature provides several examples of studies of the social and economic consequences of accounting regulation. Chow's 1983 study examined the mandatory accounting changes that resulted from the implementation of the 1933 and 1934 Securities Act in the US. ${ }^{27}$ Emenyonu and Gray (1992) examined the (accounting) measurement practices in France, Germany and the UK in 1989, after the Fourth EEC Directive on accounting harmonisation was implemented.$^{28}$ Despite harmonisation efforts, they found that a wide variety of methods to measure firms' assets, liabilities, and profit exists within these three countries and that the effects of harmonisation are therefore minimal. A study conducted by Joos and Lang (1994) reached a similar conclusion. It examined the comparability of financial accounting data in the UK, Germany and France. More specifically, it investigated measurement differences between these countries, with

\footnotetext{
${ }^{26}$ Or as Zeff ( 1978, p.65) states: ...the FASB must show that it has studied the possible consequences [of accounting standards]...

${ }^{27}$ Other studies conducted in this area are Watts and Zimmerman (1978), Leftwich (1980), Lys (1984), and Imhoff and Thomas (1988).

${ }^{28}$ This study does not compare uniformity before and after the implementation of the Fourth EEC Directive The analysis focuses only on one moment in time (1989).
} 
Germany as a representative of the continental financial reporting model (more debt and tax oriented) on the one hand, the UK as a representative of the Anglo-Saxon model (equity and "true and fair view" oriented) on the other hand, and France with an intermediate financial reporting model. These measurment differences led to differences in financial ratios (profitability) and the stock market valuation of accounting data. An evaluation of the impact of European accounting regulation (the European Economic Community Directives) on measurement (or valuation) rules within these countries revealed that the EEC Directives did not alter this situation.

Compared to this growing body of mainly Anglo-Saxon empirical literature on the effects of accounting regulations, insights into actual financial accounting practice in the Netherlands are still minimal. Bouma (1972) concluded that the report of the committee preparing the first major government regulation in 1971, the WJO, completely lacked empirical research on accounting practice at that time. Apart from three recent attempts, from Bujjink (1992), Maijoor (1994, 1996) and Bollen (1996) there have been no systematic empirical studies of the economic effects of financial accounting regulation in the Netherlands. ${ }^{29}$ Therefore, an evaluation of these effects deserves more attention.

Second, we will try to provide evidence on two competing theoretical perspectives: opportunistic behaviour versus efficient contracting. The introduction of financial accounting regulation through mandatory accounting procedures provides an opportunity to distinguish between these two perspectives as explained in the previous section. Alternative hypotheses will be designed to test efficiency and opportunistic behaviour rationales. The empirical results of the analysis may find an association between accounting method choice and the firms" contracting variables.

Third, we will use two different methods of empirical analysis that are suggested in the empirical literature in this area to detect changes in accounting procedures, i.e. changes in financial accounting policy:

(1) direct observation (i.e., counting) of (visible) changes in accounting methods in financial statements, and

(2) an empirical analysis of the time series of accounting accruals.

The first method observes accounting changes directly. The research presented here

\footnotetext{
${ }^{29}$ Maijoor (1994, 1996) studied the effects of financial reporting regulation for public accountants (size of the audit market) and firms (legal form choice) in the Netherlands; Buijink (1992, chapter four) studied financial reporting practice (voluntary auditor choice) in the Netherlands in an unregulated setting; and Bollen (1996) studied the effect of financial reporting regulation on small and medium sized companies.
} 
is based on Hoogendoorn (1990) and Bowen et al. (1992). The second method measures the impact of accounting legislation by observing changes in the variability of net income, cash-flows, and accounting accruals for the years before and after the intervention periods (1971 and 1984). The analysis of accounting accruals is based on the work by Healy (1985), DeAngelo $(1986,1988)$, Liberty and Zimmerman (1986), Jones (1991), Cahan (1992), and Guenther (1994), among others. The use of both methods enables a comparison of results and methods.

The basic question addressed in this dissertation is whether financial accounting regulation does indeed restrict management's behaviour regarding accounting method choice. This is important because of the movement towards more extensive financial accounting regulation in many developed countries. ${ }^{30}$ According to the efficient contracting perspective, financial accounting regulation is expected to increase contracting costs because the accepted set of accounting procedures will be restricted. Based on the opportunistic behaviour perspective management's discretion regarding alternative accounting procedures should be reduced in order to restrict earnings management and government regulation is intended to do so. This dissertation then analyses the impact of financial accounting regulation. It assumes that government intervention is motivated by the assumption of (ex-post) opportunistic behaviour on the part of the managers, and that firms themselves seek to design their financial accounting based contracts (ex-ante) efficiently. ${ }^{31}$

The Netherlands presents an opportunity to measure the effect of the introduction of financial accounting regulation, because in 1971 there was a change from an almost non-regulated to a regulated financial accounting environment with the implementation of the WJO. Moreover, a second opportunity to measure the effects of accounting legislation on financial accounting practice is offered at the time the Fourth European Economic Community Directive was incorporated into Dutch law in 1984: the introduction of 'Title 8 . This dissertation will compare management's flexibility in financial accounting policy choice before and after these regulatory interventions. The main research question can be formulated as follows:

\footnotetext{
${ }^{30}$ Beaver $(1989$, p. 1$)$ states: ... In an era of dergulation of our economy, legal liability for financial reporting and calls for additional regulation are at an all-time high. Furthermore, Nobes and Parker (1995, p.20) argue: ...In many contimental European countries, the importance of governments as collectors of taxation or controllers of the economy has led to the dowinance of company law, commercial codes and tax regulations.

${ }^{31}$ The assumption that government intervention is motivated by opportunistic behaviour on the part of the managers is based on our analysis of the political debates, reports and articles prior to the introduction of accounting regulation in the Netherlands. We refer to chapter two and the appendices $2 \mathrm{~A}, 2 \mathrm{~B} .1$, and $2 \mathrm{~B} .2$ for an extensive discussion.
} 
Has management's discretion regarding the choice of accounting methods been reduced as a result of the implementation of the WJO in 1971 and Title 8 in 1984 in the Dutch financial reporting system?

Even if the results indicate that there are no effects on accounting choices, costs exist due to the legislation ${ }^{32}$ These costs consist of (1) direct costs due to designing and enforcing rules and regulations by the regulatory bodies and (2) the opportunities to minimize agency costs which are lost as a result of the restriction of the optimal set of alternative accounting procedures (see figure 1.1 ). ${ }^{33}$

To test for the effects of the WJO we analysed the annual accounts of 64 nonrandomly selected public firms, listed on the Amsterdam Stock Exchange, from 1965 to 1976 . This provides us with a total of 768 annual reports. The data sets used to examine the effects of Title 8 include (1) accounting changes of 107 non-randomly selected public firms, listed on the Amsterdam Stock Exchange, between 1977 and 1986 and (2) accounting accrual numbers of 76 non-randomly selected public firms, also listed on the Amsterdam Stock Exchange, from 1974 to 1990 taken from the Central Bureau of Statistics" financial statements database. The total number of annual accounts used in this case is 1070 . To cover the period before and after the implementation of the WJO (1971) and Title 8 (1984), the empirical analysis will cover 1965 to 1990 , a period of 26 years. Table 1.1 presents research methods as well as intervention moments. Two methods will be used to analyse managements' financial accounting method choices in years before and after the two regulatory interventions.

Table 1.1: Overview of sections discussing both research methods and events

\begin{tabular}{lcc}
\hline method & wJO & Title 8 \\
\hline accounting method changes & Act of 1970 & Act of 1983 \\
accounting accruals & section 3.3 & section 3.4 \\
\hline
\end{tabular}

${ }^{32}$ See Benston (1976, p. 161) and Philips and Zecher (1981, p.51).

${ }^{33}$ However, these costs are difficult to measure. 
This chapter has introduced the motivation for this dissertation. Two different financial reporting situations were distinguished: a theoretical world without government intervention, and a setting with government intervention. Based on contracting theory it is expected that the introduction of additional financial reporting regulation (WJO and Title 8 ) will restrict the set of accepted accounting procedures, which implies (1) more (ex ante) costly contracting ${ }^{34}$ or (2) less (ex post) opportunistic behaviour.

The outline of this dissertation is as follows. Chapter two discusses the contents of both Acts and their consequences in terms of newly established accounting policy rules. Both classification and measurement rules will be analysed. At the end of this chapter research questions will be formulated regarding the effect of the WIO and Title 8 on accounting method choice. These research questions will be developed into specific hypotheses in chapters three and four.

The results of the empirical analyses on the effects of the introduction of the WJO in 1971 and Title 8 in 1984 are presented in chapters three and four. These analyses test whether government intervention has actually reduced earnings management.

Chapter three reports on the empirical analysis based on observed changes in accounting methods. Evidence will be presented on the number of accounting changes and the magnitude of their effects on earnings and equity. Also, the data will be related to certain firm characteristics.

Chapter four reports on the empirical investigation of the time series of accounting accruals conducted. The analysis focuses first on the time series of total accruals, to see whether the variability of total accruals has decreased and the variability of earnings has increased as a result of a more strict regulatory regime. Then the time series of non-discretionary and discretionary accruals will be examined to determine the actual effect of financial accounting regulation on both types of accruals.

Chapter five provides a summary of the key findings presented in chapters three and four. The strengths and weaknesses of both methods, and their results will be compared. Finally, conclusions and proposals for accounting policy makers and future research will be given.

\footnotetext{
${ }^{34}$ Although these costs are difficult to measure precisely.
} 


\section{Chapter 2}

\section{The effects of two major financial reporting regulation changes in the Netherlands on accounting method choice: description and development of research questions}

\subsection{Introduction}

Firms' choices of financial accounting methods can be influenced or determined by individual accounting standards, rules and regulations, and opinions and interpretations of these. The standards, rules and regulations include measurement rules, which affect the valuation and allocation techniques and procedures relating to the balance sheet and profit and loss statement, and disclosure rules, which affect the form, amount of detail, and arrangement of the statement.

Figure 1.1 (chapter 1) illustrated how the total set of available financial accounting methods, characterized by Demski (1994, p.2) as the 'accounting library', is partially restricted by regulatory authorities, driven by the assumption that firms' managers act opportunistically. Section I.3 discussed why such regulations invariably limit the choices and discretion available to individual firms in their financial reporting. Firms choose from the set of available and accepted accounting policies. The restriction of the available set of methods will affect the quantity and quality of financial statements.

In most Western countries, financial accounting has been subject to governmental or private regulation for several decades, and sometimes dates back to the midnineteenth century (e.g., the UK Companies Act of 1844 (Benston, 1976, p.1)). In the Netherlands, however, there was an almost unregulated financial accounting environment until 1971, although the earliest Dutch law in this area was approved in 1837, and goes back to the French occupation. The for the purpose of this study relevant articles $(6,8$, and 55$)$ of the Commercial Code of 1837 , which was mainly based on the French Code de Commerce, did not contain any obligation to publish financial information.

Two sections in the Commercial Code of 1929 , introduced after a process of law reform which already began in the early 1870 's, did not alter this situation 
substantially. The exact contents of these requirements will be discussed in appendix 2B.1.

Apart from government regulations the Stock Exchange Association also issued listing requirements regarding new companies' financial information in 1909 (Zeff et al., 1992, p.63). The Association set conditions for admission to listing at the Dutch stock exchanges (in Amsterdam, Rotterdam and The Hague). Although it was required to publish a balance sheet and a profit and loss statement, no specifications regarding the contents of those statements were given.

The implementation of the Act on Annual Financial Statements (Wet op de Jaarrekening van Ondernemingen; WJO) in 1971 put an end to this almost unregulated financial reporting environment. ${ }^{1}$ From this time on, regulations concerning financial accounting in the Netherlands have grown rapidly. As Zeff et al. (1992, p.282) summarize:

The decade of the seventies was, for auditors and companies alike, a period of intensive regulatory activity, following decades in which the contents of company financial statements had been governed by only a skeletal 1929 law....

In 1983, as a consequence of the harmonisation of financial reporting regulation in the member states of the European Economic Community, the Fourth European Economic Community Directive (FECD) was incorporated into Dutch accounting legislation, and became effective one year later (Title 8 ). ${ }^{2}$

This chapter and its appendices provide the basis for the conceptual and empirical analysis of firms' responses to regulatory restrictions of financial accounting policy choice. It analyses the contents and interpretations pertaining to financial accounting methods in two major elements of Dutch financial accounting legislation, the WJO and Title 8 . The next section provides a summary of the analyses performed to examine the extent to which managements' financial accounting choices have been modified as a result of the enforcement of the two Acts. In addition to this, a more elaborate review of Dutch accounting practices before 1970 is provided in appendix $2 \mathrm{~A}$. This appendix also discusses and summarizes the arguments used in the political debate preceding the Acts. It draws on debates, reports, and articles on firms'

\footnotetext{
'Title 6, which incorporated the WJO, was enacted into law (Book 2 of the Civil Code) five years later (1976).

${ }^{2}$ Title 8 , Book 2 of the Dutch Civil Code of 1983 . With the adaptation of the Seventh EC Directive (in 1988) and the introduction of a new Title concerning mergers into Dutch civil law, Title 8 was renumbered into Title 9 in 1990 (see also footnote 2 , chapter 1).
} 
financial reporting practices as they relate to the Dutch government's decision to move towards additional financial reporting regulations. Next, a survey of the major changes in Dutch financial accounting regulation is provided in appendix $2 \mathrm{~B} . \mathrm{l}$ and 2B.2. At the end of both appendices, the major changes in Dutch financial accounting regulation enforced in 1971 and 1984 are summarized. Based on these analyses of the contents of the Acts research questions will be developed in section 2.3. The design of these research questions draws upon the financiall reporting requirements relating to measurement and disclosure rules, and the theoretical discussion in chapter 1. The data used for the empirical analyses in subsequent chapters will be presented in section 2.4 , and a summary of the contents of this chapter will be provided in section 2.5 .

\section{2}

Analyses of the contents of two major Acts: WJO and Title 8

Our analyses of the contents of the Acts have focused on changes in financial reporting requirements as a result of the new regulations. For the purpose of this dissertation these requirements can be divided into two categories: (1) rules that refer to measurement issues and (2) rules that refer to disclosure rules. The first category, measurement rules, constitutes the most important change. Specific valuation criteria, such as those applying to tangible assets, may be ruled out or may become mandatory. This could directly affect the firm's accounting policy, since it would narrow the set of accounting procedures available. This might impose costs on the firm, because it can lead to suboptimal (accounting) contracts, as explained in the first chapter.

The history of Dutch company law can be characterized by two major streams of extensive government laws and regulations in the seventies and eighties (van der Grinten, 1983, p. 133). The first one occurred during the seventies, starting of with the implementation of the WJO. The second stream took place in the nineteen eighties, incorporating the Fourth European Economic Community Directive into Dutch financial accounting regulation (Title 8 ). The major characteristics and the consequences of the WJO and Title 8 for firms' financial reporting requirements will be discussed in the next sections.

\subsubsection{Analysis of the WJO}

The first major change took place with the implementation of the Act on Annual Financial Statements (WJO) in 1971, which significantly increased disclosure requirements for the companies affected. The provisions of the Act affect the balance sheet, profit and loss account and the notes. For a detailed discussion of the specific 
measurement and disclosure rules of the WJO we refer to appendix 2B.1. A tabular summary of the provisions relating to the balance sheet and the profit and loss account and the notes thereto is provided at the end of this appendix in tables 2.1 and 2.2 .

From an analysis of the contents of the relevant sections, it is apparent that most of the regulations relate to disclosure rules (form and detail), which meant a significant increase of the financial information to be disclosed. ${ }^{3}$ A comparison of the new regulations with previous requirements shows that, especially with regard to the contents of the balance sheet and the profit and loss account, the Act requires a far more detailed specification of the different items, along with explanatory notes. ${ }^{4}$ For example, on the asset side of the balance sheet all fixed and current asset items have to be separately mentioned, including the valuation principles applied. Another novelty was the requirement to disclose majority holdings in separate, consolidated or combined financial statements. As regards the profit and loss account, the WIO required the disclosure of sales, depreciation of durable goods, income from investments, income for shareholders, provisions for taxation and extraordinary gains and losses. The Act also required for the first time an annual audit by an independent auditor.

There were also important effects on the measurement (valuation) rules. The most important was the end to the use of secret reserves. Assets could no longer be written off in a single year; they must be valued consistent with the provisions stated in Article 5. This implied that, on the liabilities side of the balance sheet, (shareholder's) equity could no longer be understated. Ruling out the use of secret reserves was therefore an important measurement rule emanating from the Act. There are no stipulations regarding the valuation of fixed assets or inventories. Instead, the WJO uses the 'open formula', which implies that more than one valuation method is acceptable. However, material changes in valuation principles have to be shown, together with the impact of the change on the reported income and financial position.

\footnotetext{
${ }^{3}$ This is consistent with the general purpose of the WTO: its main idea was to solve information asymmetry that existed between firms" management and their shareholders, bondholders and employees.

${ }^{4}$ In a press comment article on the report of the Verdam committee (called Rapport Commissie Verdam IV: Jaarverslaggeving II-Norm) in Het Financiele Dagblad of January 30/1 February, the paper concludes that "...the proposals [of the Verdam Committee] will, if they are enacted, amount to a great step for many businesses, and will lead to a substantial change in financial reporting" (Zeff et al., 1992, p.159).
} 


\section{2 .2}

Analysis of Title 8

The second major shift occurred in 1984, the year in which Title 8 became effective. This Act embodied the requirements laid down in the Fourth EEC Directive. Its main purpose was to harmonize financial accounting regulations within the member countries of the EEC. Additional disclosure rules became effective, including prescribed schedules for the balance sheet and profit and loss statements. The Act also contained certain measurement rules. Tables 2.3 and 2.4 of appendix 2B.2 provide a summary of the additional legal reporting requirements.

This synthesis of the second major revision in the history of financial accounting regulation in the Netherlands shows that it had a significant impact on the legal financial accounting environment, as did the WJO. Firms were again faced with significantly increased disclosure requirements, such as the introduction of prescribed formats, and detailed provisions relating to the notes. Additional valuation rules were also introduced, such as those on the valuation of investments and a maximum depreciation period of five years for the (capitalized) costs of share issues and research and development. Both measurement and disclosure requirements resulting from the new Title 8 would be expected to have an impact on firms' financial reporting. As in the case of the WJO, the set of available financial accounting methods is narrowed with the introduction of some measurement rules and many more disclosure rules.

\subsubsection{Summary}

The increase in the degree of financial accounting regulation narrowed the set of alternative accounting procedures available to firms" management and therefore should have an observable effect on the firms' financial reporting decisions. Certain accounting procedures have been prohibited (for instance, the use of secret reserves), while other procedures have become mandatory, thus reducing the choices available.

Disclosure requirements have also significantly increased. Although this does not in itself limit the available set of financial accounting procedures, it does imply that changes in the selected accounting procedures will be more visible to the outside world. To amplify, the fact that the two Acts contain a substantial number of additional requirements with respect to financial reporting also implies that, although there may be few mandatory procedures with respect to valuation (measurement) procedures, the obligation to disclose information on the valuation or the determination of profits can in itself have an important restrictive effect on the choice of accounting policies and management's freedom to change their policies. For instance, the obligation to disclose the depreciation method which has been applied to fixed assets makes it more difficult to alter this method in the next year, because 
the change, including its effect on earnings and equity, has to be disclosed. So a manager who wants to alter his accounting methods may be faced with limited opportunities and increased agency costs.

The empirical evidence on the effects of the two major sets of financial accounting regulations on firms' financial reporting policy choices will be presented in chapters three and four. But first we will develop the research questions regarding these effects.

\section{3}

\section{Development of the research questions}

This section will develop the research questions regarding the reactions of Dutch publicly listed companies to the introduction of two major financial accounting regulations. The research questions are based on the analysis of the contents of the WJO and Title 8 presented in the previous sections of this chapter.

Three methods are available in the literature which can be used to test whether the implementation of regulatory changes have had an impact on management's choice of accounting procedures:

(1) observation of the changes in the frequency with which item(s) are disclosed,

(2) anallysis of changes in financial accounting policies, and

(3) an analysis of changes in accounting accruals.

In the following section the methods will be presented in detail, and research questions will be developed regarding the second and third method.

\subsubsection{Observation of the changes in the frequency of item disclosure}

The first and most straightforward method, employed by Benston (1969), is to measure the effects of regulation by comparing the frequency of disclosure of one or more items in the (annual) financial statements from a selected group of firms in years before and after the change in the legislation. Benston's examination, which was limited to the accounting disclosure requirements of the Securities Act of 1933/1934, gave results on six different financial reporting items: (1) balance sheet, (2) current assets and liabilities, (3) sales, (4) cost of goods sold, (5) depreciation, and (6) net income. Benston found that the volume of disclosure of these items prior to the passing of the Securities Acts was allready considerable, which led him to conclude that there is little justification for mandatory disclosure of financial accounts. For the regulatory bodies, which assume that requiring the disclosure of additional financial information is (economically) beneficial, the findings were counterintuitive: the Act 
did not lead to a significant increase in information disclosure. However, this method will not be employed here, because the analysis needs also to take accounting policy choices into consideration. This dissertation therefore focuses on the second and third method.

\section{3 .2}

\section{Observation of the changes in accounting policy (accounting method changes)}

The second method is used in several studies on single or multiple accounting procedure choices. Here, the focus is on (specific) changes in the accounting methods used by firms. For instance, Lilien et al. (1988) examine whether financially troubled firms are more likely to adopt accounting changes which increase their reported income than non-troubled firms. ${ }^{5}$

The accounting policy change approach is used in this dissertation to examine the financial reporting strategy of Dutch firms before and after the enactment of the WJO (effective from financial years ending on or after December 31, 1971) and Title 8 (effective from financial years ending on or after December 31, 1984). Any change in accounting policy from one financial year to another is defined as a change in the firm's financial reporting strategy. It includes both changes in the principles and rules for the valuation of assets and liabilities or the determination of profit (measurement system), and changes in the principles of presentation (disclosure techniques). Accounting policy changes do not include (1) the adaption of a new accounting principle for events or transactions which did not occur previously, (2) those that differ in substance from previously occurring events or transactions, and (3) changes in accounting estimates. ${ }^{6}$ Hoogendoorn (1990, p.23) and van der Wel (1987) argue that the Dutch equivalent for accounting method change, 'stelselwijziging' (change of system), is not similar, since an accounting change includes changes in accounting estimates. However, Lilien $e t$ al. $(1988$, p.645) explain that distinguishing between a change in accounting principle and a change in an accounting estimate is sometimes

\footnotetext{
${ }^{5}$ The Lilien to al. study is a cross-sectional study of accounting changes, while the analysis presented in this dissertation is longitudinal.

${ }^{6}$ See also chapter 3, paragraph 3.2.2. Throughout this dissertation accounting policy changes and accounting changes are used synonymous. It should however be stated that the term accounting changes, which is used in the US and Canada, usually also includes accounting estimates. In this study we have chosen to use the same definition as in Hoogendoorn (1990), because a data set used here containing accounting policy changes is also taken from Hoogendoorn (1990).
} 
difficult. Hoogendoom (1990, p.19) draws a similar conclusion. ${ }^{7}$ For reasons of consistency, changes in accounting estimates (schattingswijzigingen) were not treated as accounting changes, in accordance with the methodology used in Hoogendoorn (1990). Chapter three, the first empirical part of this dissertation, will examine the time series of these accounting policy changes. The empirical analysis is based on the theory presented in section 1.3. The research questions developed in this section will be designed to (1) examine the impact of the accounting regulation (WJO and Title 8 ) on firms sisclosure policies and (2) to provide evidence for evaluating the efficient contracting and opportunistic behaviour perspectives of accounting policy choice. Basically, our empirical analysis of accounting changes focuses on two fundamental issues: (I) the frequency and (II) the magnitude of accounting changes in terms of their effect on earnings and/or equity.

\section{(I) Frequency of accounting changes}

In the analysis presented in section 1.3 it was argued that accounting regulators assume that managers act opportunistically, and government regulation was motivated and designed to prevent this. Therefore, a first research question can be developed with respect to the expected effect of accounting regulation from the point of view of the government (i.e. the regulator).

In this particular case we assume that firms act opportunistically and accounting regulation effectively reduces management's ability to manage income through accounting method choice, i.e. opportunistic behaviour, by reducing their opportunities to use or choose alternative accounting methods. It would be expected that:

\section{(Research Question) $\mathrm{R}_{1}^{\mathrm{c}}:{ }^{8}$}

the change from an almost nonregulated (before 1971) or partially regulated financial accounting environment (before 1984) to a more regulated financial accounting environment (after 1971/1984) led to (1) an increase in the frequency of accounting changes during both intervention periods and (2) a decrease in the level of accounting changes in following years, compared to the frequency of accounting changes in the years before the implementation of the WJO and Title 8, ceteris paribus.

\footnotetext{
'For a more extensive discussion of the differences in terminology employed see Hassink and Mertens (1990).

${ }^{8}$ Research questions (and consecutive hypotheses presented in chapter 3) that refer to accounting method changes are presented as $R^{c}$, where ' $c$ ' refers to changes. Research questions (and consecutive hypotheses presented in chapter 4 ) that refer to accruals are presented as $\mathbb{R}^{\mathrm{a}}$, where 'a' refers to accruals.
} 
The level of accounting changes prior to the WJO is, according to the opportunistic behaviour perspective, indicative of opportunistic behaviour. Due to regulatory requirements, mandatory or non-discretionary accounting changes are expected to increase in the year the new regulations become effective. In the years after their implementation, the level of accounting changes is expected to decrease, since discretionary accounting choice (i.e. opportunistic behaviour) has been effectively restricted. ${ }^{9}$ Clearly, it is important to distinguish in our observations between voluntary (discretionary) and mandatory (non-discretionary) accounting changes.

The alternative research question $\left(R_{1 A}^{c}\right)$ is based on efficient contracting, which assumes that the level of accounting changes prior to the WJO represents each firm's optimal financiall reporting strategy. As outlined in chapter one, government intervention, assuming it is effective, is then expected to lead to suboptimal contracting. ${ }^{10}$ Hence, it is expected that the level of discretionary accounting changes would increase after the implementation of the WJO. The reason is that in order to alter a firm's income numbers managers would have to adopt or change (discretionary) accounting procedures to achieve results similar to those achieved prior to the WJO and Title 8 . From this viewpoint, firms will carry out more accounting changes after the implementation of the WJO and Title 8 , because they will seek to undo the effects of regulation. ${ }^{11}$

Mandatory accounting changes are again expected to increase in the intervention year due to the increase of regulatory requirements, but, in contrast to the research question $R_{1}^{c}$ which assumes opportunistic behaviour, discretionary accounting changes are expected to continue at a higher level after the implementation of the WIO and Title 8 . So in this case we assume efficient contracting behaviour on behalf of the firms, because accounting policy choices are part of a firm's wealth maximizing process. Effective government intervention will then lead to inefficiency. Consequently, research question $\mathrm{R}_{1}^{\mathrm{c}}$ should be stated alternatively:

$\left(\right.$ Research Question) $R^{c}{ }_{\mathbb{A}}$ :

the change from an almost nonregulated (before 1971) or partially regulated

\footnotetext{
That is, effective financial reporting regulation will restrict management's ex post accounting method choice discretion.

${ }^{10}$ Here we expect that through gowernment regulation the ex ante choice within the accepted set of accounting methods will be restricted which in turn will lead to suboptimal contracts.

"If the results indeed would indicate that accounting changes (i.e. measurement changes) have increased after 1971 this could also imply that regulation, at least from an opportunistic behaviour point of view, has not effectively reduced management's discretion.
} 
financial accounting environment (before 1984) to a more regulated financial accounting environment (after 1971/1984) led to (l) an increase in the frequency of accounting changes during both intervention periods and (2) an increase in the frequency of accounting changes in following years, compared to the frequency of accounting changes in years before the implementation of the WJO and Title 8, ceteris paribus.

\section{(II) Magnitude of accounting changes}

The second research question will be designed to examine the magnitude of measurement changes, where measurement changes are defined as accounting changes with an effect on earnings and/or equity. Assuming that firms act opportunistically and government regulation, designed to restrict opportunistic behaviour, is effective it would be expected that:

\section{(Research Question) $\mathbb{R}_{2}^{c}$;}

the change from an almost nonregulated (before 1971) or partially regulated financial accounting environment (before 1984) to a more regulated financial accounting environment (after 1971/1984) led to a decrease in the magnitude of accounting changes with an impact on earnings and/or equity during both intervention periods and in the following years, compared to the magnitude of accounting changes with an impact on earnings and/or equity before the implementation of the WJO and Title 8, ceteris paribus.

The alternative research question based on the efficient contracting perspective states that:

\section{$\left(\right.$ Research Question) $\mathbb{R}_{2 \mathrm{~A}}^{\mathrm{c}}$ :}

the change from an almost nonregulated (before 1971) or partially regulated financial accounting environment (before 1984) to a more regulated financial accounting environment (after 1971/1984) led to an increase in the magnitude of accounting changes with an impact on earnings and/or equity during both intervention periods and in the following years compared to the magnitude of accounting changes with an impact on earnings and/or equity before the implementation of the WJO and Title 8 , ceteris paribus.

Under the efficient contracting theory, firms are not only expected to make more accounting changes in order to undo the effect of regulation $\left(R_{1 A}\right)$, the impact of these changes on earnings and/or equity is also expected to be larger. This is because firms will use measurement changes to try to minimize increased contracting costs that result from government intervention. Thus, the increased effect on earnings 
and/or equity of these accounting changes is expected to reflect the efforts to undo the effects of regulation.

In sum, the results of the empirical analysis of accounting changes will provide answers to two important questions: (1) did the implementation of the WJO and Title 8 affect firm's accounting method choice and, if so, (2) did firms act opportunistically, as would be expected from a government point of view (i.e. decreased frequency and magnitude of accounting changes after the intervention period) or did firms act efficiently, consistent with the assumption that firms will design contracts efficiently (i.e. increased level and magnitude of accounting/measurement after the intervention period).

In chapter three, specific hypotheses based on research questions $R_{1}^{c} / R_{1 A}^{c}$ and $R_{2}^{c} / R_{2 A}^{c}$ will be developed to test for the effects of both WJO and Title 8 on the frequency and magnitude of accounting changes. These hypotheses will then be compared with the empirical results, in sections 3.3 (WJO) and 3.4 (Title 8 ).

\subsubsection{Additional explanatory variables of financial accounting method choice: size, leverage, and industry effects}

Additional analyses, focusing on specific firm characteristics, can be considered to ascertain whether a positive theory of accounting can be applied to the selection of accounting policies before and after the implementation of the WJO and Title 8. As pointed out in chapter one, the accounting literature based on the contracting costs approach suggests that there will be a relationship between various economic and firm-oriented variables and accounting policy choice. A substantial body of accounting literature has emerged in recent years suggesting that firm characteristics influence the financial reporting strategy of the firm (an influential early paper is Zmijewski and Hagerman, 1981, p.147). The empirical research has concentrated basically on three main hypotheses about manager's financial accounting procedure choices. These are the size hypothesis, the bonus plan hypothesis, and the debt/equity hypothesis. Other firm characteristics have been investigated, including industry origin, management control/ownership, and implicit contracts between the firm and customers, suppliers, creditors, etc.

With respect to efficient and opportunistic choices of accounting procedures Christie and Zimmerman (1994, p.539) state:

... Empirical tests often assume opportunism and usually reject the null hypothesis of no association between accounting choice and firm specific variables such as leverage... However, many of the empirical regularities interpreted as evidence of 
opportanism can also be interpreted as occurring for efficiency reasons, which serves to confound these findings.

Only few studies have explicitly associated efficiency rationales with accounting method choice (Christie and Zimmerman, 1994, p.539). Malmquist (1990) found evidence of efficient contracting through accounting method choice for firms in the oil and gas industry. Mian and Smith (1990) reported on efficiency incentives to disclose unconsolidated financial statements, and recently Christie and Zimmerman (1994) provide evidence that managers" selection of accounting methods in firms that become take over targets is driven by efficiency motives. Throughout this section it is assumed that a relationship between accounting policies (around the intervention periods) and these firms characteristics can add evidence in favour of the efficient contracting perspective. Efficiency assumes that the choice of accounting procedures minimizes taxes, reduces costly bond covenant renegotiations, and facilitates optimal accounting procedure choices related to the firms" specific characteristics (industry) and their economic circumstances. Three additional hypotheses will be presented, relating to: (1) size, (2) leverage, and (3) industry origin. Although other variables might also explain the observations, information is only available on these three variables.

(1) One firm characteristic often mentioned in the empirical literature on accounting method choice is firm size.. ${ }^{12}$ This hypothesis is based on the assumption that large firms are politically more sensitive and therefore are faced with higher political costs (i.e. larger potential wealth transfers to government). In other words, size is a proxy for political attention. This provides an incentive to reduce reported earnings.

(2) In the debt contracting literature, attempts are made to relate accounting method choices to the economic implications of accounting based debt covenants and provisions, which rely heavily on reported accounting numbers. ${ }^{13}$ Dhaliwal (1980) was one of the first to suggest that the debt-equity ratio is a proxy for the effects of restrictive debt covenants (for oil and gas companies in their opposition to the proposed elimination of the full cost accounting method by the FASB). ${ }^{14}$ Loan

\footnotetext{
"See for instance Jensen and Meckling (1976), Watts and Zimmerman (1978), Dhaliwal (1980), Beratty and Verrechia (1989), and Moyer (1990).

${ }^{13}$ The covenant-based hypotheses are measured by debt-equity proxies.

${ }^{\text {I4 }}$ Several accounting choice studies have used arguments similar to Dhaliwal's study, including Holthausen and Leftwich (1983), Zmijewski and Hagerman (1981), Lilien and Pastena (1982), Hunt (1985), El Gazzar, Lilien and Pastena (1986), Johnson and Ramanan (1988), Press and Weintrop (1988), and Duke and Hunt (1990).
} 
agreements and debt covenants also exist in the Netherlands. ${ }^{15}$ The use of leverage as a proxy for these covenants could be useful to explain differences in firms' reactions to the regulatory changes. The idea is that higher leveraged firms would report more accounting changes.

(3) According to Foster (1986, p.156), literature based on cross-sectional and timeseries analyses provides reason to believe that accounting policy choice and the decision to alter those choices are partially determined by industry origin. ${ }^{16}$ The number of accounting changes is expected to differ across industries.

In the next sections these variables will be used to design three additional research questions to investigate differences in the effects of the two sets of financial accounting regulations across firms in the Netherlands.

\subsubsection{Size}

Regarding the implementation of the WJO and Title 8 , there are two possible relations between accounting method changes and firm size. First, and most consistent with the political cost hypothesis, it could be argued that large firms would tend to use accounting changes more frequently to minimize political exposure and thus political costs. Large firms would therefore tend to decrease reported earnings and smooth reported earnings to prevent windfall profits, by switching to more conservative accounting methods. Thus, large firms would be expected to make more discretionary accounting changes that affect earnings (i.e. measurement changes) than small firms.

Second, it could be maintained that large firms would anticipate forthcoming mandatory financial disclosure requirements more than small firms, and therefore would alter their accounting practices earlier. Furthermore, a number of (large) Dutch firms were also listed on foreign (US and UK) stock exchanges, which had more detailed financial disclosure regulations when the Dutch environment was still largely unregulated. ${ }^{17}$ Therefore, these and other large firms are likely to have disclosed more information than was required under Dutch law at that time, which implies that small and medium-sized firms would be more affected by the financial reporting

\footnotetext{
${ }^{15}$ For instance, Veld (1989) examined the use of anti-dilution agreements in the warrant
contracts of Dutch firms.

${ }^{16}$ See for instance studies conducted by Bowen, Noreen and Lacey (1981), Lilien and Pastena (1982), Daley and Vigeland 1983) and Ayres (1986).

${ }^{17}$ Especially in the case of the WJO.
} 
regulations. ${ }^{18}$ The frequency of accounting changes during the implementation of the WJO and, to a minor extent, Title 8 is expected to be higher for small firms. The research question based on these explanations states that:

\section{(Research Question) $\mathrm{R}_{3}^{c}$ :}

(I) the frequency of accounting changes with an impact on earnings and/or equity is expected to be higher for large firms, and (2) the impact of the implementation of the WTO and Title 8 on the frequency of accounting changes is expected to be higher for smaller firms, ceteris paribus.

Both interpretations of the size hypothesis might be found to be true. This would mean that (a) the magnitude of accounting method changes on earnings and/or equity for large firms would be larger and negative (income decreasing), and (b) the total number of accounting changes, including those with no effect or a positive effect on earnings and/or equity, would be larger for smaller firms.

\subsubsection{Leverage}

The argument addressed here is that an increase in accounting regulation could require highly leveraged firms to obtain (costly) amendments to their credit agreements. ${ }^{19}$ To avoid such amendments, firms with higher debt-equity ratios would be expected to make more accounting changes to avoid violation of debt agreements. Firms with high leverage ratios are assumed to act efficiently and will therefore have incentives to alter accounting procedures in order to satisfy capital suppliers. The WJO and Title 8 contain only a few specific valuation requirements, but the mandatory increase in disclosure requirements could have an effect on firms' accounting strategies since they have to reveal more information on their financial position. This leads to the following research question:

\section{(Research Question) $R_{4}^{c}$ :}

\footnotetext{
${ }^{18}$ This does not automatically imply that the "official" financial statements contain the same information as the reports filed with foreign (stock exchange) authorities. Brink (1989, p.222) for instance, compared the contents of the Philips financial statement and the form $20 \mathrm{~F}$ filed with the SEC in the US and concluded that the latter contained more detailed information.

${ }^{19}$ From an efficient contracting point of view this could imply that debt contracts have to be renegotiated, while the opportunistic behaviour approach asserts that accounting regulation could induce managers to act opportunistically to reduce the probability of violating debt agreements.
} 
(1) the frequency of accounting changes with an impact on earmings and/or equity is expected to be higher for firms with higher debt/equity ratios, and (2) the impact of the implementation of the WJO and Title 8 on the frequency of accounting changes is expected to be higher for firms with higher debt/equity ratios, ceteris paribus.

\subsubsection{Industry}

The effect of the mandatory financial reporting requirements would be expected to vary across industries. The efficient contracting perspective would then assume that firms in different industry groups face different changes in their investment opportunities. It could therefore be expected that firms within an industry group would make similar accounting changes. It might also be argued that industries with a more complex production environment also have more complex accounting systems, which in turn imply more alternative choices regarding the financial reporting strategy. ${ }^{20}$ The effects of the two Acts will be larger for firms with a more complex production process (industrial firms) than firms representing a more simple production process (trading firms). So, it is expected that:

\section{(Research Question) $\mathbb{R}_{5}^{c}$ :}

(1) the frequency of accounting changes with an impact on earrings and/or equity is expected to be different across industries, and (2) the impact of the implementation of the WTO and Title 8 on the frequency of accounting changes is expected to be different across industries. More specifically, the frequency of accounting changes and the impact of both regulations on the frequency of accounting changes is expected to be larger for industrial firms compared to trading firms, ceteris paribus.

Based on the research questions $\left(R_{3}^{c}, R_{4}^{c}\right.$, and $\left.R_{5}^{c}\right)$ presented in this section, specific hypotheses will be formulated and tested in Chapter three.

\subsubsection{Observation of the changes in accounting accruals}

The third method (see section 2.3 ) available in the literature to test whether

\footnotetext{
${ }^{20} \mathrm{Watts}$ and Zimmerman $(1986, \mathrm{p} .252)$ discuss an alternative explanation for differences between industries: the concentration ratio as a proxy for the degree of competition in an industry. It is argued that the higher the concentration ratio, the more likely it is that firms will use income decreasing procedures to avoid potential political (anti-trust) costs.
} 
regulatory changes have had an impact on management's choices of accounting procedures, is an analysis of the time series of accounting accruals and earnings. 2. Basically, a manager can influence earnings by choosing accounting methods that defer income to later periods or that take losses now (income decreasing) or shift income forward and defer losses to later periods (income increasing). Accruals are then defined as the difference between reported earnings and cash flow from operations, where it is assumed that cash flow from operations is not or less susceptible to manipulation: ${ }^{22}$

TOTAL ACCRUALS $=$ EARNINGS $_{\mathrm{T}}-$ CASH FLOW FROM OPERATIONS $(\mathrm{CFO})_{\mathrm{T}}$

Total accruals can be separated into a non-discretionary and a discretionary component. Part of the total accruals is constrained by rules, institutions or economic circumstances. These accruals are not susceptible to management, i.e. they are nondiscretionary. The remainder is at the discretion of management. Discretionary use of accruals might involve changes in accounting methods or procedures, but also more subtle techniques. So, accruals can be classified into:

TOTAL ACCRUALS = NON-DISCRETIONARY ACCRUALS + DISCRETIONARY ACCRUALS

In sum, the 'accrual process' is considered to be the visible result of the discretionary (voluntary) and non-discretionary (mandatory) accounting procedures and methods used by the firm's management. The (bottom line) earnings number presented in the annual report reflects the cumulative effects of these choices. Because it is difficult to compare earnings across firms, as a result of the variety of methods used to calculate accruals items (i.e., accounting procedures), the firm can manage accruals to alter reported earnings.

Based on the accrual approach, it is possible to test whether the implementation of the WJO and Title 8 has had an effect on the time series of non-discretionary and discretionary accruals and earnings. Research questions analogous to those presented in section 2.5 .2 have been designed, focusing on two main issues: (I) the level of accruals and (II) the variability of accruals and earnings. The purpose of the analysis is twofold. First, it should show whether the introduction of the WJO and Title 8 has

\footnotetext{
${ }^{21}$ In the appendix (4A) to chapter four the accrual method is discussed in detail. It also includes an example of the calculation of accruals directly from the $1992 / 1993$ financial statement of Royal Sphinx NV.

${ }^{22}$ This study assumes that managers do not manipulate the production, financing, and investment decisions of the firm to smooth earnings. Therefore, the only type of earnings management inwestigated relates to management's discretion in reporting the results of operations. Chapter four will discuss accounting accruals in greater detail.
} 
had an effect on accounting accruals and earnings. More specifically, the analysis should demonstrate what has been the impact of the WJO and Title 8 on the level and variability of non-discretionary accruals, discretionary accruals and eamings. Second, the results of the analysis can also be used to provide additional evidence on the opportunistic behaviour versus efficient contracting perspective.

The analysis of the contents of the two Acts, which was presented earlier in this chapter, reveals that both Acts introduced a number of new measurement rules and many new disclosure requirements. One example highlighted in relation to the WJO was the prohibition on the use of silent and hidden reserves. Assets could no longer be written of to one guilder (the so called one guilder valuation rule), enabling management to build up silent reserves on the balance sheet. Since all assets had to be shown on the balance sheet, as a result of the new legal requirements, an increase in total assets and equity is expected, which would in turn affect write-offs or depreciation expenses. Since depreciation expenses are an important part of (non-discretionary) accruals, it follows that non-discretionary accruals are expected to have increased.

Title 8 also contains additional disclosure requirements. For instance, it introduced specific formats for the balance sheet and profit and loss account. The obligation to provide more information on the procedures and valuation rules which have been applied to the various asset and liability items on the balance sheet, and the provisions relating to the profit and loss account, have made it more difficult to alter these rules in management's favour without revealing at least a part of the effect of these alterations on earnings. ${ }^{23}$ This could also be interpreted as an increase in nondiscretionary accruals.

\section{(I) Level of accruals}

According to the opportunistic behaviour perspective, the level of total accruals before the intervention is indicative of managements' opportunism. As a result of the more detailed regulation, containing new measurement rules and various disclosure rules, we expect that, ceteris paribus, non-discretionary accruals would increase for two reasons. First, because more accounting principles are mandatorily determined. Second, because information must be disclosed on the accounting policies used and, more importantly, the changes in those policies. It follows then that accounting policy choices would become less discretionary.

Assuming that regulation effectively reduced the available set of alternative financial

\footnotetext{
${ }^{23}$ In the case of writing off fixed assets, a decision to alter depreciation rules (for instance, any increase or decrease of the depreciation expense percentage) must be disclosed. This implies that the effect of this alteration on eamings is known, making it less appropriate for earnings
management purposes.
} 
reporting choices, non-discretionary accruals are expected to have increased. ${ }^{24}$ It is expected that:

\section{Research Question $\mathrm{R}_{1}^{\mathrm{a}}$ :}

the change from an almost nonregulated (before 1971) or partially regulated environment (before 1984) to a more regulated financial accounting enviromment (after 1971/1984) led to (1) an increase in the lenel of total accruals in both intervention years and the following years, compared to the level of total aconals in years prior to the intervention years, and (2) an increase in the level of nondiscretionary accruals in both intervention years and the years thereafter compared to the level of non-discretionayy accruals in years before the implementation of the WTO and Title 8 , ceteris paribus.

According to the efficient contracting theory, firms are expected to undo the potential effects of government intervention (as far as possible). That is, if non-discretionary accruals have increased as a result of the implementation of the WJO and Title 8 , firms would use the remaining discretionary accruals to offset this impact. Therefore, discretionary accruals would be expected to decrease because we assume that firms tend to undo the impact of increased non-discretionary accruals. ${ }^{25}$ So, if nondiscretionary accruals would increase and discretionary accruals would decrease, it follows that the level of total accruals would remain constant. The alternative research. question can then be stated as:

\section{Research Question $\mathrm{R}_{1: \mathrm{A}}^{\mathrm{a}}$ :}

the change from an almost nonregulated (before 1971) or partially regulated environment (before 1984) to a more regulated financial accounting envirowment (after 1971/1984) led to (1) no change in the level of total accruals in the intervention years and the following years, compared to the level of total accruals in years prior to the intervention years, and (2) a decrease in the level of discretionary accuals in 1971 and 1984 and the following years, compared to

\footnotetext{
${ }^{24}$ To test the income smoothing hypothesis empirically, the concept of a two-part hypothesis must be applied (Watts and Zimmerman 1986, p.135). This assumes that (1) actual earnings would follow a particular pattern in the absence of manipulations by management (earnings management), and (2) managers adopt or change accounting procedures to reduce the variance in income.

${ }^{25}$ Because we defined accruals negative (earnings $/$ - cash flow from operations), an increase in non-discretionary accruals has an income decreasing effect. So, in order to undo this effect firms are expected to use discretionary accruals to restore earnings as much as possible. Therefore, they use their discretion to decrease discretionary accruals (see $R_{\mathbb{A}}^{\mathbb{A}}$ ).
} 
the level of discretionary accruals in years before the implementation of the WJO and Title 8 , ceteris paribus.

\section{(II) Variability of accruals and eamings}

According to research question $\mathrm{R}^{*}$, non-discretionary and total accruals should have become larger, assuming opportunistic behaviour has been effectively restricted. So it is also expected that, ceteris paribus, the variability of total accruals would have decreased as a consequence of the passing of the WJO and Title 8 , because the proportion of accruals which are non-discretionary has increased, and earnings management possibilities have become smaller. Hence, the second research question states that: 26

\section{Research Ouestion $\mathbf{R}_{2}^{\mathrm{a}}$ :}

the change from an almost nonregulated (before 1971) or partially regulated envinonment (before 1984) to a more regulated financial accounting environment led to (1) a decrease in the variability of total and non-discretionary accruals in the intervention years and the following years, compared to the years prior to the intervention years, and (2) an increase in the wariability of earnings in the pertod after the invlementation compared to the years before the implementation of the WJO and Title 8 , ceteris paribus.

If the empirical analysis indicates that the level of accruals did not increase duning the intervention period and subsequent years this would suggest that regulation did not have an effect on accruals and eamings. If however, an increase is reported in the level of accruals after the implementation, but no evidence is found that the variability of accruals decreased or earnings variability increased, this would suggest that managers have (successfully) undone the effects of regulation. This is precisely what is expected from the efficient contracting perspective. Since the level and variability of accruals prior to regulation are expected to reflect efficient contracting behaviour, the regulatory intervention will lead to suboptimality. As a result of this, an increased variability pattern of discretionary accruals is expected after the implementation of the WIO and Title 8, as firms tend to undo (or at least partially counteract) the effects of regulation. Thus, the alternative research question states that:

\footnotetext{
${ }^{26}$ From a regulatory point of view, one could assume that managers are involved in income smoothing practices for reasons of self-interest, and accounting regulators have attempted to reduce management's ability to alter after-tax income through accounting method choice, by reducing their opportunities to manipulate reported income. The first research question could then be formulated alternatively: With the implementation of the Act on Annual Financial Statements (and Title 8) smoothing of reported net earnings has become wore difficult.
} 


\section{Research Question $R_{2 A}^{2}$ :}

the change from an almost nonregulated (before 1971) or partially regulated environment (before 1984) to a more regulated financial accounting environment led to (I) an increase in the variability of discretionary accruals in the intervention years and the years thereafter compared to the years prior to the intervention years and (2) no change in the variability of eamings in the period after the implementation, compared to the years before the implementation of the WTO and Title 8, ceteris paribus.

In summary, the variability of earnings and accruals prior to the WJO and Title 8 is, from a regulatory point of view, indlicative of opportunistic behaviour. Moreover, earnings variability is then expected to be too low. Due to regulatory requirements, non-discretionary and total accruals are expected to have increased in the year the new regulations became effective. After the implementation the variability of accruals is expected to have decreased, since discretionary accounting choices have been effectively restricted, and earnings variability has increased.

In Chapter four specific hypotheses will be developed based on these research questions to test for the effects of both WJO and Title 8 on the time series of accruals and earnings surrounding the intervention years.

First, the empirical analysis in chapter four focuses on the level and variability of total accruals and earnings, and on time series patterns of cash flow (from operations). The latter are included because an increase in the variability of accruals would only be relevant under unchanged economic conditions (cash flows).

Second, the analysis of accruals will be enhanced. A model will be employed that enables a more sophisticated separation of the discretionary and non-discretionary components of total accruals. Based on models developed by Jones (1991), Cahan (1992), and Guenther (1994), an expectation model for total accruals is used to estimate the non-discretionary component of accruals. This is done to relax the assumption that economic circumstances do not change. This is especially important for the purpose of this dissertation since non-discretionary accruals are expected to have increased as a result of the implementation of accounting regulation. This model enables the hypotheses regarding the level and variability pattern of both nondiscretionary and discretionary accruals to be tested. 


\subsubsection{Additional explanatory variables of financial accounting method choice: size, leverage, and industry effects}

Three additional hypothesis, analogous to those relating to changes in accounting methods, will be developed. These examine the relationship between the time series properties of accruals variability ${ }^{27}$ and the size, leverage, and industry variables. Again, the results can provide additional evidence to support the efficient contracting perspective.

\subsubsection{Size}

Firm size as a proxy for political costs is also expected to influence the effect of accounting legislation on accruals. According to the size hypothesis, large firms are expected to reduce reported profits. In addition to accounting changes to reduce income, they can also apply a more subtle technique, that is, they can manage accruals. It is therefore assumed that larger firms will engage in earnings management practices more than smaller firms, which implies that the variability of accruals will be larger. As a consequence, the effect of the enforcement of the WJO and Title 8 will also have a larger impact on larger firms. It is expected that:

\section{Research Question $R_{3}^{a}$ :}

the variability of accruals, both non-discretionary and discretionary, and earnings will vary according to size, and the changes in these pariability patterns before and after the implementation of the WJO and Title 8 are expected to be larger for large firms.

\subsubsection{Leverage}

A second variable expected to have an impact on accounting accruals is leverage. As we saw in section 2.3.2.3, additional mandatory financial accounting regulation could require highly leveraged firms to obtain (costly) amendments to their credit agreements. To avoid violation of debt agreements, such firms will engage in earnings management (McNichols and Wilson, 1989). Thus the variability of accruals will be higher for firms with higher debt/equity ratios. The effects of the WJO and Title 8 are also expected to be larger for these firms, since the non-discretionary part of accruals will increase, so that total accruals are expected to be more difficult to manage. This

\footnotetext{
${ }^{27}$ In this part of the analysis the focus is only on accruals variability. The results on these tests constitute the strongest evidence on the potential impact of the WJO and Title 8.
} 
leads to the research question that:

\section{Research Question $\mathrm{R}_{4}^{\mathrm{a}}$ :}

the variability of accrials, both non-discretionary and discretionary, and earnings will vary according to leverage, and the changes in these variability patterns before and after the implementations are expected to be larger for firms with higher debt/equity ratios.

\subsubsection{Industry}

Jones (1991, p.219) reported that accrual patterns are partially determined by industry characteristics. For instance, depreciation expenses are an important component of non-discretionary accruals. Another factor determining the nondiscretionary accrual component is economic circumstances, which vary across industries. As in the case of changes in accounting methods, it is expected that more complex accounting systems will provide more opportunities to manage discretionary accruals than a simpler accounting system. A trading firm has a simpler accounting system than an industrial firm. Hence, the impact of the introduction of the WJO and Title 8 is expected to be higher for industrial firms. Thus:

\section{Research Question $\mathrm{R}_{5}^{\mathrm{a}}$ :}

the variability of accruals, both non-discretionary and discretionary, and earnings will vary across industries, and the changes in these variability patterns before and after the implementation(s) are expected to be different across industries. More specifically, changes in variability of accruals and earnings are expected to be higher for industrial firms compared to trading firms.

Based on the accruals research questions $\left(\mathrm{R}_{3}^{\mathrm{a}}\right.$ to $\left.\mathrm{R}_{5}\right)$ presented in this section, specific hypotheses will be formulated and tested in chapter three.

To determine the impact of the two Acts, three different samples of companies will be followed during the period $1965-1990 .{ }^{28}$ These sets consist of non-financial firms

\footnotetext{
${ }^{28}$ Of these, the first set uses both accounting changes and accruals to examine the impact of the first Act, the second set uses accounting changes surrounding the introduction of the second Act, and the third set uses accruals in the period surrounding the second Act. More details will
} 
affected by the WJO and Title 8 and whose shares were traded on the Amsterdam Stock Exchange. Because of their listing, these firms published annual financial statements, even in the years prior to the WJO. Since the analyses focus on the effects of the requirements as laid down in the Acts of 1970 and 1984 , only NV/ ${ }^{29}$ (as defined in the Act) listed on the Amsterdam Stock Exchange before the WJO will be examined. Also, listed NVs have been chosen for the fact that the provisions of the WJO were applicable to all NVs (but only some categories of $\mathrm{BVs}^{30}$ ), and also because we assume, on theoretical grounds, that the effect of the requirements on NVs will be larger than on firms of other legal forms. ${ }^{31}$ Therefore the data used in the empirical tests in chapters three and four comes from a set of Dutch publicly listed, manufacturing, trading and service firms, excluding those providing financial services.

\subsubsection{Method I: Accounting method changes}

The data used in chapter three for the analysis of the accounting method changes has been gathered from two different sources. First, annual financial statements from the period 1965-1976 were collected to examine the effects of the WJO. Second, information on accounting method changes over the period 1977-1986, during which Title 8 became effective, were taken from Hoogendoorn (1990)..$^{32}$

\subsubsection{Method II: Accruals}

The data required to analyse the effects of accounting regulation on accounting accruals, presented in chapter four, has been taken from (1) the firms' annual financial reports for the years 1965-1974, in order to examine the impact of the WJO, and (2) a computer tape with annual financial data collected by the Central Bureau of Statistics for the years 1974-1990, in order to analyse the effects of the implementation of Title 8.

be provided in the next chapter.

${ }^{29} \mathrm{NV}$ (naamloze vennootschap) refers to a public limited liability company. See also Appendix
2B. 1 .

${ }^{30} \mathrm{BV}$ (beslotem penmootschap) refers to a private limited liability company. See also Appendix
2B.1. ${ }^{31}$ Compared to other legal forms $\mathrm{NV}$ s could be characterized as companies in which the
separation of management and ownership is the most distinct.

${ }^{32}$ For which II would like to thank Martin Hoogendoorn. 
This chapter has provided an overview of the introduction of two major sets of accounting regulations in the Netherlands. The social and political setting that led to these changes has also been discussed (see appendices to this chapter). After a historical overview of the major events that led to the implementation of the two Acts, their contents have been analysed and described.

The discussion and summary presented in appendix $2 \mathrm{~A}$ of the reasons why accounting regulation was considered desirable or even indispensable revealed that many politicians involved in the reformation process of Dutch financial accounting regulation believed that existing accounting practices were inadequate. The reason for this was twofold. First, it was said that managers of firms disclosed so little financial information that a sound judgement of the firms' economic performances was not possible. Second, there was far too much discretion in the way that a firm's economic performance, i.e. its profit, could be determined. Managers were able to alter earnings in the way most favourable to themselves, thereby harming the interests of the other parties related to the firm such as shareholders, employees, suppliers and creditors. Whether these assumptions are true remains to be empirically examined. It is significant that no empirical investigations were conducted at the time to support these assumptions.

The first major change took place with the implementation of the Act on Annual Financial Statements in 1971, which significantly increased disclosure requirements for the companies affected. The provisions of the Act affect the balance sheet, profit and loss account and the notes. Section 2.2 .1 provided a brief summary of the major changes in financial reporting regulations accounting, while the most important changes are reported in tables 2.1 and 2.2 of appendix $2 \mathrm{~B}$. $\mathrm{L}$.

The second major shift occurred in 1984, the year in which Title 8 became effective. This Act embodied the requirements laid down in the Fourth EEC Directive. Its main purpose was to harmonize financial accounting regulations within the member countries of the EEC. As reported in section 2.2.2, additionall disclosure rules became effective, including prescribed schedules for the balance sheet and profit and loss statements. The Act also contained certain measurement rules. Tables 2.3 and 2.4 of appendix $2 \mathrm{~B} .2$ provide a summary of the additional legal reporting requirements.

Section 2.3 introduced the main research questions of this dissertation. Assuming that the aim of the government in introducing more rigorous financial accounting requirements was to reduce the possibilities of earnings management, it is expected that managements' opportunities to alter earnings by means of accounting policy 
choices will have been curtailed. First, this would have had an effect on accounting (policy) changes, that is, the number of accounting changes is expected to have changed (increased) in the year of enactment and thereafter. Second, the legal requirements for financial accounting are also expected to have had an impact on accounting accruals, defined as the difference between cash flow (from operations) and earnings. The non-discretionary part of accruals is expected to have changed (increased) with the implementation of both Acts. In the following years the variability of (total) accruals would then have decreased, while earnings variability would be expected to have increased.

Additional research questions were developed to examine the effect of firm size and leverage, and the industry in which it operates, on accounting policy choice. Existing empirical literature has suggested that these characteristics may have an effect. These research questions may provide evidence to distinguish between efficient contracting and opportunistic behaviour. They will be developed into specific hypotheses in chapters three and four, and compared with the data.

Finally, section 2.4 presented the data used in this dissertation. Empirical evidence on the effects of both Acts on the phenomena described will be provided in subsequent chapters. 


\section{Chapter 3}

\section{Empirical evidence on the effects of the implementation of the WJO in 1971 and Title 8 in 1984: an analysis of accounting method changes ${ }^{1}$}

\section{1}

Introduction

The previous chapter presented a historical overview of the Dutch regulatory system in the field of financial accounting. The contents of two major regulatory changes, the introduction of the WJO and the enactment of Title 8, have been discussed. Based on this, research questions were generated with respect to the impact of these accounting regulations on accounting method choices. This and the following chapter will present the results of an empirical analysis of the way in which managements' choices regarding the use of accounting policies, i.e. accounting method choices, have been affected by these two regulatory interventions. The effects of the mandatory changes in financial reporting regulation on firms' accounting method choices will be the central theme.

This chapter is organized as follows. Section 3.2 elaborates the research questions proposed in section 2.3.2. It also discusses the research method and data selection in more detail. The results of the empirical analyses will then be presented in the subsequent two sections. Section 3.3 reports on the analysis of the time-series on accounting changes surrounding the introduction of the WJO. Then, in section 3.4 the results on the analysis of the second time-series on accounting changes, the period surrounding the implementation of Title 8 , will be provided. The final section of this chapter summarizes the results and provides concluding remarks.

\footnotetext{
'Earlier drafts of this chapter were presented at the Accounting Workshop, Uniwersity of Leuven, March 1995, and the Annual Congress of the European Accounting Association, Birmingham, May 1995.
} 
The research question to be tested in the first part of the empirical analysis of this dissertation is that, ceteris paribus, accounting changes increased or decreased as a result of the passing of (1) the WJO and (2) Title 8 in the years the two Acts became effective and thereafter. Therefore, firms' accounting method choices are examined in the periods surrounding the implementation of the two Acts. In general, the provisions concerning the content of the WJO became effective from financial years ending on or after December 31, 1971, while the stipulations regarding Title 8 were enforced from 1984 onwards. So the years 1971 and 1984 are the first in which firms had to comply with the new financial reporting regulations.

In section 2.3.2, five research questions $\left(R_{1}^{c}\right.$ to $R_{5}^{c}$ ) have been developed regarding the frequency and magnitude of accounting changes, reflecting firms' responses to the introduction of the additional legal requirements regarding the preparation of their financial statements. Based on research question $R_{1}^{c}$ (i.e. opportunistic behaviour) the basic idea was that the number of accounting changes after the year(s) of introduction has decreased. The alternative research question $R_{1 \mathrm{~A}}^{c}$ (i.e. efficient contracting) stated that accounting changes would increase after the introduction of government regulation. ${ }^{2}$ Note that during the intervention periods accounting changes are expected to have increased, due to mandatory financial reporting procedures introduced by both Acts.

The expected pattern of accounting method changes surrounding the WJO and Title 8 , according to research question $R_{1}$ and $R_{1 A}$ can be visualized as follows. ${ }^{3}$ Figure 3.1 represents the expected level of accounting method changes before, during, and after the implementation of the WJO (period I) and Title 8 (period II).

First, and consistent with research question $R_{1}$, the increase in the year of the implementation would be followed by a decrease in following years. More specifically,

${ }^{2}$ Another explanation for this is, as far as the WJO is concerned, that the law prior to 197 I did not require disclosure of accounting method changes. The analysis of the contents of the WJO revealed that the Act of 1971 contained a separate section on this matter, so an increase in the number of accounting changes would be expected with the implementation of the WJO.

${ }^{3}$ It is assumed that there is a nomal level of accounting method changes as a result of (1) changing economic circumstances, (2) natural growth of the firm, and (3) innovations in financial accounting. 
Figure 3.1: Expected average levels of accounting changes surrounding the implementation of the WIO (period $I$ ) and Title 8 (period II) according to $\mathrm{K}_{1}$ and $\mathrm{R}^{\mathrm{c}}{ }_{\mathrm{AA}}$

- - -. Average anawal anumber of accounting changer (RIA; efficenx contracting)

...- Average annual number of accounting changes (RI; opportunistic behaviour)

Period II

Period ll:

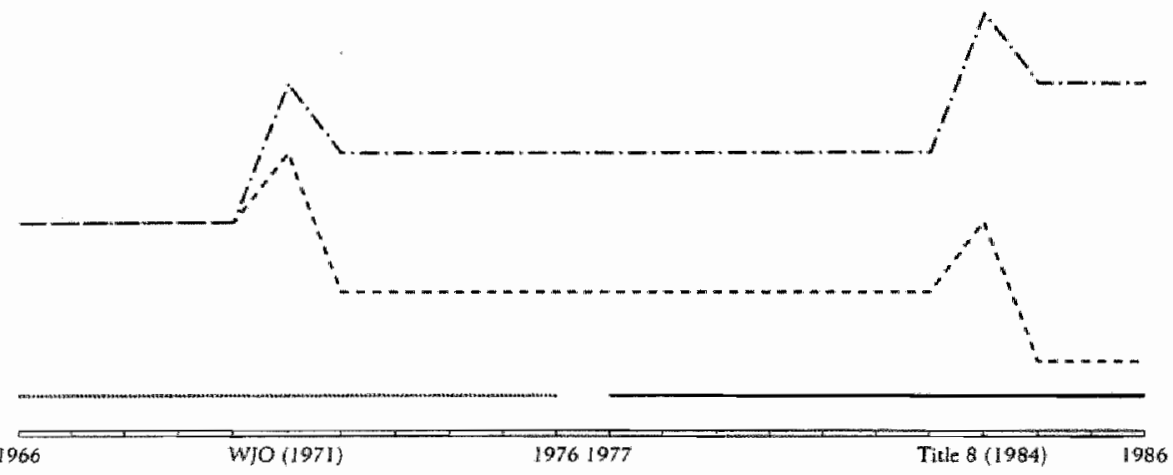

the number of accounting changes after the implementation is expected to be lower compared to the number of accounting changes before the implementation of both Acts. This would suggest that accounting regulators have been effective in reducing management's discretion in their accounting method choices.

Second, according to research question $R_{1 A}^{c}$ the increase in the years of implementation is not followed by a decrease in the number of accounting method changes, but now the number of accounting method changes after the 
implementation is higher than before the implementation of both Acts.

The research questions presented so far are based on the assumption that the implementation of financial reporting regulation will have an effect on accounting method choice. However, apart from the patterns described in figure 3.1 there is a third alternative outcome possible, which will be referred to as the no-effects hypothesis. The no-effects hypothesis refers to a situation in which the number of accounting method changes will increase only in the year of implementation, but with no further effect (i.e. no increase or decrease) in subsequent years. This would imply that the regulatory restrictions of the Acts have not effectively narrowed the firm's accepted financial reporting set. The changes (i.e. increase in accounting changes) in 1971 and 1984 would then constitute primarily mandatory accounting changes regarding disclosure issues. For, instance, it could be argued that the implementation of the WJO was only a codification of existing financial reporting practice in the Netherlands, in which case one might expect no effect or only a small (insignificant) effect in 1971, and none thereafter. A similar line of reasoning holds for the implementation of Title 8.

In sections 3.3 and 3.4 the assumptions underlying the two alternative research questions $\left(R_{1}^{c}\right.$ and $R_{1 A}^{c}$ ) regarding the effects of the implementation of the WTO and Title 8 will be tested through specific hypotheses. These hypotheses are based on either opportunistic behaviour or efficient contracting assumptions. The alternative no-effects hypothesis will not be tested directly in these sections, since the research questions developed in chapter two were constructed around the opportunistic behaviour/efficient contracting theory. But, if the results of the empirical analysis support neither the opportunistic behaviour nor the efficient contracting based hypotheses, this would implicitly provide evidence in favour of the alternative noeffects hypothesis.

\subsubsection{Method}

Throughout this dissertation the terms 'changes in financial accounting method' or 'accounting method changes' are used. A change in the firm's accounting policy, or an accounting method change, relates to changes in the specific measurement systems and disclosure techniques previously selected from the total set of available alternative financial reporting rules (see also Hoogendoorn 1990, p.6). Accounting changes
include:

(1) Discretionary (voluntary) accounting method changes and non-discretionary (mandatory) accounting method changes. 
(2) Accounting method changes with an effect on equity and/or net income (measurement changes) and changes that do not influence equity or net income (classification changes).

The term accounting method change will be used to refer to all these types of changes in a firm's set of financial reporting policies.

The newly established legal requirements applicable since 1971 and 1984 regarding financial accounting regulation induced mandatory accounting changes. As concluded in the previous chapter, these regulations largely concern classification requirements (with no effect on equity and/or income), while to a smaller extent measurement. requirements were induced.

As shown in table 3.1, the empirical analysis of the effects of the first Act, the WJO, differs from the analysis of the effects of Title 8 in that we examine the impact of the WJO on all four categories of accounting changes, whereas the analysis of Title 8 excludes classification changes (accounting changes that do not have an effect on net income and/or equity). The reason for this will be explained in the next section. This implies that the total number of accounting changes reported in the second analysis is smaller than in the first, since this includes classification changes.

Table 3.1: Accounting changes included in the empirical analyses

\begin{tabular}{lll}
\hline types & WIO & Tite 8 \\
\hline discretionary accounting changes & yes & yes \\
non-discretionary accounting changes & yes & yes \\
\hline measurement changes & yes & yes \\
classification changes & yes & no \\
\hline
\end{tabular}

Note that: all accounting changes $=$ discretionary + non-discretionary changes all accounting changes $=$ measurement changes + classification changes

In this dissertation the data on the above mentioned types of accounting changes were determined directly from firms" annual financial statements. ${ }^{4}$ Accounting

${ }^{4}$ Unlike the United States, for which there are a variety of data bases to identify firms making accounting changes, no such readily available data sets exist in the Netherlands. Data bases in the United States include the Compustat tapes, National Automated Accounting Research 
changes are defined as changes in the specific measurement systems and disclosure techniques selected previously (from the total set of alternatively available financial reporting rules) by a firm. For the purpose of this dissertation annual financial statements of the sample firms, comprising of a balance sheet, profit and loss account and the notes thereto, were analysed for the years 1966-1986 in order to obtain accounting changes.

It should be noted that basically three possible situations can be encountered in determining accounting changes directly from the financial statements:

(1) The notes to the balance sheet and profit and loss account contain information on the accounting change(s) and its effect on earnings and/or equity.

(2) The notes to the balance sheet and profit and loss account contain information on the accounting change(s) but not on its effects on earnings and/or equity.

(3) The notes to the balance sheet and profit and loss account contain no information whatsoever on the accounting change(s).

To collect information in the first and most straightforward situation is simple: the relevant data on accounting changes are directly entered into the database. The second and third scenario provide potential problems, since some or all of the necessary information is not disclosed. To determine the effects of an accounting change (situation 2) or to determine that an accounting change took place (situation 3), a comparison of two subsequent annual financial statements is necessary to (a) detect the accounting change and (b) determine it's nature and possible magnitude.

The outcomes of the analysis of the different types of accounting changes by the sample firms are combined in a database containing information on all accounting changes for each separate year and firm. ${ }^{5}$ Hoogendoom (1990) applies the same methodology.

In order to analyse the accounting changes, three different approaches are available (Lilien et al., 1988, p.645). These are:

(a) An all-change appraach, where each accounting change is treated as an independent observation.

(b) A firm-year approach, whereby the impact of all accounting changes in one year

System (NAARS), Accounting Trends and Techniques (ATT), the Wall Street Journal Index, and the $8-K$ reports filed with the Security and Exchange Commission (SEC).

"The database used in this dissertation contains all information on accounting method changes in the periods 1965-1976 and 1977-1986. Appendix 3C.I and 3C.2 list all accounting
changes and their features. 
are added together to produce one observation per year.

(c) A cumulative or total-effect approach, where the total effect of all accounting changes over the entire period for a firm are treated as one observation.

In this research the all-change approach is selected, since this provides the most detailed information, at the level of individual accounting changes, and this is crucial to the analysis of the impact of financial accounting legislation. The total-effect method is inadequate since it will dilute firm-year results. Detailed information on all accounting changes found in the years 1966-1986 is given in appendices 3C.1 and $3 \mathrm{C} .2$.

The research method of observation of accounting method changes involves another important choice: that is the trade-off between choosing more detailed (firm specific) information and a small(er) sample size or less detailed information and a large(r) sample size. The first alternative would then represent a case study approach, which would not only involve data from annual financial statements but also additional (non-financial) information on each specific firm. However, the empirical tests conducted in this dissertation are based on two large samples, from which information on accounting changes was gathered from the annual reports of these firms. Consequently, the results of these analyses are reported on an aggregate level. It should be mentioned that this approach precludes certain firm-specific information ${ }^{6}$ and therefore obviously bears certain limitations in that it includes no information which might be of interest in further analysing a firms' accounting change behaviour in relation to firm specific circumstances. The case study approach would require more information than is provided in the financial statements. Especially, with respect to the older years, recollection of this information is very difficult. ${ }^{7}$

\subsubsection{Sample selection and test period}

To determine the impact of the Acts, two non-random samples of publicly traded firms were examined in the period surrounding the implementation. In order to identify the effects of the new legal financial accounting requirements on accounting practice a multi-year analysis is conducted over a period covering 21 years, i.e. 1966 1986. This period has been divided into two sub-periods based on the events

${ }^{6}$ Although it should be mentioned that appendices $3 \mathrm{C} .1$ and $3 \mathrm{C} .2$ do provide detailed information per accounting change per firm.

${ }^{7}$ Nevertheless, the choice for the research method applied in this dissertation has been carefully made, considering both aspects of internal and external validity (Ryan et al., 1992, pp.85-101). 
described. Figure 3.2 illustrates the two periods. The first period covers five years before and five years after 1971 (1966-1976), the year in which the WJO became effective. The second period links up with the first time-series, and covers a period of 10 years, $1977-1986$, including 1984 , the year in which Title 8 was implemented. ${ }^{8}$ In the second the period data is available for seven years before 1984 and three years since 1984, so both periods are not equally long.

Figure 3.2: Sample periods I and II based on the events related to the introduction of the WJO and Title 8

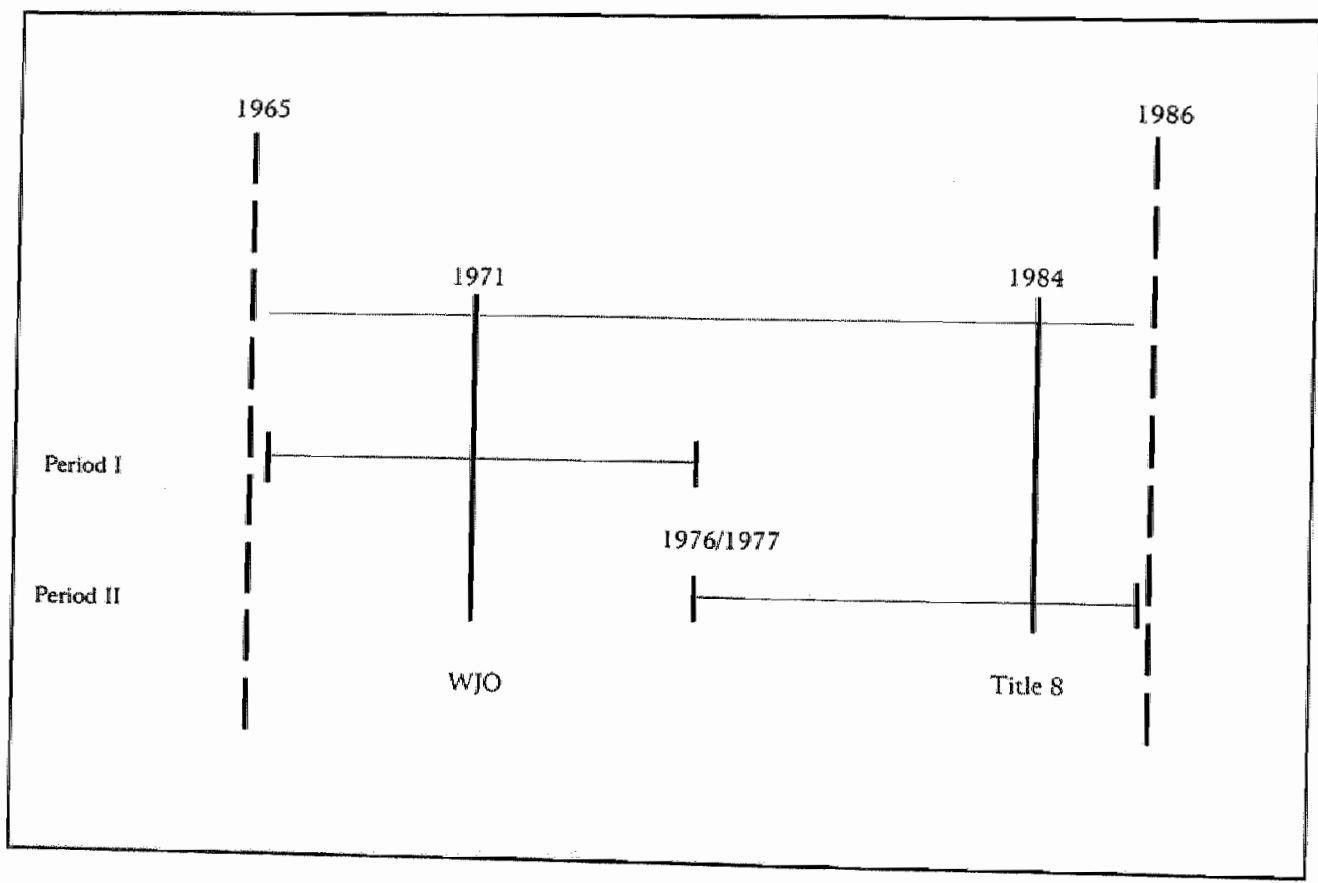

Both samples of firms consist of non-financial firms affected by the WJO and Title 8, whose shares were traded on the Amsterdam Stock Exchange (ASE). This means that only large (as defined in the Act) public companies (NVs) were examined, since

${ }^{8}$ Data for the second period is derived from the database used in Hongendoorn (1990), which covers the years 1977-1986. As a consequence, no data were available after 1986. 
only these companies had to meet all the requirements laid down in the Act of 1970 (and subsequently Title 8).

\section{Sample 1}

To measure the effects of the implementation of the Act on Annual Financiall Statements, an original sample of 118 companies was selected from the total population of 328 companies listed on the Stock Exchange in January 1965 (Financiele Dagblad, January 5, 1965, pp.10). Of these 118, financial statement information was available. Subsequently, the sample size was further reduced by omitting all remaining banking firms, financial institutions and insurance companies (22 banks and insurance companies). Further 27 firms were eliminated from the original sample because their time series data was incomplete because of problems due to data availability in the $1960 \mathrm{~s}$, bankruptcy and mergers. The final sample used in the first part of the empirical analysis consists of 64 firms listed on the ASE between 1966 and 1976. From these, all annual accounts in the period 1965-1976 were obtained in order to search for relevant accounting method changes. ${ }^{9}$ A full list of the names of these companies is presented in appendix 3A.1.

\section{Sample 2}

To test for possible effects of Title 8 a second sample of companies was taken from the original sample used by Hoogendoorn (1990), covering accounting changes for the period 1976-1986. The original Hoogendoorn sample also included companies in the banking, financial institutions, and insurance industry. For reasons explained in chapter two these firms were deleted from the original sample, so the final sample used to assess the impact of Title 8 consists of 107 firms.

Also, it should be mentioned that for this second sample no information was available on accounting changes that do not have an effect on income and/or equity (classification accounting changes), because the data set did not contain information on this type of accounting change. ${ }^{10}$ The names of the sample firms are also listed in appendix 3 A. $2 .^{11}$

\footnotetext{
${ }^{9}$ In total, $64^{*} 12=768$ annual accounts have been examined. These were all collected from the Economic Historic Archives at the Erasmus University Rotterdam, for which I thank Mrs. A. Stichova, Dr. I. Brezet and Mrs. M. Dupon.

${ }^{10}$ The data used here is from Hoogendoorn's accounting method changes dissertation (Hoogendoorn, 1990). Hoogendoom focuses on the category of accounting changes which is expected to have the most significant economic effect; those with an effect on equity and/or income.
}

${ }^{11}$ The number of firms common to both samples is 39 . See also appendices $3 \mathrm{~A} .1$ and $3 \mathrm{~A} .2$. 
Table 3.2: Selection of sample firms

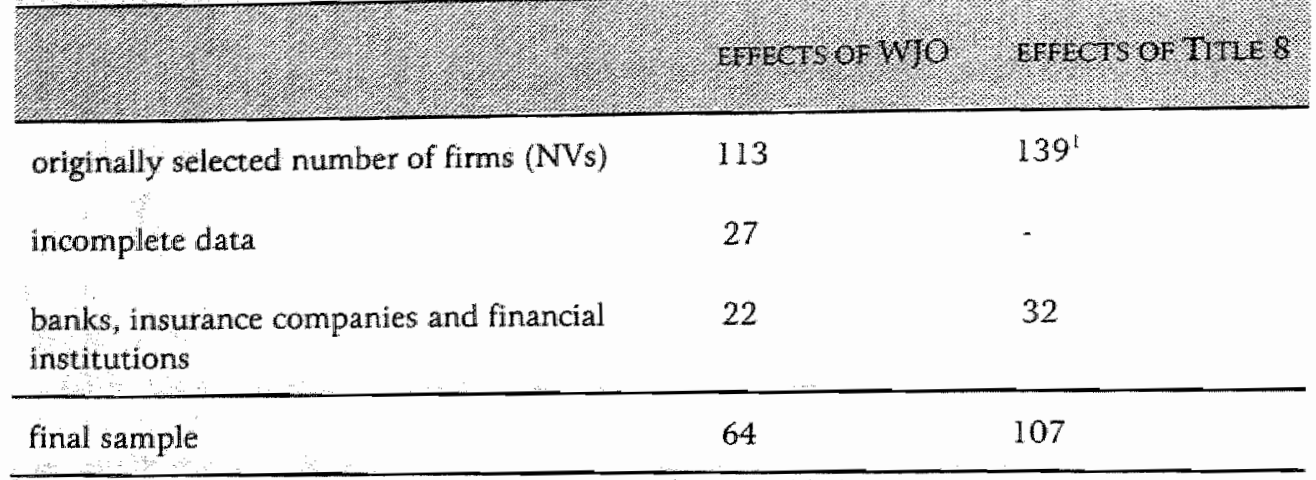

${ }^{2}$ Original sample is exactly the same as Hoogendoorn (1990)

The following sections will outline the results of the empirical analyses with respect to the number of accounting changes and their impact on earrings and equity. 
Hypotheses and results of the empirical analysis of accounting method changes ( 1 ): introduction of the first major accounting regulation in the Netherlands (WJO)

\subsubsection{Introduction}

This section reports the results of the analysis of the first time series, between 1966 and $1976 .{ }^{12}$ The analysis focuses on the five research questions formulated in section 2.3.2. First, descriptive statistics will be presented on the frequency of accounting changes during this period in order to provide an answer to the question underlying the first research question $\left(R_{1}^{c}\right.$ and $\left.\mathbb{R}_{1 N}^{c}\right)$. Second, information will be provided on the nature and magnitude of the accounting changes which affect equity and/or earnings (i.e. measurement changes), the second research question $\left(\mathbb{R}_{2}^{c}\right.$ and $\left.R_{2 A}^{c}\right)$. Third, the results of the tests regarding research questions 3,4 , and 5 are reported. These tests are again based on the frequency and nature of accounting changes, only this time for subsamples. The results (1) provide insight into the impact of the WJO on financial reporting practice, and (2) they may point to inferences about the two competing hypotheses (opportunistic behaviour/efficient contracting).

\subsubsection{Hypotheses}

Based on the research questions stated in section 2.3.2, specific hypotheses will now be formulated to empirically examine the impact of the WJO. The hypotheses to be tested in subsequent sections are summarized below.

\section{Hypotheses:}

$\mathrm{H}_{1}^{\mathrm{c}}$ : the change from an almost nonregulated financial accounting environment (before 1971) to a more regulated financial accounting enviromment (after 1971) led to (1) an increase in the frequency of accounting changes during the intervention period, and (2) a decrease in the frequency of accounting changes in following years, compared to the frequency of accounting changes in years before the implementation of the WJO.

\footnotetext{
${ }^{12}$ As explained in the previous section, in order to detect accounting changes not reported in the notes to the financial statement, a comparison with the previous year financial statement is required. Since no financial statement data prior to 1965 was collected. 1966 is the first year for which these accounting changes can be reported.
} 
$\mathrm{H}_{1 \mathrm{~A}}$ : the change from an almost nonregulated funancial accounting environment (before 1971) to a more regulated financial accounting environment (after 1971) led to (1) an increase in the frequency of accounting changes during the intervention period, and (2) an increase in the frequency of accounting changes in following years compared to the frequency of accounting changes in years before the implementation of the WJO.

$\mathrm{H}_{2}^{c}$ : the change from an almost nowregulated finarcial accounting environment (before 1971) to a more regulated financial accounting environment (after 1971) led to a decrease in the magnitude of accounting changes with an impact on eamings and/or equity during the intervention period and following years compared to the magnitude of accounting changes with an impact on earnings and/or equity before the implementation of the WJO.

$\mathrm{H}_{2 \mathrm{~A}}$ : the change from an almost nonregulated financial accounting environment (before 1971) to a more regulated financial accounting environment (after 1971) led to an increase in the magnitude of accounting changes with an impact on eanings andlor equity during the intervention period and following years compared to the magnitude of accounting changes with an impact on earnings and/or equity before the implementation of the WrO.

$\mathrm{H}_{3}{ }_{3}$ : the frequency of accounting changes with an impact on eamings and/or equity is expected to be higher for large firms, and the impact of the implementation of the WTO on the frequency of accounting changes is expected to be higher for smaller firms.

$\mathrm{H}_{4}^{\mathrm{c}}$ : the frequency of accounting changes with an impact on eamings and/or equity is expected to be higher for fims with higher debt/equity ratios, and the impact of the implementation of the WTO on the frequency of accounting changes is expected to be higher for firms with higher debtlequity ratios.

$\mathrm{H}_{5}^{\mathrm{i}}$ : the frequency of accounting changes with an impact on eamings and/or equity is expected to be different across industries, and the impact of the implementation of the WJO on the frequency of accounting changes is expected to be different across industies. More specifically, the frequency of accounting changes and the impact of the WJO on the frequency of accounting changes is expected to be larger for industrial firms compared to trading finms. 

and 1976

To provide evidence on the first hypothesis $\left(\mathrm{H}_{1}^{\mathrm{c}} \mathrm{JH}^{\mathrm{c}} \mathrm{LA}\right)$, table 3.3. presents distribution data on the frequency of accounting changes in the period 1966-1976. There were a total of 1308 changes made by the 64 sample firms over a period of eleven years, an average of 119 changes per year for all firms, or 1.86 accounting changes per year for each firm (i.e., a 'firm/year average' of 1.86 ). Of these 1308 accounting changes, $81 \%$ (1060) were classification changes and $19 \%(248)$ were measurement changes (with an effect on earnings and/or equity). The 248 measurement changes consisted of 214 changes with an effect on equity and 149 changes with an effect on earnings. Of all measurement changes 115 had an effect on both earnings and equity. The firm/year average for classification changes was 1.51 , and for measurement changes it was 0.35 .

As expected, 1971, the year in which the WJO became effective, is the year with the highest number of accounting changes (334). In that year the firm/year average for all changes was 5.22. This pattern is also consistent when looking at classification and measurement changes separately. Classification and measurement changes also show the highest annual averages in 1971. Firm/year averages for classification accounting changes and accounting changes with an effect on earnings and/or equity were 4.39 and 0.83 respectively. The smallest number of total accounting changes found was for 1966, with an average of 1.00 accounting change per firm, while 1967 had the lowest total number of accounting changes with an effect on earnings and/or equity, only 12 .

In order to analyse the yearly changes in the pattern of accounting changes, a comparison of all subsequent annual average numbers was conducted for both types of accounting changes. Table 3.3 shows the corresponding t-values. ${ }^{13}$ In essence, the t-values for both types of accounting changes show the pattern already noted: a significant increase in 1971, followed by a significant decrease in 1972. Differences in means between the other years are not significant.

The next step was to examine the average number of accounting changes in the period following the implementation of the WJO (1971), to see whether it was greater than in the period before its introduction. Table 3.4 shows the results. The first period,

\footnotetext{
${ }^{13}$ Throughout this study parametric test results will be presented. Howewer, if the test results from an equivalent nonparametric test are substantially different these will also be provided. In table 3.3 for instance, differences were also tested with a nonparametric Wilcoxon signed rank test. This led to similar results.
} 


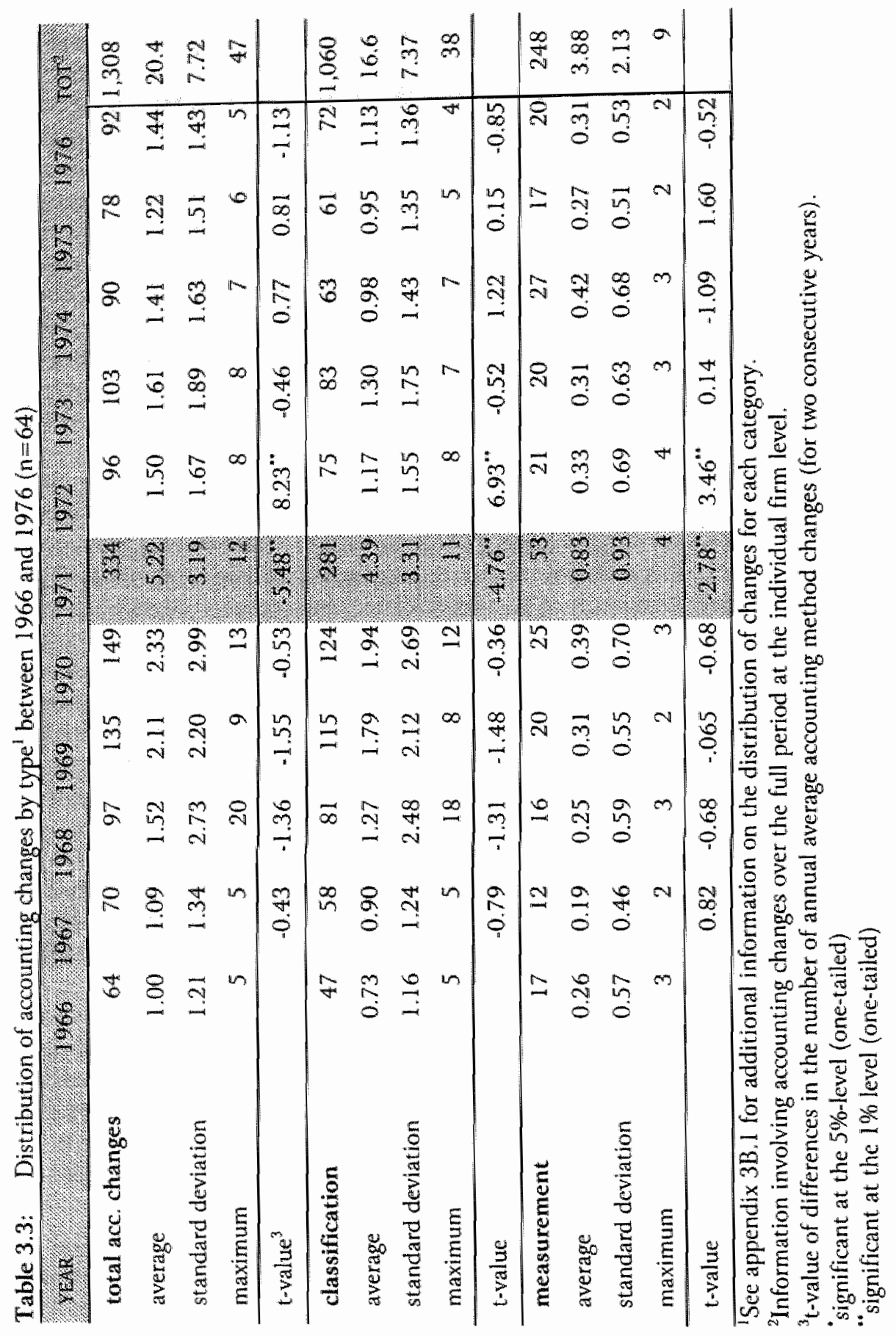


1966-1970, covers 5 years during which there were 515 changes, and the second period, 1971-1976, covers 6 years during which there were 793 changes. The firm/year averages before and after the implementation of the WJO are thus 1.6I and 2.07. A similar pattern is reported on classification and measurement changes. The table reports significant differences in means with respect to both types of accounting changes: the average level of accounting changes increased significantly after the enactment of the WJO ${ }^{14}$ As was already clear in table 3.3, the increase is due solely to one year, 1971. To investigate this in more detail, the average number of accounting changes after the introduction of the WJO was determined, but with 1971 excluded. The effect reported in table 3.5 is a decrease in the average number of all types of accounting changes after $197 \mathrm{I}$ (firm/year average 1.43), in accordance with the annual pattern evident in table 3.3.

Table 3.4: Comparison of accounting changes before and after 1971, including 1971 $(n=64)$

\begin{tabular}{|c|c|c|c|}
\hline 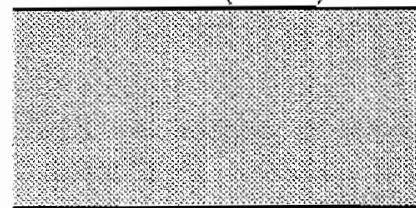 & gerore (1) 1960 & 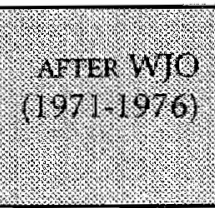 & 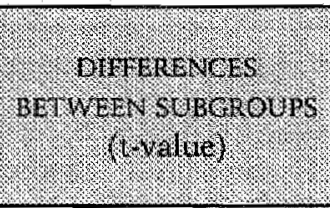 \\
\hline total accounting changes & 515 & 793 & \\
\hline firm/year average & 1.61 & 2.07 & $-2.56^{\circ}$ \\
\hline standard deviation & 0.99 & 1.00 & \\
\hline classification changes & 425 & 635 & \\
\hline firm/year average & 1.33 & 1.65 & $-1.91^{* *}$ \\
\hline standard deviation & 0.94 & 0.97 & \\
\hline measurement changes & 90 & 158 & \\
\hline firm/year average & 0.28 & 0.41 & $-2.5 \mathrm{I}^{* *}$ \\
\hline standard deviation & 0.27 & 0.29 & \\
\hline
\end{tabular}

"Significant at the $1 \%$ level (one-tailed)

\footnotetext{
${ }^{14}$ If 1970 is considered as a year in which companies already anticipated the new legislation, and this year is therefore included in the post-WJO period, the test results are all significant at the $0.5 \%$ level.
} 
This decrease is caused by a decrease in classification changes. ${ }^{15}$ However the firm/year average for measurement changes actually increased after the implementation of the WJO (from 0.28 to 0.33 ).

Table 3.5: Comparison of accounting changes before and after 1971, excluding 1971 $(n=64)$

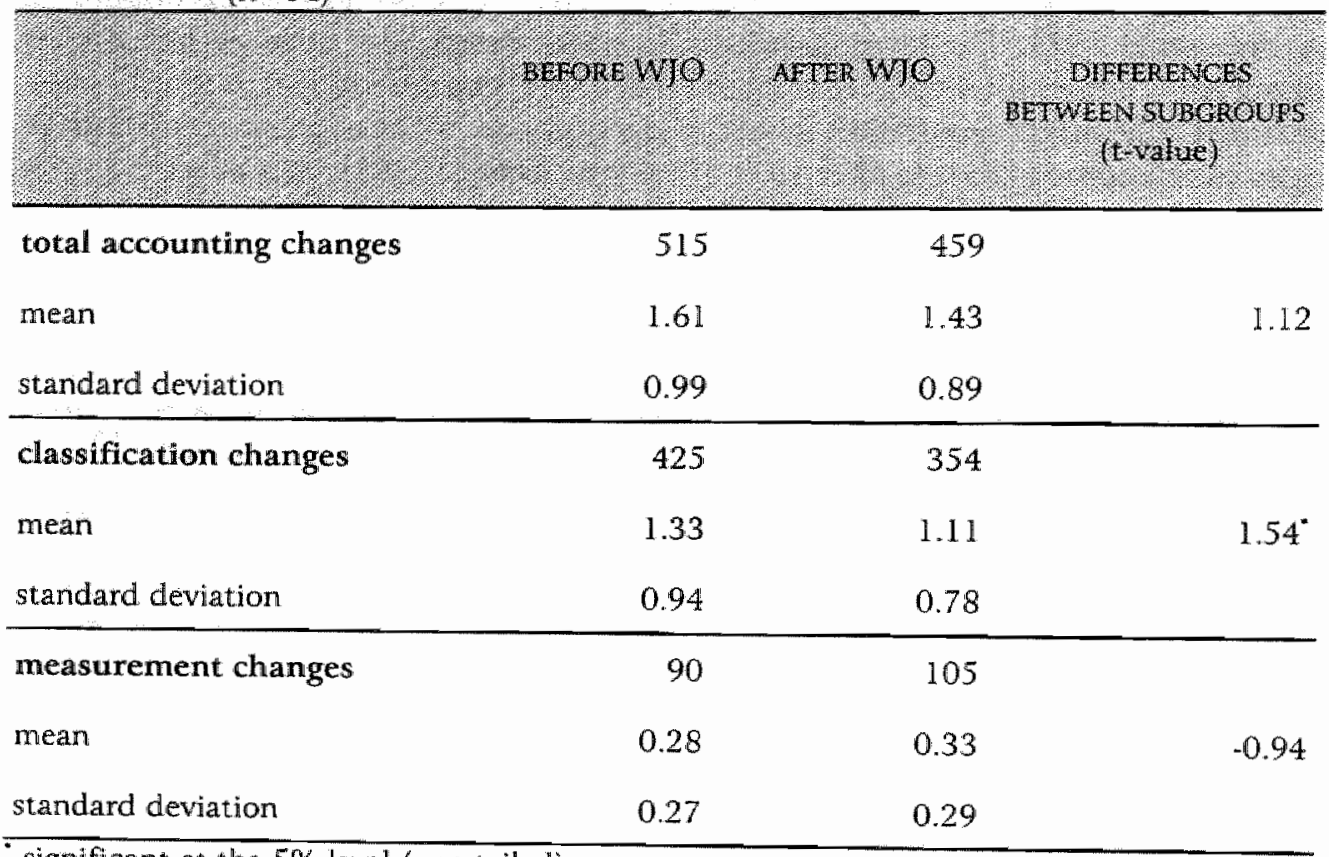

significant at the $5 \%$ level (one-tailed)

As mentioned in table 3.3, information is also available on separate categories of accounting changes. Appendix 3B reports on the distribution of accounting changes per category between 1966 and 1976. The two largest categories of changes constitute (1) fixed asset valuation and (2) participations. The appendix also illustrates the distribution of changes per category over time, which enables us to control for patterns in accounting changes that might have been induced by external (economic) circumstances, which might not be directly related to the introduction of the WJO in 1971.

\footnotetext{
${ }^{15}$ This might be expected, since most classification changes reported in 1971 are the result of the disclosure requirements in the WJO. After 1971, classification changes would not be
expected to in
} 


\subsection{4}

Magnitude of accounting method changes with an effect on earnings and/or equity

Hypothesis $\mathrm{H}^{\mathrm{c}}{ }_{2}$ focuses on the magnitude of the accounting changes with an impact on earnings and/or equity (i.e. measurement changes), stating that the impact of these accounting changes decreased as a result of the increase in regulatory financial reporting restrictions. The alternative hypothesis $\left(\mathrm{H}_{2 A}^{c}\right)$ states that, in reaction to the introduction of the WJO, the impact of these changes increased in comparison with the situation prior to the WJO. The analysis of the magnitude of measurement changes will also provide information on whether the accounting changes have a positive or a negative effect on earnings. Accounting changes with an impact on equity will also be analysed. This is of interest since the use of secret reserves was no longer accepted and an increase is therefore expected in the level of accounting changes with a positive effect on equity, specifically in the case of the WJO. Descriptive statistics are provided on the direction (sign) of the change, the average firm/year effect of the change on earnings and/or equity, and the cumulative (absolute) effect of accounting changes for each firm over the entire period.

The total number of accounting changes with an effect on earnings, as shown in table 3.6 , is 149 , which constitutes $11.5 \%$ of all accounting changes. Of these, 41 accounting changes had a positive effect on earnings, 38 decreased earnings, and the actual impact of the remaining changes could not be determined. The year in which the WJO was implemented had the largest number of accounting changes with a positive earnings impact (10), but also the largest number of changes with a negative earnings impact (8). Both positive and negative changes occurred more frequently after the implementation of the WJO.

A closer look at the cumulative earnings effects of the changes suggests that the impact of the accounting changes increased in the years after the WJO, measured in absolute numbers. ${ }^{16}$ The absolute cumulative earnings impact of accounting changes (that is, the sum of all negative and positive changes) is highest in 1972. The average absolute cumulative earnings effect of accounting changes with an impact on earnings is approximately 6.2 million Dutch guilders (last column). In addition, the mean effect of accounting changes with an effect on earnings is negative: $-259,442$ Dutch guilders. This is mainly due to the highest (negative) average for 1972 .

\footnotetext{
${ }^{16}$ Although it should be mentioned that the absolute numbers are not corrected for inflation.
} 


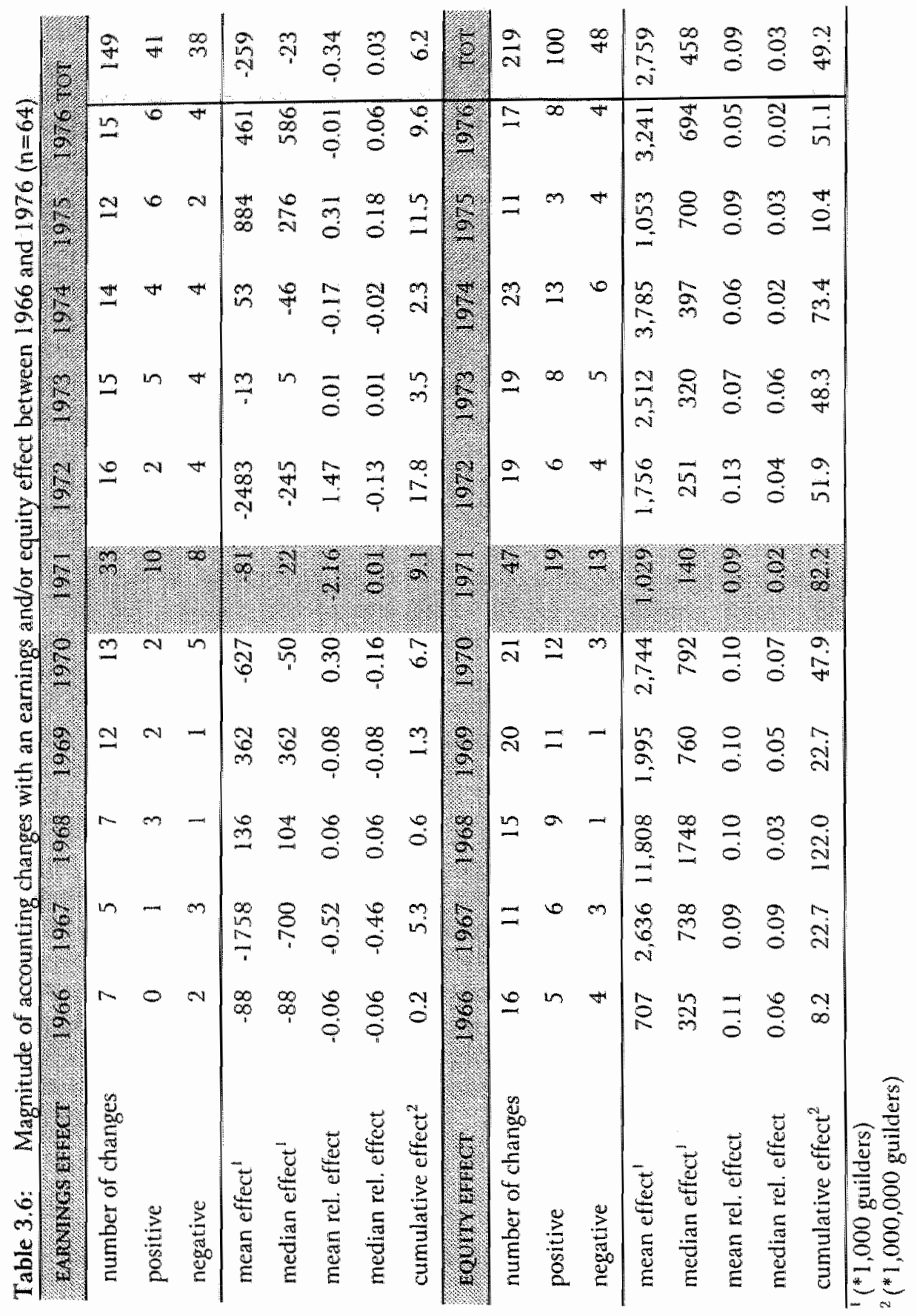


Another important finding is that the data on the relative impact on earnings also indicate that the average effect of the changes on earnings are higher in the years after the implementation (mean and median relative effects).

The results for accounting changes with an impact on equity are presented in the second part of table 3.6. The 64 sample firms made 219 accounting changes with an effect on equity, of which 100 had a positive and 48 a negative effect. ${ }^{17}$ The year with the highest number of accounting changes is 1971 (47). Of these 47,19 were positive and 13 negative (leaving 15 accounting changes undetermined).

The increased number of changes with a positive effect on equity could be related to the fact that firms were no longer able to hold secret reserves. If the assets on the debit side of the balance sheet had to be (re)valued on a historical or current cost basis, this would also lead to higher equity capital on the credit side of the balance sheet. The number accounting changes with a positive effect on equity increased since the introduction of the WJO in 1971. This picture is confirmed by the magnitude of these changes. The overall effect of the accounting changes on equity is positive. Apart from 1968, most years after 197 I show changes with a larger impact on equity than in the years before 1971 . These results would appear to indicate an impact from the introduction of the WJO.

Table 3.7 presents the pre-WJO and post-WJO averages of the data which was presented in table 3.6. The results indicate that for changes with an earnings impact: - the number of changes increased after the implementation of the WJO, - positive accounting changes after the WJO are 3.4 times higher than before, - negative changes also increased ( 1.8 times), but the effect is less spectacular; - the median and median relative effect switched from negative to positive, and - the cumulative effect is 3.2 times higher after the WJO.

The exact effects of 71 accounting changes on equity could not be determined.

${ }^{18}$ The absolute numbers presented in this table are not corrected for inflation and should be interpreted with care. 
Table 3.7: Magnitude of accounting changes with an earnings or equity effect before and after 1971, including $1971(n=64)$

\begin{tabular}{|c|c|c|}
\hline 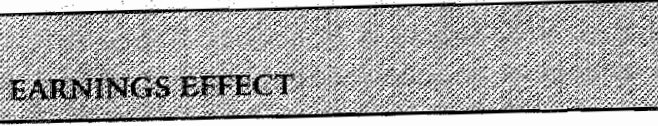 & Prefone Wo & HFTEP WTO \\
\hline average number of changes & 8.8 & 17.5 \\
\hline positive & 1.6 & 5.5 \\
\hline negative & 2.4 & 4.3 \\
\hline undetermined & 4.8 & 7.7 \\
\hline mean effect $\left({ }^{*} 1,000\right.$ guilders $)$ & -395 & -197 \\
\hline median effect $\left({ }^{*} 1,000\right.$ guilders $)$ & -74.4 & 99.7 \\
\hline mean relative effect & -0.06 & .0 .09 \\
\hline median relative effect & -0.14 & 0.02 \\
\hline cumulative effect $(* 1,000,000$ guilders) & 2.8 & 9.0 \\
\hline \multicolumn{3}{|l|}{ 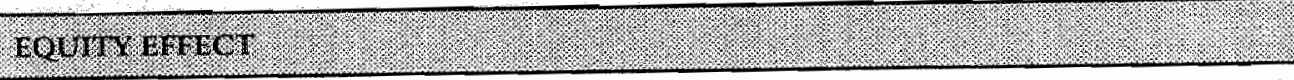 } \\
\hline average number of changes & 16.6 & 22.8 \\
\hline positive & 8.6 & 9.5 \\
\hline negative & 2.4 & 6.0 \\
\hline undetermined & 5.6 & 7.3 \\
\hline mean effect $\left({ }^{*} 1,000\right.$ guilders $)$ & 3,978 & 2,229 \\
\hline median effect $\left({ }^{*} 1,000\right.$ guilders $)$ & 872.5 & 417 \\
\hline mean relative effect & 0.10 & 0.08 \\
\hline median relative effect & 0.06 & 0.03 \\
\hline cumulative effect $(* 1,000,000$ guilders) & 44.7 & 52.9 \\
\hline
\end{tabular}

In sum, the results on the first hypothesis $\left(\mathrm{H}^{\mathrm{c}} \mathrm{d} / \mathrm{H}^{\mathrm{c}}{ }_{\mathrm{A}}\right)$, regarding the impact of the WIO on the frequency of accounting changes, have indicated that during the intervention period the number of accounting changes increased significantly, for both classification and measurement changes. Second, the frequency of accounting changes with an impact on earnings and/or equity was higher in years after the implementation of the WJO than in the years before its implementation (1971 excluded). Although this is consistent with hypothesis $\mathrm{H}^{\mathrm{c}}{ }_{1 \mathrm{~A}}$, the increase was not significant. The level of classification changes after the implementation of the WJO 
returns to a level which is lower than the pre-WJO level.

The evidence presented on the second hypothesis $\left(\mathrm{H}_{2}^{c} / \mathrm{H}_{2 \mathrm{~A}}^{\mathrm{c}}\right)$, concerning the magnitude of the measurement changes, indicates that firms made more accounting changes with an income-increasing effect during and after the implementation of the WJO. The magnitude of these changes also appeared to be higher than it was prior to 1971 . The relatively large number of accounting changes with an equity increasing effect can be partially explained by the abolition of secret reserves. These findings are consistent with predicted sign of hypothesis $\mathrm{H}_{2 \mathrm{~A}}^{\mathrm{c}}$, but the differences between preWJO and post-WJO frequencies and magnitudes are not significant. So, the empirical results reported on the effects of the WJO on the frequency and magnitude of accounting method changes partially support the alternative hypotheses $\mathrm{H}^{\mathrm{c}}{ }_{\mathrm{IA}}$ and $\mathrm{H}_{2 \mathrm{~A}}^{\mathrm{c}}$, since they only predicted the sign of the changes correctly. To a limited extent they suggest that firms demonstrated efficient contracting behaviour in reaction to the implementation of the WJO.

The remaining subsections will present results regarding the firm characteristics of size, leverage, and industry to examine whether these might explain differences in the frequency of accounting changes between firms.

\subsubsection{Size}

In addition to the previous analysis of accounting changes for the full sample, the data was also analysed on a sublevel. To examine any differences in the patterns of accounting changes according to firm size (hypothesis $\mathrm{H}_{3}{ }_{3}$ ), the sample was divided into three size categories according to the sample's frequency distribution. Size was measured by total assets. ${ }^{19}$ Small firms were those with total assets of less than fl20,000,000 $(n=20)$, and large firms were those with total assets of more than fl $100,000,000(n=15)$. The remaining firms $(n=19)$ with total assets exceeding f120,000,000 but less than f1100,000,000 were designated as medium-sized $(n=25)$. Panel I of table 3.8 presents the descriptive statistics on the sizes of the sample firms.

The results in panel II of the table support the size hypothesis: large firms had the highest number of total accounting changes per firm over the entire period, with a firm/year average of 2.07 . Medium-sized firms have the lowest firm/year average

${ }^{19}$ For each firm, size was computed as:

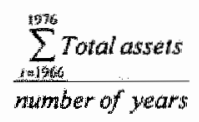


(1.72). However, the difference between small and intermediate firms is not significant. The second panel of table 3.8 also shows the distribution of accounting changes by size for classification and measurement changes. The firm/year average of measurement changes for large firms is significantly higher than for the medium-sized firms.

Table 3.8: Descriptive statistics on size and accounting changes for small, medium-sized and large firms between 1966 and $1976(n=64)$

\begin{tabular}{|c|c|c|c|c|}
\hline 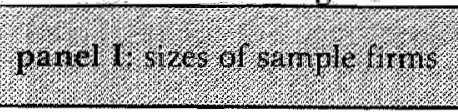 & sitis & nediun & 1arge & wotal \\
\hline number of firms & 20 & 25 & 19 & 64 \\
\hline mean total assets ${ }^{1}$ & 12,034 & 47,017 & 113,020 & 57,656 \\
\hline median total assets ${ }^{l}$ & 9,921 & 42,375 & 70,473 & 42,834 \\
\hline standard deviation total assets & 5,532 & 19,435 & 378,714 & $2,086,674$ \\
\hline pariel 11: acconinging eqranges & singlu & medrin & rarge & total \\
\hline total accounting changes & 402 & 473 & 433 & 1,308 \\
\hline percentage & 31 & 36 & 33 & 100 \\
\hline firm/year average & 1.83 & 1.72 & 2.07 & 1.86 \\
\hline classification changes & 335 & 384 & 341 & 1,060 \\
\hline percentage & 32 & 36 & 32 & 100 \\
\hline firm/year average & 1.52 & 1.40 & 1.63 & 1.51 \\
\hline measurement changes & 67 & 89 & 92 & 248 \\
\hline percentage & 27 & 36 & 37 & 100 \\
\hline firm/year average & 0.31 & 0.32 & $0.44^{* *}$ & 0.35 \\
\hline
\end{tabular}

"significant at the $1 \%$ level (one tailed)

The data for the separate size categories was then analysed further to check for possible differences concerning the impact of the WJO. The first part of hypothesis $\mathrm{H}^{\mathrm{c}}{ }_{3}$ stated that the effect of the financial reporting regulations would be higher for smaller firms, i.e., they would experience the largest increase in total accounting changes. Table 3.9 shows the results of this analysis. The increase in total accounting changes for the small firms was significant (t-value -2.78 ) and also larger than for 
both other categories. The increase is mainly due to classification changes. This indicates that the impact of the WJO has indeed been larger for small firms than for large firms.

The increases in accounting changes with an effect on earnings and equity for small and medium-sized firms are also significant, with t-values of -1.57 and -2.05 . The result for the large firms indicates that large firms might have anticipated the mandated financial reporting requirements of $\mathbb{1 9 7 1}$, so that the effect for this group is smaller in 1971.

Table 3.9: Comparison of average firm/year accounting changes for small, medium-sized and large firms before and after 1971 , including $1971 \quad(n=64)$

\begin{tabular}{|c|c|c|c|c|c|c|c|c|c|}
\hline \multirow{3}{*}{ 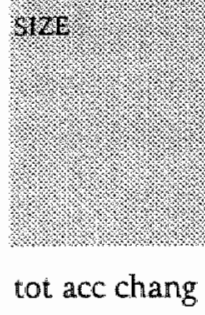 } & \multirow{2}{*}{ 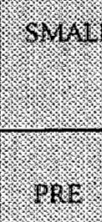 } & \multicolumn{2}{|c|}{ 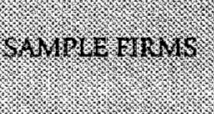 } & \multicolumn{3}{|c|}{ 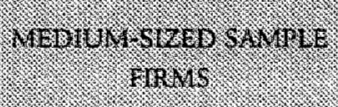 } & \multicolumn{3}{|c|}{ 1) } \\
\hline & & (20) & 4.4. & He & 1.081 & (t) & tor & pous & $+2 \times 1$ \\
\hline & 1.44 & 2.15 & $-2.78^{* *}$ & 1.38 & 2.01 & $-2.06 *$ & 2.09 & 2.05 & 0.12 \\
\hline classification & 1.21 & 1.78 & $-2.28^{*-}$ & 1.14 & 1.61 & $-1.74^{\circ}$ & 1.69 & 1.58 & 0.32 \\
\hline measurement & 0.23 & 0.37 & $-1.57^{*}$ & 0.23 & 0.40 & $-2.05^{* *}$ & 0.40 & 0.47 & -0.69 \\
\hline
\end{tabular}

significant at the $5 \%$ level (one-tailled)

"significant at the $1 \%$ level (one-tailed)

Thus, while it is true that large firms made more accounting changes than small and medium-sized firms, especially when attention is focused on measurement changes, the results also support hypothesis $\mathrm{H}_{3}{ }_{3}$. That is, the impact of the WIO would be larger for small firms than for large firms. Small firms appear to have been affected. most by the numerous disclosure rules of the WJO. ${ }^{20}$

\footnotetext{
${ }^{20}$ The analysis of the impact of the WJO on subgroups was repeated, only now 1971 was excluded. The overall results indicate that: (1) the sign of the changes (increase/decrease) did not change, (2) the overall significance of the changes decreased in all cases, and (3) the exclusion of 1971 has a greater impact on classification changes than on measurement changes. These findings are consistent with the results presented on the entire sample in table 3.5 .
} 


\subsubsection{Leverage}

Hypothesis $\mathrm{H}_{4}^{c}$ predicts that the increase in accounting regulation will put more highly leveraged firms (with a higher debt/equity ratio) in the position of having to obtain (costly) amendments to their credit agreements. So these firms would be expected to make more accounting changes. Table 3.10 summarizes descriptive statistics on accounting changes for three different groups, disaggregated by leverage level.

Table 3.10: Descriptive statistics on leverage and accounting changes for low, intermediate and high leverage firms between 1966 and $1976(n=64)$

\begin{tabular}{|c|c|c|c|c|}
\hline 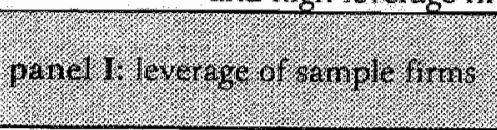 & row & internedinte & $\sqrt{1,136}$ & $\sqrt{1017}$ \\
\hline number of firms & 15 & 35 & 14 & 64 \\
\hline mean leverage & 0.58 & 1.28 & 2.28 & 1.34 \\
\hline median leverage & 0.54 & 1.30 & 2.28 & 1.29 \\
\hline standard deviation leverage & 0.17 & 0.27 & 0.41 & 0.65 \\
\hline panell It accouniting clanges & low: & internediate & light: & total: \\
\hline total accounting changes & 311 & 721 & 276 & 1,308 \\
\hline percentage & 24 & 55 & 21 & 100 \\
\hline firm/year average & 1.88 & 1.87 & 1.79 & 1.86 \\
\hline classification changes & 255 & 573 & 232 & 1,060 \\
\hline percentage & 24 & 54 & 22 & 100 \\
\hline firm/year average & 1.55 & 1.49 & 1.51 & 1.51 \\
\hline measurement changes & 56 & 148 & 44 & 248 \\
\hline percentage & 22 & 60 & 18 & 100 \\
\hline firm/year average & 0.34 & 0.38 & 0.29 & 0.35 \\
\hline
\end{tabular}

The first panel of the table presents these three leverage ratio groups, where leverage is measured as total debt divided by total equity. The average leverage ratio for the entire sample is 1.34 , the median is 1.29 . The three subgroups were labelled the low, 
intermediate and high leverage firms, where the cutoff point for low leverage was $<0.75$ and the threshold for the high leverage category was $>1.75$. The second part of the table shows the number of accounting changes for each of the three leverage categories. The average number of total accounting changes is highest in the low leverage category, followed by the intermediate group. Surprisingly, highly leveraged firms have the smallest number of total accounting changes. This is due mainly to the distribution of classification changes within these three groups.

The analysis of the two different types of accounting changes yields consistent patterns for the subcategories, except in the case of measurement changes, where the intermediate subgroup shows the highest average number of changes $(0.38)$. However, none of these differences are significant.

To provide evidence about the effects of the WIO on the number and type of accounting changes for each of the three categories, table 3.11 presents the average number of accounting changes before and after the implementation of the WJO for each category.

Table 3.11: Comparison of average firm/year accounting changes for low, intermediate and high leverage firms before and after 1971, including $1971(n=64)$

\begin{tabular}{|c|c|c|c|c|c|c|c|c|c|}
\hline throrkthe & .80 & Herver & Ex. & Whe & 36. & 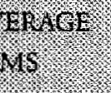 & 411919 & mortho & Mrrot. \\
\hline & rind & (25r) & $1+4$ & mow & 1087 & 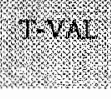 & rot & P. & H W \\
\hline tot acc chang & 1.63 & 2.10 & -1.36 & 1.60 & 2.10 & $-1.97^{* *}$ & 1.61 & 1.94 & .0 .86 \\
\hline classification & 1.28 & 1.77 & -1.38 & 1.30 & 1.64 & $-1.74^{\circ}$ & 1.44 & 1.56 & .0 .32 \\
\hline heas & 0.35 & 0.33 & 0.11 & 0.30 & 0.46 & $-2.20^{* *}$ & 0.17 & 0.38 & $-2.84^{* *}$ \\
\hline
\end{tabular}

significant at the $5 \%$ level (one-tailed)

"significant at the $1 \%$ level (one-tailed)

The results show that measurement changes increased significantly in the intermediate and high leverage firm categories. This findirg is consistent with hypothesis $\mathrm{H}^{c}$, that the impact of the WJO on firms with higher debt/equity ratios is larger (i.e. they will make more accounting changes in order to avoid the costs of possible amendments to debt agreements). Note that the average pre-WJO level of 
measurement changes for high leverage firms is the lowest of the three groups. ${ }^{21}$

\subsubsection{Industry}

Additional information will be presented on the classification of accounting changes by industry. Hypothesis $\mathrm{H}^{\mathrm{c}}{ }_{5}$ predicts that the break-down of accounting changes by industry will reveal industry effects, since accounting method choice and the decision to alter those methods are determined by industry characteristics. To examine industry effects, sample firms were classified into ten different industry groups. First, accounting changes for each industry group will be analysed to examine differences between industries. Secondly, the accounting changes before and after the implementation of the WJO will be compared for each industry.

The industry classification of the sample firms is based on the SBI two-digit codes of the Central Bureau of Statistics. The firms originate from 23 different industries (twodigit). In order to be able to compare means across industry groups, these categories were combined in 10 groups, so that each group contained at least 5 firms. ${ }^{22}$ Table 3.12 provides information on the number of firms per industry involved in the analysis and the pattern of accounting changes based on industry representation.

The two largest industry groups in the sample, the Food and Beverage and Paper and Publishing industries, had the largest absolute numbers of total accounting changes, 190 and 200 . The average numbers of annual total accounting changes varied from 1.61 for the Transport and Manufacturing industry sector to 2.02 for the Paper and Publishing industry firms. The firm/year average of total accounting changes for the entire sample was 1.86 .

${ }^{21}$ Similar to the results presented in the previous section, the analysis for subgroups was repeated, excluding 1971 . Again, the results indicated that the observed sign of the changes remained unchanged The overall significance of the changes also decreased.

\footnotetext{
${ }^{22}$ The only exception to this is the Construction industry, which contains only two companies. Despite the few observations this industry category is maintained, because in the second sample, containing firms effected by Title 8, this category contains 5 firms. The groups consist of the following SBI industry codes: food and beverages $=20,21$; textile/clothing $=22,23$; paper/publishing $=25,26,27$; oil-gas/chemical $=29,31,32$; steel $=33,34$; manufacturing/ machinery $=35$; electrical engineering $=36$; transport/other $=37,38,39$; construction $=51$; and whollesale and retail $=61,62,63,65,66$.
} 


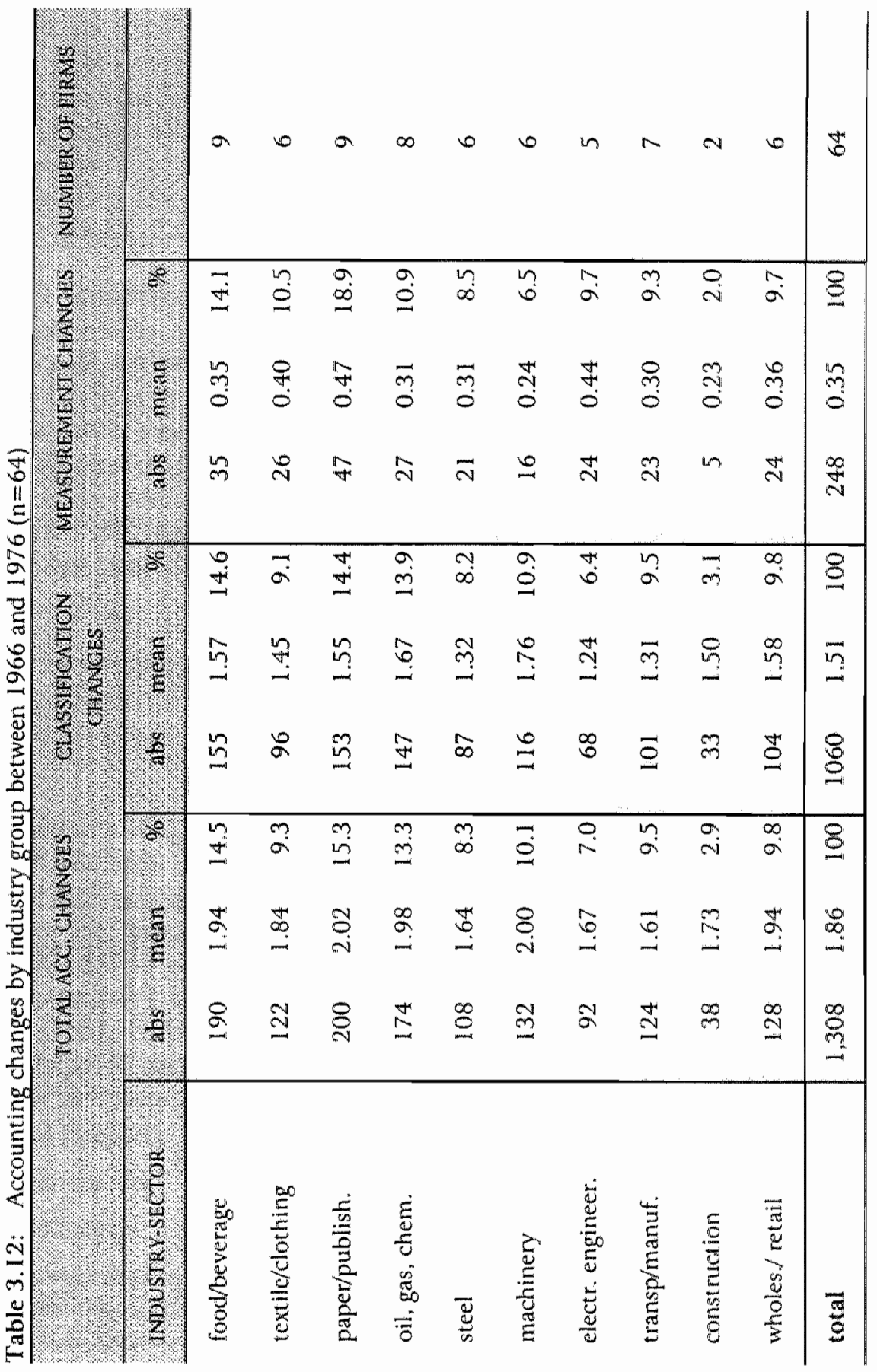


The highest firm/year average regarding classification changes was for the Machinery industry (1.76), followed by the Oil, Gas and Chemical industry (1.67). The industry groups with the lowest firm/year averages were Electrical Engineering (1.24), Transport and Manufacturing (1.31), and Steel (1.32). The average number of classification accounting changes across all industries was 1.51 . The trading firms (Wholesale/Retail) had the third highest firm/year average, which is not consistent with the reasoning behind hypothesis 5 , which would lead one to expect a low number of accounting changes for this particular group (see section 2.3.2.4).

The analysis of measurement changes shows an identical pattern. Firms in the Paper and Publishing industry had the highest firmlyear average $(0.47)$, where the full sample average was 0.35 . It is interesting to see however that the Electrical Engineering firms have the second largest average number of measurement changes, but the lowest average number of classification accounting changes. Finally, the results in table 3.12 show that the Construction industry had the lowest number of accounting changes with an effect on equity and/or earnings, followed by the Machinery industry. Overall, these results suggest that there are differences between industries, although no evidence was found that Wholesale and Retail firms make less accounting changes than industrial firms.

Subsequently, we analysed the effects of the new financial reporting requirements on the various industry groups. Table 3.13 provides data on the frequency of accounting changes before and after the introduction of the WJO in 1971 per industry category, including $\mathrm{t}$-ratios for the before-and-after differences. The data indicates that there were differences across different industry groups. Except for the Food industry, all categories show an increase in the total number of accounting changes. Significant tratios are found for the Textile, Paper and Publishing, Oil, Gas, Chemicals and Construction industries. For classification changes, there were similar significant differences in the means for these industries. Finally, four industry groups had significant increases in the number of measurement changes after the implementation of the WJO: the Food, Textile, Transport \& Manufacturing, and Wholesale and Retail industries. ${ }^{23}$ Although these findings provide evidence for the hypothesized differences across industries, they are inconsistent with the second part of hypothesis $\mathrm{H}_{5}^{\mathrm{c}}$ which suggested that trading firms - assuming they have a simpler production process - would be less affected by the WJO than industrial firms.

\footnotetext{
${ }^{23}$ If we exclude 1971 from the analysis, the differences between the two periods are smaller, consistent with results presented previously, especially in the case of classification changes. Across industries test results are less significant. No differences occur with respect to the sign
of the changes across industries.
} 
Table 3.13: Comparison of accounting changes before and after 1971, including 1971 , by industry group $(n=64)$

\begin{tabular}{|c|c|c|c|c|c|c|c|}
\hline & \multicolumn{3}{|c|}{ phroir ro vale } & \multicolumn{3}{|c|}{ - r r r $=1110$} & 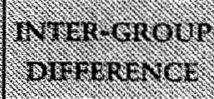 \\
\hline 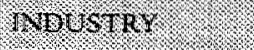 & & $\sqrt{18} \cdot$ & 4rotes & & 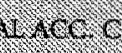 & $1 / 1 x_{1}=1$ & \\
\hline & . & 2veragr & staind trey & n & intrage & 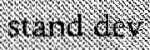 & tritilie \\
\hline food/beverage & 95 & 10.6 & 8.1 & 95 & 8.8 & 4.5 & 0.75 \\
\hline textile/clothing & 43 & 7.2 & 3.0 & 79 & 13.2 & 4.1 & $-3.49^{\circ *}$ \\
\hline paper/publish. & 71 & 7.9 & 3.3 & 129 & 14.3 & 8.3 & $-1.69^{\prime \prime}$ \\
\hline oil, gas, chem. & 62 & 7.8 & 3.0 & 112 & 14.0 & 6.6 & $-1.49^{\circ}$ \\
\hline steel & 53 & 8.8 & 4.7 & 55 & 9.1 & 4.7 & -0.04 \\
\hline machinery & 53 & 8.8 & 4.9 & 79 & 13.2 & 8.5 & -0.57 \\
\hline electr. engineer. & 32 & 6.4 & 2.1 & 60 & 12.0 & 6.2 & -1.23 \\
\hline transp/manuf. & 51 & 7.3 & 6.3 & 73 & 10.4 & 4.1 & -0.42 \\
\hline construction. & 11 & 5.5 & 3.5 & 27 & 13.5 & 0.7 & $-2.76^{* *}$ \\
\hline wholesale/retail & 44 & 7.3 & 7.1 & 84 & 14.0 & 5.6 & -1.32 \\
\hline total & 515 & 8.1 & & 793 & 12.4 & & $-2.56^{\circ}$ \\
\hline 1010ustrol & (6.7. & 1.r. $10 \%$ & 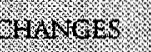 & & Sstris 1 & (1) W ratas & \\
\hline & $x$ & average & $\operatorname{tand} d e$ re & n & prorrase & stind der & Fratue \\
\hline food/beverage & 84 & 9.3 & 8.1 & 71 & 6.5 & 3.8 & 1.16 \\
\hline textile/clothing & 36 & 6.0 & 2.1 & 60 & 10.0 & 4.8 & $-2.09^{*=}$ \\
\hline paper/publish & 51 & 5.7 & 3.7 & 102 & 11.3 & 8.0 & $-1.60^{\circ}$ \\
\hline oil,gas, chem. & 52 & 6.5 & 2.6 & 95 & 11.9 & 6.0 & $-1.51^{\circ}$ \\
\hline steel & 47 & 7.8 & 3.9 & 40 & 6.7 & 4.4 & 1.10 \\
\hline machinery & 45 & 7.5 & 5.0 & 71 & 11.8 & 7.8 & -0.66 \\
\hline electr. engineer. & 25 & 5.0 & 2.6 & 43 & 8.6 & 6.2 & -0.76 \\
\hline transp/manuf. & 40 & 5.7 & 5.6 & 61 & 8.7 & 3.7 & .0 .51 \\
\hline construction & 8 & 4.0 & 1.4 & 25 & 12.5 & 0.7 & $-11.0^{* *}$ \\
\hline wholesale/retail & 37 & 7.4 & 6.1 & 67 & 11.1 & 6.4 & -0.95 \\
\hline total & 425 & 6.6 & & 635 & 9.9 & & $-1.91^{* *}$ \\
\hline
\end{tabular}




\begin{tabular}{|c|c|c|c|c|c|c|c|}
\hline 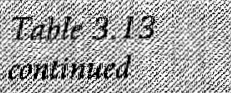 & \multicolumn{3}{|c|}{ (x) } & \multicolumn{4}{|c|}{ 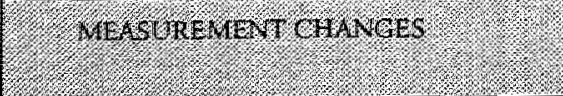 } \\
\hline & x & aterge & $\operatorname{tand} 4$ la & 4 & - retag & stand det & $6.7 .11 \mathrm{me}$ \\
\hline food/beverage & 11 & 1.2 & 1.6 & 24 & 2.2 & 2.1 & $-1.93^{*}$ \\
\hline textille/clothirig & 7 & 1.2 & 1.2 & 19 & 3.1 & 1.5 & $-1.68^{\prime \prime}$ \\
\hline paper/publish. & 20 & 1.3 & 1.5 & 27 & 3.0 & 2.9 & -0.24 \\
\hline oill, gas, chem. & 10 & 1.3 & 1.2 & 17 & 2.1 & 1.2 & -0.82 \\
\hline steel & 6 & 1.0 & 1.5 & 15 & 2.5 & 1.4 & -1.11 \\
\hline machinery & 8 & 1.3 & 1.4 & 8 & 1.3 & 1.2 & 0.33 \\
\hline electr. engineer. & 7 & 1.4 & 0.9 & 17 & 3.4 & 1.9 & $-3.47^{m=}$ \\
\hline transp/manuf. & Il & 1.6 & 1.6 & 12 & 1.7 & 1.1 & -0.22 \\
\hline construction & 3 & 1.5 & 2.1 & 2 & 1. .0 & 0.0 & 0.44 \\
\hline wholesale/retail & 7 & 1.4 & 0.9 & 17 & 2.8 & 1.3 & $-3.26^{*}$ \\
\hline total & 90 & 1.4 & & 158 & 2.5 & & $-2.5 I^{* *}$ \\
\hline
\end{tabular}

significant at the $5 \%$ level (one-tailed)

" significant at the $1 \%$ level (one-tailed) 
3.4 Hypotheses and results of the empirical analysis of accounting method changes (2): introduction of the second major accounting regulation in the Netherlands (Title 8)

\subsubsection{Introduction}

This section presents the results of the second time series, on accounting changes between 1977 and 1986. The structure of this section is similar to section 3.3. Due to the inavailability of data the analysis presented here is limited to measurement changes, but these are the most important category for the purpose of this analysis. The database used here to test for the effects of Title 8 is taken from Hoogendoorn (1990). The data consists of information on accounting changes with an effect on earnings and/or equity, but no information on classification accounting changes. The analysis is based on a sample of 107 firms. ${ }^{24}$

Descriptive statistics, analogous to those in section 3.3, will be presented on the number and nature of accounting changes during this period to show whether the implementation of Title 8 had an impact on accounting policy choice. Information will also be provided on the magnitude of these accounting changes, to test hypothesis $\mathrm{H}_{2}^{\mathrm{c}} / \mathrm{H}_{2 \mathrm{~A}^{\mathrm{c}}}^{\mathrm{c}}$. Finally, disaggregated analyses will test hypotheses $\mathrm{H}_{3}^{\mathrm{c}}, \mathrm{H}^{c}{ }_{4}$, and $\mathrm{H}_{5}{ }_{5}$ on the distribution of accounting changes for subsamples based on size, leverage and industry.

\subsubsection{Hypotheses}

The hypotheses to be tested, based on research questions $R_{\mathbb{1}}^{c} / R_{1 A}^{c}$ and $R_{2}^{c} / R_{2 A}^{c}$ in section 2.3 .2 , are repeated below.

Hypotheses: ${ }^{25}$

$\mathrm{H}_{1}^{\mathrm{c}}$ : the change from a less regulated financial accounting environment (before 1984) to a more regulated environment (after 1984) led to (1) an increase in the frequency of accounting changes during the intervention period, and (2) a decrease in the frequency of accounting changes in following years, compared to the

\footnotetext{
${ }^{24}$ See section 3.2.3 for a detailed description of the sample.

${ }^{25}$ The numbering of hypotheses in this section is similar to that of section 3.3 because the hypotheses to be tested are also similar to section 3.3. In the summary of this chapter the test results on both sets of hypotheses (WJO and Title 8) will be compared.
} 
frequency of accounting changes in the years before the implementation of Title 8 .

$\mathrm{H}^{\mathrm{c}}{ }_{1 \mathrm{~A}}$ : the change from a less regulated financial accounting environment (before 1984) to a more regulated environment (after 1984) led to (1) an increase in the frequency of accounting changes during the intervention period, and (2) an increase in the frequency of accounting changes in following years, compared to the frequency of accounting changes in years before the implementation of Title 8 .

$\mathrm{H}_{2}^{c}$ : the change from a less regulated financial accounting environment (before 1984) to a more regulated environment (after 1984) led to a decrease in the magnitude of accounting changes with an impact on earnings and/or equity during the intervention period and following years, compared to the magnitude of accounting changes with an impact on eamings and/or equity before the implementation of Title 8.

$\mathrm{H}_{2 \mathrm{~A}}^{c}$ : the change from a less regulated financial accounting environment (before 1984) to a more regulated environment (after 1984) led to an increase in the magnitude of accounting changes with an impact on eamings andlor equity during the intervention period and following years, compared to the magnitude of accounting changes with an impact on earnings and/or equity before the implementation of Title 8.

$\mathrm{H}_{3}^{c}$ : the frequency of accounting changes with an impact on earnings and/or equity is expected to be higher for large firms, and the impact of the implementation of Title 8 on the frequency of accounting changes is expected to be higher for smaller firms.

$\mathrm{H}_{4}^{\mathrm{c}}$ : the frequency of accounting changes with an impact on eamings and/or equity is expected to be higher for firms with higher debt/equity ratios, and the impact of the implementation of Title 8 on the frequency of accounting changes is expected to be higher for firms with higher debt/equity ratios.

$\mathrm{H}_{5}^{c}$ : the frequency of accounting changes with an impact on earnings and/or equity is axpected to be different across industries, and the impact of the implementation of Title 8 on the frequency of accounting changes is expected to be different across industries. More specifically, the frequency of accounting changes and the impact of Title 8 on the frequency of accounting changes is expected to be larger for industrial firms compared to trading firms.

We will first present descriptive statistics on the number of measurement changes between 1977 and 1986, to test hypothesis $\mathrm{H}_{1}^{c} / \mathrm{H}^{c}{ }_{1 \mathrm{~A}}$ This will be followed by additional results on the magnitude of measurement changes before and after the implementation of Title 8 , to test hypothesis $\mathrm{H}_{2}^{c} / \mathrm{H}^{c}{ }_{2 \mathrm{~A}}$. Finally, to test hypotheses $\mathrm{H}^{c}{ }_{3}$ 
$\mathrm{H}_{4}^{c}$, and $\mathrm{H}_{5}^{c}$, information will also be provided on firm characteristics that might be rellated to firms' accounting changes. The analysis incorporates firm characteristics introduced in section 2.3.2.1: firm size, leverage, and industry origin.

\subsubsection{Results: distribution of accounting method changes between 1977 and $1986^{26}$}

The total number of accounting changes with an effect on earnings and/or equity for all 107 sample firms over the second time-series are shown in table 3.14. During the ten-year period, the firms made a total of 444 measurement changes, compared to 248 in the first time series. This yields a firm/year average of 0.42 compared to 0.35 in the first time-series (section 3.3.1). The results show that, as with the WIO, the number of measurement changes is the highest in the year in which Title 8 became effective (1984). This is consistent with expectations.

Table 3.14: Distribution of measurement changes ${ }^{1}$ between 1977 and $1986(n=107)$

\begin{tabular}{|c|c|c|c|c|c|c|c|c|c|c|c|}
\hline fient & $197 \%$ & 1978 & 1979 & 1980 & 198 & 1082 & 1083 & 1984 & 1998 & 1986 & tor \\
\hline changes & 36 & 33 & 40 & 39 & 64 & 44 & 27 & 6 & 37 & 45 & 444 \\
\hline mean & 0.34 & 0.31 & 0.37 & 0.36 & 0.60 & 0.41 & 0.25 & 0,74 & 0.35 & 0.42 & 4.15 \\
\hline stand dev. & 0.54 & 0.64 & 0.55 & 0.72 & 0.59 & 1.01 & 0.80 & 1858 & 0.96 & 0.68 & 2. \\
\hline maximur & 3 & 2 & 4 & 3 & 6 & 4 & 3 & 4 & 3 & 4 & 4 \\
\hline t-value & - & 0.20 & -0.55 & -0.10 & $-3.13^{*}$ & $2.31^{* *}$ & $2.67^{\circ *}$ & $5.62^{4}$ & $4.28^{\circ}$ & -1.24 & \\
\hline
\end{tabular}

See appendix 3B.2 for additional information on the distribution of changes for each category ${ }^{2}$ Information on the total number of measurement changes, the average and standard deviation of the number of measurement changes per firm over the full period, and the maximum number of measurement changes made by one firm

. significant at $1 \%$ level (one-tailed)

Similar to section 3.3 .3 additional information is also available on the type

\footnotetext{
${ }^{26}$ The data used here is a subsample of the Hoogendoorn (1990) database, since banks and financial institutions were excluded from the analysis. The method employed by Hoogendoorn to determine accounting changes is similar to the method used in section 3.3. See section 3.2.3. for a detailed description.
} 
accounting changes during the second time-series. Appendix 3B.2 reports on the distribution of accounting changes per type between 1977 and 1986. Here the largest category of changes is related to foreign currency translation. ${ }^{27}$ Except for 1981, there were significantly fewer measurement changes in all other years. It should be noted that the potential effect of these and other types of accounting changes on the distribution of accounting changes over the time period examined have been considered. It is also interesting to see that the year prior to the implementation of the new financial reporting requirements, 1983, had the lowest number of measurement changes. This could be because firms postponed their plans to alter financial accounting methods and practices until the implementation of Title 8 , or delayed changes because, in the year of its introduction, they could to a certain extent veil their real motives. ${ }^{28}$ This finding contrasts with the outcome of the first timeseries, where it was argued that firms anticipated the new legislation in the years preceding the WJO (particularly 1970).

The number of measurement changes in 1976, at the end of the first time series, was $20(n=64)$ and the firm/year average was 0.31 . This shows that the two time-series fit in very well. There was an average of 4.2 measurement changes per firm over the ten year period, which is higher than the firm average in the first time-series (3.9). The highest number of measurement changes for one firm during the entire period is 14 (first time-series: 9), while the maximum number of measurement changes adopted by a single firm in one year is 6 (compared to 4 in the first time-series).

Finally, the last row of table 3.14 presents the t-ratios for the mean differences for subsequent years. ${ }^{29}$ A significant increase is reported in 1981 , followed by two years with a (significant) decrease in the number of measurement changes. The implementation of the Fourth EEC Directive in 1984 resulted in the largest increase in measurement changes. This finding is consistent with the first part of hypothesis $\mathrm{H}^{\mathrm{c}}{ }^{\mathrm{A}} \mathrm{A}^{\mathrm{*}}$

\footnotetext{
${ }^{27}$ The increase in 1981 is mainly attributable to the high number of accounting changes that relate to foreign currency translation. Almost one third of all changes in 1981(20) refers to this type of accounting change. These changes in 1981 (and other years prior to and after 1981 as well) are the result of the decline of the Bretton Woods exchange rate system during the 1970 s and into the early 1980s (Samuelson and Nordhaus 1989, pp. 844-849). During these two decades the dollar volatility increased, which prompted many export and/or import oriented firms to reevaluate their foreign currency (accounting) policies.

${ }^{28}$ See also Hoogendoorn (1990, p.241).

${ }^{29}$ Using a (parametric) paired sample t-test.
} 
The next table (3.15) reports the results of t-tests for years prior to and after the introduction. The measurement changes were first grouped into two separate periods and then compared. ${ }^{30}$ The average number of measurement changes per year before 1984 is significantly lower than in the period 1984-1986. The firm/year average increased from 0.38 to 0.52 , yielding a t-ratio of -2.79 , which is significant (at the 0.5 percent level). As we saw in the results presented in the previous section, changes in the year of introduction account for most of the increase in the average number of changes in the post-Title 8 period.

According to table 3.14, the numbers of measurement changes in 1985 and 1986 were not significantly higher than in pre-Title 8 years. In fact 1985 had the third lowest number of measurement changes. Table 3.16 shows the results of a test similar to the t-test described in table 3.15, only this time 1984 is excluded.

Table 3.15: Comparison of measurement changes before and after 1984, including 1984 $(n=107)$

\begin{tabular}{|c|c|c|c|}
\hline & W.6.2. & (1) & 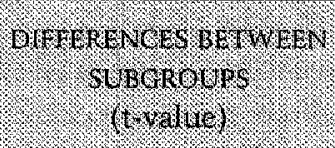 \\
\hline measurement changes & 283 & 161 & \\
\hline mean & 0.38 & 0.52 & $-2.79^{* *}$ \\
\hline standard deviation & 0.275 & 0.496 & \\
\hline
\end{tabular}

"Significant at the $1 \%$-level (one-tailed)

It can be seen that the average level of measurement changes did increase, although not significantly. Nonetheless, the empirical results at least indicate that measurement changes did not decrease, in which case hypothesis $\mathrm{H}^{c}{ }_{1}$ can be rejected. However the increase in the level of measurement changes after the implementation of Title 8 was only minor and therefore not significant (see table 3.16 ). ${ }^{31}$

\footnotetext{
${ }^{30}$ Note that the two periods are not equally long. Data is available for seven years before 1984, while the period after 1984 contains only three years. Therefore, a comparison of the numbers of measurement changes over the two periods is inappropriate.

${ }^{31}$ But since the post-Iitle 8 period contains only two years, conclusions should be drawn with caution.
} 
Table 3.16: Comparison of measurement changes before and after 1984, excluding 1984 $(n=107)$

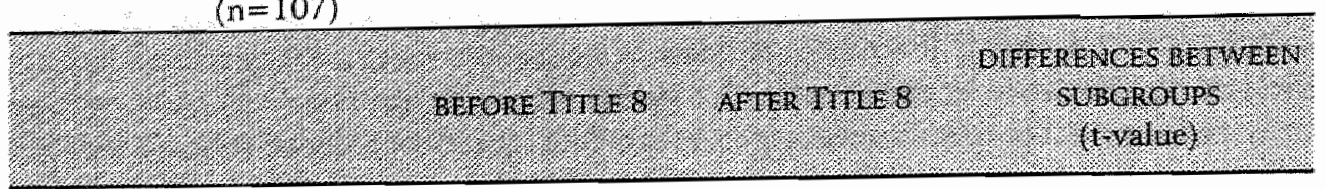

measurement changes

mean

standard deviation
283

0.38

0.275
82

0.39

$-0.90$

Magnitude of accounting method changes with an effect on earnings and/or equity

The magnitude of the accounting changes with an effect on earnings and/or equity will now be analysed, to test hypothesis $\mathrm{H}_{2}^{\mathrm{c}} / \mathrm{H}^{\mathrm{c}}{ }_{2 \mathrm{~A}}$. Table 3.17 provides information regarding the sign of changes, the average firm/year effect of the changes on earnings and/or equity, and the cumulative effect of the changes for each firm over the entire period.

The table shows that there was a total of 356 measurement changes with an impact on earnings (first time-series: 149). The firm/year average of the second time series is 3.3 , compared to 2.3 for the first time series. The number of measurement changes with a positive effect on earnings was twice as high as the number of negative changes. The largest number of changes was in 1984, followed by 1981 . The cumulative effect on earnings was also largest in 1981. Further analysis of the changes by sign reveals no increase in measurement changes which increase earnings after 1984 .

With respect to the absolute cumulative effect of the changes on earnings (sum of positive and negative changes), measurement changes in 1984 had the second largest impact on earnings: (480 million), with the highest impact being for 1981 . The annual average effect on earnings in 1980 and 1981 was also higher than the average effect in 1984.

The distribution of measurement changes with an impact on equity, shown in the 


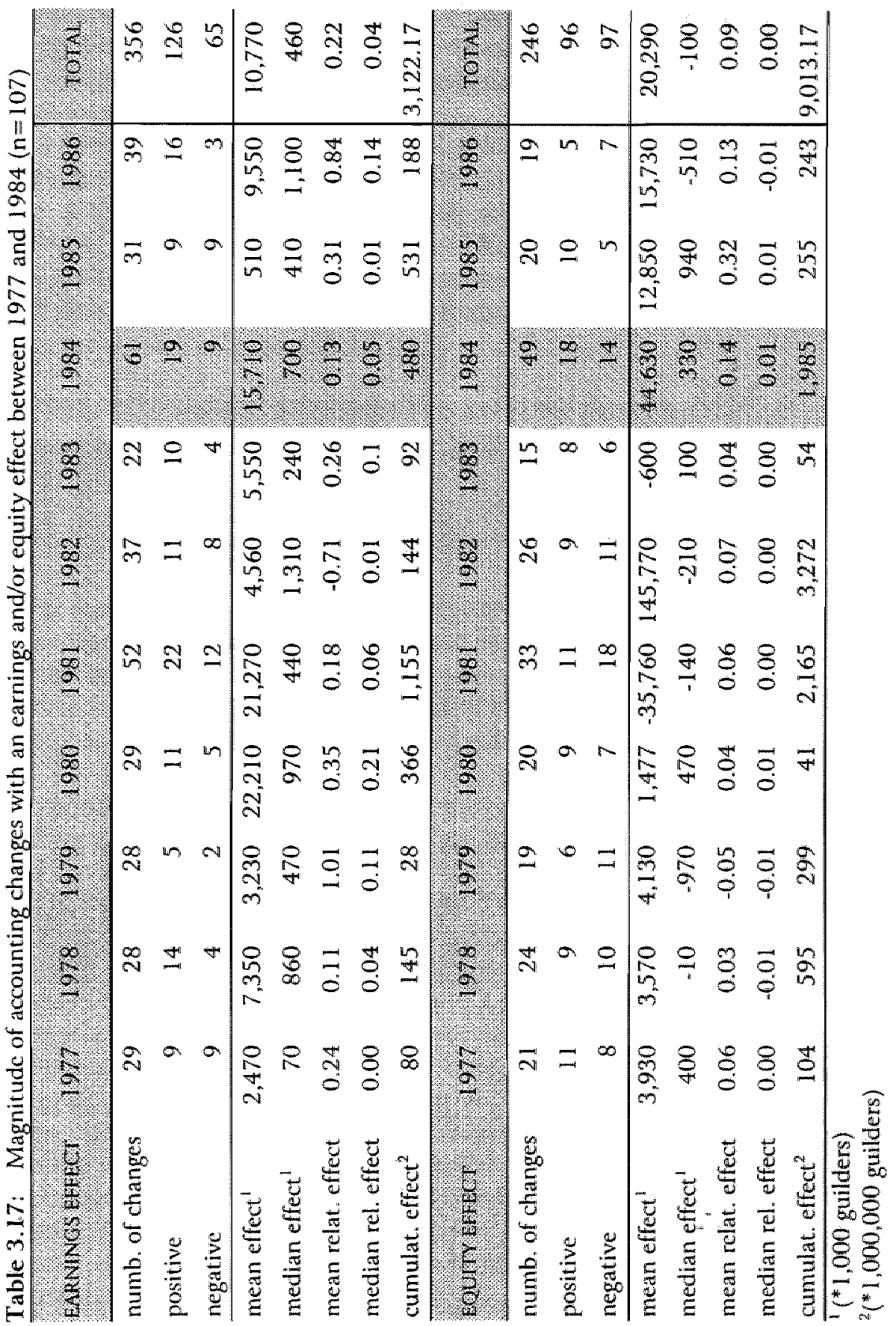


second panel of the table, illustrates the same distribution pattern over time. The highest number of accounting changes with a negative impact on equity is reported in 1981, followed by 1984. Consistent with table 3.16, the number of measurement changes did not increase after 1984 compared to pre-Title 8 levels.

The signs of the changes are about equally distributed: 96 changes increased equity and 97 changes decreased equity. This is different from the results presented on the first time-series. The year in which the largest absolute cumulative effect of the measurement changes was measured is 1982, followed by 1981 and 1984 . The annual average effect of the measurement changes on equity in 1982 is more than three times the average effect in 1984, although the relative impact in 1982 is much lower.

Table 3.18: Magnitude of accounting changes with an earnings or equity effect before and after 1984 , including $1984(\mathrm{n}=107)$

\begin{tabular}{|c|c|c|}
\hline gatumigs ertiert & Bergan Thus & 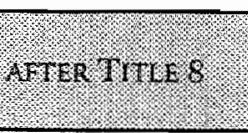 \\
\hline average number of changes per year & 29.0 & 43.6 \\
\hline positive & 11.7 & 14.7 \\
\hline negative & 6.3 & 7.0 \\
\hline mean effect $\left({ }^{*} 1,000\right.$ guilders $)$ & 952 & 859 \\
\hline median effect $\left({ }^{*} 1,000\right.$ guilders) & 262 & 374 \\
\hline mean relative effect & 0.21 & 0.43 \\
\hline median rel. effect & 0.02 & 0.08 \\
\hline cumulative effect ( $1,000,000$ guilders) & 287.1 & 399.7 \\
\hline EQum errect & Berore TIJIE 8 & 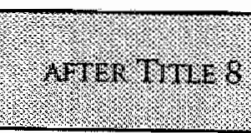 \\
\hline number of changes & 22.6 & 29.3 \\
\hline positive & 9.0 & 11.0 \\
\hline negative & 10.1 & 8.7 \\
\hline mean effect ( ${ }^{*} 1,000$ guilders) & 1,940 & 2,444 \\
\hline median effect $\left({ }^{*} 1,000\right.$ guilders $)$ & -600 & 250 \\
\hline mean relative effect & 0.04 & 0.20 \\
\hline median relative effect & -0.001 & 0.003 \\
\hline cumulative effect ( $1,000,000$ guilders) & 932.9 & 827.7 \\
\hline
\end{tabular}


Also, in 1981 the average effect of the measurement changes on equity is negative, while at the same time the effect of the changes with an impact on earnings was positive. This seems to indicate that the overall effect of the accounting changes in this particular year has increased firms" earnings levels, while the effect on equity was overall negative.

Additional analysis of the magnitude of the measurement changes reveals that the impact of the changes on earnings and equity is higher in 1981 and 1982 than in 1984. This finding suggests that external economic circumstances (i.e., economic recession) might have affected accounting method changes, especially with respect to the numbers presented for 1981. Information on the averages for pre- and post-Title 8 years are presented in table 3.18 .

The results indicate that for changes with an earnings impact:

- the average number increased after the implementation of Title 8 ,

- positive measurement changes increased by $25 \%$,

- negative changes also increased, but by only $11 \%$,

- the cumulative effect increased by $39 \%$.

And for measurement changes with an equity effect the table shows that:

- the average number of changes increased, but by less than the increase in changes with an earnings impact,

- only measurement changes with a positive effect on equity increased,

- the cumulative effect of the changes decreased.

The overall results of the analysis are partially consistent with hypothesis $\mathrm{H}_{1 \mathrm{~A}}^{\mathrm{c}}$, providing evidence that the number of changes with an effect on earnings and/or equity was highest in the year Title 8 was introduced, and that on average the level of measurement changes after 1984 increased only slightly, but not significant. Also, the total number of changes with a positive effect on earnings was twice as high as the number of changes with a negative effect, whereas the changes with an impact on equity are equally distributed with respect to sign. This provides reason to believe that measurement changes are used more frequently to increase reported earnings than to decrease them, which might be a response to changes in external economic circumstances and earnings management behaviour. However, the results did not indicate that the number of positive accounting changes changed after 1984 . Especially in 1984, firms seem to have taken the opportunity provided to them by standard setters to adjust their financial reporting policies. One category of changes accounted for the high number of changes in 1981. Finally, the cumulative effect of measurement changes with an impact on earnings increased after the implementation of Title 8 , consistent with hypothesis $\mathrm{H}_{2 \mathrm{~A}}^{\mathrm{c}}$. The results indicate, as suggested previously, that firms making accounting changes in that year did not reveal their true 
motives, at least to a certain extent. ${ }^{32}$

The remaining subsections will present results as regards the firm characteristics of size, leverage, and industry, to examine whether these might explain differences in the frequency of accounting changes between firms.

\subsubsection{Size}

First, the data was disaggregated by size, which is measured by total assets. ${ }^{33}$ The first column of table 3.19 shows that the average size of the 107 firms was 1.3 billion guilders. ${ }^{34}$

Table 3.19: Descriptive statistics on size and measurement changes for small, medium-sized and large firms between 1977 and $1986(n=107)$

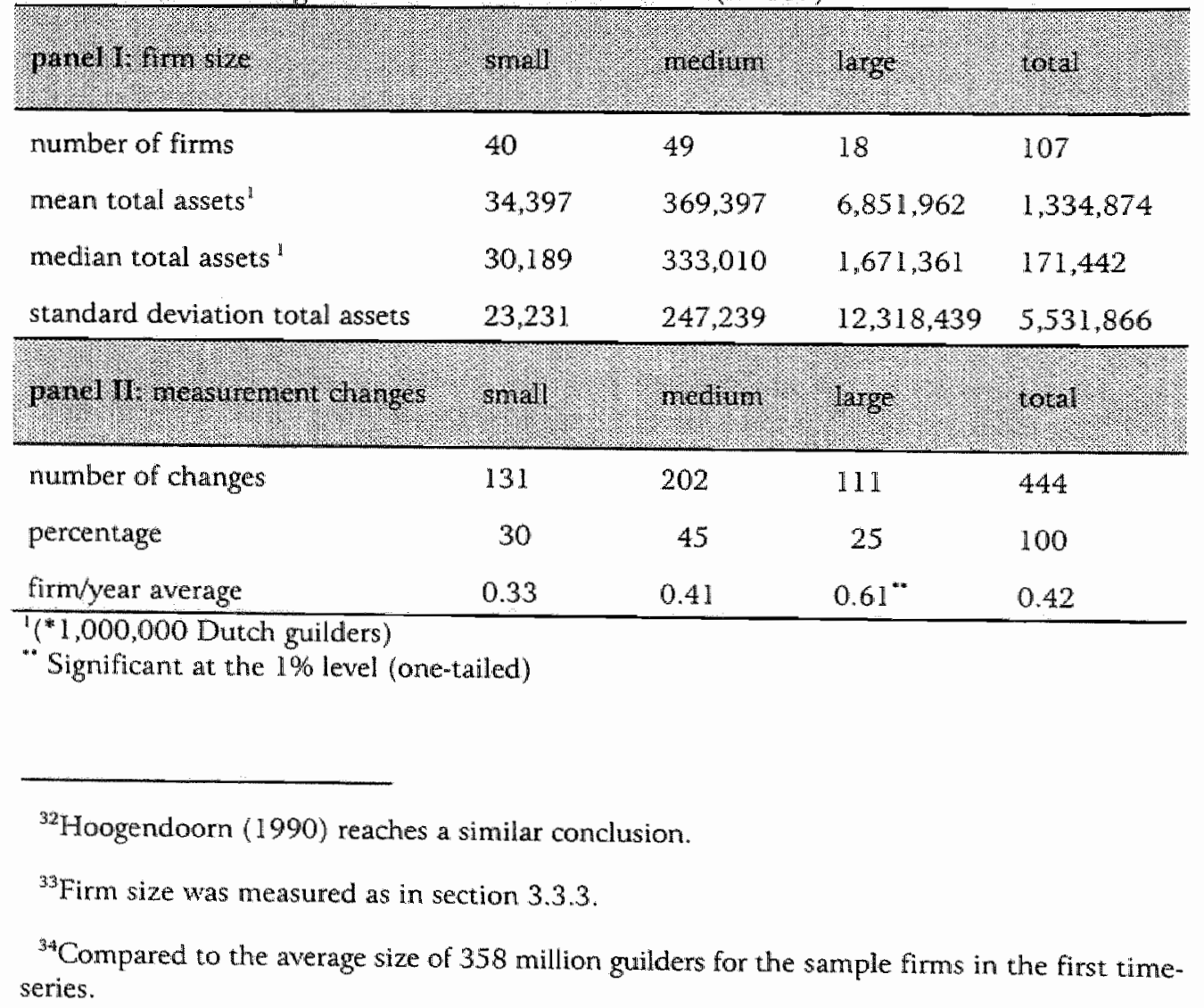


Based on the frequency distribution of the entire sample, small firms were defined as those with total assets of less than $100,000,000$ guilders $(n=40)$, and large firms as those with total assets of more than $1,000,000,000$ guilders $(n=18)$. The remaining firms ( $n=49$ ), with total assets between 100 million and 1 billion guilders, were designated as medium-sized. The second part of the table shows the distribution of measurement changes over the entire period by firm size categories. Large firms had the highest firm/year average, and small firms had the lowest average. The firm/year averages of medium-sized and large firms differ significantly. The results are consistent with hypothesis $\mathrm{H}_{3}{ }_{3}$, which predicts that large firms will tend to make more measurement changes so as to avoid potential political costs.

As in the case of the WJO, the data was analysed further to test for differences between the three size categories regarding the impact of Title 8 on the number of measurement changes (i.e., before and after 1984). Table 3.20 shows the outcome of the t-tests for the firm size categories. Although the number of changes increased for all categories after the enactment in 1984, the increase in measurement changes is significant in the case of small (significant at the $5 \%$ level) and medium-sized firms (significant at the $1 \%$ level). The increase for the large firms is not significant. As in the case of the $\mathrm{WJO}$, this provides evidence to support hypothesis $\mathrm{H}_{3}^{\mathrm{c}}{ }_{3}{ }^{35}$

Table 3.20: Comparison of average firm/year measurement changes for small, medium- sized, and large firms before and after 1984 , including $1984(\mathrm{n}=107)$

\begin{tabular}{|c|c|c|c|c|c|c|c|c|c|}
\hline \multirow[t]{2}{*}{$812 \mathrm{C}$} & \multicolumn{3}{|c|}{ 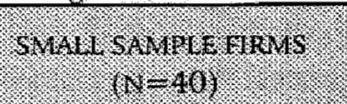 } & \multicolumn{3}{|c|}{ 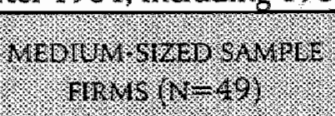 } & \multicolumn{3}{|c|}{ 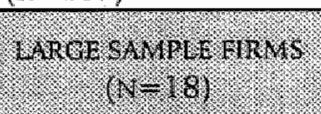 } \\
\hline & $\mathrm{rrO}$ & P. & rrora & & rorr. & t r.al & P11. & resti & rya \\
\hline $\begin{array}{l}\text { measurem. } \\
\text { changes }\end{array}$ & 0.29 & 0.41 & $1.65^{\circ}$ & 0.36 & 0.55 & $2.24^{\circ *}$ & 0.60 & 0.65 & 0.35 \\
\hline
\end{tabular}

significant at the $5 \%$ level (one-tailed)

"significant at the $1 \%$ level (one-tailed)

${ }^{35}$ The analysis of the impact of Title 8 for subgroups was repeated, excluding 1984. The overall results indicate that: (1) the sign of the changes (increase/decrease) did not change, and (2) the overall significance of the changes decreased in all cases. These findings are consistent with the results presented on the full sample in table 3.16 . 


\subsubsection{Leverage}

Table 3.21 presents descriptive statistics on the number of measurement changes made by the 107 sample firms, segregated into three subgroups on the basis of the firms' leverage. The first panel provides information on the sample firms' leverage ratios, where leverage is measured as total debt divided by total equity. Based on the frequency distribution, firms were divided into three subgroups for low, intermediate and high leverage. The average leverage ratio for the entire sample was $2.400^{36}$

The second panel presents statistics on the number of measurement changes for each of the three leverage categories. The lowest average number of total measurement changes was in the low leverage category. The intermediate group had the highest firm/year average. The same result was found for the first time series. The highly leveraged firms had a firm/year average slightly lower than the intermediate group $(0.01)$. Although there seems to be some difference between low leveraged firms and the other two categories, the differences between these subgroups are not significant.

Table 3.2 1: Descriptive statistics on leverage and measurement changes for low, intermediate and high leverage firms between 1977 and $1986(\mathrm{n}=107)$

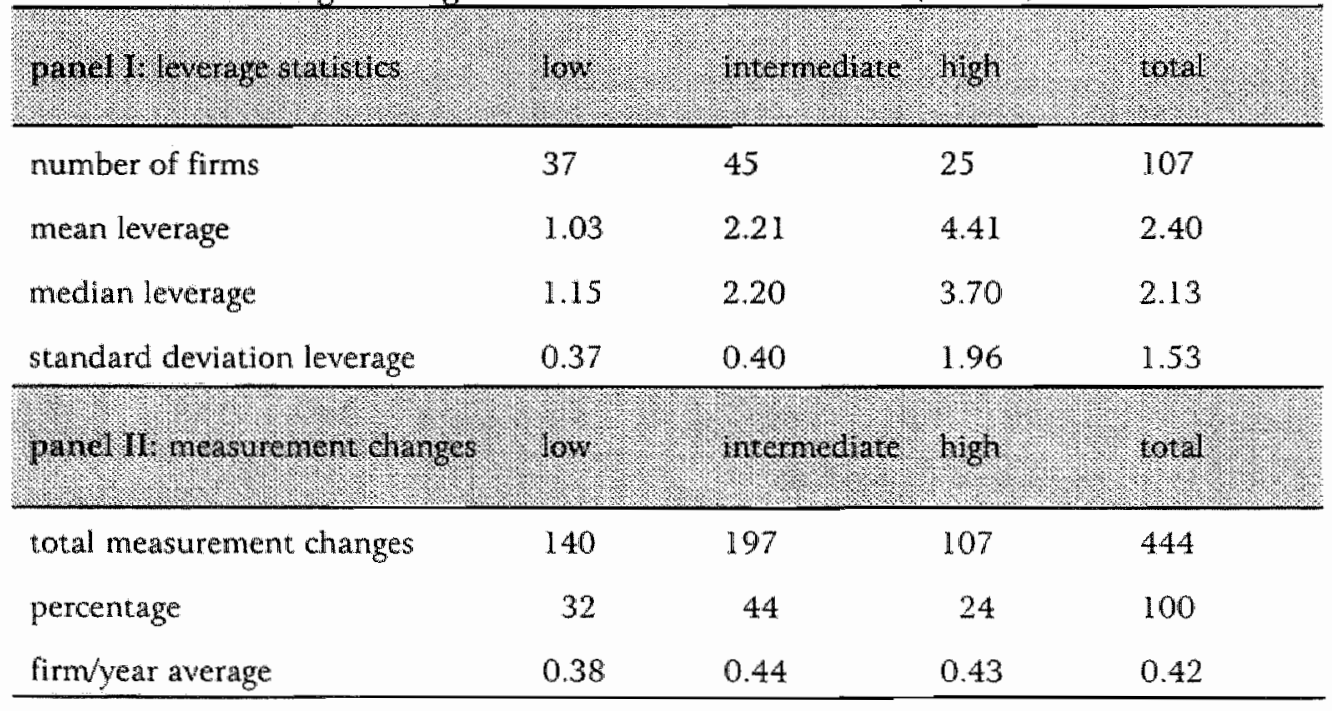

Table 3.22 presents information specifying the impact of Title 8 on the number of

${ }^{36}$ The average and median debt/equity ratios were higher than in the first sample $(2,40$ and 2.13, compared to 1.34 and 1.29$)$. 
measurement changes for the sample firms per leverage subgroup. The table presents the average number of measurement changes before and after the enactment of the new accounting legislation and the test results of the differences between the two periods for each subgroup.

Table 3.22: Comparison of average firm/year measurement changes for low, intermediate, and high leverage firms before and after 1984, including $1984(\mathrm{n}=107)$

\begin{tabular}{|c|c|c|c|c|c|c|c|c|c|}
\hline \multirow[t]{2}{*}{ 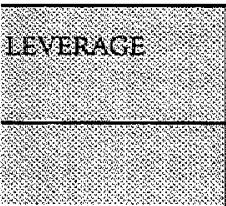 } & \multicolumn{3}{|c|}{ 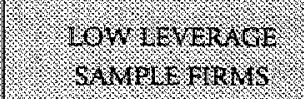 } & \multicolumn{3}{|c|}{ 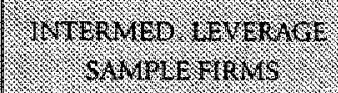 } & \multicolumn{3}{|c|}{ 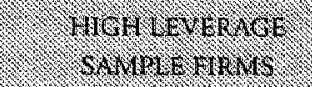 } \\
\hline & Pro. & 198s & 1.2. & freq & POST & $1 / 28$ & frey & ros & $1+2 \times$ \\
\hline $\begin{array}{l}\text { measurement } \\
\text { changes }\end{array}$ & 0.34 & 0.46 & 1.39 & 0.39 & 0.53 & $1.62^{\circ}$ & 0.39 & 0.55 & $1.68^{\circ}$ \\
\hline
\end{tabular}

significant at 5\% level (one-tailed)

The table shows that firm/year averages have increased for all three categories after 1984. A comparison of the differences between the pre- and post Title 8 firm/year averages by means of a t-test yields significant changes only for the intermediate and high leverage categories (at the 5\% level). These findings are consistent with the prediction that firms with higher debt/equity ratios have been affected more by the implementation of Title 8 and therefore would tend to make more measurement changes. The results on the impact of regulation on measurement changes are consistent with the evidence presented on the first time-series, although the significance level is lower. ${ }^{37}$

\subsubsection{Industry}

Finally, measurement changes were analysed on an industry level (see table 3.22) using an industry-group classification similar to that presented in the previous section. The sample firms represent 22 different industries (two digit SBI-codes). ${ }^{38}$

\footnotetext{
${ }^{37}$ We repeated the analysis of the changes in firm/year averages belore and after 1984 for subgroups, excluding 1971. Again, the results indicate that the observed sign of the changes remained unchanged (i.e. increased), while none of these changes were significant.

${ }^{38} \mathrm{As}$ in the first time-series, there is one industry group that contains only two firms, in this case the steel industry. The groups in this time-series comprise the following SBI industry codes: food $=20,21$; textile $=22$; paper/publishing $=26,27$; oil, gas $/$ chemical $=29,31,32$;
} 
To test hypothesis $\mathrm{H}_{5}^{\mathrm{c}}$, the number of measurement changes will first be compared across industries. The largest industry group is the Wholesale and Retail firms $(n=25)$, which accounts for $19 \%(85)$ of all measurement changes, although the firm/year average is relatively low at 0.34 . The Paper and Publishing industry is the second largest: the fifteen firms made 69 measurement changes during the ten year period. The firm/year average is 0.46 . The highest firm/year averages for measurement changes were found for the Steel industry (0.65), followed by Electrical Engineering (0.64). The latter also ranked high in the first time-series. The lowest firm/year average was found for the Oil, Gas and Chemical industry, with an average of 0.27 . Other industry groups with low firm/year averages were Transport and Manufacturing (0.28) and Wholesale and Retail. The firm/year industry averages vary more than in the first time series. The difference between the highest and lowest averages is 0.38 , compared to 0.24 in the first time-series.

Table 3.23: Measurement changes by industry group between 1977 and $1986(n=1.07)$

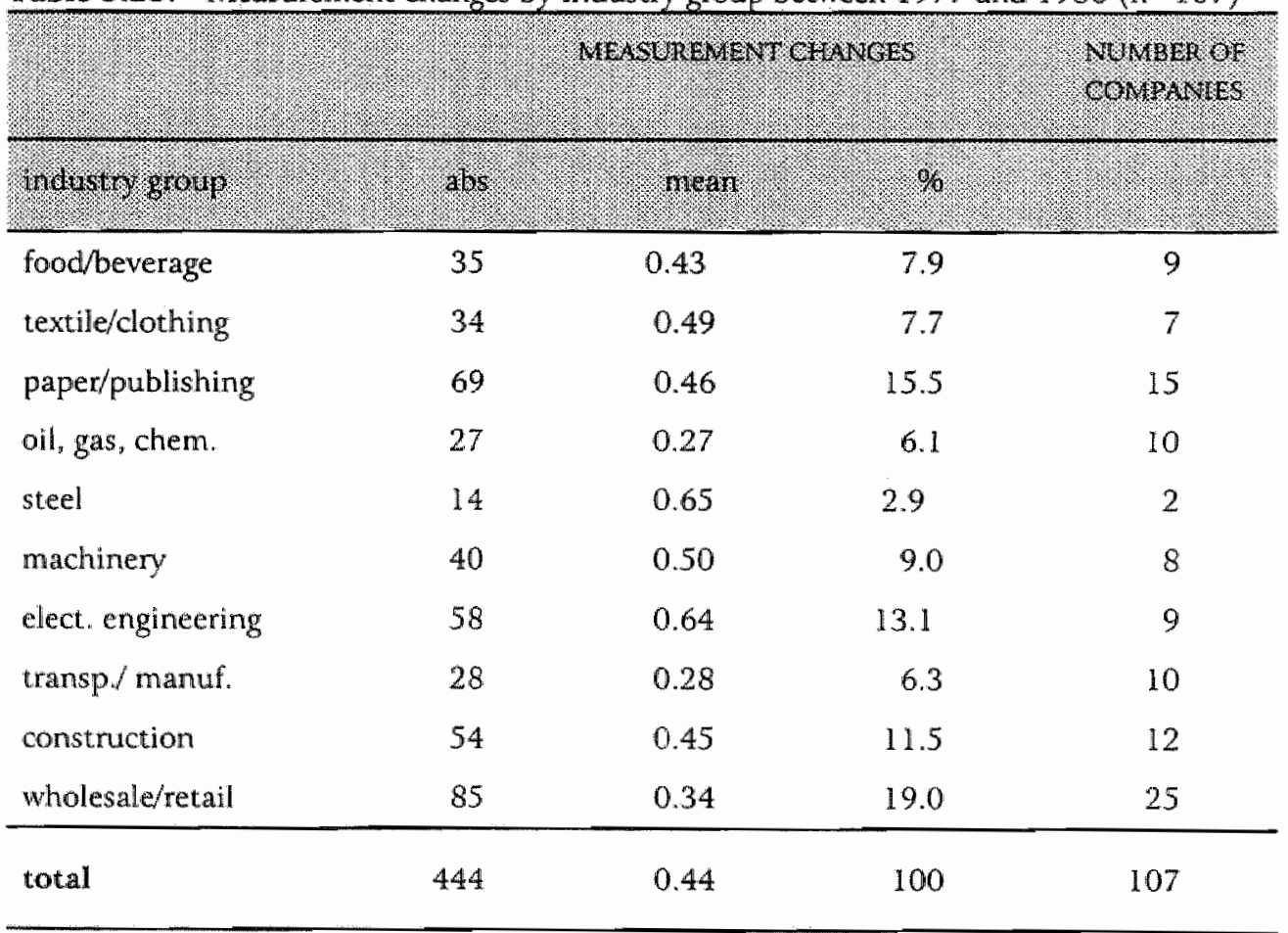

steel $=33,34 ; \quad$ machinery $=35$; electrical engineering $=36$; transport/other $=37,38,39$; construction $=51$; and wholesale and retail $=61,65,99$. 
Again, the findings indicate that there are significant differences between industries, which could be explained by industry-specific macro-economic circumstances which affect firms' operating, investing, and financing activities. Accounting method choice might then be linked to these characteristics.

Hypothesis $\mathrm{H}_{5}^{\mathrm{c}}$ also suggested that trading firms would make fewer measurement changes than industrial firms. The trading firms' firm/year average is in fact relatively low compared to other industries, but two industry groups report lower averages. This contrasts with the results found in the first time-series.

The effects of the implementation of Title 8 on the firms in each industry group was then examined. Table 3.24 presents firm/year industry averages for the numbers of measurement changes before and after the implementation of Title 8 .

Table 3.24: Comparison of measurement changes before and after 1984 , including 1984 , by industry group $(\mathrm{n}=107)$

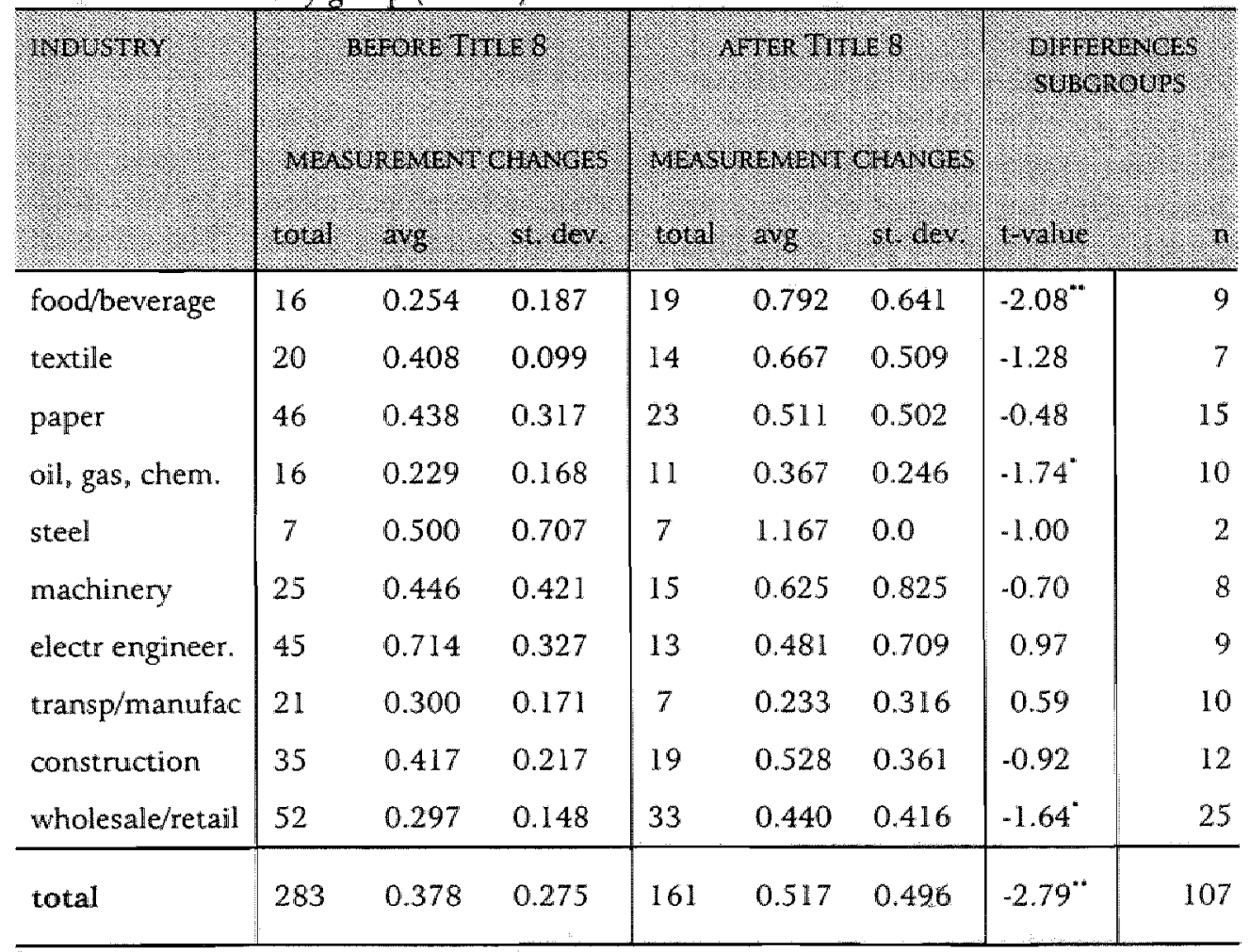

significant at the 5\%-level (one tailed)

"significant at the $1 \%$-level (one tailed) 
The results show that firm/year averages for eight of the ten industry groups increased in the years from 1984 on, compared to the average numbers of measurement changes in the preceding years (1977-1983). Only firms in the Electrical Engineering and Transport and Manufacturing industry groups show a decrease in the average number of measurement changes. Of the eight industry groups with an increase in the average number of measurement changes, three reported a significant positive change. These were the Food industry, Oil, Gas, Chemicals, and Wholesale and Retail firms.

The impact of financial accounting regulation varies across industry groups, since both the firm/year average of measurement changes per industry and the changes in the firm/year averages before and after the implementation of Title 8 vary significantly. Although a significant increase is reported for the Wholesale and Retail firms, which is contrary to expectations, the pre- and post- Title 8 averages remain the second lowest of all industries. It should be remembered that at the industry level, as for the full sample, the increase in measurement changes was largely due to the increase in the year in which Title 8 became effective. ${ }^{39}$

\subsection{Summary and Conclusions}

'This chapter presented empirical evidence concerning the way in which managements' choices regarding alternative accounting procedures have been affected by two major regulatory intervention periods in Dutch financial accounting history. The effects of the mandatory changes in accounting rules and standards on firms' financial accounting choices was chosen as the central theme, focusing on changes from one accounting method to another and the effect of such changes on reported income and equity.

Table 3.25 presents a summary of the results of the hypotheses that were tested to examine the impact of the WJO and Title 8 on accounting method changes. These hypotheses were developed to distinguish between two alternative perspectives: opportunistic behaviour versus efficient contracting.

The results in this chapter concerning the first major shift in the Dutch regulatory financial accounting regime show an increase in the number of accounting changes in the year the Act became effective, 1971, which is consistent with expectations. This particular year shows the largest number of classification accounting changes and

\footnotetext{
${ }^{39}$ The analysis of the changes before and after Title 8 excluding 1984 is consistent with previous findings. The significance level reduces in all cases, while the sign of the changes remains equal.
} 
measurement changes (i.e. changes with an effect on earnings and/or equity). These accounting changes relate mainly to disclosure issues, which is consistent with our expectations based on the analysis of the contents of the WJO in chapter two.

Table 3.25: Summary of the test results ${ }^{1}$ of hypothesis $\mathrm{H}_{1}^{c}$ to $\mathrm{H}_{5}^{c}$ on the impact of the WJO and Title 8

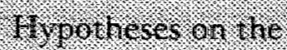

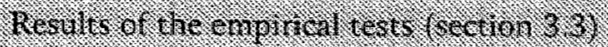

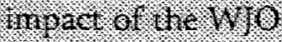

Hypotheses $\mathrm{H}_{1}^{c}$ and $\mathrm{H}^{\mathrm{c}}{ }_{1 \mathrm{~A}}$

not significant, only sign consistent with $\mathrm{H}^{\mathrm{c}}{ }_{\mathrm{IA}}$

Hypotheses $\mathrm{H}_{2}^{c}$ and $\mathrm{H}^{c}{ }_{2 A}$

not significant, only sign consistent with $\mathrm{H}_{2 A}^{c}$

Hypothesis $\mathrm{H}_{3}^{c}$

significant

Hypothesis $\mathrm{H}^{\mathrm{c}}$

first part not significant, second part significant

Hypothesis $\mathbb{H}_{5}^{c}$

first part significant, second part not significant

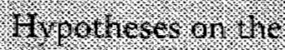

inuart of TII] 8

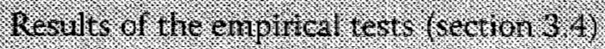

Hypotheses $\mathrm{H}^{\mathrm{e}}$, and $\mathrm{H}^{\mathrm{c}}{ }_{\mathrm{A}}$

not significant, only sign consistent with $\mathrm{H}^{\mathrm{e}}{ }_{\text {IA }}$

Hypotheses $\mathrm{H}_{2}^{\mathrm{c}}$ and $\mathrm{H}_{2 \mathrm{~A}}^{\mathrm{c}}$

not significant, only sign consistent with $\mathrm{H}^{\mathrm{c}}{ }_{2 \mathrm{~A}}$

Hypothesis $\mathrm{HC}_{3}$

significant

Hypothesis $\mathbb{H}^{c}$

first part not significant, second part significant

Hypothesis $\mathrm{H}^{\mathrm{c}}{ }_{5}$ significant

All hypotheses were tested using both a parametric t-test and a non-parametric Wilcoxon Signed rank test. For the specific results on these tests we refer to the corresponding tables.

The increase in 1971 was followed by a significant decrease in 1972, due to classification changes (which constitutes the majority of accounting changes). This is consistent with expectations, since many of these classification changes were induced by the new requirements of the WJO and the total number of accounting changes was not expected to remain at this high level. They were expected to return to a lower level, but to remain above the level before the WTO. The results indicated that the number of classification changes decreased after 1971, causing the level of total accounting changes in the years after 1971 to be lower. The only increase in the frequency of accounting changes after 1971 was for measurement changes. This is consistent with the theoretical assumption that any restriction of the accepted set of accounting procedures would tend to prompt firm managements to use accounting changes to alter the firms" financial position. However, the increase after 1971 was 
not significant. This means that the sign of the changes is consistent with hypothesis $\mathrm{H}_{\mathrm{iA}}^{\mathrm{A}}$, which suggested that firms made more accounting changes after the introduction of the WJO in order to mitigate the effects of the regulation. But the direct tests of the first hypothesis did not yield significant results.

Furthermore, it was found that there was already a significant increase in the year prior to the implementation of the WJO, which could be explained by anticipatory behaviour. Firms expecting mandatory financial reporting regulations changed their accounting policies in the year prior to the implementation of the WJO.

To provide additional evidence on measurement changes, the magnitude and sign of the effects of measurement changes were also examined (second hypothesis). There were more changes with a positive effect on earnings and/or equity than with a negative effect, indicating that accounting changes to positively adjust reported earnings numbers are made more often. There were also more measurement changes with an earnings impact after the implementation of the WJO than in the period before (excluding 1971), and the number of measurement changes with a positive effect on earnings was highest in 1971. The cumulative effect of measurement changes on earnings was three times higher after 1970.

Then there was also a larger number of changes with a positive effect on equity following the introduction of the WJO, apparently because secret reserves were (largely) ruled out by the new regulation. This particular finding provides an example of the impact of financial accounting regulation on firms' financial reporting practice. In summary, we concluded that the results on the magnitude of accounting changes were consistent with the expected direction of the change, but these changes were not significant.

Tests were also conducted to see whether firm characteristics frequently referred to in other empirical research, such as size, leverage and industry classification, might reveal different effects.

The results of the size tests indicated that large firms made more accounting changes, although the increase in the number of accounting changes due to the impact of the WJO was highest in the small firm category. This was explained by the fact that large firms might have made already changes ahead of the mandatory financial regulations of the WJO (hypothesis $\mathrm{H}_{3}^{\mathrm{c}}$ ). Overall, the results of the size hypothesis were significant.

As regards the tests for a leverage effect, highly leveraged firms made fewer total accounting changes, but there was a significant increase in the number of measurement changes made by this group after 1970, consistent with hypothesis $\mathrm{H}_{4}^{c}$. 
This finding suggests that the impact of regulation seems to have been different according to firms' capital structure, and consequently their response has also been different. This might be a result of the fact that highly leveraged firms might have been closer to the limits set in their loan agreements.

Finally, an industry-based comparison of the frequency of accounting changes over the entire period indicates that the number of accounting changes differs across industry groups. All industries showed increased levels of accounting changes after 1971, but the impact of the WIO also varied across industries. This is consistent with the first part of hypothesis $\mathrm{H}_{5}^{\mathrm{c}}$. Contrary to expectations, Wholesale and Retail firms were not those with the lowest firm/year averages. In addition to this there was a significant increase in the numbers of measurement changes made by this group.

In short, the results on firm characteristics indicate that there is a relationship between firm characteristics and the impact of the WJO (i.e. on accounting method changes). In fact, the overall results of these hypotheses are more significant than in the case of the first two hypotheses. These findings therefore lend support to the efficient contracting perspective.

Part two of the empirical analysis in this chapter dealt with the effects of the second major shift in financial accounting regulation: Title 8 . In this case data was available only for measurement changes. The results are largely similar to those for the first time series. The number of accounting changes was highest in 1984. Accounting change levels in the two subsequent years were only slightly higher than in the years preceding 1984, which provides no significant support for hypothesis $\mathrm{H}^{\mathrm{c}}{ }_{\mathrm{IA}}$. This time, no indication was found that firms made anticipatory changes in the year prior to Title 8 . On the contrary, the results suggest that firms postponed accounting changes they might have made in 1983.

As for the magnitude and signs of the accounting changes, the number of accounting changes with a positive effect on earnings was twice as high as the number of accounting changes with a negative earnings effect. Again, the highest number of positive accounting changes was found in 1984. Compared to the results of the first time-series, the patterns of the annual average and cumulative effect of these changes were less consistent with the pattern of the frequency of accounting changes. In this particular case, changes in the economic monetary system during the early mineteeneightees (Bretton Woods) have had a significant effect on the number and magnitude of the measurement changes. This explained the high number of (foreign currency translation) accounting changes reported in 1981. Nevertheless, the (average) effects of the changes on earnings and equity, as with the first time-series, were higher in the years after the implementation. 
The additional tests on hypotheses $\mathrm{H}_{3}$ to $\mathrm{H}_{5}$ produced similar results compared to the first time-series. Again, the results of tests of the size hypothesis revealed that large firms made more accounting changes than medium-sized and small firms. However, the impact of Title 8 appeared to have been larger for medium-sized firms and small firms. Again, this could imply that large firms had already anticipated the new requirements, which would be consistent with hypothesis $\mathrm{H}_{3}{ }_{3}$.

The results on leverage effects were also similar to those for the first time-series. Although the low-leverage category accounted for the largest number of accounting changes, the increase in the number of accounting changes was significant only in the high-leverage category, which lends support to the debt/equity hypothesis $\left(\mathrm{H}_{4}^{\mathrm{c}}\right)$ that the impact of regulation on these firms would be higher.

Finally, tests on differences across industry groups led to similar results as far as the first part of hypothesis $\mathrm{H}_{5}$ is concerned. The differences in firm/year averages between industry groups were even larger. In the second time series, Wholesale and Retail firms made a low number of accounting changes, and there was a significant decrease after 1984, as compared to other industries. This finding therefore also supports the second part of hypothesis $\mathrm{H}_{5}^{\mathrm{c}}$.

In sum, our analysis of the effects of the implementation of the WJO and Title 8 has showm that the number of accounting changes increased significantly in both years of implementation. However, the levels and magnitude of accounting changes after the introduction of both Acts were not significantly higher. Although there was an increase in both cases, it was not significant. The overall assessment of our analysis is that the findings are inconsistent with hypotheses $\mathrm{H}_{1}^{c}$ and $\mathrm{H}_{2}^{c}$, whereas only the signs of the changes are consistent with $\mathrm{H}^{\mathrm{c}}{ }_{1 \mathrm{~A}}$ and $\mathrm{H}^{\mathrm{c}}{ }_{2 \mathrm{~A}}$. These findings could also be interpreted as providing some evidence for the no-effects hypothesis, which has been introduced in section 3.2. However, the additional tests on firm characteristics size, leverage, and industry yielded more significant results. These tests indicate that some firms indeed have been affected by regulation, depending on their specific characteristics (i.e. size, leverage, industry). The reported differences in the levels of accounting changes and changes therein therefore seem to provide more substantial evidence in favour of the efficient contracting perspective.

The results also have indicated that, in the absence of regulatory interventions like the WJO and Title 8, a certain (normal) level of accounting changes exists and that specific economic developments can also influence the pattern of accounting changes. This was clearly demonstrated in the case of the second time series. However, these accounting changes surrounding the introduction of the WJO and Title 8 have not biased our results regarding the potential impact of the WIO or Title 8 , since they were on average equally distributed over both time-periods. 
Note again that although the WJO and Title 8 contained very few measurement rules, this does not imply that firms' discretion concerning accounting method choice was not affected. The increase in disclosure requirements appears to have had an effect on management's accounting policy choices which goes beyond the direct effects of mandatory measurement changes. Thus, this result would suggest that the no-effects hypothesis introduced in section 3.2.1 was not found to be true. Furthermore, the overall effect of the implementation of WJO appears to be stronger than that of Title 8. This was expected because the WJO represents the first major shift in the Dutch financial reporting environment. The introduction of the WJO reflects a change from a situation (almost) without financial reporting regulation to a situation with financial reporting regulation, while Title 8 reflects a situation with additional or more financial reporting regulation.

In the next chapter results will be presented on the empirical analysis of accounting accruals to complement the results reported here. 


\section{Chapter 4}

\section{Empirical evidence on the effects of the implementation of the WJO in 1971 and Title 8 in 1984: an analysis of accounting accruals ${ }^{1}$}

\subsection{Introduction}

The empirical analysis of the previous chapter focused on accounting changes as a means to investigate possible effects of the introduction of two major financial accounting regulations on financial reporting by Dutch firms. This chapter reports on the analysis of accounting accruals, the third method available in literature which has been described in section 2.3.3. Its purpose is to add evidence to the results presented in chapter three. The motivation for this is that management has a certain discretion over a firm's accruals not only through visible changes in accounting procedures, as examined in the previous chapter, but also through more subtle techriques and specific transactions. This discretion can be used to influence earnings in present and future periods.

This chapter proceeds as follows. Section 4.2,1. elaborates on the research questions presented in chapter two with respect to changes in accruals, both discretionary and nondiscretionary, and in earnings. The details concerning the research method and the data selection process, and a review of accruals literature, are discussed in sections 4.2.2. and 4.2.3.

The results of the empirical analyses on both time series of accruals and earnings are presented in the remaining sections of this chapter. The analysis of the first timeseries, covering the years from 1965 to 1974 surrounding the introduction of the WJO, is described in section 4.3. Section 4.4 presents the analysis of the second timeseries, covering the years 1975-1990, to examine the effects of the implementation

\footnotetext{
'Early versions of this chapter are Mertens (1991) and Mertens and Hassink (1992).
} 
of Title 8 . The conclusions from the empirical analyses are presented in section 4.5 .

\section{2}

\section{Method and data selection}

\subsection{I \\ Introduction: some further remarks about accruals measurement}

In this chapter the key hypothesis is that nondiscretionary accruals increased as a result of the passing of (1) the WIO and (2) Title 8 , because financial reporting regulation reduced discretionary financial reporting choices by introducing more measurement and disclosure rules. In order to examine this, the research questions outlined in chapter two (section 2.3.3) will be developed into specific hypotheses with respect to the time-series patterns of accruals and earnings.

The basic idea introduced in chapter two was that accounting accruals of firms subjected to the new financial reporting regulations would change in the year(s) of introduction and thereafter. Accounting accruals were defined as the difference between earnings and cash flow from operations: ${ }^{2}$

TOTAL ACCRUALS = EARNINGS - CASH FLOW FROM OPERATIONS (CFO)

An important assumption is that cash flows (from operations) ${ }^{3}$ are expected to follow a random walk.

In sum, the accrual concept is based on the assumption that cash flows represent a more untempered (but not necessarily better) measure of a firm's economic performance. The 'accrual process' can be seen as the visible result of the discretionary (voluntary) and nondiscretionary (mandatory) accounting procedures and methods used by the firm's management, where the bottom line earnings number presented in the annual report reflects the cumulative effects of these choices.

\footnotetext{
${ }^{2}$ See Healy (1985, p.86), Liberty and Zimmerman (1986, p.701), DeAngelo (1986, p.408), Rayburn (1986, p.119), Wilson (1986, p.294).

${ }^{3}$ Using cash flow from operations mitigates timing and matching problems related to the effect of investment and finance activities. Because it only reflects cash flow generated from the firms operating activities, cash flow from operations represent a more objective performance measure (Dechow, 1994, p.7). For an extensive discussion of the use of cash flow measures see also Rayburn (1986). Wilson (1986) and Bernard and Stober (1989).
} 
Part of the accruals are constrained by rules, institutions, and economic conditions." The part that is not susceptible to management choice is nondiscretionary. The remaining part of accruals is discretionary. In other words, discretionary accruals and nondiscretionary are subsets of total accruals, where total accruals are defined as the difference between reported eamings and cash flow (from operations). If we assume that nondiscretionary accruals are constant, the cumulative effect of discretionary accrual choices can thus be estimated by the change in total accruals:

$\triangle$ TOTAL ACCRUALS $_{T}=$ TOTAL ACCRUALS $T=1$ - TOTAL ACCRUALS $=0$

and as explained, total accruals can be subdivided:

TOTAL ACCRUALS = NONDISCRETIONARY ACCRUALS + DISCRETIONARY ACCRUALS

Because it is not possible to observe the nondiscretionary accruals separately, some mechanism, technique or assumption must be used to obtain a proxy for discretionary accruals. This involves choosing a partitioning variable, to define the portion of accruals that is being managed. Three different approaches can be distinguished (Schipper, 1989 , p.99-100):

(1) Total accruals is the measure of the construct being managed. It is assumed that all accruals are substantially subject to managerial discretion. Put differently, economic conditions are assumed not to significantly influence the levels of these accruals.

(2) Only part of total accruals are thought to be manageable, but nondiscretionary accruals are assumed to be constant, so the first differences in total accruals measure the amount of discretionary accruals.

(3) Direct estimation of nondiscretionary accruals, where it is recognized that (external) economic conditions influence at least some portion of accruals.

A fourth approach can be distinguished where attention is focused on a single account, such as the provision for bad debts. This approach is not based on partitioning but it enables the use of accounting rules in order to make an accountspecific prediction of the nondiscretionary accrual component.

\footnotetext{
${ }^{4}$ One obvious example of accounting rules affecting accruals are those defining depreciation expenses. The effect of changing economic conditions can be seen, for example, in the effect of changes in sales levels on accounts receivable and payable.
} 
These approaches will be illustrated with some examples of empirical studies. ${ }^{5}$

\section{Approach 1 and 2}

The potential for earnings management has been investigated in several different contexts using both methods (1) and (2). Healy's (1985) test of the related bonus plan hypothesis was the initial study on specific accrual choices. Liberty and Zimmerman (1986) examined firms' accruals during labour contract negotiations, expecting to find abnormal accruals during negotiation periods, to lower reported earnings. DeAngelo's (1986) study is based on a similar idea, but this time in the context of management buyouts. Pourciau (1993) examined the relationship between discretionary accounting choices and (nonroutine) top executive changes. She reports evidence of earnings management in the period of incoming and departing executives. Incoming executives make income decreasing accounting methods in the year of the change and income increasing accounting methods in the following year. Contrary to expectations, departing executives also choose income decreasing accounting methods in the year of departure.

\section{Approach 3}

Iones (1991) used a regression model in order to estimate discretionary accruals. This study documents the use of accounting numbers by the federal government during import relief investigations. An estimate of the discretionary component of total accruals is used as a measure of eamings management. Firms that would benefit from import relief were expected to attempt to decrease earnings through eamings management during import relief investigations by the US International Trade commission. Explicit use of accounting numbers in import relief regulation provides incentives to manage eamings in order to obtain import relief. A similar study was conducted by Ravburn and Lenway (1992), examining the unusual accrual behaviour in the US semi-conductor industry. In order to obtain import relief from foreign (Japanese) firms, US firms systematically lowered their earnings (by increasing their negative accruals) during the Trade Commissions' investigations in 1985. Cahan (1992) also directly estimated discretionary accruals to refine the political costs hypothesis in the specific context of antitrust investigations. Managers in firms being investigated for monopoly-related violations would have incentives to use accounting accruals that produce abnormally low levels of income to reduce the possibility of unfavourable ruling. The research provides empirical evidence that discretionary (negative) accruals increased so as to lower reported income. Guenther (1994) also estimated discretionary accruals directly and demonstrates accrual changes "i.e. earnings management practices, in response to corporate tax rate changes such as the Tax Reform Act of 1986. The author explains that taxes and financial reporting are

${ }^{5}$ So it is not intended as a complete literature review. 
linked because deductibility of an accrued expense (or the deferral of revenue) for tax purposes is a condition for accrual of the expense (or the deferral of revenue) for financial statement purposes (Guenther, 1994, p.4). The results reported by Guenther show that in the year prior to the tax rate reduction the firms investigated lowered their current accruals significantly so as to maximize tax rate savings.

\section{Approach 4}

McNichols and Wilson (1988) carried out a study based on the fourth (single accrual) approach. Rather than using an estimate of total discretionary accruals, they employed the provision for bad debt as their only accrual measure. They found that firms use the provision for bad debt to either smooth earnings or, when faced with extremely high earnings, firms will choose income-decreasing accruals.

Finally, an extension of the fourth approach is the study by Bowen, et al. (1992). It demonstrates the use of more than one accrual component instead of only one accrual component. They concentrate on what they believe to be the most important components of discretionary accruals. ${ }^{6}$

Table 4.1 lists empirical studies in chronological order using four accounting accrual techniques. The table shows that early studies (Healy, DeAngelo, and Liberty and Zimmerman) basically assume that nondiscretionary accruals are constant over time, implying that a change in total accruals is caused by an alteration of the discretionary part of the accruals (approach 2). More recent studies (Jones, Cahan, Guenther) have relaxed this assumption, in that discretionary accruals are measured through the use of an expectations model (approach 3).

This chapter uses two different approaches: approach 2 and 3. From here on these approaches will be referred to as method I and method II. First, total accruals and changes in total accruals are examined (method I). The research questions regarding the pattern of total accruals and the variability of total accruals which were formulated in chapter two are tested. Second, a model similar to that used in Jones, Cahan, and Guenther will be employed to distinguish between the discretionary and nondiscretionary components of total accruals (method II). The objective of the methods put forward in this chapter is to establish whether the time series of nondiscretionary and discretionary accruals have changed, assuming that nondiscretionary accruals are not constant over time. Indeed, a permanent increase in

\footnotetext{
"These are inventory valuation (FIFO/LIFO), depreciation (straight line/accelerated), investment tax credit (flow through/defer), interest (capitalize/expense), $R$ \& $D$ (capitalize/expense), and preopening costs (capitalize/expense costs related to preparing retail stores) (Bowen et al. 1992, p.8-9).
} 
nondiscretionary accruals is expected since the accounting methods and procedures used by fims" management were altered by the shifts in financial accounting legislation.

Table 4.1: Previous accrual studies and the expected sign of the accrual change

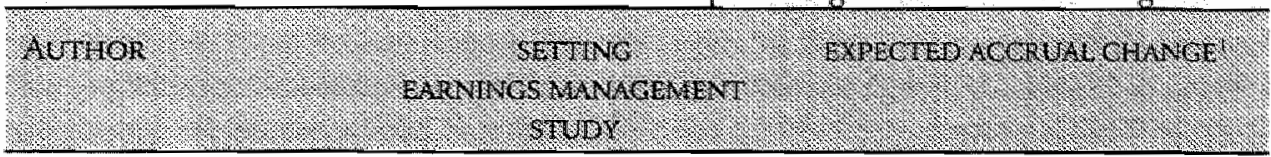

Heally

(1985)

DeAngelo

(1986)

Liberty and

Zimmerman (1986)

McNichols and

Wilson (1988)

Jones

(1991)

Cahan

(1.992)

Rayburn and

Lenway (1992)

Bowen et al.

(1992)

Pourciau

(1993)

Guenther

(1994)

(1994)

a positive change refers to an increase in accruals and lower reported earnings

a negative change refers to a decrease in accruals and higher reported earnings
(1) if earnings below lower bound or above upper bound: positive

(2) if earnings between upper and lower bound: negative

positive

positive negotiations

unuisual highlow eamings and the provisions for bad debt

(1) high earnings: positive

(2) low earnings: negative

positive

negative

positive

negative

claims and firms"

accounting choices

executive changes

(1) incoming executives: positive in first year negative in second year

(2) departing executives: negative in year of departure

corporate tax rate changes positive 


\subsubsection{Method}

Where the previous chapter focused on counting individual accounting method changes, the present analysis is aimed at accruals, based on the idea that accruals play an important role in determining reported eamings. The previous section pointed out that two different methods will be used. We will now focus on both methods I and II. First, section 4.2.2.1 will present method I to study the time-series pattern of total accruals. Second, method II will be used in section 4.2 .2 .2 to develop a regression model to provide evidence on the pattern of both discretionary and nondiscretionary accruals.

\subsubsection{Discretionary accruals: method I}

According to research questions $R_{1} \backslash R_{1 A}$ and $R_{2} \backslash R_{2 A}$ (section 2.3.3) the (1) level and (2) variability of total accruals is expected to have changed as a result of the implementation of the WJO and Title 8 . This is because nondiscretionary accruals are expected to have become larger due to increased regulatory financial reporting restrictions, assuming no change in the economic circumstances. For instance, one important nondiscretionary accrual component that is expected to have increased as a result of the WJO regulations is depreciation expenses. ${ }^{7}$ And, as a result of the increase in the nondiscretionary part of accruals, it is also assumed that the variability of earnings has changed $\left(R_{2} \backslash R_{2 A}\right)$.

In the models used by Healy (1985), DeAngelo (1986), and Jones (1991), which will be used here as a basis, total accruals from a prior period $(t-I)$ are used as a measure for normal accruals. The change in total accruals between periods $t$ and $t-I$ is then defined as discretionary accruals or abnormal accruals (see equation number 2). Previously, total accruals were defined as earnings less cash flow from operations (see equation no. 1):

TOTAL ACCRUALS $_{\mathrm{T}}=$ EARNINGS $_{\mathrm{T}}-$ CASH FLOW FROM OPERATIONS $(\mathrm{CFO})_{\mathrm{T}}$

According to the definition used by Jones (1991, p.207), total accruals are then

\footnotetext{
"See section 2.3.3.

${ }^{8}$ The models used by Jones (1991), Cahan (1992) and Guenther (1994) originate from DeAngelo's expectations model.
} 
defined as: ${ }^{9}$

$$
\begin{aligned}
T A_{t}= & {\left[\Delta \text { Current Assets }_{t}-\Delta \text { Current }_{\text {Cash }}\right] } \\
- & {\left[\Delta \text { Current Liabilities }_{t}-\Delta \text { Current Maturities of Long Term Debt } t_{t}\right] } \\
-\quad & {[\text { Depreciation Expense }] }
\end{aligned}
$$

The definition of accruals employed in this study is based on previous research conducted by Mertens and Hassink (1992). This study particularly focused on the use of different definitions of accruals and cash flow proxies to assess the effect of the choice of this partitioning variable on the outcome of the empirical tests within the context of earnings management. We emphasize that this is important for two reasons. First, previous studies (Bowen et al., 1986; Bernard and Stober, 1989) have indicated that (the signals provided by) different cash flow measures can lead to different results of empirical analyses. For instance, a simple but frequently used cash flow measure like net income plus depreciation does not appear to be an accurate proxy for cash flow from operations. More elaborate cash flow proxies (Healy, 1985; Jones, 1991) use changes in current assets (other than cash) and current liabilities, which are usually obtained from changes in the individual accounts of the balance sheet and profit and loss account. So, the impact of the choice of different accruals and cash flow measures has to be evaluated very carefully prior to conducting the time series analyses of accruals and cash flow from operations. Second, the reason why the definition of accruals should be considered carefully is that to some extent differences exist in financial reporting concepts between the US and the Netherlands. These potential differences between US and Dutch generally accepted accounting principles (GAAP) must be considered in the light of their potential impact on the specific accrial components. We will therefore analyse whether any adjustment to the accruals model used by Jones would be necessary as a result of differences between the US and Dutch GAAP. This analysis is mainly based on the study by Mertens and Hassink (1992).

Recall that the purpose of the accruals definition is to adjust net earnings for effects and transactions of a non-cash nature. The method used in the accruals literature is similar to the indirect method to determine CFO. According to both the International Accounting Standard Committee (IAS 7 on cash flow statements) and the Annual Reporting Committee (Guideline 4.20 on cash flow statements), CFO is determined by adjusting reported earnings for (a) changes during the period in inventories and operating receivables and payables, (b) non-cash items like depreciation and provisions, and (c) all other items for which the cash effects are investing or financing

${ }^{9}$ The reason for choosing cash flows from operations was explained previously in section 4.2 .1 . 
cash flows. We can now compare the contents of the specific cash flow statement elements (based on the indirect method) with the accruals definition (4) to determine which accrual components are or should be included. First, the definition captures all changes in net working capital. This includes changes in inventories, receivables, and payables. The net working capital also includes changes in interest and dividend receivables and payables. Dividend and interest are, according to the IASC and the Annual Reporting Committee, also part of the firm's operational cash flow. Another important category of accruals constitutes non-cash items: depreciation expenses and (changes in) provisions. Depreciation expenses are also included in the definition. The second item however, provisions, is not included in the definition of accruals as a separate item. In Mertens and Hassink (1992) the impact of the (changes in) provisions has been further examined. First, the most frequently used definitions of accruals and CFO in recent literature ${ }^{10}$, that were all constructed within the US framework of generally accepted accounting principles, have been thoroughly examined. The outcome of this process was that apart from the definition used by Healy (1985) and others, a second accruals definition was tested. This definition included the change in provisions, because this constitutes one of the non-cash items described earlier. ${ }^{11}$ After using these two definitions to calculate accruals and cash flow from operations, the correlation coefficients showed that the proxies were significantly correlated. ${ }^{12}$ The changes in the provision accounts, which can be an important accrual, appeared to be of relative minor importance when compared to other accruals. The outcome of the empirical results presented in this paper, using these two accrual and cash flow proxies, were very similar. In order to interpret this result two aspects should be considered. First, although the changes in the 'provisions' account are not included in the definition, the accruals definition does take into account changes in at least two categories of provisions. These are 'provisions for bad debt' and 'obsolete inventory' (both components of current assets). Second, although provisions in itself may represent a substantial (liability) account, this does not automatically imply that changes in provision represent large

${ }^{10}$ All these methods use the indirect method to estimate cash flow from operations.

"This reflects an adjustment to the Dutch financial accounting environment, where provisions constitute a separate liability. The counterpart for provisions in the US is contingent liabilities. But contingent liabilities are not disclosed as a separate balance sheet item, they are part of current liabilities. Also, it should be noted that provisions are more broadly diefined and therefore (potentially) contain more aspects than contingent liabilities. In addition to this, a third accruals definition was used, based on Livnat and Zarowin (1990). We refer to Mertens and Hassink (1992) for more details on this definition.

${ }^{12}$ The Spearman rank correlation coefficient for the cash flow from operations proxies was 0.92, which is significant at the 1\%-level (Mertens and Hassink, 1992, p. 15). 
accruals. To amplify, the nature of a provision is different from depreciation expenses, because the latter only causes a cash (out)flow at one point in time (e.g. the time of purchase of an asset). This results in a large accrual. A provision amount, however, can be created or added (to an already existing provision) in one year, which will result in an accrual, but it is most probable that this provision will also be used (debited) in that same year. Then, the net change in the provision amount or accrual is (relatively) smaller. For instance, a warranty provision is usually related to the sales volume (percentage of sales) of a period (year). If warranty claims occur in that same year, the warranty provision will be debited. The net accrual in that specific year would therefore be relatively small. ${ }^{13}$

A final comment refers to the item 'paid income tax'. According to the indirect method this is also an adjustment item to determine CFO. Within Dutch GAAP, the tax accrual is somewhat difficult to determine. The actual amount of income tax paid must be derived from (a) the amount of income tax stated in the profit and loss account, (b) the changes in income tax payable, which is part of the current liabilities and, (c) changes the tax provision. Since provisions were not included in the accruals definition the exact amount of income taxes paid cannot be determined. The changes in income tax payable, included in the current liabilities, is therefore at best a proxy for the actual income tax paid.

In summary, the most important conclusion drawn from the previous empirical analysis was that the adjusted accrual definition (which included changes in provisions) did not lead to changes in the results and conclusions of the empirical tests. Therefore, it was decided that the accruals model used in this dissertation would be based on a similar definition as used by Jones (1991), since this would enable a comparison of the results of this chapter with the results of previous (international) research conducted. ${ }^{14}$ A more detailed explanation of the definition

\footnotetext{
${ }^{13}$ In addition to this, it could be questioned whether provisions represent a (discretionary) accruals component for firms to (frequently) manage earnings, since provisions must serve a specific purpose and this information must be disclosed in the notes to the financial statement. The use of a provision is therefore restricted to the defined purpose (for instance, a provision for maintenance or a pension provision). Although they bear important subjective elements in that the amount and timing of a provision is to a large extent at the discretion of the management, the use of a provision is restricted to its previously defined purpose. Apart from provisions, other components might also be subject to discussions about whether they represent discretionary or nondiscretionary accruals. We refer to the next section and also appendix $4 \mathrm{~A}$ fora more extensive discussion of this aspect.
}

${ }^{14}$ The samples used in Hassink and Mertens (1992) and this dissertation are almost similar. In this chapter the original sample of 57 is extended to 76 firms. 
of total accruals, as well as the choice and motivation of the different accruals components is presented in appendix $4 \mathrm{~A}$. It also provides an example of how accruals are calculated.

After determining accruals, we calculate cash flow from operations as:

CASH FLOW FROM OPERATIONS $(C F O)_{T}=$ EARNINGS $_{T}-$ TOTAL ACCRUALS $_{T}$

Based on this definition, total accruals and the changes in total accruals can be calculated for each individual firm for each year. Sections 4.3. and 4.4 report on the time series analysis of the levels, changes in levels, and variability of annual total accruals, earnings and cash flows to examine the impact of the WJO and Title 8. Expectations regarding the level and variability patterns are described in the subsequent sections. The hypotheses to be tested are based on research questions $R_{1} \backslash R_{1 A}$ and $R_{2} \backslash R_{2 A^{*}}$

\subsubsection{Discretionary accruals: method II}

Simple prediction models, like the one used so far, assume that discretionary accruals are equivalent to changes in total accruals, defined as the year ${ }_{t}$ end accruals minus the year $_{t-1}$ end accruals. This method has certain limitations. For example, if total accruals have increased after the implementation of regulations, it remains unclear (a) whether nondiscretionary accruals have increased or (b) whether the variability of nondiscretionary accruals had decreased as a result of this. A more elaborate test procedure is therefore necessary.

Because the two components of total accruals (discretionary and nondiscretionary) cannot be observed directly, a proxy must be used. The method employed by Jones, Cahan, and Guenther, mentioned in the previous section, incorporates a more sophisticated expectations model for nondiscretionary accruals. They control for changes in the economic circumstances of the firm by using a regression model to estimate the nondiscretionary accruals component. The model estimates nondiscretionary accruals by regressing deflated (by total assets) total accruals on two variables, the change in sales ( $\triangle \mathrm{REV}$ ) and the fixed asset balance (PPE, gross Property, Plant and Equipment), which are also deflated (by total assets). The basic model can be presented as:

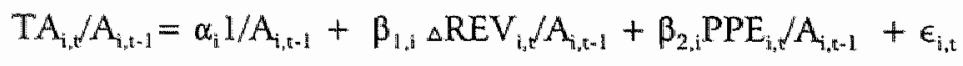

where, 


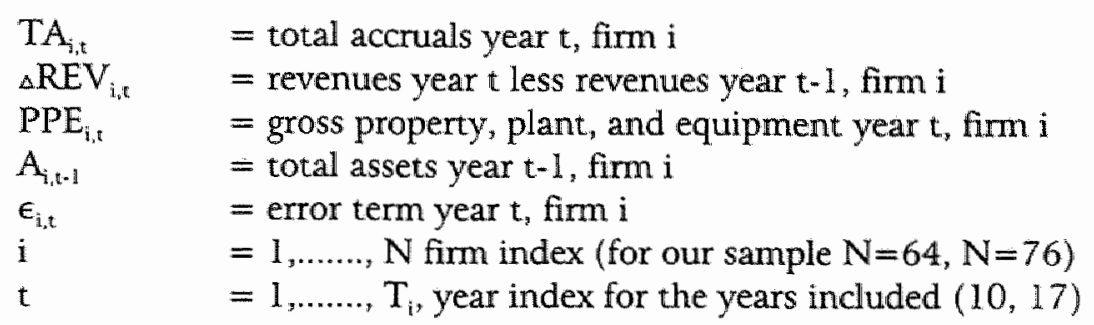

The choice of the regression variables can be motivated as follows:

(1) $\triangle \operatorname{REV}_{i, t}$

Revenues are used to control for changes in nondiscretionary accruals caused by changing economic conditions. They can be seen "...as an objective measure of the firms' operations before managers' manipulations" (Jones, 1991, p.212). Recall that changes in working capital accounts depend on changes in revenues. Nevertheless, revenues are not completely exogenous, since managers may increase or decrease revenues in order to alter reported earnings.

(2) $\quad \operatorname{PPE}_{\mathrm{i}, \mathrm{t}}$

Gross property, plant, and equipment is included to estimate nondiscretionary accruals related to depreciation expenses. Notice that PPE is included rather than the change in PPE because total depreciation expenses are also included in total accruals (Jones, 1991, p.212).

(3) $\mathrm{WJO}_{\mathrm{i}, \mathrm{t}} / \operatorname{TITLE} 8_{\mathrm{i}, \mathrm{t}}$

As outlined in chapter two, the basic idea is that the implementation of the WJO and Title 8 has led to an increase in nondiscretionary accruals. To test this assumption, the model presented so far will be expanded with an additional explanatory variable. A dummy variable "legislation" is added to the equation to separate the observations before and after the introduction of both Acts. The dummy variable legislation (WJO/Title8) is coded 0 in the years before the introduction of relevant act (1971 or 1984), and 1 in all other cases. ${ }^{15}$ If nondiscretionary accruals increased due to the financial reporting requirements deriving from the implementation of the WJO in 1971 and Title 8 in 1984, the dummy variable should be significant. The dummy variable is expected to have a negative sign because nondiscretionary accruals are expected to increase after the WJO and Title 8 was implemented (because accruals are defined as earnings less cash flow from operations).

${ }^{15}$ The regression will also be run with 1970 coded as 1 , consistent with the findings presented in the previous chapter. 
(4) $\epsilon_{i, \text { t }}$

In this model the variation in nondiscretionary accruals is explained by changes in sales and gross property, plant and equipment, and regulatory intervention. It follows then that the remaining (cross-sectional) variation in accruals (the residual term) is assumed to be the result of the firm's discretion. In other words, the error term in this model represents the discretionary accruals component.

The accruals model for the first period (introduction of the WJO) can now be written as:

$\left.\mathrm{TA}_{\mathrm{i}, \mathrm{t}} / \mathrm{A}_{\mathrm{i}, \mathrm{t}-1}=\alpha_{\mathrm{i}} 1 / \mathrm{A}_{\mathrm{i}, \mathrm{t}-1}+\beta_{\mathrm{i}, \mathrm{i}} \Delta \mathrm{REV}_{\mathrm{i}, \mathrm{t}} / \mathrm{A}_{\mathrm{i}, t-1}+\beta_{2, \mathrm{i}} \mathrm{PPE}_{\mathrm{i}, \mathrm{t}} / \mathrm{A}_{\mathrm{i}, \mathrm{t}-1}+\beta_{3, \mathrm{i}} \mathrm{W}\right) \mathrm{O}_{\mathrm{i}, \mathrm{t}}+\epsilon_{\mathrm{i}, \mathrm{t}}$

and in the case of the second period (introduction of Title 8):

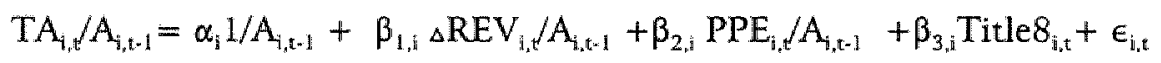

where the dummy variables WJO and Title8 test for the impact of regulation on nondiscretionary accruals and the error term represents the discretionary accruals component. $^{16}$

After having identified the two accrual components, the time series of accrual totals and components can be analysed to examine the impact of the WJO and Title 8 on the level and variability of nondiscretionary and discretionary accruals and thus test the assumptions underlying research questions $R_{1}$ to $R_{5}$ (which will be formally stated as hypotheses $\mathrm{H}_{1}{ }_{1}$ to $\mathrm{H}_{5}{ }_{5}$ in sections 4.3 .2 and 4.4.2). The results are presented in sections 4.3 .4 to 4.3 .7 (WJO) and 4.4.3. to 4.4 .7 (Title 8 ).

\subsubsection{Sample selection and test-period}

The research questions developed in section 2.3 .3 are tested using financial statement data for two samples of firms to examine the time series patterns of accruals and earnings surrounding the introduction of the WJO and Title 8 . Three kinds of data were initially collected for each sample firm: (1) total accruals, (2) earnings, and (3) cash flows (from operations). Figure 4.1 illustrates the time series investigated.

The data is for two non-random samples of publicly traded firms listed on the ASE.

\footnotetext{
${ }^{16}$ See also Cahan $(1992$, p.83), who introduces a dummy variable YEAR which is coded one in the years accruals are expected to be lower because of antitrust investigations by Government, and zero in all other years.
} 
The samples are restricted to manufacturing, non-financial services and wholesalle and retail firms, as in chapter three. The first sample is identical to that used in chapter three to analyse accounting method changes between 1965 and 1974. It consists of 64 firms and ten years of data (1965-1974). See Appendix 4B.I for a list of the firms included. The second sample, used to examine the effects of the Title 8 , is taken from the Central Bureau of Statistics' database of publicly listed NVs. ${ }^{17}$ The sample is also restricted to manufacturing, non-financial services and wholesale and retail firms.

Figure 4.1: Time series of accruals, earnings and cash flows to be analysed

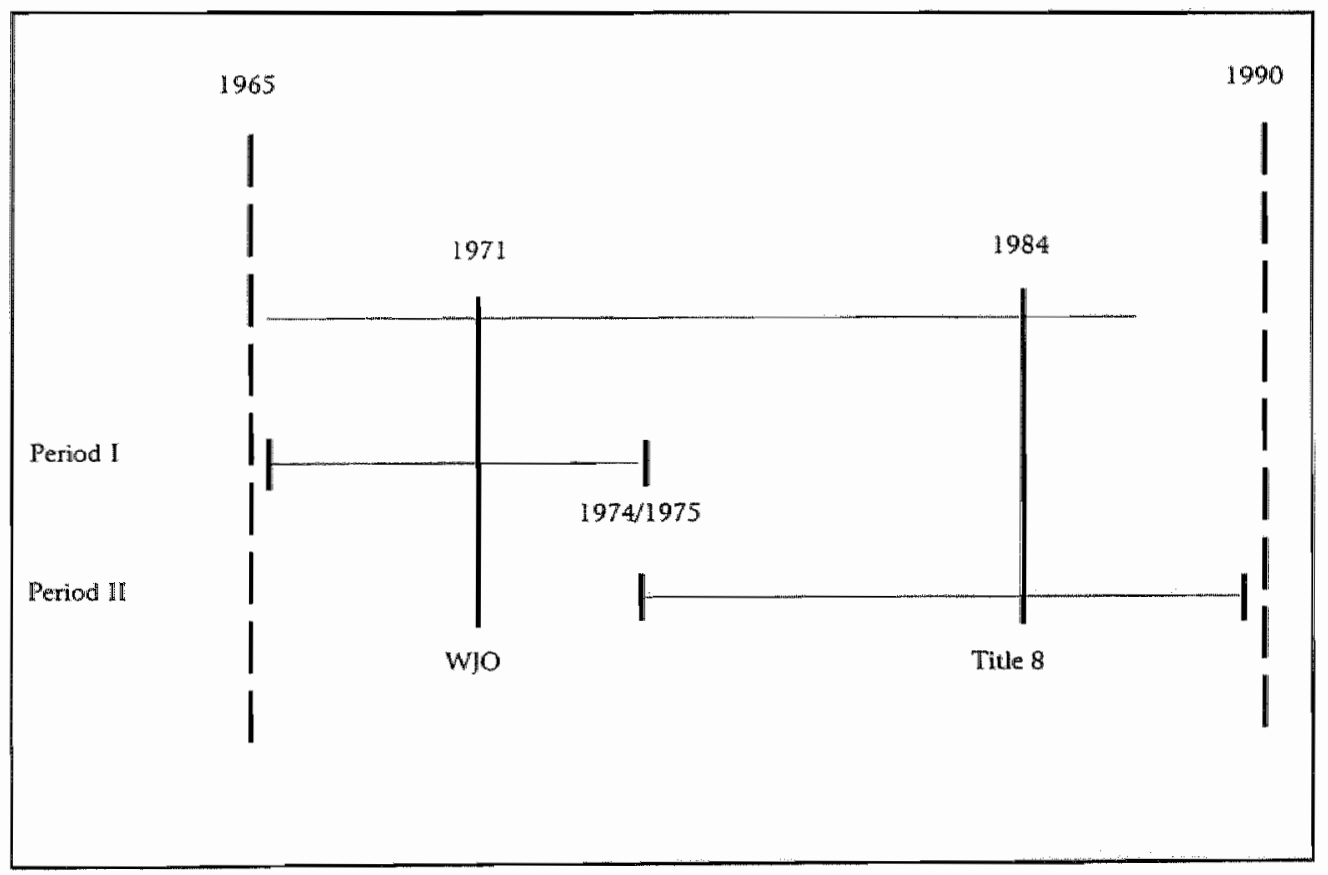

After deleting firms with incomplete time series a final sample of 76 firms remained. Data was available for seventeen years (1974-1990). Appendix 4B.2 presents a complete list of the firms involved.

The sample selection procedure is summarized in table 4.2. The hypotheses and the empirical results of the tests based on the samples described will be presented in the remainder of this chapter.

\footnotetext{
${ }^{17} \mathrm{CBS}$ statistiek voor beurs-NVs.
} 
Table 4.2: Selection of sample firms

\begin{tabular}{|c|c|c|}
\hline (n) & 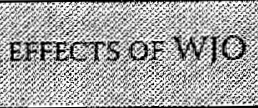 & erfects of ThTH 8 \\
\hline $\begin{array}{l}\text { originally selected number } \\
\text { of firms (NVs) }\end{array}$ & 113 & 187 \\
\hline incomplete data & 27 & 93 \\
\hline $\begin{array}{l}\text { banks, insurance firms } \\
\text { and financial institutions }\end{array}$ & 22 & 18 \\
\hline final sample & 64 & 76 \\
\hline
\end{tabular}

\subsection{Hypotheses and results of the empirical analysis of accounting accruals (1): introduction of the first major accounting regulation in the Netherlands (WJO)}

\subsubsection{Introduction}

This section describes an empirical analysis of the impact of the first major financial reporting regulation in the Netherlands: the implementation of the WJO in 1971. The analysis of the time series on accruals, earnings and cash flows between 1965 and 1974 aims to supplement the evidence presented in chapter three on the impact of financial accounting regulation on financial reporting practice. ${ }^{18}$ It will focus on the five research questions formulated in section 2.3.3. But first these research questions will be presented as hypotheses to test the impact of the implementation of the WJO.

\subsubsection{Hypotheses}

Based on the research questions stated in section 2.3.3, specific hypotheses will now be formulated to empirically examine the impact of the first major change in financial accounting regulation in the Netherlands. The hypotheses to be tested in this section are:

\section{Hypotheses:}

\footnotetext{
${ }^{18}$ Because the CBS data used for the second time series is available from 1974 on, the first time series is two years shorter than the first time series presented in chapter three.
} 
$\mathrm{H}_{1}{ }_{1}$ : the change from an almost nonregulated financial accounting envirosment (before 1971) to a more regulated environment (after 1971) led to (1) an increase in the level of total accuals in the intervention year and following years compared to the level of total accuals in the years before the implementation of the WJO. and (2) an increase in the level of nondiscretionary accuals in the intervention year and following years compared to the level of nondiscretionary accruals in years prior to the intervention year ceteris paribus.

$\mathrm{H}^{\mathrm{a}}{ }_{1 \mathrm{~A}}$ : the change from an almost nonregulated financial accounting environment (before 1971 ) to a more regulated enviromment (after 1971) led to (1) no change in the level of total accruals in 1971 and following years compared to the level of total acculals in years before the implementation of the WJO, and (2) a decrease ${ }^{19}$ in the level of discretionary accruals in the intervention year and following years compared to the level of discretionary accruals in years prior to the intervention years, ceteris paribus.

$\mathrm{H}_{2}^{3}$ : the change from an almost nonregulated financial accounting environment (before 1971) to a more regulated environment led to (1) a decrease in the variability of total and nondiscretionary accruals in the intervention year and following years compared to the years prior to the intervention year, and (2) an increase in the variability of eamings in the period after the implementation compared to the years before the implementation of the WJO, ceteris paribus.

$\mathrm{H}^{\mathrm{a}}{ }_{2 \mathrm{~A}}$ : the change from an almost nonregulated financial accounting environment (before 1971) to a more regulated environment led to an ( 1 ) increase in the variability of discretionay accruals in the intervention year and following years, and (2) no change in the variability of earnings in the period after the implementation compared to the years before the implementation of the WJO, ceteris paribus.

$\mathrm{H}^{*}$ : the variability of accruals, both nondiscretionary and discretionary, and eamings will vary according to size, and the changes in these variability patterns before and after the implementation of the WJO will be larger for large firms.

$\mathrm{H}^{\mathrm{*}}{ }_{4 *}$ the variability of accruals, both nondiscretionary and discretionary, and eamings will vary according to leverage, and the changes in these wariability patterns before and after the implementation of the WJO will be larger for firms with higher debt/equity ratios.

\footnotetext{
${ }^{19}$ See section 2.3 .3 for an explanation of the difference between expectations based on the opportunistic behaviour (hypothesis $\mathbb{H}_{1}^{3}$ ) versus the efficient contracting perspective (hypothesis $\mathrm{H}_{1 \mathrm{~A}}^{\mathrm{a}}$ ) regarding the pattern of discretionary and nondiscretionary accruals.
} 
$\mathrm{H}^{\mathrm{a}}{ }_{5}$ : the variability of accruals, both nondiscretionary and discretionary, and earnings will vary across industries, and the changes in these variability patterns before and after the implementation of the WJO will also differ across industries. More specifically, changes in variability of accruals and earnings are expected to be higher for industrial firms compared to trading firms.

\subsubsection{Results: accruals method: I}

The results presented in this section are based on the first time series (1965-1974). The purpose of the analysis is to determine the effect of the WJO on accruals and reported earnings. First, descriptive statistics will be presented on the average amount of total accruals, earnings, and cash flows, both scaled and unscaled. ${ }^{20}$

Table 4.3 presents unscaled averages for each sample year. Total accruals were expected to increase after the introduction of the WJO (hypothesis $\mathrm{H}_{1}{ }_{1}$ ). The only years in which average accruals decreased were 1968 and 1974. Taking cash flow changes into account, this reflects the effect of changing economic circumstances (declining economic growth). All other sample years report average accrual increases, with the highest increases in 1970 and 1971 . The average level of accruals from $\mathbb{1 9 7 0}$ onwards is also higher than in the years prior to $1970 .^{21}$ The pattern of average accruals appears to be partially determined by changes in the sample firms' economic circumstances, because cash flow averages also increased in that year. The results also indicate that the increase in average accruals in 1970 and 1971 resulted in a decrease in average earnings for the two subsequent years. The observed increase in total accruals might be related to the introduction of the WJO, which became effective in $1971 .^{22}$ The differences in average and median numbers reported in table 4.3 also

\footnotetext{
${ }^{20}$ In most studies only scaled averages are presented because these numbers are corrected for possible size effects and also because potential statistical problems can be circumvented. However, the unscaled data provides information on the average absolute size and variation of the variables for the sample firms, which is of interest for hypothesis $\mathrm{H}^{\mathrm{a}} / \mathrm{H}^{\mathrm{a}}{ }_{\mathrm{A}}$. The potential problems mentioned here are of less concern because we are comparing data from the same firms throughout the period.

${ }^{21}$ As already mentioned these absolute numbers are not corrected for inflation. The purpose of this table is to show unscaled accrual numbers to illustrate the changes in total accrual levels. However, all statistical analyses presented in this chapter are based on scaled accruals.

${ }^{22}$ The increase in 1970 , one year prior to the enforcement of new financial accounting regulations, might be due to firms' anticipatory behaviour. Knowing that their financial reporting in 1971 would have to comply with the new legislation, management may have (partially) adjusted their financial reporting in anticipation of the requirements.
} 


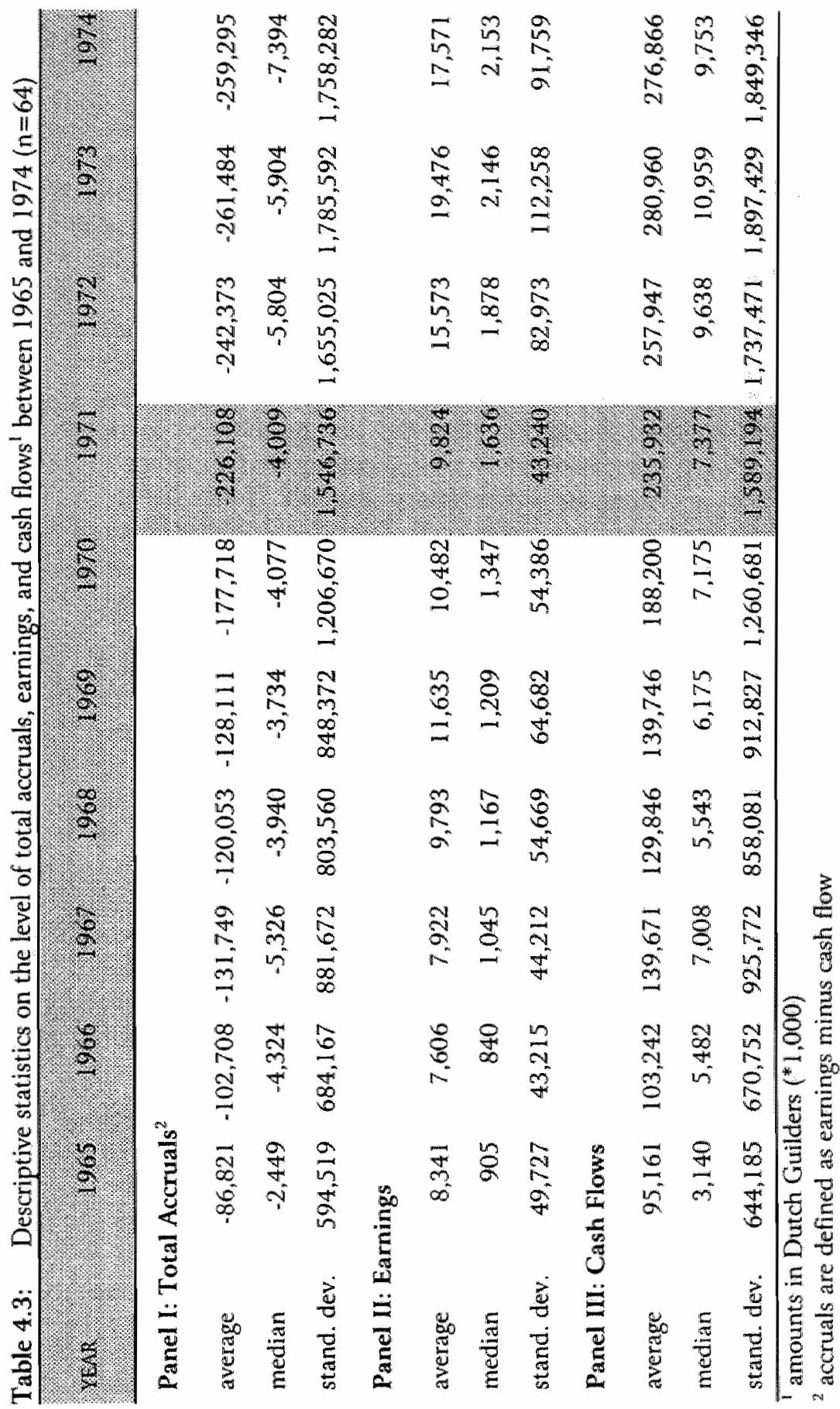


suggest that the results are driven by size effects.

According to hypotheses $\mathrm{H}^{\mathrm{a}}{ }_{1} / \mathrm{H}^{2}{ }_{1 \mathrm{~A}}$, the level of total accruals is expected to have changed. To test this, the next table (4.4) shows changes in scaled average total accruals, earnings, and cash flow numbers. Cash flows are used as a proxy for possible changes in the economic circumstances of the sample firms. The changes have been computed as the first differences of the variables $\left(X_{t}-X_{t .1}\right)$ divided by total assets. ${ }^{23}$ The table presents the average and median change for each of the variables, the number of positive and negative changes, and $t$-values from a parametric t-test used to ascertain whether the average change from year to year is different from zero, as well as significance levels for the non-parametric Wilcoxon signed-ranks test. This test. normally relies on the assumption that the average change in nondiscretionary accruals $\left(N A_{t}-N A_{t-1}\right)$ is approximately zero, meaning that a change in total accruals basically reflects a change in discretionary accruals (Jones 1991, p.207). Here, however it is expected that the average level of nondiscretionary accruals will increase with the implementation of new financial reporting regulations. So, a change in total accruals after the implementation of the WJO primarily reflects a change in nondiscretionary accruals. ${ }^{24}$

Changes in total accruals, scaled by total assets $(t-1)$, are shown in the first panel of table 4.4. First we tested the assumption underlying hypotheses $\mathrm{H}^{a}{ }_{1} \backslash \mathrm{H}^{\mathrm{a}}{ }_{\mathrm{l} \text {, }}$, that changes in total accruals are not significantly different from zero in the years prior to the implementation of the WJO. The statistics presented in the first panel indicate that significant changes did occur in two years, 65/66 and 69/70. ${ }^{25}$ Both years show significant increases (a negative sign means an increase, since accruals are defined negative). For both years, total accruals increased for 43 of the 64 firms. The table shows a significant accrual increase in the year prior to the enactment, which might indicate anticipatory behaviour. Accrual changes in all other years are not significant. As noted earlier, these results should be interpreted with caution because panel III of table 4.4 on cash tlow changes also showed an increase significantly higher than

\footnotetext{
${ }^{23}$ Both Jones and Guenther scale the variables by total assets $t-1$. The reason for this will be explained later in this section, when the data are used to run a regression.

${ }^{24}$ That is, assuming equal economic circumstances.

${ }^{25}$ Jones (1991) uses a one tailed t-test and Wilcoxon signed ranks test in the year accruals were expected to be managed. In her study, accrual changes were expected to be negative. She made no prediction concerning the changes in earnings, cash flow, and revenues. Here, the reported change in 1970 would be highly significant if a one-tailed test was used, which is permitted since the sign is also expected be negative (i.e. negative accrual changes).
} 


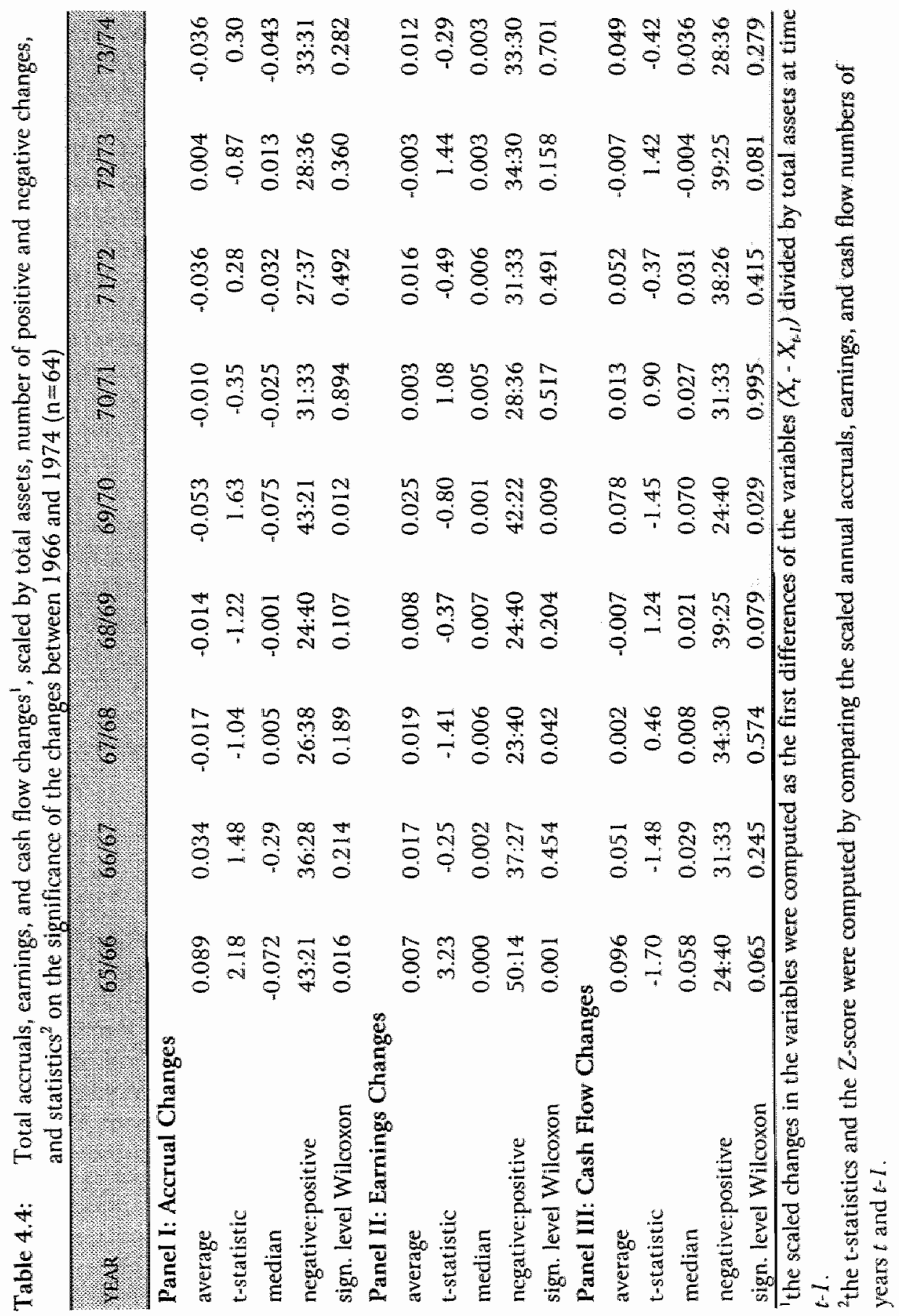


zero. Economic circumstances have an effect on changes in accruals, since several working capital accounts, and thus accruals, are a function of revenues and the firm's cash flows. This means that an increase in nondiscretionary accruals, which is of special importance in this study, might be caused by changes in economic conditions rather than by a shift in mandatory financial accounting regulations. There were significant cash flow changes in $65 / 66$, which could explain the significant accruals change between these years, while the cash flow increase in $69 / 70$ coincides with the accruals increase reported earlier. According to hypothesis $\mathrm{H}_{2}{ }_{2}$, the variability of earnings is expected to have increased after the passing of the Act in 1971, because accruals variability is expected to have decreased. Cash flows are assumed to follow a random walk (i.e. no differences). The second panel, on annual average earnings changes, indicates that the only significant earnings changes occurred in the years prior to the WJO ${ }^{26}$ The 1970 change might however be related to the reported accruals and cash flow changes earlier in the table.

The results presented on the level of total accruals (table 4.3) support hypothesis $\mathrm{H}_{1}{ }_{1}$, which stated that the level of total accruals increased after the introduction of the WJO, although the increase was reported one year earlier which is consistent with the findings presented in chapter three. The increase was expected to reflect the increase in nondiscretionary accruals. It should be noted that 1970 reported significant cash flow changes as well. The results of table 4.4 on the variability of accruals and earnings (see hypothesis $\mathrm{H}_{2}{ }_{2}$ ) did not indicate that the variability of both has increased after the WJO had been introduced. Subsequent tests on variability changes are presented in the next section.

\subsection{3. \Test-results on variability}

In order to specifically test for differences in the variability of total accruals and earnings (hypotheses $\mathrm{H}_{2}{ }_{2}{ } \mathrm{H}_{2 A}^{\mathrm{a}}$ ) firms' average coefficients of variation were calculated, representing each individual firm's standard deviation of total accruals, earnings and cash flow divided by the mean total accruals, earnings, and cash flow. For each firm, two coefficients of variation are calculated: one for the period prior to the WJO, and one for the years after its implementation. If accruals variability decreased after the implementation, this would suggest that the nondiscretionary component of accruals increased and financial reporting restrictions have effectively narrowed firms' discretion in accounting policy choice (hypothesis $\mathrm{H}_{2}^{3}$ ). Furthermore, if accruals can

\footnotetext{
${ }^{26}$ Nonparametric Wilcoxon tests indicate that there were significant changes for $1966, \mathbb{1 9 6 8}$, and 1970 , but using the parametric t-test only the 1966 change is significant.
} 
no longer be used to smooth earnings, it follows that eamings variability should have increased, ceteris paribus. Table 4.5 shows the results with respect to total accruals, earnings and cash flow coefficients of variation.

Since the results presented in the previous chapter and earlier in this chapter "table 4.3 and 4.4) indicated that the major effect of the introduction of the WJO occurred one year before its formal implementation (1970), the test was run twice with different periods. First, the variability coefficient for the years 1965-1970 was compared with the variability coefficient of 1971-1974. Then the same test was run again, but with 1970 excluded from the period prior to the implementation and included in the post-WJO period. Consistent with the previous results, the latter test produced the most significant differences in variability coefficients, as illustrated in table 4.5 .

Table 4.5 Variability coefficients for total accruals, earnings and cash flows before and after the implementation of WJO $(n=64)$

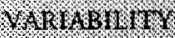 \\ 1.8.1.t. \\ 2.8.811}

Total Accruals

larger:smaller $24: 40 \quad-1.62^{\circ} \quad-1.752^{\circ}$

Earnings

larger:smaller $\quad 40: 24 \quad-1.93^{*} \quad-2.140^{\circ}$

Cash Flows

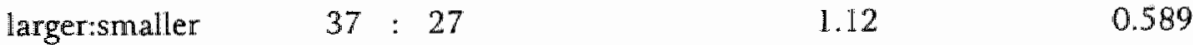

Larger means that the variability increased after the implementation of the WJO;

Smaller means that the variability decreased

significant at 5\% level (one-tailed)

"significant at $1 \%$ level (one-tailed)

First, 40 of the 64 firms show a decrease in accruals variability in the period after the introduction of the WJO, which is consistent with hypothesis $\mathrm{H}_{2}{ }_{2}$. The increase in nondiscretionary accruals could explain this. In other words, the decrease in variability after 1970 might be caused by a relatively larger nondiscretionary accruals component. This in turn would limit managements' opportunities to use accruals to 
smooth earnings, which also explains the observed increase in eamings variability, for 40 of the 64 firms. The findings support hypothesis $\mathrm{H}_{2}^{a}$. The table allso indicates that the variability of cash flows increased, but the change was not significant.

The descriptive statistics presented so far give some support for hypotheses $\mathrm{H}^{2}{ }_{1}$ and $\mathrm{H}_{2}^{2}$. It was assumed that the increase in the variability of total accruals was due mainly to changes in nondiscretionary accruals as a result of the passing of the WJO. First, based on the evidence regarding the impact of the WJO on total accruals, it can be concluded that absolute total accruals increased in the year prior to the introduction of the WJO and in following years. Scaled total accruals show a significant increase only in the year prior to the new regulation. Second, the variability of earnings, measured by the variability coefficients before and after 1970 , increased significantly, which could be explained by managements having fewer opportunities to manage accruals (i.e. decreased variability of accruals). Third, the variability of cash flows does not seem to be affecting the results on variability patterns of accruals and earnings (no significant increase was found).

In order to test the predictions on the level and variability pattern of nondiscretionary and discretionary accruals embodied in hypotheses $\mathrm{H}_{1}^{\mathrm{a}} / \mathrm{H}^{\mathrm{a}} \mathrm{A}$ and $\mathrm{H}_{2}^{\mathrm{a}} / \mathrm{H}_{2 \mathrm{~A}}^{\mathrm{a}}$, the analysis will now focus on method II: the use of the accruals model.

\subsubsection{Results: accruals method II}

The accruals model presented in section 4.2 .2 was:

$\mathrm{TA}_{\mathrm{i}, \mathrm{l}} / \mathrm{A}_{\mathrm{i}, \mathrm{t}-1}=\alpha_{\mathrm{i}} 1 / \mathrm{A}_{\mathrm{i}, t-1}+\beta_{\mathrm{i}, \mathrm{i}} \Delta \mathrm{REV}_{\mathrm{i}, \mathrm{l}} / \mathrm{A}_{\mathrm{i}, \mathrm{t}-1}+\beta_{2, \mathrm{i}} \mathrm{PPE}_{\mathrm{i}, \mathrm{l}} / \mathrm{A}_{\mathrm{i}, \mathrm{t}-\mathrm{l}}+\beta_{3, \mathrm{i}} \mathrm{WJO}_{\mathrm{i}, \mathrm{t}}+\epsilon_{\mathrm{i}, \mathrm{t}}$

where the dummy variable WJO tests for the impact of the WJO on nondiscretionary accruals.

The variables used in the regression model are scaled using total assets, lagged by one year. This is done to reduce heteroscedasticity. ${ }^{27}$ The parameters of the regression model are estimated using a linear regression model for the sample firms over the entire period. The results based on regression equation (5) are given in table 4.6. The F-statistic for the model employed here is significant at the 0.000 level. The adjusted $\mathrm{R}^{2}$ is 0.31116 (Jones: 0.232 , Cahan: 0.6365 , Guenther: $0.381 / 0.474$ ). Two of the

\footnotetext{
${ }^{27}$ Heteroscedasticity can bias the regression parameters, and the error terms of the regression equation might also be influenced by large firms in the sample.
} 
four variables specified in the model are significant. Most important, the dummy variable WJO (legislation) is significant $(0.0005)$ and the sign is negative, which is consistent with expectations. According to hypothesis $\mathrm{H}_{1}{ }_{1}$ nondiscretionary accruals and thus total accruals were expected to increase as a result of the passing of the WJO. The coefficient of the variable is -0.115 . Another significant variable, PPE, has a negative sign. Thus plant, property and equipment are related to income-decreasing nondiscretionary accruals (depreciation). ${ }^{28}$ The expected sign for revenues is not so easy to determine, because some of the working capital itens which are related to revenues have an income-decreasing effect (accounts payable) while other changes result in income-increasing changes (accounts receivable). ${ }^{29} 30$

Table 4.6: Results for the multiple regression equation for total accruals $(n=64)$

Independent variable expected sign $\quad$ coefficient $t$-value Signif.

Adjusted $R^{2}=.31116 \quad F=73.27 \quad$ Signif $=0.000$ Durbin-Watson test $=1.62^{\circ}$

significant at the $5 \%$ level

"significant at the $1 \%$ level

\footnotetext{
${ }^{28}$ Since accruals are defined as negative, an increase means that accruals became more negative (larger negative).

${ }^{29}$ Since not all companies provided revenue information over the complete time-series, operating results were used as a proxy for revenues. Therefore a Spearman rank correlation coefficient of revenues and operating results was computed for the companies used in the second sample. This dataset includes both items. This coefficient $(0.82)$ was significant at the $0.1 \%$ level $(n=64)$.
}

${ }^{30}$ See also Jones (1991, p.213) and Cahan (1992, p.83-85) for a discussion of the expected sign of the regression equation variables. 


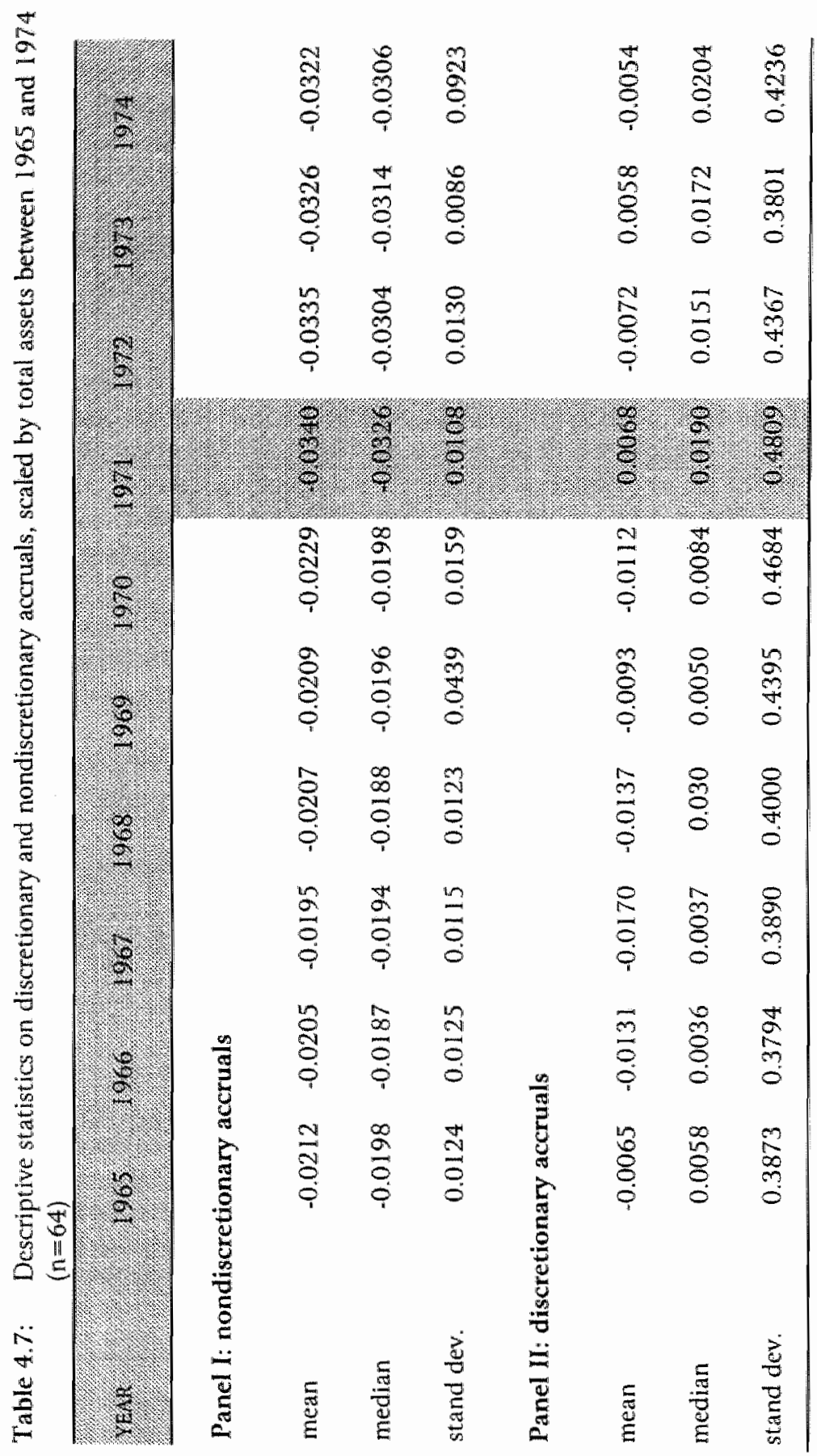


The results indicate that the variable WJO is significantly related to total accruals and has a negative sign, indicating that nondiscretionary accruals increased, consistent with hypothesis $\mathrm{H}_{1}{ }_{1}$. Prior to 1970 , mean nondiscretionary accruals varied within a relatively small range (between -0.0195 and -0.0212 ). In 1970 there was an increase which was larger than in any previous year, followed by another large increase in 1971. The increase in 1970 is consistent with the results presented previously in this chapter and those in the previous chapter, where it was argued that the pattern of accounting method changes showed that firms demonstrated anticipatory behaviour. Furthermore, the level of nondiscretionary accruals in the years after 1970 is higher than in the years prior to 1970 (see also median nondiscretionary accrual numbers), which is consistent with hypothesis $\mathrm{H}^{a}{ }_{1}$.

Subsequently, the results of the regression model are used to determine discretionary accruals in order to test the alternative hypothesis $\mathrm{H}^{a}{ }_{\mathrm{IA}}$. It was argued that firms would use discretionary accruals to offset the potential effects of financial reporting regulation. In other words, if nondiscretionary accruals increased, discretionary accruals would be expected to have decreased after the introduction of the WJO. The residual or error terms from the model in equation (6) represent discretionary accruals. To compute the prediction errors regarding discretionary accruals, the parameters of equation (6) were first estimated over the 10-year estimation period 1965 to 1974 . The estimated parameters from this regression are then used to derive nondiscretionary accruals. Table 4.7 presents descriptive statistics concerning both discretionary and nondiscretionary accruals. The second panel of table 4.7 shows that mean discretionary accruals decreased, beginning in 1971. However, median. discretionary accruals increased from 1970 on. Furthermore, the sign of these median discretionary accrual numbers is positive, meaning that these discretionary accruals have an income-increasing effect. Because this effect was larger in years after the implementation of the WJO, firms seem to have partially offset the effects of the WJO, which would add evidence to support the alternative hypothesis $\mathrm{H}^{\mathrm{a}}{ }_{\mathrm{A}}$.

Figure 4.2 shows time series for both discretionary and nondiscretionary average annual accruals between 1965 and 1974. The pattern of average annual nondiscretionary accruals exhibits the expected increase in 1971 and in subsequent years (see also table 4.7 ).

The accruals model (when using method II) indicates that the level of average annual discretionary accruals decreased after 1971, as the graph demonstrates. Figure 4.2 also suggests that the variability of annual average discretionary accruals has increased. To examine this further, variability coefficients were calculated to measure changes in the variability of both discretionary and nondiscretionary accruals, before and after 1970 to test hypotheses $\mathrm{H}_{2}^{a}{ }_{2} \mathrm{H}_{2 \mathrm{~A}}^{\mathrm{a}}$, similar to method $\mathrm{I}$. 
Figure 4.2: Scaled annual average nondiscretionary and discretionary accruals between 1965 and $1974(n=64)$

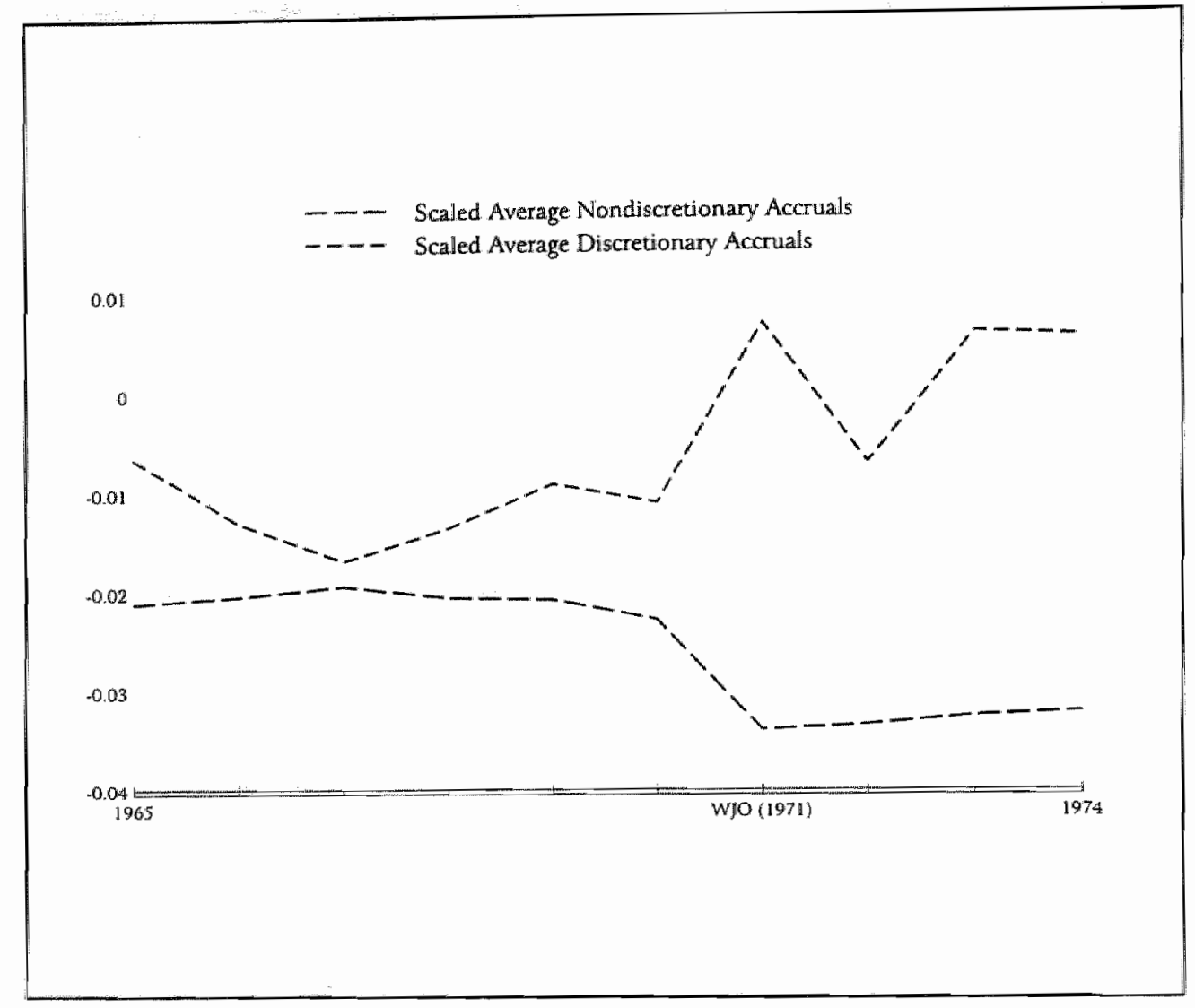

\section{3 .4 .1}

Test-results on variability

Table 4.8 presents the results, which show that (1) the variability of nondiscretionary accruals decreased ( $5 \%$ significance level, parametric t-test), and (2) the variability of discretionary accruals increased (5\% significance level, nonparametric Wilcoxon signed rank test). These results are consistent with hypothesis $\mathrm{H}_{2 \mathrm{~A}}^{\mathrm{a}}$. In essence, the results of accruals method II presented here support the findings presented in the previous section of the empirical analysis based on accruals method I. The use of the model underlying the second method provides more reliable evidence that (1) the 
expected decrease in the variability of nondiscretionary accruals did indeed occur and (2) the variability of discretionary accruals increased. Since the variability of total accruals decreased, it would appear that firms have attempted to counteract the effects of increased financial reporting regulations after 1970 but, based on the increase in earnings variability, it appears that firms discretion in financial reporting policies has been affected by the implementation of the WJO.

The results of the empirical analyses of the three additional variables for firm characteristics, introduced in section 2.3.3, will be described in sections 4.3 .5 to 4.3 .7 of this chapter. These tests will focus on differences in variability patterns.

Table 4..8: Variability coefficients of nondiscretionary accruals, discretionary accruals, and earnings before and after the implementation of the WTO $(n=64)$

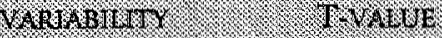

2.1.1.6.

Nondiscretionary accruals

larger:smaller

26.38

$-1.61^{*}$

$-0.88$

Discretionary accruals

larger:smaller

$38: 26$

$-1.02$

$-1.65^{\circ}$

Earnings

larger:smaller

$40: 24$

$-1.93^{m * *}$

$-2.14^{*}$

Larger means that the variability increased after the implementation of the WTO;

Smaller means that the variability decreased

significant at 5\% (one-tailed)

- significant at $1 \%$ (one-tailed)

\subsubsection{Size}

To test whether the results vary by size of the company, as hypothesized in $\mathrm{H}^{\mathrm{a}}{ }_{3}$, the sample was disaggregated by firm size to test for differences in total accruals, earnings and cash flow variability. As in the analysis conducted in chapter three, size is 
measured by total assets, and the firms are divided into three subgroups. ${ }^{31}$ Table 4.9 presents the variability coefficients for total accruals, earnings and cash flows for each subgroup.

\subsubsection{Accruals method I}

A comparison of the differences between the variability coefficients of total accruals for the subgroups shows that variability decreased after the implementation of the WJO for all three groups, although the only significant change was for medium-sized firms. Eamings variability also changed significantly for this group. The increase in earnings variability can be attributed to the increase in cash flow variability, which also explains the significant change for the medium-sized firms. These results do not support the hypothesis that the effect of the WJO on accruals and earnings variability would be different for small and large firms.

Table 4.9: Variability coefficients of accruals, earnings, and cash flows before and after the implementation of the $W J O$, for size categories $(n=64)$

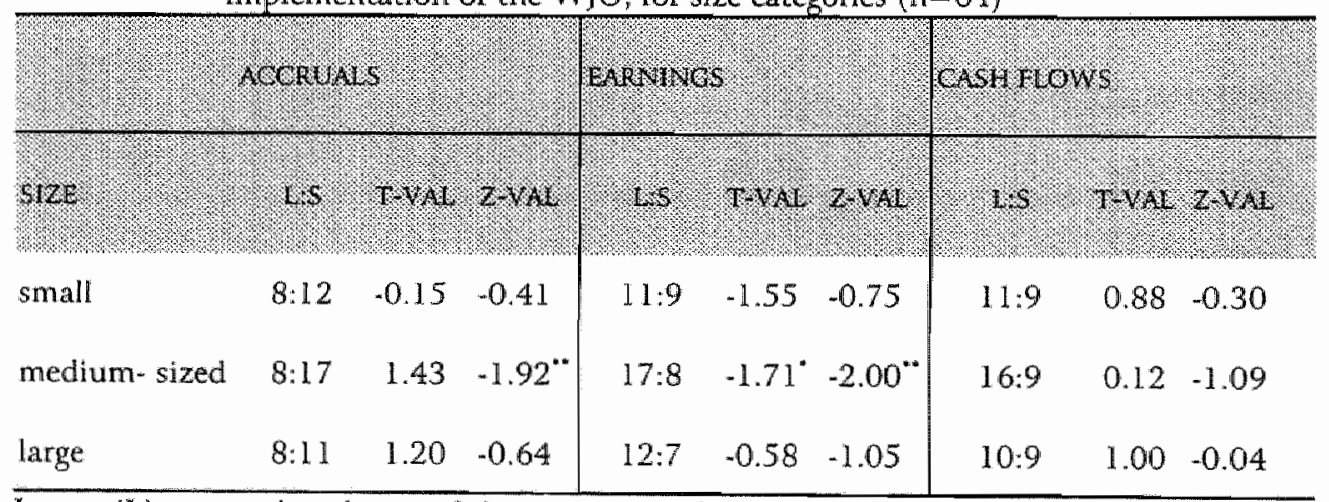

Larger (L) means that the variability increased after the implementation of the WJO;

Smaller (S) means that the variability decreased

significant at $5 \%$

"significant at $1 \%$

${ }^{3 / 1}$ Small firms were those with total assets of less than 20 million Dutch guilders, large firms were those with total assets exceeding 100 million. 


\subsubsection{Accruals method II}

Based on method II, total accruals are now separated into a nondiscretionary and discretionary component. The results of the variability tests on nondiscretionary and discretionary accruals conducted for the three size subgroups are presented in table 4.10.

First, and consistent with hypothesis $\mathrm{H}_{3}{ }_{3}$, the first panel shows that the variability of nondiscretionary accruals decreased among medium-sized and large firms. Although the change was not significant, it does appear that the pattern of nondiscretionary accruals provides more useful information on potential effects of the WIO additional to the pattern of total accruals, especially since small firms show no change in variability. The variability of discretionary accruals shown in the second panel exhibit the reverse pattern. Although this is consistent with the assumption that the variability of discretionary accruals would increase after the implementation of the WJO, no indication was found that variability increased significantly more among large firms than small firms. In fact, only medium-sized firms show a significant increase ( $5 \%$ significance level using nonparametric Wilcoxon signed rank test). It should be noted that table 4.9 reported a significant change in earnings variability for the same subgroup.

Table 4.10 Variability coefficients of nondiscretionary and discretionary accruals before and after the implementation of WJO, for small, medium-sized and large firms $(\mathrm{n}=64)$

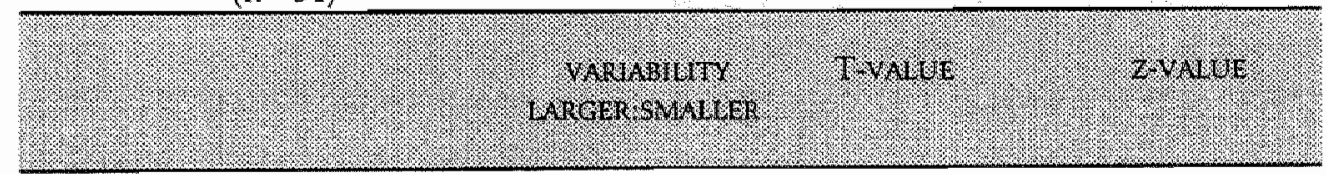

Panel I: nondiscretionary accruals

small

$\begin{array}{rrr}10: 10 & -1.18 & -0.23 \\ 9: 16 & -1.31 & -0.93 \\ 7: 12 & -0.75 & -0.64\end{array}$

medium-sized

$-0.64$

Panel II: discretionary accruals

small

$-0.01$

$-0.41$

medium-sized

$15: 10$

$-1.14$

$-1.52^{\circ}$

large

11:8

1.09

$-1.01$

Larger means that the variability increased after the implementation of the WTO;

Smaller means that the variability decreased

significant at 5\% level (one-tailed)

"significant at $1 \%$ level (one-tailed) 


\subsubsection{Leverage}

To provide evidence on hypothesis $\mathrm{H}_{4}^{2}$ (the debt/equity hypothesis), sample firms were then categorized according to debt/equity ratios. As in chapter three, three different groups were identified (low d/e $(<0.89)$, high $\mathrm{d} / \mathrm{e}(>1.75)$, and intermediate). The results are presented in table 4.11 .

\subsubsection{Accruals method I}

A comparison of the coefficients of variability of total accruals between the leverage categories reveals significant differences. Low and intermediate leverage firms show an increase, while the variability of accruals for the highly leveraged group decreased. Earnings variability for low leverage firms decreased, at least for a majority of the firms, though the reported differences are not significant. However, earnings variability for the intermediate and highly leveraged group increased. The increase in earnings variability for the intermediate group can be explained by the changes in cash flow variability. However, highly leveraged firms show no significant cash flow change, which might indicate that they were more affected by the WJO, consistent with the debt/equity hypothesis.

Table 4.11: Variability coefficients of accruals, earnings, and cash flows before and after the implementation of the WJO, for debt/equity categories $(n=64)$

\begin{tabular}{|c|c|c|c|c|c|c|c|c|c|}
\hline 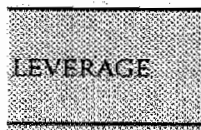 & erivis & & & Eativing & $S$ & & 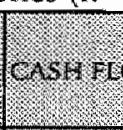 & wis & \\
\hline & 1.8 & $1+7.11$ & 7.1.1. & 4.5 & TYYo & tring & . & 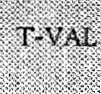 & 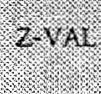 \\
\hline $\begin{array}{l}\text { low leverage } \\
(<0.89)\end{array}$ & $8: 7$ & -0.30 & -0.23 & $6: 9$ & -0.35 & -0.45 & $7: 8$ & -0.46 & -0.63 \\
\hline $\begin{array}{l}\text { intermediate } \\
\text { leverage }\end{array}$ & $10: 25$ & 1.33 & $-1.70^{\circ}$ & $24: 11$ & $-1.57^{\circ}$ & $-2.13^{* *}$ & $22: 13$ & $1.69^{\circ}$ & $-1.66^{\circ}$ \\
\hline $\begin{array}{l}\text { high leverage } \\
(>1.75)\end{array}$ & $6: 8$ & 1.58 & -1.10 & $10: 4$ & $-2.19^{\circ}$ & $-1.68^{\circ}$ & $8: 6$ & 0.59 & -0.47 \\
\hline
\end{tabular}

Larger (L) means that the variability increased after the implementation of the WJO;

Smaller (S) means that the variability decreased

"significant at 5\% level (one-tailed)

"significant at $1 \%$ level (one-tailed) 


\subsubsection{Accruals method II}

In table 4.12 , the focus is on changes in the variability of nondiscretionary and discretionary accruals (method II). The variability of nondiscretionary accruals decreased for the majority of firms in the low and intermediate leverage categories. The result for the intermediate group was significant at the $1 \%$ significance level (nonparametric Wilcoxon singed rank test). The decrease in variability for the intermediate group cannot be explained by changes in economic circumstances (see cash flow pattern in table 4.11). This is further illustrated by the changes in variability of discretionary accruals. The discretionary accruals show a significant increase in variability (using a nonparametric test). However, the increase in variability is reported for all three subgroups. This result, for both nondiscretionary and discretionary accruals, is not consistent with the expectations stated in hypothesis $\mathrm{H}_{4}^{\mathrm{a}}$. Differences in variability patterns before and after the WJO indicate that the impact on intermediate and highly leveraged firms is not larger than on low leverage firms. The results therefore do not suggest that firms with higher debt/equity ratios used discretionary accruals more to offset the effects of the WJO.

Table 4.12 Variability coefficients of nondiscretionary and discretionary accruals before and after the implementation of WJO, for low, intermediate, and high leverage categories $(n=64)$

r.

Panel I: nondiscretionary accruals

$\begin{array}{lccc}\text { low leverage } & 6: 9 & -0.58 & -0.57 \\ \text { intermediate } & 12: 23 & -1.58^{\circ} & -1.79^{\circ} \\ \text { high leverage } & 8: 6 & 1.24 & -0.44\end{array}$

Panel II: discretionary accruals

$\begin{array}{lccc}\text { low leverage } & 9: 6 & 1.01 & -0.74 \\ \text { intermediate } & 20: 15 & -0.99 & -1.21^{\circ} \\ \text { high leverage } & 9: 5 & 0.65 & -0.66\end{array}$

Larger means that the variability increased after the implementation of the WJO;

Smaller means that the variability decreased

significant at $5 \%$ level (one-tailed)

*significant at $1 \%$ level (one-tailed) 


\subsubsection{Industry}

The third characteristic to be examined is the firms' industry. According to hypothesis $\mathrm{H}_{5}^{a}$, the time series of accrual numbers should reveal industry effects, since nondiscretionary accruals are partially determined by industry characteristics. Additionally, economic conditions will be different across industry, which could also explain part of the variance in the cross-sectional accrual patterns. To examine this, sample firms were classified into ten different industry categonies, as in chapter three.

\subsubsection{Accruals method I}

Table 4.13 shows the industry-specific coefficients of variability for accruals, earnings and cash flows before and after the implementation of the WJO. The coefficients of variability for accruals reveal differences in variability between industries, although overall accruals variability decreased for seven out of the ten industries, of which 4 changes were significant. Wholesale and Retail firms were the only category with a significant increase in the variability of total accruals. ${ }^{32}$ It shows that there are differences with respect to the variability patterns of accruals between industrial and trading firms. Earnings variability increased for 8 out 10 industries, and the electrical engineering industry was the only one with a significant decrease. This cannot be explained by changing economic circumstances (see the cash flow changes). For the Paper and Printing, Textile and Clothing, and Machinery industry the table does reveal that economic circumstances changed. But as demonstrated in the Paper and Printing industry, for instance, the significant increase in cash flows coincides with a significant accruals decrease.

\subsubsection{Accruals method II}

We then focused on differences between nondiscretionary and discretionary accruals. Panel I of table 4.14 shows that the variability of nondiscretionary accruals decreased for five industries (of which only Textiles and Clothing is significant), while three industries show equally distributed changes and two show an increase (Paper/Printing and Electrical Engineering). Note that Wholesale and Retail firms also exhibit a decrease (although not significant).

\footnotetext{
${ }^{32}$ The accruals of two other industry groups also increased: the Food/Beverage and Construction groups. However, the latter group contains only two firms, so that no conclusions can be drawn, and the increase for the Food industry was not significant.
} 


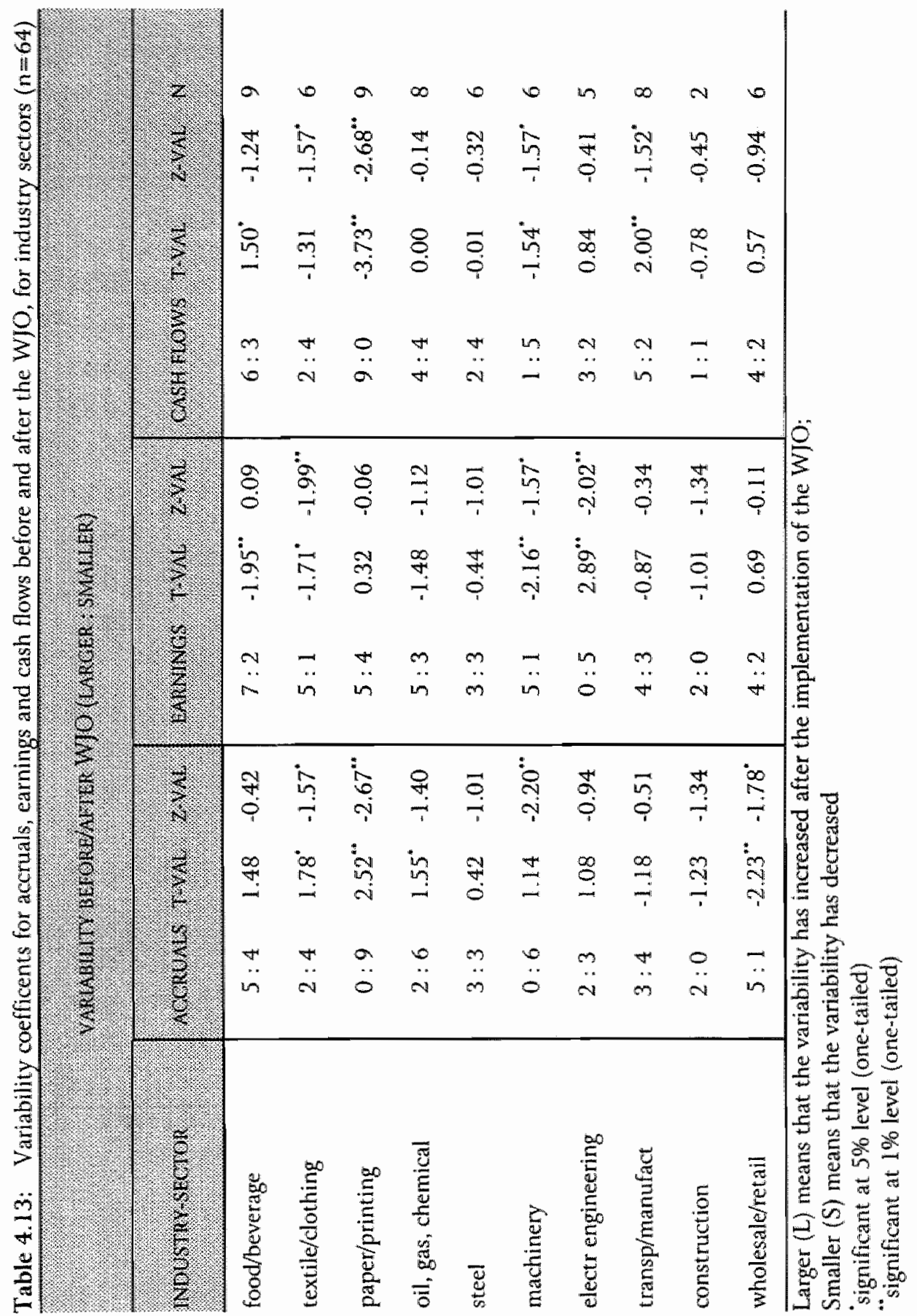


Table 4.14 Variability coefficients of nondiscretionary and discretionary accruals before and after the implementation of the WJO, for industry sectors $(n=64)$

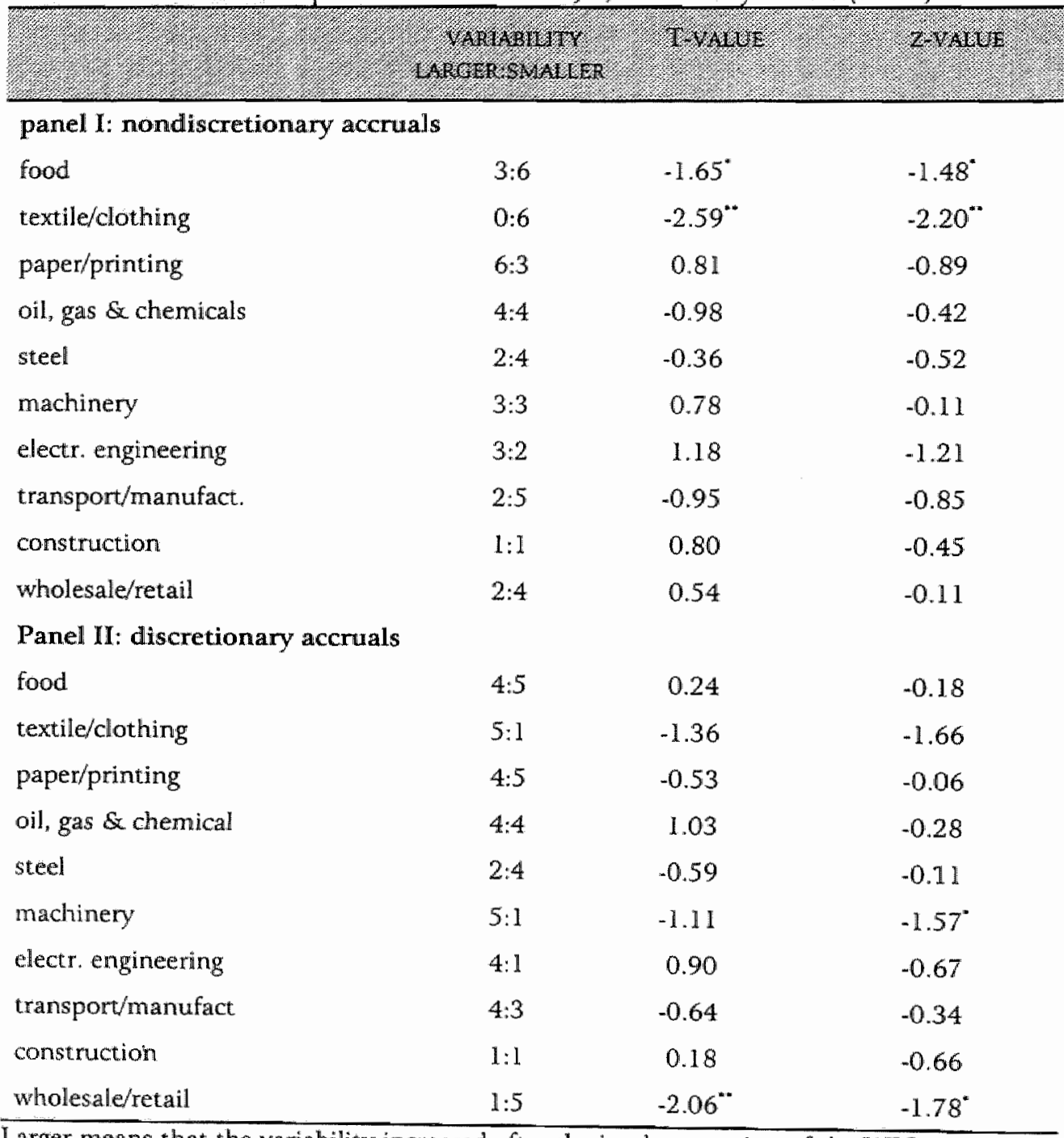

Larger means that the variability increased after the implementation of the WJO;

Smaller means that the variability decreased

significant at 5\% level (one-tailed)

"significant at $1 \%$ level (one-tailed) 
Panel II of Table 4.14 shows the test results on variability changes in discretionary accrual patterns. Two industries, Textiles and Clothing and Machinery, show significant increases in discretionary accruals variablity. Two other industries also show increases (Electrical Engineering and Transport/Manufacturing), but these are not significant. Of the remaining industries, three show a decrease in variability. Remarkably, the only category that shows a significant decrease is the Wholesale and Retail group. Recall that hypothesis $\mathrm{H}_{5}^{3}$ stated these firms were expected to be less affected by the WJO than industrial firms. Overall, the empirical results indicate that there are differences across industrial firms for both nondiscretionary an discretionary accruals. 
4.4 Hypotheses and results of the empirical analysis of accounting accruals (2): introduction of the second major accounting regulation in the Netherlands

\subsubsection{Introduction}

This section outlines the results of the empirical analysis of the impact of the second major financial reporting regulation in the Netherlands: the implementation of Title 8 in 1984. To empirically examine the second time series of accruals, eamings and cash flows between 1975 and 1990 , hypotheses will be formulated based on the research questions developed in chapter two (section 2.3.3).

\subsubsection{Hypotheses}

The hypotheses examining the impact of the second major change in financial accounting regulation in the Netherlands are similar to those presented in section 4.3.2. Here they will be used to examine the impact of Title 8 . The hypotheses are summarized below: ${ }^{33}$

Hypotheses:

$\mathrm{H}_{1}^{2}$ : the change from a partially regulated environment (before 1984) to a more regulated environment (after 1984) led to (1) an increase in the level of total accruals in the intervention year and following years compared to the level of total accruals in the years before the implementation of Title 8, and (2) an increase in the level of nondiscretionary accruals in the intervention year and following years compared to the level of nondiscretionary accruals in the years prior to the intervention year, ceteris paribus.

$\mathrm{H}^{\mathrm{a}}{ }_{1 \mathrm{~A}}$ : the change from a partially regulated financial accounting environment (before 1984) to a more regulated environment (after 1984) led to (1) no change in the level of total accruals in 1984 and following years compared to the level of total accruals in years before the implementation of Title 8 , and (2) a decrease in the level of discretionary accruals in the intervention year and following years compared to the level of discretionary accruals in the years prior to the intervention year, ceteris paribus.

\footnotetext{
${ }^{33}$ Like in chapter three the numbering of the hypotheses in this section is similar to that of section 4.3 because we test the same hypotheses. In the summary of this chapter the test results on both sets of hypotheses (WTO and Title 8 ) will be compared.
} 
$\mathbb{H}_{2}^{2}$ : the change from a partially regulated financial accounting environment (before 1984) to a more regulated enviromment led to (1) a decrease in the variability of total and nondiscretionary accruals in the intervention year and following years compared to the years prior to the intervention year, and (2) an increase in the variability of earnings in the period after the implementation compared to the years before the implementation of Title 8 , ceteris paribus.

$\mathrm{H}^{\mathrm{a}}{ }_{2 \mathrm{~A}}$ : the change from a partially regulated financial accounting environment (before 1984) to a more regulated enviromment led to (1) an increase in the variability of discretionary accruals in the intervention year and following years compared to the years prior to the intervention year, and (2) no change in the variability of earnings in the period after the implementation compared to the years before the implementation of Title 8 , ceteris paribus.

$\mathrm{H}_{3}^{\mathrm{a}}{ }_{3}$ : the variability of accruals, both nondiscretionary and discretionary, and eamings will vary according to size, and the changes in these variability patterns before and after the implementation of Title 8 will be larger for large firms.

$\mathrm{H}^{\mathrm{a}}{ }_{4}$ : the variability of accruals, both nondiscretionary and discretionary, and eamings will vary according to leverage, and the changes in these variability patterns before and after the implementation of Title 8 will be larger for fins with higher debt/equity ratios.

$\mathrm{H}^{\mathrm{a}}{ }_{5}$ : the variability of accruals, both nondiscretionary and discretionary, and eamings will vary across industries, and the changes in these variability patterns before and after the implementation of Title 8 will also differ across industries. More specifically, changes in variability of accuals and earnings are expected to be higher for industrial fims compared to trading firms.

\subsubsection{Results: accruals method I}

This section presents descriptive statistics on the pattern of total accruals, earnings and cash flows in the second time series, from 1975 to 1990 . The analysis is based on a sample of 76 firms obtained from the CBS database. Specific details on the sample selection procedure were provided in section 4.2.3. As in section 4.3.1, unscaled accruals, earnings and cash flows will be presented first.

Table 4.15 provides information regarding hypotheses $\mathrm{H}^{\mathrm{a}} / \mathrm{H}^{\mathrm{a}}{ }_{\mathrm{A}}$, using the unscalled levels of total accruals, earnings and cash flows. Average total accruals are negative for all years, as would be expected, except for 1979. However, median accruals for 1979 
are negative, like all other years. We are mainly interested in 1984 , in which the regulations of Title 8 came into effect. The results clearly indicate that the average and median (total) accrual level for 1984 was significant higher than in the previous year. In fact, 1984 had the highest average level of total accruals. Note also that the average accrual numbers in the first year after the enactment decreased. This finding does not seem to be consistent with expectations concerning the higher level of total accruals after the new financial accounting requirements became effective. But despite this decrease, all mean and median accruals after the implementation of Title 8 were higher than before. ${ }^{34}$ To determine whether economic circumstances might have caused the observed accruals pattern, especially in 1984 and 1985, we examined the annual average changes in cash flows more closely. The average annual changes in cash flow in 1984 and 1985 were similar to the accruals changes, which indicates that economic circumstances might have led to the observed accruals pattern.

The pattern of average earnings is similar to that for accruals: there was an increase in 1984, followed by a decrease in 1985, although the magnitude of the accruals decrease in 1985 was larger. The increase in average total accruals and earnings in 1984 and the decrease in 1985 can be explained by the increase in average cash flows in 1984 and the decrease in 1985 . Therefore the data has to be interpreted with caution, because the assumption that economic circumstances remain constant cannot be maintained.

Following accruals method $I$, table 4.16 shows changes in average and median total accruals, earnings and revenues. As in the first sample, changes were computed as first differences of the variables $\left(X_{t}-X_{t-1}\right)$ scaled by total assets at time $t-1$. The table presents additional information on parametric t-statistics and the significance levels of nonparametric Wilcoxon signed rank test. As explained, a change in total accruals could be due to a change in nondiscretionary accruals. With the implementation of Title 8 , the level of total accruals is expected to have increased (see hypothesis $\mathrm{H}^{\mathrm{a}}{ }_{1}$ ), while cash flows are assumed to follow a random walk. The table illustrates the time series pattern of changes in scaled total accruals, earnings and cash flows.

The first panel shows annual changes in total accruals. These are not significantly different from zero, except for 1984 and 1985. In 1984, when Title 8 was implemented, there was a significant increase (t-statistic 3.71 and significance level Wilcoxon 0.00 ). In the following year there was a significant decrease in accruals,

\footnotetext{
${ }^{34} \mathrm{As}$ pointed out in section 4.3 .1 , these numbers are not deflated. Subsequent analyses of the annual changes use scaled accruals, earnings and cash flows.
} 


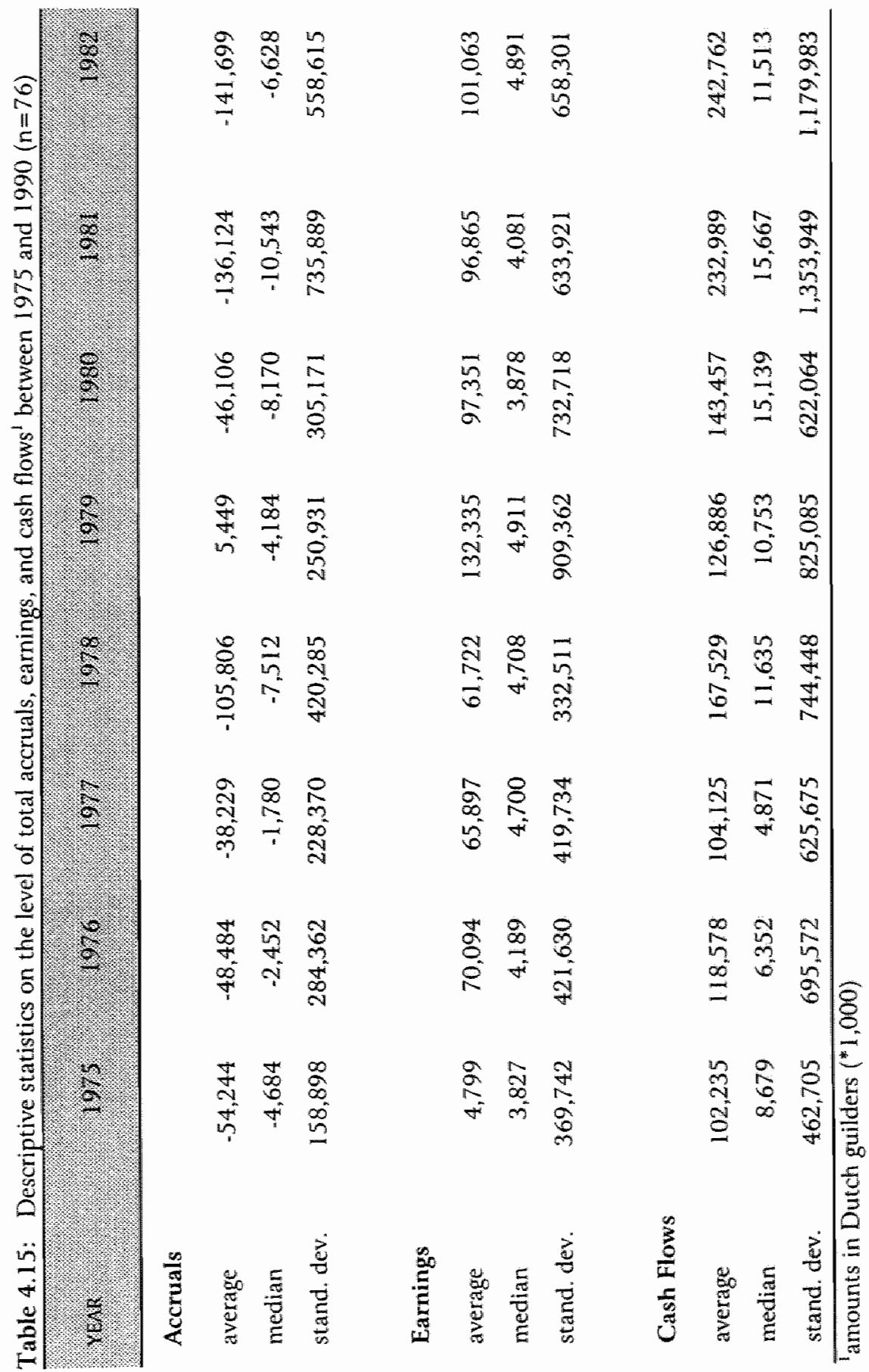




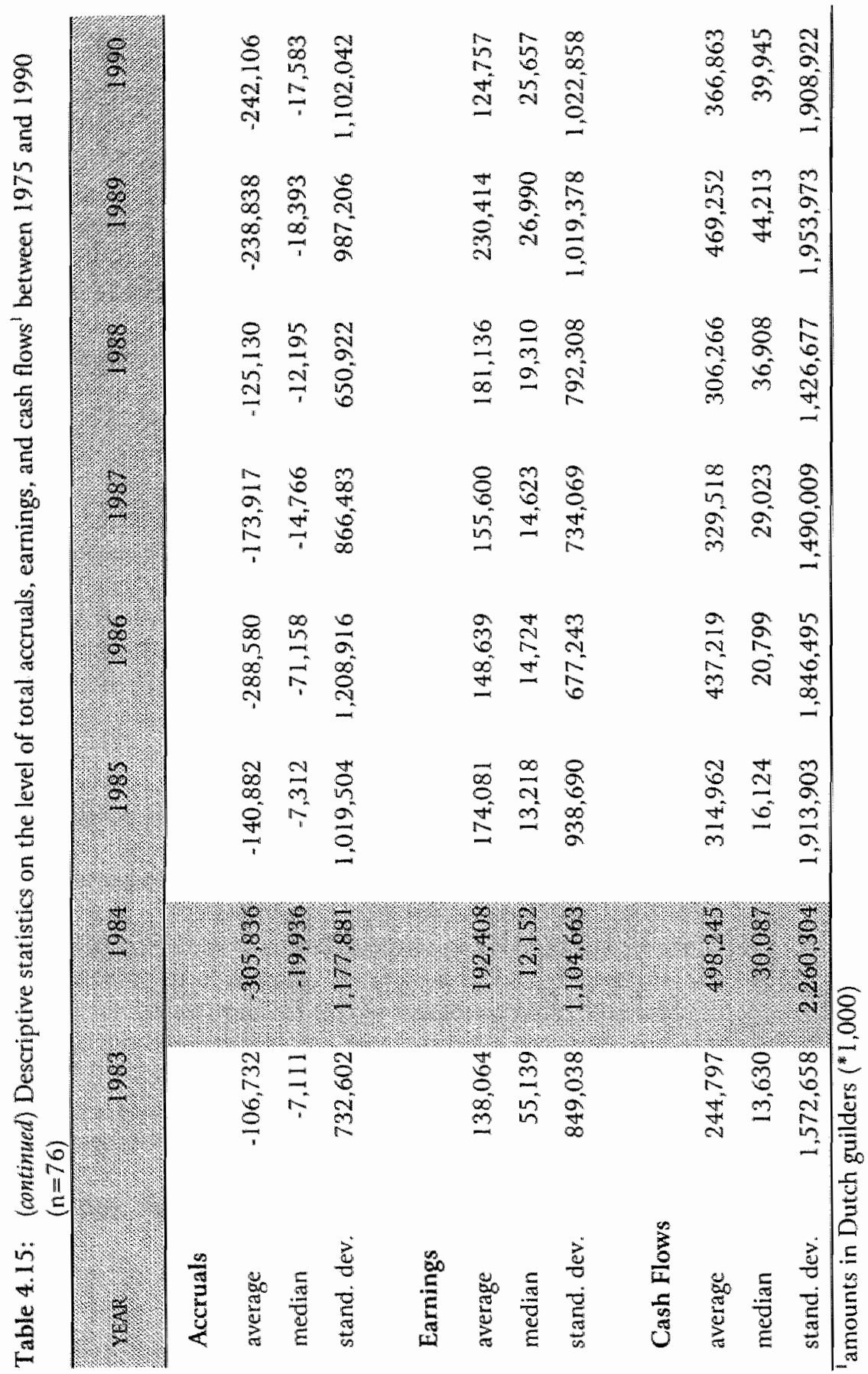


similar to the pattern described in the previous table.

One difference between the results presented here and the analysis of the effects of the WJO is that there was no indication that firms exhibited anticipatory behaviour. The data for this series seem to be consistent with the results presented in chapter three, where it was argued that firms postponed some changes in their financial accounting strategies (i.e. accounting changes) for one year so that these coincided with the implementation of Title 8 in 1984.

The second panel contains data on eamings changes (hypothesis $\mathrm{H}_{2}^{\mathrm{a}}$ ). This indicates that the magnitude of the changes was larger after 1984 than in the period before (i.e. variability increased). There were earnings changes significantly different from zero in 1983 (before Title 8), 1984, 1986 and 1988. This suggests that earnings variability did increase: the extent of the increase compared to the years prior to the implementation of Title 8 remains to be examined.

The cash flow changes reported in the third panel show a pattern similar to accruals. The sample firms' average cash flow pattern shows two years, 1984 and 1985 with a significant change. ${ }^{35}$ The first earnings change in 1984 was due to an increase in cash flows, while 1985 shows an almost identical change in the opposite direction (a decrease). This could imply that the change in total accruals was triggered by changing economic circumstances.

Based on the results presented in tables 4.14 and 4.15 we conclude that the level of total accruals increased in 1984, consistent with hypothesis $\mathrm{H}^{\star}{ }_{1}$, although 1985 reported a significant decrease. Cash llow changes might have caused this clange. The changes in annual accruals and earnings numbers reported in table 4.15 indicate that the variability of earnings increased after Title 8 was introduced, which is consistent hypothesis $\mathrm{H}_{2}^{\mathrm{a}}$. However, no indication was found that accruals variability has also increased after 1984. Additional results on the variability patterns of total accruals, earnings and cash flows before and after 1984 are reported subsequently.

\footnotetext{
${ }^{35}$ According to the t-statistics for cash flows, 1979 was a year with a significant change. However, the nonparametric Willcoxon signed rank test for this year was not significant in 1979, but this test reveals a significant change one year earlier.
} 


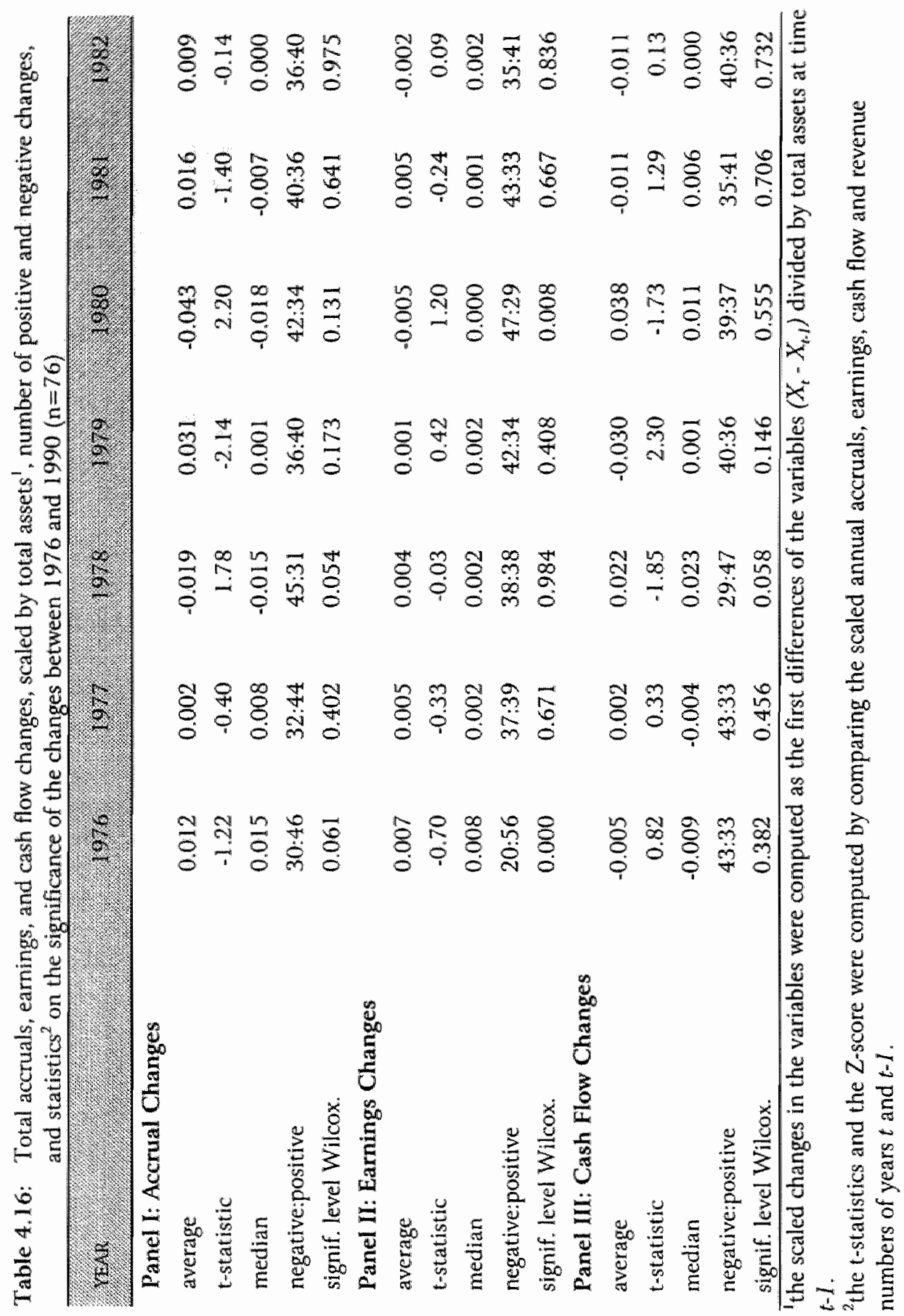




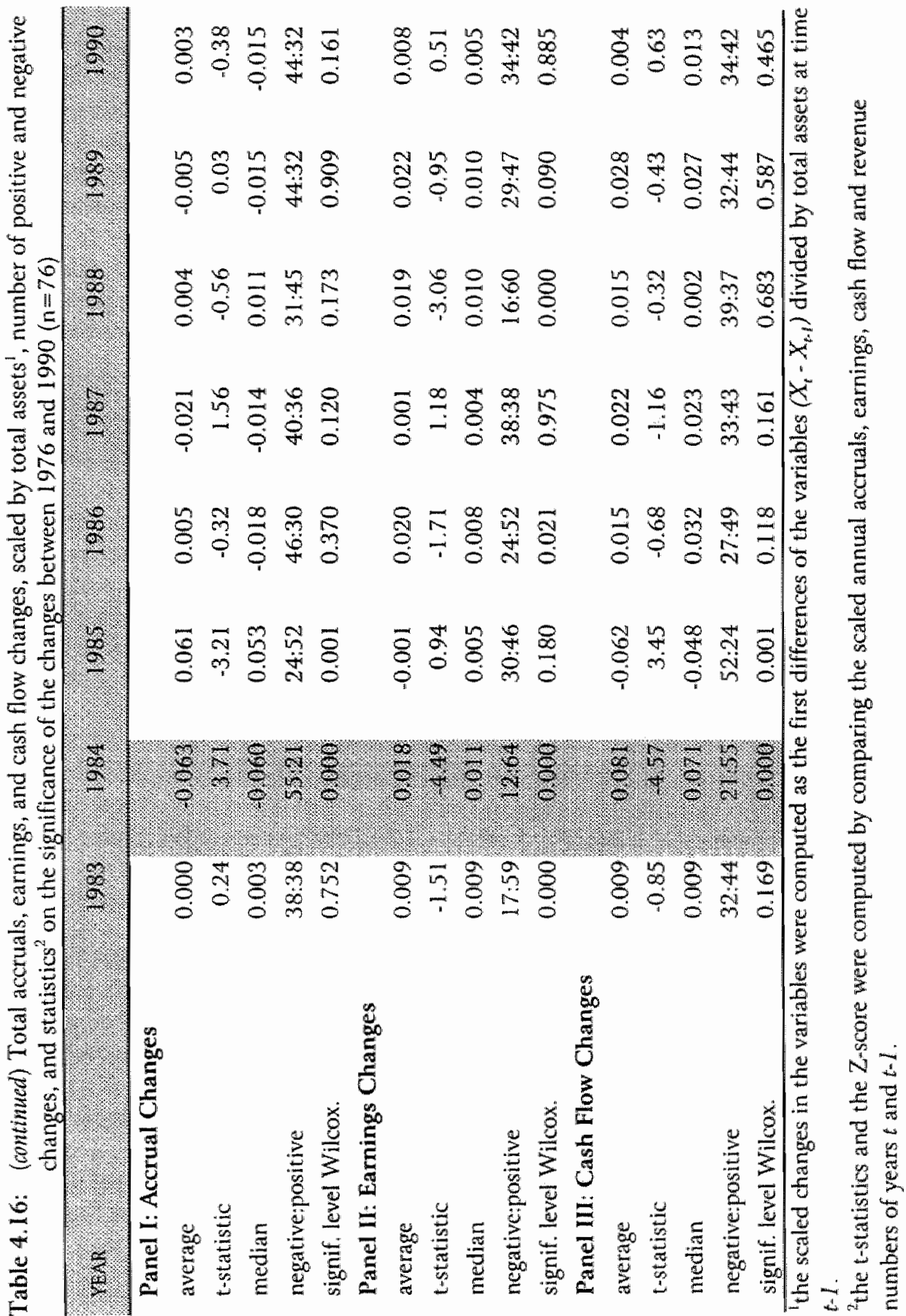




\subsubsection{Test-results on variability}

In order to examine changes in the variability of accruals and earnings (see hypothesis $\mathrm{H}_{2}^{a}$ and $\mathrm{H}_{2 \mathrm{~A}}^{\mathrm{a}}$ ), average coefficients of variability were calculated, defined as the firm's standard deviation of total accruals ${ }_{7}$ earnings and cash flows before and after 1984, divided by average total accruals, earnings, and cash flows (before and after 1984). The results are presented in table 4.17 .

Table 4.17: Variability coefficients of total accruals, earnings and cash flows before and after Title $8(n=76)$

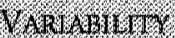 \\ t. 1.10 \\ $2+1010$}

\section{Total Accruals}

larger:smaller

$44: 32$

$-0.59$

$-1.22$

\section{Earnings}

larger:smaller

$-0.86$

$-1.55^{*}$

\section{Cash Flows}

larger:smaller

$30: 46$

$-0.57$

$-2.71^{* *}$

Larger means that the variability increased after the implementation of Title 8;

Smaller means that the variability decreased

"significant at $5 \%$ level (one-tailed)

significant at $1 \%$ level (one-tailed)

The analysis is similar to section $4.3 .2 .^{36}$ First, the table shows that accrual variability increased for 44 of the 76 sample firms after 1984, although not significantly. This is inconsistent with the results from the first time-series, and does not support hypothesis $\mathrm{H}_{2}{ }_{2}$. Instead, this might provide evidence for the alternatively stated hypothesis $\mathrm{H}_{2 A}$, which predicted an increase in the variability of discretionary accruals. This might account for the increase in total accruals variability.

Second "the variability of earnings increased after the implementation of the Act in 1984 (but this was only significant at the 5\%-level using a Wilcoxon signed rank

\footnotetext{
36 The period before covers data from 1975 to 1983 , the period after includes data from 1984 to 1990 .
} 
test). This finding is consistent with hypothesis $\mathrm{H}_{2}^{3}$. The analysis of the variability of cash flows revealed no increase in variability that could account for the increase in earnings or accruals variability. Thus, while accruals variability did increase, which suggests that firms have tried to counteract the effects of the additional financial reporting regulations, firms seem nevertheless to be affected by the financial reporting regulations embodied in Title 8.

In summary, the empirical evidence presented based on method I on the impact of Title 8 supports hypothesis $\mathrm{H}_{1}{ }_{1}$, while it is partially consistent with $\mathrm{H}_{2}$ and $\mathrm{H}_{2 \mathrm{~A}}$. First, there was a major increase in total accruals in 1984. The decrease in cash flow contributed to the decrease in accruals and earnings in the year following the implementation of Title 8 . Second, the information presented on annual earnings numbers indicated that earnings changed significantly not only in 1984, but also in subsequent years. A comparison of the variability of earnings before and after 1984 (table 4.17) confirmed this. In contrast to the results for the first time series, the variability of total accruals also increased. Although the change was not significant, it does indicate that the results for the second time series are different from the first. In this case, the analysis of total accruals does not indicate that the increase in the level of total accruals also led to a decrease in variability. The increase in the variability total accruals could point to firms' reaction to (partially) offset the effects of Title 8.

As in the case of the WJO, additional information that reveals the actual pattern of nondiscretionary and discretionary accruals is necessary to enhance the conclusiveness of the test results and to determine the effect of legislation more precisely. Therefore, a similar model representing method II will be employed to examine the data more closely.

\subsubsection{Results: accruals method II}

To provide more conclusive evidence on the impact of Title 8 on accounting accruals, we will apply the second method of analysis, as in section 4.3 .4 , to test hypothesis $\mathrm{H}^{\mathrm{a}} / \mathrm{H}^{2}{ }_{1 \mathrm{~A}}$ and $\mathrm{H}_{2}^{\mathrm{a}}{ }_{2} \mathrm{H}^{\mathrm{a}}{ }_{2 \mathrm{~A}}$ again. The actual pattern of nondiscretionary and discretionary accruals will be analysed to determine the impact of financial accounting regulations in 1984 on both nondiscretionary and discretionary accruals (second part of hypothesis $\mathrm{H}_{1}^{\mathrm{a}}{ }_{1} \mathrm{H}^{\mathrm{a}}{ }_{1 \mathrm{~A}}$ and $\left.\mathrm{H}_{2}{ }_{2} \mathrm{H}^{\mathrm{a}}{ }_{2 \mathrm{~A}}\right)$ more precisely. The regression model that estimates total accruals is basically similar to that used in section 4.3.4. To capture the effect of legislation, a dummy variable (Title 8 ) will again be introduced. The model can be defined as: 


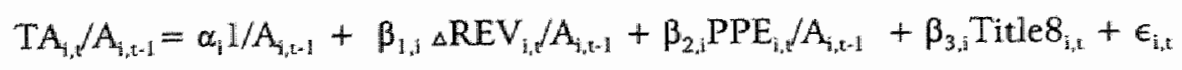

The regression procedure is analogous to the first accruals model. First, coefficients of the model are estimated using a linear regression technique, based on time series of 16 years and a sample consisting of 76 firms. This yields a total of 1216 firm year observations. To test whether Title 8 had an effect on nondiscretionary accruals, the variable Title 8 (legislation) was dummy coded 0 for years 1975-1983 and I from 1984 to 1990 . The error term, $e_{i, c}$, again reflects the discretionary component of accruals. Table 4.18 provides the results for the regression model based on the 1216 firm year observation.

Table 4.18: Results for the multiple regression equation for total accruals $(n=76)$

Independent variable expected sign coefficient t-value Signif.

\begin{tabular}{|c|c|c|c|c|}
\hline $1 / A_{, x-1}$ & +1 & -15.693 & -0.146 & 0.9602 \\
\hline$\triangle \operatorname{REV}_{\mathrm{i}, \mathrm{r}} / \mathrm{A}_{\mathrm{i}, \mathrm{t}-\mathrm{l}}$ & $+/=$ & 0.013 & 3.780 & $0.0002^{*}$ \\
\hline $\mathrm{PPE}_{\mathrm{l}, \mathrm{e}} / \mathrm{A}_{\mathrm{s}, \mathrm{l}, \mathrm{l}}$ & - & -0.111 & -12.266 & $0.0000^{*}$ \\
\hline Title $8_{1, t}$ & - & -0.013 & -2.383 & $0.0173^{* *}$ \\
\hline
\end{tabular}

$\operatorname{Adj} R^{2}=0.21281 \quad F=83.18164 \quad$ Signif $=0.000$ Durbin-Watson test $=1.89^{*}$

"significant at the $1 \%$ level

The estimated coefficient for property, plant and equipment is negative $(-0.111)$. This negative sign could be expected since these assets relate to depreciation expenses, i.e. an income-decreasing accrual. The reported sign for revenue changes is positive (0.013). In section 4.3.4 it was explained that the sign of this variable is somewhat difficult to interpret because changes in revenue can cause income increasing or decreasing effects. The coefficient for the variable Title 8 (legislation) is also negative. which means that the legislation caused (nondiscretionary) accruals to increase. These accruals have an income-decreasing effect. The $R^{2}$ for the regression equation is 0.213 (compared to 0.311 based on the model estimated in the previous section).

Based on these results, we can conclude that the overall explanatory power of the regression equation is less than the model presented in section 4.3.4. The overall 
significance level is nonetheless comparable to the Jones results. For the purpose of this study, however, it is important to note that the dummy variable Title 8 was significant, indicating that the change in legislation did indeed have an impact on nondiscretionary accruals.

To determine the effect on discretionary accruals, this regression equation will now be used to calculate annual discretionary and nondiscretionary accruals for each sample firm, in a procedure similar to that described in section 4.3.4. Table 4.19 shows the descriptive statistics (mean, median and standard deviation) of nondiscretionary and discretionary accruals from 1975 to 1990.

First, attention is focused on nondiscretionary and discretionary accrual levels before and after 1984. The table shows an increase in nondiscretionary accruals one year after the implementation of Title 8. All years from 1985 on show higher nondiscretionary levels than the years prior to 1985. In contrast to the implementation of the WJO, the effect on nondiscretionary accruals appears one year later. Based on the information provided in tables 4.15 and 4.16 , no indication was found that the expected increase in nondiscretionary accruals was delayed by one year because of lower cash flows in 1984. In fact, cash flows decreased in 1985 but that did not prevent an increase in nondiscretionary accruals.

Panel II of the table reveals additional information on the pattern of discretionary accruals. It is interesting that the numbers reported here show a large negative change (increase) in discretionary accruals in 1984. Since mean and median numbers were negative in this year, this implies that these discretionary accruals are incomedecreasing.

Recall that table 4.16 revealed a significant increase in cash flows in 1984, which did not lead to a (significant) increase in earnings in $1984 .^{37}$

The pattems of annual average discretionary and nondiscretionary accruals are shown in figure 4.3 , which clearly indicates that nondiscretionary accruals increased after 1984. It also illustrates the large negative discretionary accruals in 1984.

\footnotetext{
${ }^{37}$ Therefore, the pattern of discretionary accruals in 1984 appears to provide evidence of income smoothing behaviour, because firms seem to have successfully shifted part of their income into the next period (i.e. year). It appears that they used the change in the Dutch regullatory regime to accomplish this.
} 


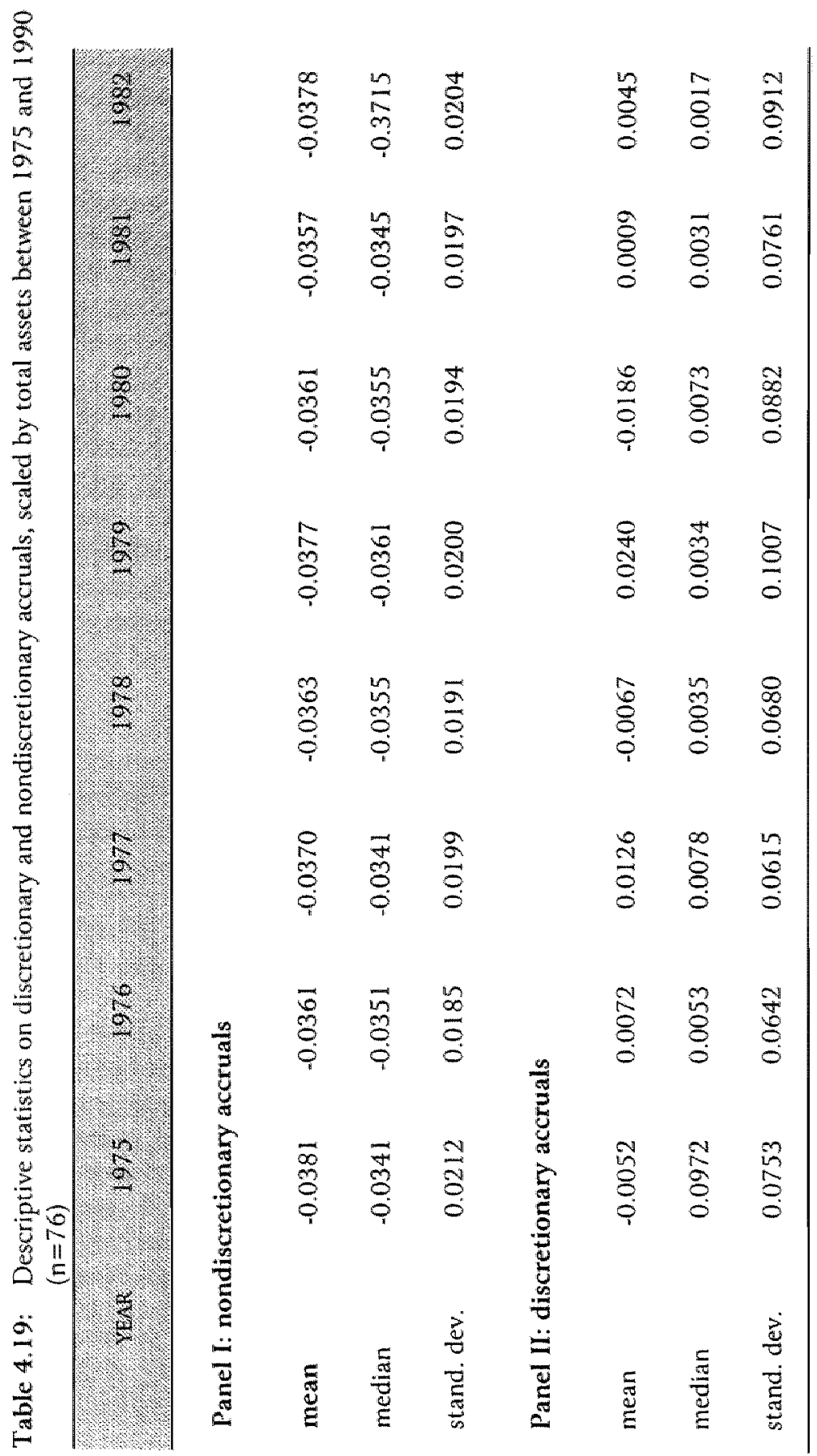




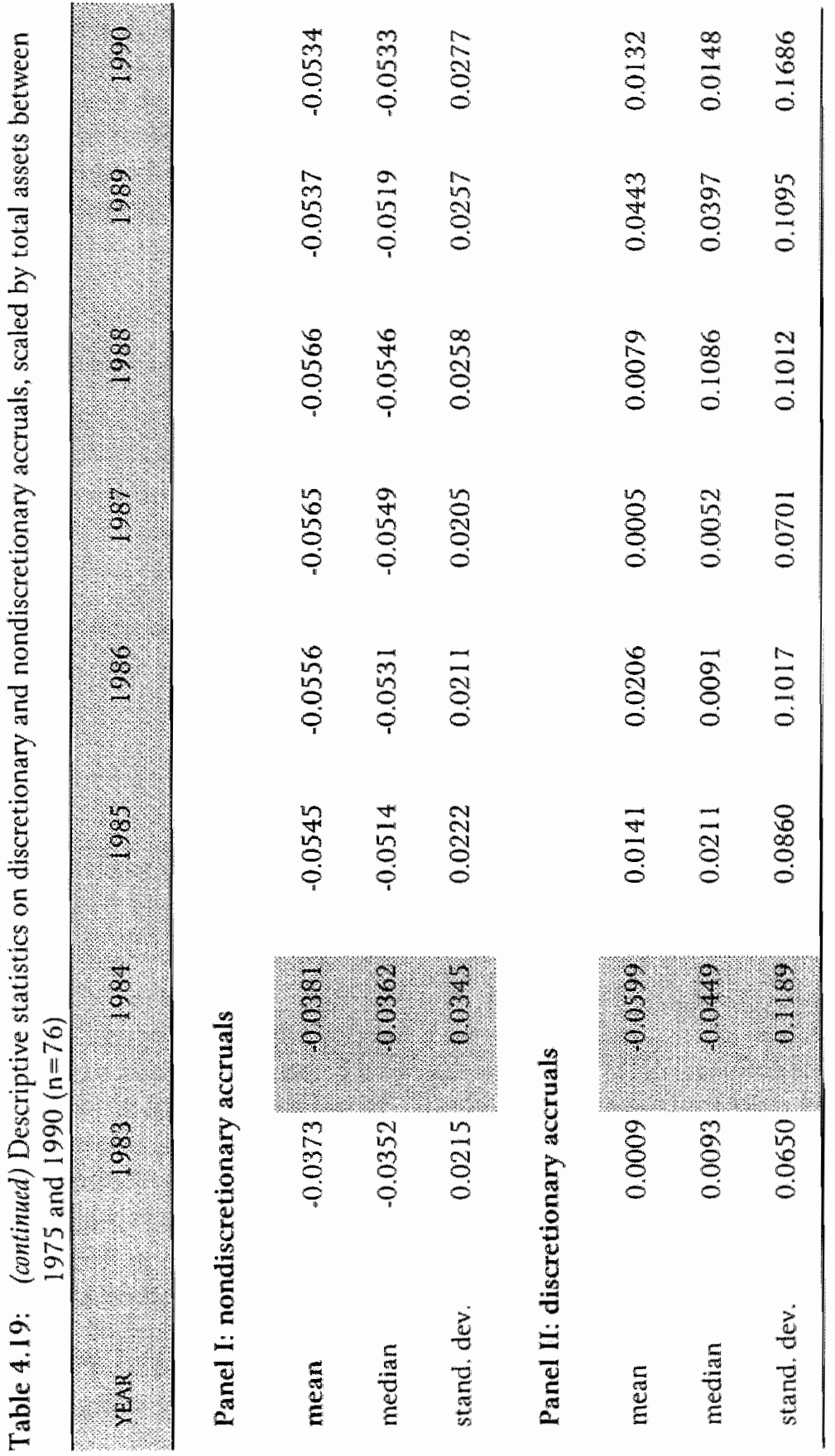


Figure 4.3: Scaled annual average nondiscretionary and discretionary accruals between 1975 and $1990(n=76)$

\section{- - Scaled Average Nondiscretionary Accruals \\ - - - Scaled Average Discretionary Accruals}

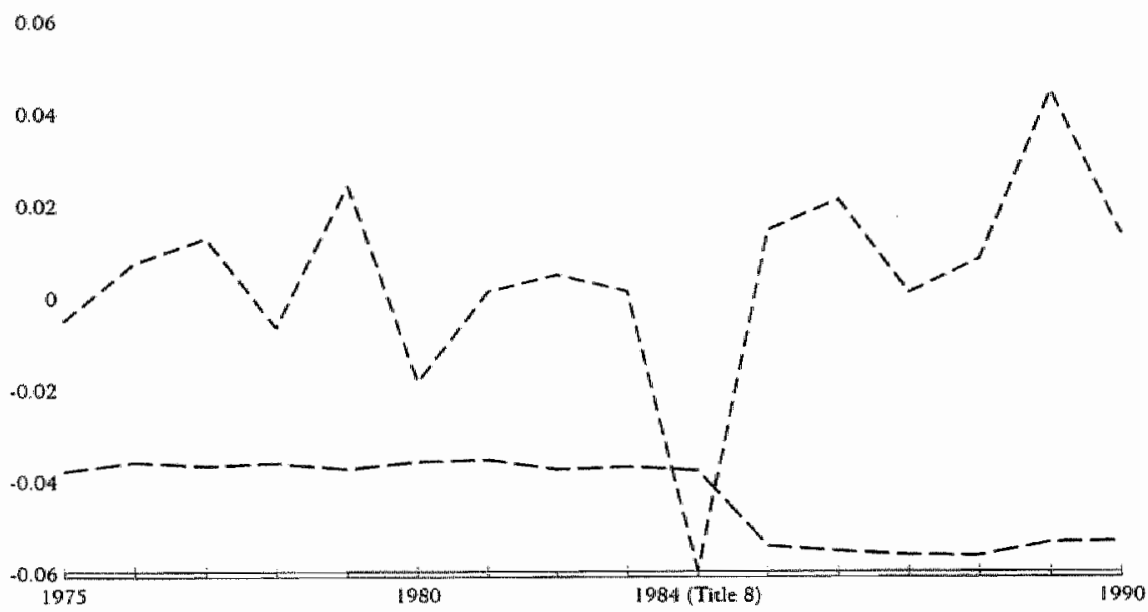

\section{4 .4 .1}

Test-results on variability

Table 4.20 shows additional results on the variability patterns of nondiscretionary and discretionary accruals before and after the implementation of Title 8. A majority of the sample firms show a decrease in nondiscretionary accruals variability (40 out of 76). Although this finding is consistent with the second part of hypothesis $\mathrm{H}^{a}{ }_{1}$, where it was argued that the implementation of Title 8 would lead to a decrease in variability, the test results are only significant at the $5 \%$-level using a parametric t- 
test. Also, it should be noted that the decrease in nondiscretionary accruals might be attributed to the decrease in cash flow variability reported previously in table 4.17.

The result on the variability coefficients of discretionary accruals reported in the second panel of table 4.20 shows that variability increased for 40 out of 76 firms. According to hypothesis $\mathrm{H}_{2 \mathrm{~A}}^{\mathrm{a}}$ this variability increase was expected, but the change in the coefficient of variability is not significant.

Table 4.20 Variability coefficients of nondiscretionary accrualls, discretionary accruals, and earnings before and after the implementation of Title $8(n=76)$

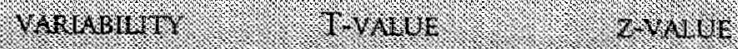

Nondiscretionary accruals

larger:smaller

$36: 40$

$-1.61^{\circ}$

$-0.84$

\section{Discretionary Accruals}

larger:smaller

$40: 36$

$-1.02$

$-0.83$

\section{Earnings}

larger:smaller

43:33

$-0.86$

$-1.55^{*}$

Larger means that the variability increased after the implementation of Title 8 ;

Smaller means that the variability decreased

significant at 5\% level (one-tailed)

In summary, the results for the second time series indicate that the variability of nondiscretionary accruals decreased and the variability of discretionary accruals has increased after the implementation of Title 8 . This is consistent with expectations, but the test results are not very strong. It does however provide more conclusive evidence than in the case of method I, based on changes in total accruals, where the variability had increased. This was contrary to expectations.

The remainder of this chapter focuses on variability patterns of (nondiscretionary and discretionary) accruals for the firm characteristics size, leverage and industry. The results based on both methods (I and II) are reported separately. 


\subsubsection{Size}

First, the data were dissagregated by size. Hypothesis $\mathrm{H}_{3}^{\mathrm{a}}$ predicted that the effect of Title 8 would be greater for large firms. Again, three size subgroups were defined, where size was measured by total assets. Small firms (from the first quartile) were designated as those with total assets less than fl $81,000,000(n=19)$. Firms in the fourth quartile were defined as large: their total assets exceeded fl 1,400,000,000 $(n=20)$. The remaining firms $(n=37)$ were defined as medium-sized.

\subsubsection{Accruals method I}

Table 4.21 shows the distribution of accruals, earnings, and cash flow changes by firm size. The variability of accruals for small firms remained almost unchanged. Mediumsized firms show a significant change in accrual variability after the implementation of Title 8. A look at the variability of cash flows shows that this change cannot be explained by the reported change (decrease) for these firms. Large firms' accruals variability did not change significantly.

Tablle 4.21: Variability coefficients of accruals, earnings, and cash flows before and after the implementation of Title 8 , for size categories $(n=76)$

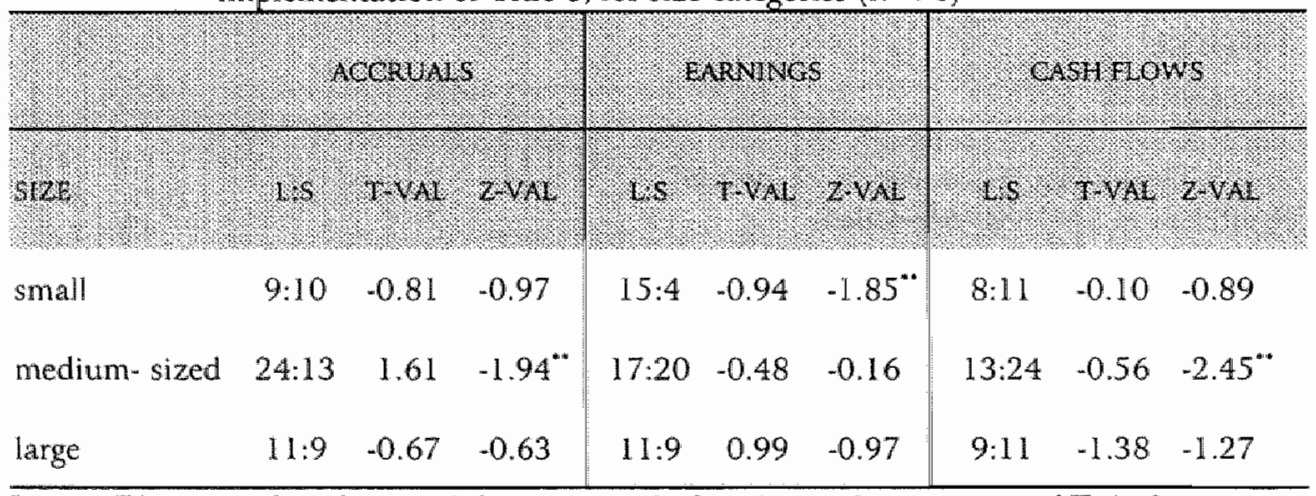

Larger (L) means that the variability increased after the implementation of Title 8;

Smaller (S) means that the variability decreased

"significant at $1 \%$ level (one-tailed)

The table also shows that earnings variability increased significantly for small firms. This result suggests that small firms were more affected by the regulations of Title 8 than large firms. This would support hypothesis $\mathrm{H}_{3}^{\mathrm{a}}$ and it is also consistent with the 
results previously presented in chapter three. The information on cash flow variability shows that the increase in earnings variability was not caused by changes in economic circumstances.

'Thus, we find that small firms' earnings variability did increase significantly, although no evidence was found that these firms were subject to a significant decrease in accrual variability. Accruals variability differences did exist between the subgroups, medium size sample firms reported a significantly increase after 1984, the other two reported no differences. The analysis of nondiscretionary and discretionary accruals might provide additional information on the impact of Title 8 in relation to firm size.

\subsubsection{Accruals method II}

In the next table the results of accruals method II are presented. Panel I of table 4.22 indicates that nondiscretionary accruals variability decreased significantly for the medium-size category ( $1 \%$ significance level nonparametric Wilcoxon signed rank test), but there was no significant change for either small or large firms.

Table 4.22: Variability coefficients of nondiscretionary and discretionary accruals before and after the implementation of Title 8 , for small, medium-sized, and large firms $(n=76)$.

\begin{tabular}{|c|c|c|c|c|}
\hline & & 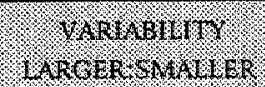 & 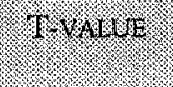 & 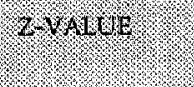 \\
\hline
\end{tabular}

Panel I: nondiscretionary accruals

small $10: 9$ $-1.18$

0.00

medium-sized

$15: 22$

$-1.31$

$-1.82^{* *}$

large

$11: 9$

0.75

$-0.71$

Panel II: discretionary accruals

small

$-0.01$

$-0.44$

medium-sized

$17: 20$

$-1.14$

$-0.46$

large

$12: 8$

1.09

$-1.61^{\circ}$

Larger means that the variability increased after the implementation of Title 8; Smaller means that the variability decreased

"significant at 5\% level (one-tailed)

-"significant at $1 \%$ level (one-tailed) 
This finding does not support the argument that the impact of Title 8 on changes in variability patterns of nondiscretionary accruals before and after 1984 would be significantly different in relation to the size of the sample firms.

Panel II of table 4.22 reports on changes in discretionary accruals variability before and after the implementation of Title 8 . Here, size categories small and large show an increase, but this increase is significant only for large firms (5\%-level of significance, nonparametric Wilcoxon signed rank test). Based on the pattern of discretionary accruals it appears that large firms have used their discretion to undo the impact of Title 8 . This result is consistent with the size hypothesis $\left(\mathrm{H}_{3}{ }_{3}\right)$. It might also explain why the increase in earnings variability after the implementation of Title 8 for small firms, as reported previously in table 4.21 , was significantly larger than the increase in earnings variability reported for large firms.

\subsubsection{Leverage}

To test hypothesis $\mathrm{H}_{4}^{\mathrm{a}}$, firms were grouped according to their debt/equity ratios. Again, three different groups were identified: low leverage $(\mathrm{d} / \mathrm{e}<0.7)$, high leverage (d/e $>2.4$ ) and an intermediate group. The results on variability patterns are presented in tables 4.23 and 4.24 .

\subsubsection{Accruals method I}

The results of the analysis based on accruals method $I$ are presented in table 4.23 . Low leverage firms show a decrease in accruals variability, while the intermediate and large groups' variability increased after 1984. Earnings variability also increased for these firms, although the difference was not significant. Cash flow variability changes do not explain these resuits. The changes in earnings variability would support the assumption that the effect of the implementation of Title 8 would be larger for firms with higher debt/equity ratios, but the results are not significant. 
Table 4.23: Variability coefficients of accruals, eamings, and cash flows before and after the implementation of Title 8 , for debt/equity categories $(n=76)$

\begin{tabular}{|c|c|c|c|c|c|c|c|c|c|}
\hline & & Crove & & & Nive & & (2) & in & 15 \\
\hline Horatise & 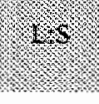 & the & $\mathrm{z} / \mathrm{r}$ & 1 & 17 & $(7 / 1)$ & 18 & ( & $2 / 4$ \\
\hline low d/e & $9: 11$ & -1.69 & -0.71 & $11: 9$ & -0.88 & -0.41 & $8: 12$ & -1.23 & $-1.56^{\circ}$ \\
\hline intermed d/e & $20: 11$ & $1.77^{\circ}$ & $-1.80^{* *}$ & $17: 14$ & $=0.95$ & -0.84 & $11: 20$ & -0.40 & $-1.84^{* *}$ \\
\hline high d/e & $15: 10$ & 0.33 & -0.82 & $15: 10$ & 1.19 & -1.31 & $11: 14$ & -0.02 & $-1.3 d$ \\
\hline
\end{tabular}

Larger (L) means that variability increased after the implementation of Title 8 ;

Smaller (S) means that variability decreased

significant at $5 \%$ level (one-tailed)

" significant at $1 \%$ level (one-tailed)

\subsubsection{Accruals method II}

Based on the regression model used for accruals method II total accruals were also separated into discretionary and nondiscretionary components. Table 4.24 shows that there are differences between leverage categories. Panel I reports that the variability of nondiscretionary accruals for intermediate and highly leveraged firms decreased, whereas low leverage firms showed an increase. This is consistent with the (expected sign of the) debt/equity hypothesis $\left(\mathrm{H}_{4}^{\mathrm{a}}\right)$, but none of the reported changes are significant.

Panel II of table 4.24 reports on changes in the variability patterns of discretionary accruals before and after the implementation of Title 8 . This time discretionary accruals increased for the categories low and high leverage, although none of these changes were significant. Furthermore, the variability patterns of discretionary accruals reported appear not to be different between the leverage subgroups. Therefore, the results presented in the second panel of table 4.24 on discretionary accruals do not indicate that intermediate and high leverage firms, that seem to have been more affected by Title 8 , have used discretionary accruals to (at least partially) undo the regulatory impact. 
Table 4.24: Variability coefficients of nondiscretionary and discretionary accruals before and after the implementation of Title 8, for low, medium, and high leverage categories $(n=76)$

\begin{tabular}{|c|c|c|c|}
\hline & 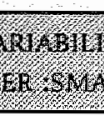 & 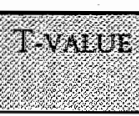 & 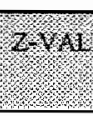 \\
\hline \multicolumn{4}{|c|}{ Panel I: nondiscretionary accrualls } \\
\hline low leverage & $15: 5$ & 0.58 & -1.27 \\
\hline intermediate & $12: 19$ & $-1.49^{*}$ & -1.04 \\
\hline high leverage & $9: 16$ & -1.24 & -1.17 \\
\hline \multicolumn{4}{|c|}{ Panel II: discretionary accruals } \\
\hline low leverage & $12: 8$ & 1.01 & -1.23 \\
\hline intermediate & $15: 16$ & -0.99 & -0.51 \\
\hline high leverage & $13: 12$ & 0.65 & -0.79 \\
\hline
\end{tabular}

Larger means that the variability increased after the implementation of Title 8;

Smaller means that the variability decreased

significant at 5\% level (one-tailed)

\subsubsection{Industry}

Hypothesis $\mathrm{H}_{5}{ }_{5}$ stated that time series of accrual numbers would reveal industry effects, since nondiscretionary and discretionary accruals are partially determined by industry characteristics. To examine this, the sample firms were classified into ten different industry groups, as in section 4.3.7.

\subsubsection{Accruals method I}

Table 4.25 presents industry-specific coefficients of variability for accruals, earnings and cash flows before and after the implementation of Title 8. Six industries (including Steel) showed increases in accrual variability, of which two were significant (Machinery and Construction). The remaining four industries, including Wholesale and Retail firms, showed decreases in variability. The differences across industries are similar to the first sample, although for the first sample there was an overall significant decrease in accrual variability.

Eight of the ten categories showed increases in eamings variability. This increase was significant for one industry: Machinery. Almost all industries show a decrease in 


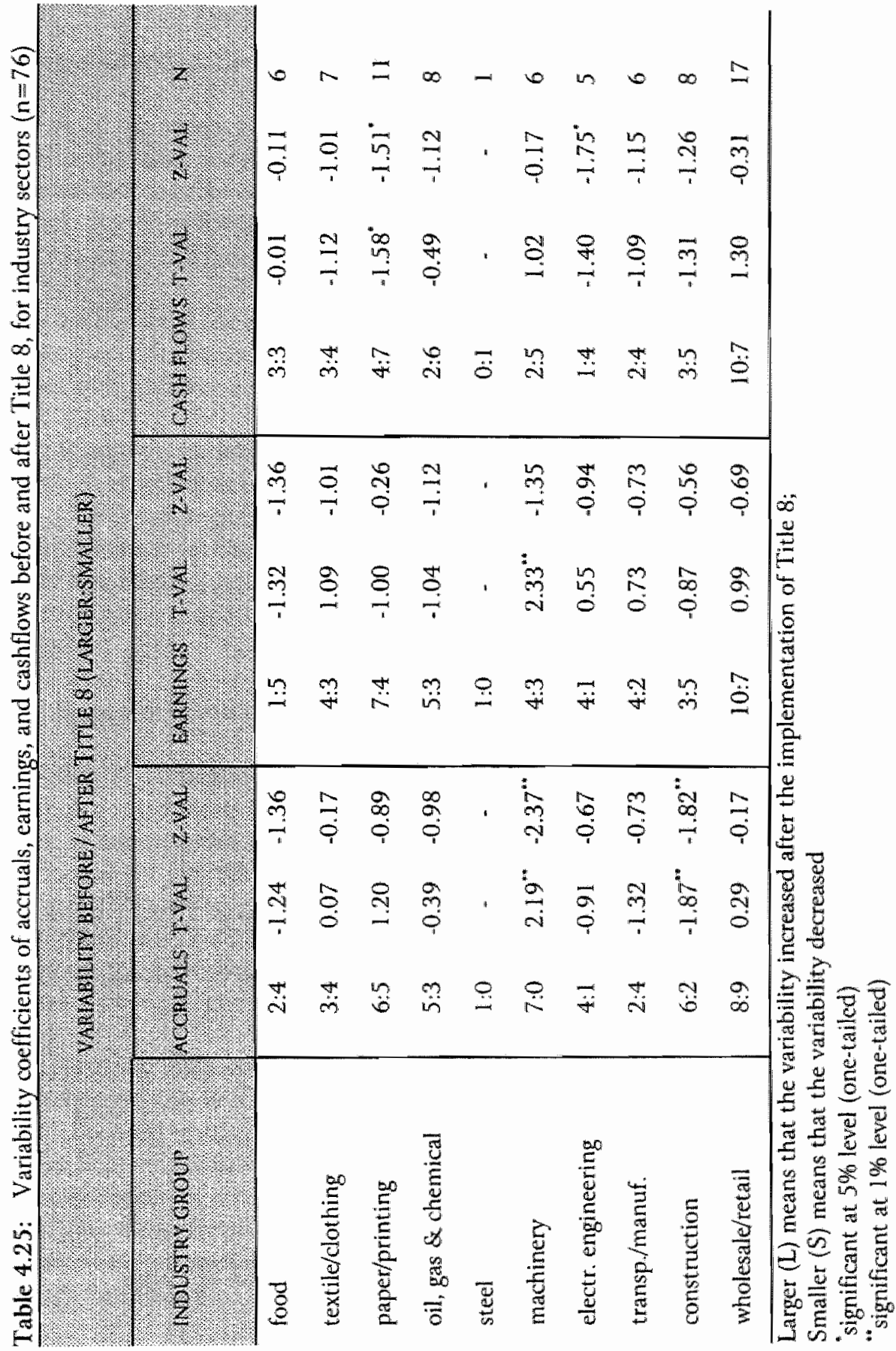


cash flow variability after 1984 , with the exceptions of the Food and Wholesale and Retail industries.

Table 4.26: Variability coefficients of nondiscretionary and discretionary accuals before and after the implementation of Title 8 , for industry sectors $(n=76)$

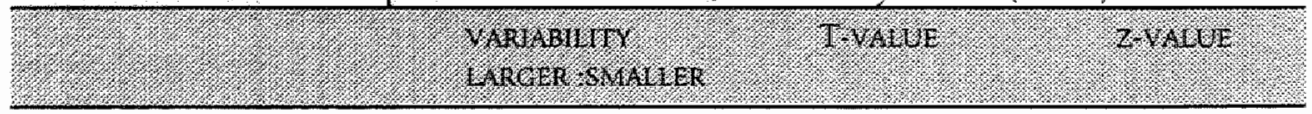

panel I: nondiscretionary accruals

\begin{tabular}{|c|c|c|c|}
\hline food & $2: 4$ & -11.52 & -1.15 \\
\hline textile/clothing & $4: 3$ & -0.48 & -0.17 \\
\hline paper/printing & $6: 5$ & -0.74 & -0.18 \\
\hline oil,gas \& chemicals & $6: 2$ & 0.70 & -1.12 \\
\hline steel & - & - & - \\
\hline machinery & $3: 4$ & 0.44 & -0.17 \\
\hline electr. engineering & $2: 3$ & -0.52 & -0.41 \\
\hline transport/manufact. & $4: 2$ & 0.64 & -0.32 \\
\hline construction & $3: 5$ & -0.89 & -0.28 \\
\hline wholesiale/retail & $5: 12$ & -1.32 & $-2.06^{*}$ \\
\hline \multicolumn{4}{|c|}{ Panel II: discretionary accruals } \\
\hline food & $5: 1$ & 1.01 & -1.36 \\
\hline textile/clothing & $5: 2$ & 0.19 & -0.85 \\
\hline paper/printing & $5: 6$ & -0.59 & -0.36 \\
\hline oil, gas \& chemicals & $7: 1$ & -0.23 & -1.40 \\
\hline steel & - & - & - \\
\hline machinery & $4: 3$ & 0.57 & -0.51 \\
\hline electr. engineering & $3: 2$ & 0.84 & -0.67 \\
\hline transport/manufact. & $3: 3$ & -0.04 & .0 .32 \\
\hline construction & $5: 3$ & -0.84 & -0.42 \\
\hline wholesale/retail & $9: 8$ & 0.53 & -0.45 \\
\hline
\end{tabular}

Larger means that the variability increased after the implementation of Title 8 ;

Smaller means that the variability decreased

significant at $5 \%$ level (one-tailed)

"significant at $1 \%$ level (one-tailed) 


\subsubsection{Accruals method II}

Table 4.26 provides additional information on the changes in the variability of discretionary and nondiscretionary accruals for each industry group. Five industry groups showed a decrease in nondiscretionary accruals variability (consistent with $\mathrm{H}_{5}^{a}$ ), but the only significant decrease was for the trading firms, which were expected to be less affected by Title 8 than industrial firms. Therefore, the results on this hypothesis are counterintuitive; there does appear to be a difference but the direction of the difference is the opposite of what was expected. The pattern presented in this table is also different from table 4.14 (for the first time series), where most industries showed seen to have a decrease in variability (of nondiscretionary accruals).

Panel II shows variability increases for all industries except for Transport and Manufacturing. Although the sign of the changes is consistent with expectations, none of these changes are significant. The result for Wholesale and Retail firms is quite different from those presented in the first time series. Again, no indication was found that trading firms in the second time series were less affected by the new regulation than industrial firms.

\subsection{Summary and conclusions}

This chapter continued the investigation into the effects of two major financial accounting regulations on managements' choices. Two cases have been examined: (1) the implementation of the Act on Annual Financial Statements in 1971 and (2) the adoption of the Fourth European Economic Community Directive in 1984 (Title 8 in the Netherlands). These mandatory changes in the market for accounting information have been used to extend the understanding of earnings management behaviour. We specifically focused on managements' flexibility in choosing accounting methods (i.e. on accounting accruals).

Fundamentally, we have examined whether financial accounting regulation, first with the enactment the WJO and then with the implementation of Title 8 , affected firms' financial reporting strategies. According to hypotheses $\mathrm{H}_{1}{ }_{1}$ and $\mathrm{H}_{2}{ }_{2}$, firms discretion over accounting accruals was expected to have been restricted through the implementation of additional financial accounting regulation, assuming that the regulations were effective. This would imply an increase in nondiscretionary accruals, a decrease in the variability of total accruals and, as a result of this an increase in earnings variability.

Alternative hypotheses $\mathrm{H}^{\mathrm{a}}{ }_{1 \mathrm{~A}}$ and $\mathrm{H}_{2 \mathrm{~A}}{ }$ were based on the assumption that (according 
to the efficient contracting perspective) firms would use discretionary accruals to undo the effects of regulation. Hence, although the level of nondiscretionary accruals was expected to have increased, discretionary accruals would be used to offset the impact of government regulation. As a consequence, the variability of discretionary accruals would have increased after the implementation of both Acts, and earnings variability would not have changed significantly.

Table 4.27 presents a summary of the results on the hypotheses that were tested to examine the impact of the WJO and Title 8 on accounting accruals. Similar to chapter three, these hypotheses were developed to distinguish between the opportunistic behaviour and the efficient contracting perspective.

Hypothesis $\mathrm{H}^{\mathrm{a}}{ }_{1}$ stated that the level of total accruals and nondiscretionary accruals would increase as a consequence of the increased number of financial reporting requirements. One year prior to the introduction of the WJO (1970) and in the case of Title 8 during the year of introduction (1984), the levels of total accruals increased significantly. The level of total accruals after 1970 remained at a higher level. However, there was a decrease in accrual levels in the years following the introduction of Title 8. Apparently, economic circumstances gave rise to the observed accruals pattem. Cash flow changes were negative and significant. Therefore, it was necessary to control for these effects.

Then the variability of discretionary accruals and eamings was tested (hypotheses $\mathrm{H}_{2}{ }_{2}$ and $\mathrm{H}_{2 \mathrm{~A}}^{\mathrm{a}}$ ). According to accruals method I we found that accruals variability decreased in the case of the WJO, consistent with hypothesis $\mathrm{H}_{2}{ }_{2}$. Recall that it was assumed that the level of nondiscretionary accruals increased and, since this increases the portion of total accruals not susceptible to management's discretion, the variability of total accruals would also decrease, ceteris paribus. The results on the second time series indicate that the variability of accruals increased, contrary to expectations, although the increase was not significant.

The tests on earnings variability (hypotheses $\mathrm{H}_{2}^{2}$ and $\mathrm{H}_{2 \mathrm{~A}}^{2}$ ) yielded results consistent with hypothesis $\mathrm{H}_{2}^{\mathrm{a}}$ in both cases. Earnings variability increased after the introduction of the WJO and Title 8 , although the increase after the introduction of Title 8 was less significant. The fact that cash flow changes are not attributable to these findings provided reason to believe that income smoothing has become more difficult.

Another conclusion that can be drawn from the results presented in this chapter is that (1) firms acted in anticipation of the requirements of the WJO and (2) postponed changes in their financial reporting strategy until the year in which Title 
Table 4.27: Summary of the test results of hypothesis $\mathrm{H}^{\mathrm{a}}{ }_{1}$ to $\mathrm{H}_{5}^{2}$ on the impact of the WJO and Title 8

\begin{tabular}{|c|c|}
\hline 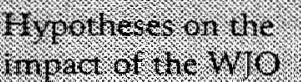 & 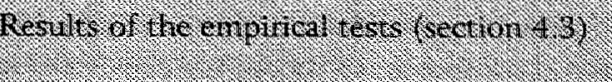 \\
\hline
\end{tabular}

Hypotheses $\mathrm{H}^{\mathrm{a}}{ }_{1}$ and $\mathrm{H}^{\mathrm{a}}{ }_{\mathrm{A}}$

method I: significant increase in level of total accruals method II: significant increase in level of nondiscr. accruals

Hypotheses $\mathrm{H}_{2}{ }_{2}$ and $\mathrm{H}^{\mathrm{a}}{ }_{2 \mathrm{~A}}$

significant increase in earnings variability method $I$ : significant decrease in total accruals variability method II: significant decrease in nondiscr. accruals and significant increase in discr. accruals variability

Hypothesis $\mathrm{H}_{3}{ }_{3}$ method $I$ : not significant method II: not significant

Hypothesis $\mathrm{H}^{\mathrm{a}}{ }_{4}$ method $I$ : significant method $I I$ : not significant

Hypothesis $\mathrm{H}_{5}$ method $I$ : significant method $I I$ : significant, second part not significant

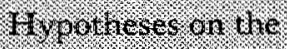

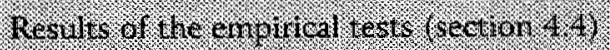
112.

Hypotheses $\mathrm{H}_{1}^{\mathrm{a}}$ and $\mathrm{H}^{\mathrm{a}}{ }_{1, \mathrm{~A}}$ method I: significant increase in total accruals only in 1984 method II: significant increase in level of nondiscr. accruals

Hypotheses $\mathrm{H}_{2}^{\mathrm{w}}$ and $\mathrm{H}^{\mathrm{a}}{ }_{2 \mathrm{~A}}$ significant increase in earnings variability method $I$ : no significant increase in total accruals variability method II: significant decrease in nondiscr. accruals and no significant increase in discr. accruals variability

Hypothesis $\mathrm{H}_{3}{ }_{3}$ method I: significant method $I$ : significant

Hypothesis $\mathbb{H}^{*}$ method I: not significant method II: not significant

Hypothesis $\mathrm{H}^{\mathrm{a}}{ }_{\mathrm{g}}$ method I: significant, second part not significant method II: significant, second part not significant 
8 was implemented. This is consistent with the findings presented in chapter three.

Additional analysis based on method II, which represented a more refined measurement technique of both nondiscretionary and discretionary accounting accruals, would be necessary to explain the increase that occurred in the case of Title 8.

The use of accruals method II enabled a direct test of the impact of accounting regulation on nondiscretionary accruals and it also controls for changes in economic conditions. The regression model underlying method II was used to test the hypothesized impact of regulation on the level and variability of nondiscretionary and discretionary accruals.

According to hypothesis $\mathrm{H}^{2}$, nondiscretionary accruals would increase due to legislation. Using the regression model with a dummy variable 'legislation' it was possible to determine the effect of legislation on discretionary and nondiscretionary accruals. The variables representing the effect of legislation were found to be significant in both time series. The results also indicate that nondiscretionary accruals increased in the years in which the new financial reporting requirements came into effect and the level of nondiscretionary accruals was higher in years after the implementation.

Furthermore, the variability pattern of average annual nondiscretionary and discretionary accruals showed that nondiscretionary accruals variability decreased in the case of the WJO and Title 8 (as expected). In the case of Title 8 we concluded that this was inconsistent with the results presented on variability changes for total accruals, based on accruals method $\boldsymbol{I}$.

Another important finding was that the variability of discretionary accruals increased with the introduction of the WJO and Title 8 (although the latter was not significant). This was consistent with hypothesis $\mathrm{H}_{2 \mathrm{~A}}^{\mathrm{a}}$, which was based on the efficient contracting perspective.

So, the decrease in the variability of nondiscretionary accruals provided evidence that the financial reporting requirements of the WJO and Title 8 did have an effect in addition to the previously reported increase in the level of total accruals. Only in the case of the WTO we also saw a decrease in total accruals variability. The increased variability of discretionary accruals shows that firms have tried to offset these effects. The results for earnings variability indicated that they have not fully succeeded. This conclusion holds for both time series. These empirical findings suggest that the introduction of additional financial reporting regulations did indeed have an impact 
on firms' financial reporting contracts and that firms have responded to this in a way which is consistent with the efficient contracting perspective. Based on the fact that the overall test results of the WJO are more significant compared to those of Title 8 , we conclude that the impact of the WJO has been larger.

Additional tests, similar to those conducted for accounting method changes in chapter three, were run to test for effects of the firm characteristics of size, leverage, and industry in order to provide additional evidence on the opportunistic behaviour versus efficient contracting perspective. These tests, based on method I and II, focused on changes in variability patterns.

Beginning with the WJO, tests based on the size hypothesis did reveal differences in variability changes. Medium-sized firms reported the only significant decrease in the variability of total accruals, and a significant increase in earnings variability. The analysis based on accruals method II indicated that nondiscretionary accruals seem to have been more affected (i.e. variability was reduced) in the case of medium-sized and large firms, but not significantly. Discretionary accruals variability increased for all three groups, although only medium-sized firms reported a significant change.

Comparisons of the variability of earnings and accruals for firms with different leverage ratios, the second firm characteristic, indicated that the WIO had the greatest effect on intermediate and highly leveraged firms: the decrease in the variability of nondiscretionary accruals and the increase in the variability of earnings were both significant. This was consistent with hypothesis $\mathrm{H}_{4}^{a}$.

Finally, industry groups were examined for differences between industries. Accrual variability decreased for 6 out of the 10 industries. The only significant increase in total accruals variability was for Wholesale and Retail firms and the Paper and Printing industry. The results of the analysis on the WJO data also showed that for most industry groups earnings variability increased. Additional analysis of nondiscretionary and discretionary accruals showed that the variability of nondiscretionary accruals decreased for half of all industry groups. The variability changes of discretionary accruals also varied across industry groups. Wholesale and Retail firms reported a significant decrease in variability. This results suggested that these firms were not actively involved in undoing the potential impact of the WoO. The reason for this might be that firms were less affected by the regulations of the WJO than the firms in the remaining industry groups.

The same tests were also conducted for the second sample. It should be noted that the increase in total accruals variability was inconsistent with expectations, therefore attention should be mainly focused on the results of method II. The conclusion of the 
size test was that earnings variability increased significantly for small firms, which would be consistent with the size hypothesis. Reported changes in the variability of nondiscretionary accruals provided no indication that the impact of Title 8 was different according to size. However, the only significant increase in discretionary accruals was reported for large firms. This also suggests that large firms were more engaged in earnings management activities. So, method II does provide evidence for hypothesis $\mathrm{H}_{3}^{\mathrm{a}}$.

The results on leverage indicated both methods (I and II) provided no significant support for hypothesis $\mathrm{H}_{4}{ }_{4}$. The reported increase in accruals variability was caused mainly by the intermediate leverage group. No significant changes were reported for earnings variability. The variability patterns of discretionary accruals before and after 1984 were not significantly different, in all three cases. Therefore, changes in the variability of discretionary accruals did not support the leverage hypothesis $\left(\mathrm{H}_{4}^{\mathrm{a}}\right)$.

Finally, the analysis on industry level reported differences between industry groups. In this case, there was a decrease in the variability of total accruals for 4 of the 10 industries, but none of the changes were significant. Earnings variability increased in seven cases, of which two were significant. Based on accruals method II we reported that the variability of nondiscretionary accruals for trading firms decreased significantly, which was inconsistent with the (second part of) hypothesis $\mathrm{H}_{5}^{2}$. In this case, the findings on nondiscretionary and discretionary accruals did not support the assumption that trading firms were less affected by the mandatory requirements than industrial firms.

In summary, the results do suggest a relationship between these firm characteristics and the impact of the WJO and Title 8. Based on the theoretical assumptions underlying hypotheses $\mathrm{H}_{3}^{a}$ to $\mathrm{H}_{5}^{a}$, which were previously outlined in chapter two, we conclude from these findings that firms' reactions to the increase in financial reporting regulations would suggest efficient contracting behaviour. The results on debt/equity and industry classification were significant in the case of the WIO. In the case of Title 8 the size and industry hypotheses yielded significant results. The overall results reported on the impact of 'Title 8 are not as conclusive as in the case of the WJO. In most cases this can be attributed to unexpected pattern of total accruals. Although the introduction of Title 8 led to an increased level of nondiscretionary accruals, the variability of discretionary accruals did not increase significantly. 


\section{Chapter 5}

\section{Summary and discussion}

\subsection{Introduction}

This dissertation is concerned with the question of whether firms discretion in determining their earnings, through the choice of accounting methods, has been affected as a result of the implementation of two major Dutch financial reporting regulations: the Act on Annual Financial. Statements in 1971 and the implementation of the Fourth European Economic Community Directive (Title 8) in 1984. The key findings of the research conducted in this dissertation will be summarized and discussed in this chapter, together with the methodological strengths and weaknesses of the study. It will also discuss the practical implications and provide suggestions for potential research areas.

The next section will provide a summary of the results of this dissertation. Section 5.3 will discuss the methodological issues concerning the advantages and disadvantages of the two different methods employed in this dissertation. The final section will make some suggestions for future research.

\subsection{Summary}

This dissertation has examined the effects of accounting regulation on financial reporting practices in the Netherlands, an area in which there has been little previous research. A number of new results were presented. For instance, the comment made by several Dutch authors (Klaassen, 1981, p. I 43; Zeff et al., 1992, p. 173) that the implementation of the WJO was no more than a codification of existing accounting practices was not empirically confirmed. Our finding that the number of accounting changes increased significantly at the time the WJO was introduced indicates that this was not the case. This dissertation, along with other recent studies (Maijoor, 1991; Buijink, 1992; Bollen 1996), provides empirical evidence that there are economic consequences of accounting regulation. It provides empirical analyses of the effects of regulation on accounting practice, enabling an explanation and evaluation of government policy on this specific issue. 
Thus far, the majority of empirical studies on the impact of accounting regulation on earnings management have been conducted in Anglo-Saxon contexts. Because of the comparatively late introduction of accounting regulation in the Netherlands, the Dutch context offers an excellent opportunity for empirical accounting regulation research. The setting described in chapter two and empirically tested in the two following chapters is one of increased financial accounting regulation, in which firms' reactions can be examined.

Chapter 1 discussed economic theory explaining choice of financial accounting methods (i.e., accounting standards, opinions, interpretations, rules and regulations) based on the recognition of contracting costs. These theories distinguish between (1) a theoretical world without government intervention and (2) a situation in which, due to government or quasi-government regulation, the set of available accounting policies ('the accepted set') has been limited. The theories explain the rationale for firms to supply financial accounting information, the factors that determine firms' choices of financial accounting methods, and it discussed the effect of government financial reporting regulation on firms' accounting method choices. If we assume that the set of available accounting policies ('the accepted set') has been limited through the introduction of additional financial reporting regulations, two competing theoretical perspectives can be distinguished regarding the effects of government financial reporting intervention. The first perspective, opportunistic behaviour, is based on the assumption that managers increase their welfare at the expense of other stakeholders in the firm, such as the shareholders, bondholders, and employees. A restriction of the accepted set through financial reporting regulation will then prevent managers from acting opportunistically, assuming that this regulation will be effective. The second perspective, efficient contracting, asserts that firms will choose the optimal mix of accounting methods from a set of accounting methods voluntarily determined by the firm and its stakeholders. In this case, a restriction of the accepted set through government intervention would therefore lead to suboptimal and thus more costly (contracting) solutions.

Based on a historical analysis of the political debates, articles and government reports, we then pointed out that Dutch policy-makers assumed that firms' management acted opportunistically. They expected that regulatory intervention would limit firms' opportunistic actions. From a theoretical perspective it was argued that additional regulation of financial reporting will have economic consequences- but these might. be different if the assumptions were based on an efficient contracting perspective. Empirical research can test both sets of expectations. This dissertation has focused on testing the effects of the implementation of the WTO (1971) and Title 8 (1984). It sought to provide insight into the effects of these two Acts on firms' accounting policy choices. More specifically, if it is true that firms engage in opportunistic earnings 
management practices, the shift from an almost nonregulated, or only partially regulated, financial accounting environment to one with greater regulation is expected to have an effect on accounting method choice.

Chapter 2 discussed the history of financial reporting regulation in the Netherlands and analysed the contents of the two financial reporting Acts. The WJO was finally implemented in 1971. Its main purpose was to increase firms" disclosure of financial accounting information. The second major shift in accounting regulations, the implementation of the Fourth European Economic Community Directive in 1984 into Dutch legislation, was motivated by the desire of the European Community members to harmonize financial reporting within the Member States. The analysis of the content of the sections relating to disclosure policy and accounting methods has shown that the regulations in the two Acts stipulate many disclosure rules (form and detail) and only a limited number of valuation principles.

Based on these analyses, two sets of research questions, or sets of hypotheses, were developed. The first set was specifically related to accounting method changes, while the second set of questions related to accounting accruals. Alternative research questions were designed to distinguish between the opportunistic behaviour perspective and the efficient contracting perspective.

The first set of research questions, based on accounting method changes, predicted that in the introductory year of implementation of the WJO and Title 8 the number of accounting changes increased significantly due to mandatory financial reporting requirements. In addition to this, the research question based on opportunistic behaviour then expected a decrease in accounting changes after the implementation of the Acts, while the altemative research question based on the efficient contracting perspective expected an increase in accounting changes, reflecting managements ${ }^{3}$ efforts to undo the effects of mandatory financial reporting regulations.

The second set of research questions was based on another type of research to measure accounting changes: the study of accounting accruals. Accruals are interpreted as the cumulative effect of all accounting policy choices made by firms in a specific period (year). Compulsory regulation, assuming it would be effective, would have increased the part that is not susceptible to eamings management, i.e. nondiscretionary accruals. Ceteris paribus, earnings management has become more difficult, which should in turn lead to an increase in eamings variability. Assuming that govermment regulation is effective and managers act opportunistically, the variability of eamings was therefore expected to increase after the implementation of both Acts. The alternative research questions, under the efficient contracting perspective, predicted that earnings variability did not significantly change, because 
management was expected to (at least partially) undo the effects of government regulation through the use of discretionary accruals.

Additional research questions for both sets, accounting method changes and accruals, were introduced to test for the impact of three firm characteristics: size, leverage and industry. The argument was that differences regarding the impact of regulation based on these firm characteristics would support the efficient contracting perspective.

Chapter 3 provided an analysis of the number, nature, and magnitude of accounting method changes made by firms in the periods before and after the introduction of the WJO and Title 8 . The results showed that in the years the Acts were introduced, 1971 and 1984, the number of accounting changes increased significantly. Consistent with the analysis of the regulations presented in chapter 2 , most accounting changes were classification changes. The levels of (measurement) changes were not significantly higher in the periods after 1971 and 1984 compared to those before. The evidence therefore suggested that firms' managements used accounting changes more intensively only during the implementation of both Acts. In the case of the $W J O$, the number and magnitude of accounting changes with an effect on eamings and equity increased after its implementation. Accounting changes with a positive effect on eamings and equity were observed more frequently than negative earnings changes. The evidence regarding the effects of Title 8 in this respect was less strong. Both levels and magnitude, including the sign of the changes, did not change. It was concluded that these findings could be interpreted as providing partial evidence for the no-effects hypothesis. However, more significant findings were reported on the firm characteristics size, leverage, and industry. They indicated that: (1) larger firms made more measurement changes, but the increase in total accounting changes was the highest for small firms suggesting that small and medium sized firms were more affected by both regulations (while large firms anticipated more to the regulation), (2) higher leveraged firms appeared to have been affected more by regulation since they showed the largest increase in accounting changes with an effect on earnings and/or equity, and (3) the effect of the legislation varied across industries. These results provides evidence in favour of the efficient contracting hypothesis.

Chapter 4 continued the empirical analysis of the effects of mandatory financial reporting legislation on financial reporting practices. In this chapter, attention was focused on accruals and earnings patterns. In order to determine accruals two methods were used: accruals method I and II. Method I is based on the assumption that any change in total accruals from one year to another reflects a change in discretionary accruals. Method II uses a regression model to determine the nondiscretionary and discretionary part of total accruals. The aim was to test whether income smoothing (as an example of the opportunistic behaviour assumed by 
government) became more difficult due to the mandatory financial reporting requirements of WJO and Title 8 , implying an increase in earnings variability and a decrease in accrual variability. It was found that, as a result of the regulation, (1) earnings variability increased, (2) the level of total accruals increased (especially in the years of implementation), and (3) the variability of total accruals decreased only in the case of the WJO.

Subsequent analysis of nondiscretionary and discretionary accruals, based on a regression model (accruals method II), provided additional evidence that the reported increase in nondiscretionary accruals was due to increased financial accounting regulation. A dummy variable legislation, representing the effects of the mandatory requirements of WJO and Title 8 , was significantly negative in both regression equations. According to the model, discretionary accruals variability increased. Such an increase might be partially explained by managements' limited opportunities to switch accounting methods, which also provides reason to believe that management spent more (costly) resources on earnings management using more subtle techniques, but without quite succeeding in nullifying the effects of the Acts. The analysis of nondiscretionary and discretionary accruals also revealed differences between the WJO and Title 8 . Both Acts led to a decrease in the variability of nondiscretionary accruals, but the variability decrease in the case of Title 8 was not significant. The results reported on the variability patterns of discretionary accruals are similar. The increase in discretionary accruals variability after both interventions provided additional evidence that firms have tried to eliminate part of the effect of the mandatory financial reporting restrictions, although only the increase reported after the WJO was significant. The evidence on earnings variability supports the idea that income smoothing has become more difficult despite increased discretionary efforts. Finally, tests to examine whether firm characteristics might affect the impact of the regulation and firms' responses showed that earnings and accruals variability also vary across industries. The evidence presented also supported the size and debt/equity hypotheses, although the latter was not significant in the case of the WJO.

Many of today's legally mandated reporting techniques initially developed in a voluntary contracting setting. It has been suggested that the WJO was just a codification of existing financial reporting practices. Furthermore, the analysis of the contents showed that emphasis of both regulations was mainly on disclosure rules and format and less on restriction of measurement or valuation rules. But, the evidence presented in this dissertation has indicated that firms indeed were affected by the new regulatory regime of the WJO and Title 8 . The dissertation also provided evidence that the impact of both regulations on firms' financial reporting went beyond the increase in detail and format of firms' required by the new regulations. Apart from numerous disclosure adjustments, especially during the years the WJO and Title were 
introduced, the empirical analyses showed that the number of measurement changes and their magnitude on earnings and/or equity increased not only during the introduction years, but also in years thereafter (although not significant). Also, we found evidence that the variability of eamings increased both times after an increase in financial reporting regulation took place.

\subsection{Comparison of methods and results: consistency, limitations and opportunities}

As outlined in the introductory chapter, two research methods have been employed. This section will make some comments about the research design, compare the results and their consistency, and describe the limitations and potentials of the two methods. First, the results and their consistency will be considered.

\subsubsection{Results and consistency}

The results of the empirical analyses based on the analyses of accounting changes and accounting accruals are presented in table 5.1. Analyses of the number, nature, and magnitude of accounting changes in the periods observed have indicated that the introduction of two major accounting regulations in the Netherlands resulted in a significant increase in the number of accounting changes. Similar conclusions were drawn from the analysis of accounting accruals, indicating that the introduction of the WJO and Title 8 had a significant impact on accounting accruals. The finding that the frequency of accounting changes after the implementation of Title 8 were not at a significant higher level compared to the years prior to Title 8 , is also consistent with fact that the level of total accruals decreased in the years after the implementation. Further analysis of the measurement changes indicated that (1) the number of changes with an earnings increasing effect increased after both Acts and (2) the magnitude of these changes on earnings and/or equity was also higher after the regulatory interventions. This is consistent with the reported increase in variability of discretionary accruals. However, it should be noted that earnings variability increased as well, which led us to the conclusion that firms' efforts to undo the impact of accounting regulation were not fully effective. Another similarity was found regarding anticipatory behaviour of firms in the case of the WJO: accounting changes in 1970 were already significantly higher than in the year before, although the WJO only became effective one year later. The same pattern was observed in the time series of the accrual data. To amplify, in comparing the variability of accruals before and after the WJO it was found that the analysis including 1970 in the postWIO years yielded better results than when 1970 was excluded from the post-WJO 
Table 5.1: Comparison of the main test results based on the analyses of accounting changes and accounting accruals

\begin{tabular}{|c|c|}
\hline 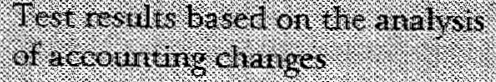 & 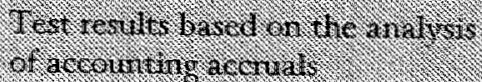 \\
\hline
\end{tabular}

significant increase in the frequency of accounting changes in 1971 and 1984

a significant increase in level of total increase in measurement changes after 1971 and 1984; although not significant

overall more positive than negative accounting changes affecting earnings

increase in the number of positive changes affecting earnings after the WJO accruals in 1971 and 1984

level of total accruals did not increase after 1971 and 1984; variability of earnings increased after 1971 and 1984

Method I: variability of accruals decreased after 1971 (significant) and increased after 1984 (not significant)

Method II: variability of discretionary accruals increased after 1971 (significantly) and 1984 (not significantly)

number of changes affecting equity higher are higher in the case of the WJO

Method II: variability of nondiscretionary accruals decreased (significant) in 1971 and 1984

WJO: anticipatory behaviour

WJO: anticipatory behaviour

overall impact of the WIO larger than impact of Title 8

overall impact of the WJO larger than impact of Title 8

size: larger firms make more accounting changes, but small firms are most affected by WJO and Title 8

size: variability of discretionary accruals significantly higher for large firms only after Title 8

leverage: higher leveraged firms report significant increase in measurement changes after WJO and Tide 8

leverage: variability of nondiscretionary accruals decreased for intermediate and high leveraged firms only after WIO (no differences in effects on discretionary accruals)

industry: changes in frequency of accounting changes after WTO and Title 8 industry: changes in wariability of nondiscretionary and discretionary accruals after the WJO and Title 8 vary across industries

period. The results based on both accounting changes and accruals indicated that the impact of Title 8 was less compared to that of the WJO. The significance levels of the 
test results on the impact of Title 8 were on average lower compared to the WJO. Finally, the analysis of accounting changes in relation to firm characteristics reported the most clear and significant results on tests of the size, debt/equity and industry hypotheses. Although the results of the accruals analysis on these firms characteristics showed similar trends, the evidence from the analysis of nondiscretionary and discretionary accruals patterns was overall less conclusive compared to that of accounting changes, especially in the case of the debt/equity hypothesis.

Therefore, based on a companison of the major findings of both methods employed in chapter 3 and 4 we conclude that the results of the empirical analyses are largely consistent.

\subsubsection{Limitations and opportunities}

Any study is limited by the data available and methodological limitations. In our case, one of the major problems relating to the registration of accounting methods has already been discussed in chapter 2 . It relates to the lack of databases on accounting changes made by Dutch firms, in contrast to the situation in the US, where detailed information required by the SEC (Securities and Exchange Commission) regulations in financial statements is readily available on data tapes (Compustat). This implies that the required Dutch information has to be hand-collected and mostly handcalculated from the annual accounts. Not only is this very time-consuming, it is often difficult to determine the nature of an accounting change and its magnitude, since adequate and detailed information is not always provided. This is especially the case in the period prior to the WJO, when often only limited information was provided in the annual financial statements. The outcome of such an analysis is therefore at most a fairly accurate proxy of the real number of accounting changes and their possible impact on eamings and/or equity. On the other hand, since these data have been hand-collected, potential problems related to the use of large databases are not present in this study.

A second problem is related to the method applied in chapter three: the observation of the changes in accounting policy (accounting method changes). In this dissertation we chose to include all accounting changes and not only those resulting directly from specific (measurement) regulations of the WJO and Title 8 . The reason for this was explained in chapter one and two. Through a restriction of the accepted set of accounting procedures, not only as a result of measurement rules but also due to a significant increase in disclosure rules, we expected that firms were affected by the regulation beyond actual measurement rules. A consequence of this approach is that the analysis includes accounting changes not directly related to a specific accounting 
regulation, which can bias the results of the time-series analysis. A prominent example was provided by accounting changes related to foreign currency translation (during the second time series surrounding Title 8 ). However, additional analyses which results were presented in appendix 3B. I and 3B.2 showed that these and other types of accounting changes were equally distributed over the entire period so they could not have led to biased results.

A third problem, of a methodological nature, inherent in the use of accounting changes is that, even if it were possible to analyse all accounting changes, this only captures partly managements' total earnings management activities. As explained in chapter one, there are other techniques used to alter reported eamings which are more subtle than changing accounting methods. Management may prefer to use methods which are less evident to the outside world. This dissertation has adapted and applied a technique to capture the effects of those activities, by analysing accounting accruals. Accruals capture the cumulative effect of managements' activities regarding earnings management. The accrual methodology has been successfully used in several research settings.

This study differs from previous studies in that, due to the mandatory regulations, the nondiscretionary part of accrualls increased, where other studies have assumed that nondiscretionary accruals are constant. Of course, there are also limitations to this method.

First, the use of accruals as a summary measure of accounting suffers from a lack of control: we do not know what the accruals would be in the absence of managerial accounting discretion (Watts and Zimmerman, 1990, p.138). Second, the determination of cash flow from operations is not without problems (see appendix 4A). The definition of cash flows and thus accruals can have a significant effect on the outcome of the analysis (Mertens and Hassink, 1992). The basic idea of the accrual concept is to compare the accounting performance, represented by eamings, with the real economic performance, measured by cash flow (where the difference is accruals). But the cash flow definitions are at best proxies for real cash flows, since they are derived from accounting numbers. Despite this, the proxies used in the empirical literature are fairly consistent.

Another limitation relates to the models employed to divide total accruals into nondiscretionary and discretionary accruals. In this dissertation we have taken the step to relax the assumption that nondiscretionary accruals remain constant over time, so that a change in total accruals reflects a change in discretionary accruals. Nonetheless, the regression models on which the separation of nondiscretionary and discretionary accruals are based require further improvement. One way of improving 
the explanatory power of the models would be to add other independent variables as demonstrated, for instance, by Bowen et al. (1992). Another major improvement might be to use real cash flow data instead of cash flows derived from accounting data. An increasing number of (Dutch) firms provide cash flow information (cash flow/funds flow statements) in their annual accounts, which could then be used instead of the 'accounting based' cash flows.

\subsection{Further research opportunities}

The study of accounting method choice in this dissertation is separated into two types of research, examining accounting method changes and accounting accruals. Before discussing research opportunities in these two fields, some suggestions will be made for the development of a refined theoretical concept.

Watts and Zimmerman (1990, p.149) suggested the further development of:

".. a unified theory that incorporates both ex ante efficient restrictions on the managers' accepted accounting methods and the ex post exercise by managers of their discretion to choose accounting methods within the accepted set".

Another reason for seeking a more comprehensive theory is that the independent variables, such as firm size and leverage, are often related to one another, causing bias due to interaction, while other important variables are often omitted from research.

General criticisms have been made of the research methods and methodology used in positive accounting research (Watts and Zimmerman 1990, p. 140). But the most essential requirement for the further refinement of the theory is to identify the variables that determine accounting method choice in a Dutch context. So far, positive theoretical assumptions about managerial behaviour are based solely on English and American empirical observations. For instance, areas such as the use and structure of debt covenants in the Netherlands, remain almost unexplored.

Research based on the size hypothesis could also be further developed. Dutch researchers could contribute to a more refined political cost hypothesis in some areas. For instance, the accounting method choices of companies trying to obtain government subsidies, such as the shipyard industry in the seventies (RDM) and more recently the car industry (DAF, NedCar) and aviation industry (Folker) could be investigated to reveal the specific motives and means of management's financial reporting strategies. Future empirical research efforts should therefore be directed towards more specific contexts in which similar incentives exist for firms to alter their 
reporting strategy. This would enable (1) the use of control samples, (2) a comparison of empirical results from different contexts, leading to a more complete understanding of an overall firm reporting strategy.

The first part of the empirical research presented in chapter three examined accounting method changes made by Dutch public companies in the periods before and after the implementation of two major financial reporting regulations. It covered both classification changes and measurement changes. Future research might also focus on a subset of accounting changes in combination with specific events (subsidies, going public), as in Bowen ot al. (1992), who consider implicit (unwritten) agreements with stakeholder other than the usual stakeholders that can influence accounting decisions. It would be important to investigate the individual effects of the accounting changes, since management is expected to choose an optimal income strategy that comprises a portfolio of accounting method choices. Focusing on a subset would enable the researcher to construct a model of reporting strategies that can be tested using specific hypotheses.

The second part of the empirical research focused on accounting accruals. One way of improving these models would be to extend the time series of data employed. Secondly, firm-specific models are more accurate, since they fully capture specific accrual components. Jones (1991) and Cahan (1992) have provided examples of this line of research. Third, more attention could be focused on the construction of more homogenous groups, such as the use of specific industry categories. A fourth refinement of the methodology would be to remove the bias from accruals (and cash flow from operations). Finally, research on accounting accruals in the Netherlands could also focus on specific settings or events in which firms have incentives to either decrease or increase discretionary accruals. One such opportunity is when public firms obtain an officiall listing on the Amsterdam Stock Exchange. Firms would be expected to have incentives to increase reported earnings in the years surrounding the listing to draw the attention of potential shareholders. Anecdotal evidence suggests that some of these firms are faced with financial problems in the years thereafter. 
Appendices 


\section{Appendix 2A}

\section{Assessment of the debates, reports, and articles on Dutch accounting practice prior to the WJO}

This appendix provides information on some features of Dutch accounting practice prior to the WJO, drawing on the debates, reports, and articles on firms' financial reporting practices as they relate to the Dutch government's decision to move towards statutory regulation. The structure is as follows. Section I briefly illustrates disclosure practices prior to and after World War II. Section II discusses the contents of the four major reports on financial reporting in the Netherlands published between 1955 and 1962. A summary of the main articles published in Dutch literature, with a focus on the desirability of more extensive accounting regulation, is provided in section III. Section IV discusses the report of the Verdam committee. Finally, sections V and VI summarize the arguments in favour and against additional regulation, as used by the proponents and opponents of additional accounting regulations.

\section{Inadequate disclosure practices}

Assessing the financial reporting practice in the years before World War II, Zeff et al. (1992, p.73) conclude that:

Notwithstanding the attempts by a few companies to imprope their financial reponting, the general nun of company financial statements was dismal.' The great majority of companies disclosed no more than the law required. And the law required wery little.

In one of the very few examinations of financial reporting practice at the time, Munnik (1931) studied the financial statements of Dutch and foreign companies for years ending before 1930 . The author concluded that the state of financial reporting was very deficient (Zeff $e t$ al., 1992, p.63). ${ }^{2}$

However, this situation changed after the Second World War. The responsibilities of companies' management towards the shareholders and the public were increasingly emphasized, and as a result the conservative financial reporting practices of most companies "became no longer supportable" (Zeff et al., 1992, p.75). The 1950 s could therefore be described as a period in which an increasing number of organisations and

\footnotetext{
"No empirical validation on this statement is provided.

${ }^{2} \mathrm{No}$ information is available regarding the number of statements Munnik examined, only that it concerned a "very large sample" of banks and industrial firms.
} 
institutions, such as trade unions, auditors, journalists, lawyers, and bankers, initiated a process of adaption of financial reporting in the Netherlands. ${ }^{3}$

At the same time, a discussion of changes in financial reporting started within the Dutch political system. According to the parliamentary working papers, reports and articles on the debates which we have reviewed, regulations concerning the balance sheet and profit and loss accounts of enterprises were inadequate. Several other statements within these papers, reports and articles referred to the lack of provisions and the meagre financial reporting practices. For instance, the Annual Reporting Committee (1955, p.5), a study committee consisting of four employers' federations that studied the annual reporting of listed public companies, stated that the actual or current demands regarding modern financial reporting that have to be met are far beyond the existing legal requirements of article $42 \mathrm{c}$ of the Code of Commerce. ${ }^{4}$

The Dr. Wiardi Beckman Foundation (1959, p.45), which is the research institute of the Labour Party (PvdA), formulated its concern in the following way:

... the uncommunicativeness of the company directors regarding the results of a business and its equity position are a serious hindrance to properly evaluating the company policies of our large public companies ... the legal requirements according to article $42 \mathrm{c}$ are far from satisfactory and the information provided to the public is also insufficient. (Dr. Wiardi Beckman Foundation, 1959, p.47)

Van Berckel (1965, p.173) and The Council of Dutch Employers Federations (1962, p.24) argued that the existing legal requirements regarding the contents of financial reporting were concise. The Verdam Committee (1965, pp.34-35) considered existing standards to be very brief and, according to general perception, inadequate. Hence, it was felt that Dutch company law had to be reconsidered. Economic and social changes had led to a need for more precise definitions of the contents of annual accounts (Coelingh, 1965, p.5). Several arguments were used to explain why the statutory regulations of existing company law were no longer adequate. The most important of these will be discussed here.

The statements above have been drawn from several reports that resulted from the discussion on the revision of financial reporting regulation, as part of a broader process of democratization of companies. The four most important (in chronological order) are:

\footnotetext{
${ }^{3}$ See van Bruinessen (1975) and Burgert (1981) for alternative discussions of the major forces that led to the changes in financial reporting.
}

${ }^{4}$ Own translation. 
(1) Het jaanverslag (The Annual Report) by the Annual Reporting Committee (1955), representing the four major Dutch Employer Federations; 5,6

(2) De hervorming van de onderneming (The Restructuring of the Enterprise) by the Dr. Wiardi Beckman Foundation (1959); ${ }^{7}$

(3) Verslaggeving verantwoording en voorlichting door de besturen van maxaloze vennootschappen (Reporting, Rendering an Account and the Provision of Information by the Managements of Public Companies) by the Council of Dutch Employers' Federations (1962); ${ }^{8}$ and

(4) Open ondernemerschap (Open entrepreneurship: the growth of enterprise and of company law) by the Prof. Mr. B.M. Telders Foundation (1962).

These reports focused on existing (inadequate) financial reporting practices and made proposals for improvements in company law. The central issues discussed in the studies related to employees' rights and the position and rights of shareholders and the public.

\section{Discussion of the contents of the reports}

\section{(1) Rijkens Report}

One of the main reasons for the Federation of Dutch Employers to publish the Rijkens report in 1955 was the fear of "far-reaching plans in the Ministry of Finance regarding standards to be set for financial reporting" if companies did not improve financial reporting themselves (Zeff et al. 1992, p.95). The report, relating to public companies, emphasized the role not only of shareholders and creditors, but also of potential capital suppliers, business associates, government and in a broader context. the public (Annual Reporting Committee, p.5). The report included four general demands which had to be satisfied in order to present a faithful picture. These were:

${ }^{5}$ The Committee was named after its chairman, Dr. P. Rijkens, also chairman of Unilever.

${ }^{6}$ The committee consists of (1) the Federation of Dutch Employers (Het verbowd wan Nederlandsche werkgevers, WNW), (2) the Central Social Employers' Federation (Het Centrack Sociaal Werkgevers-Verbord, CSWV), (3) the Catholic Federation of Employers Associations (Het Kathaliek Verbond van Werkgevers-verenigingew, KVW), and (4) the Federation of Protestant. Christian Employers in the Netherlands (Het Verbond van Protestants-Christelijke Werkgevers in Nederland, VPCWN) (Commissie Jaarverslaggeving, 1955).

'This foundation is the "think tank" of the Labour Party (PvdA).

${ }^{8}$ This follow-up committee to the Rijkens committee was called the Hamburger Committee, after its chairman J.A. Hamburger, a member of the Federation of Dutch Employers (NNW), and a director of N.V. De Koninklijke Nederlandse Lood en Zinkpletterijen.

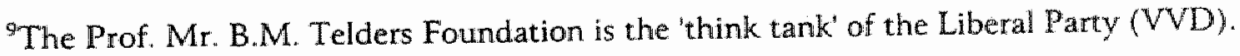


(1) specification of the operating income in such a way that it provides insight into income composition and the rate of return on the invested capital, (2) specification of assets and liabilities to provide insight into solvency and liquidity, (3) valuation principles of assets and liabilities (preferably current cost valuation) and principles for the calculation of operating income, and (4) for reasons of comparability, the presentation of changes in accounting methods and principles with their possible effect on the figures (Annual Reporting Committee, 1955, p.8). On the issue of secret and hidden reserves, the committee took the view that the principle of the so called minimum position was out of date, although certain situations could arise in which formation of secret reserves could be justifiable (Annual Reporting Committee, 1955, pp.9-10).

\section{(2) Wiardi Beckman Foundation Report}

Four years later, the Dr. Wiardi Beckman Foundation study committee on financial reporting discussed the negative consequences of financial reporting malpractice on wage claims and stated in its report that:

... it has become almost impossible to measure a company's performance within the existing inadequate accounting practice of publication of annual accounts. This inadequate accounting practice can no longer be used to cover the consequences of malpractice or to camouflage capital gain. (1959, p.119).

... adequate financial reporting is also of the utmost importance for the employees of the company. The current situation, in which, when negotiating on wages and terms of employment, which inevitably involves a balance between the claims of the employees and the financial potential of the company, only the management has possession of releyant figures, while the negotiating unions remain almost in the dark, is unacceptable. (1959, P. 119$)$

The report went on to discuss the reasons for the reluctance in the business community to "break down the walls of secrecy". Businesses had expressed a fear of excessive wage claim and dividend demands, which they then could not refuse. Also, unfavourable earnings would attract too much attention, and the competitive capacity of the company would be endangered (Wiardi Beckman Foundation, 1959, p.120).

Structural changes in economic and social life gave rise to three major questions: (1) should there be additional provisions regarding the protection of the suppliers' of capital, now that the power within the company rested solely in the hands of the managers, (2) are subsequent arrangements necessary to guarantee the interests of the employee and specify his responsibility towards the company, and (3) is the public interest represented adequately, now that modern companies have assumed such a dominant social position (Wiardi Beckman Foundation, 1959, pp.15-16). Concerning 
the relation between the company and its capital suppliers the report concludes that:

....the practical meaning of the legal authorities assigned to the shareholders meeting is much smailer than suspected. ... It is therefore disappointing to conclude from recent annual reports that only a few companies have responded to the prior reports in a positive way. (Wiardi Beckman Foundation, 1959, p.45)

Suggestions to improve financial reporting, requiring the disclosure of the accounting principles used for the valuation of assets and liabilities and for income determination, focused especially on the phenomenon of secret and hidden reserves. ${ }^{10}$ On this issue the report commented that:

...The prime objective of improving financial reporting should be ruling out the widespread practice of camouflaging the real capital and profit position. For instance, the practice of hiding reserves under accounts payable. (Wiardi Beckman Foundation, 1959, p.122)

The use of secret and hidden reserves enabled companies to report a stable earnings pattern over the years. Therefore, reductions of reserves that increased incone or net assets should be disclosed. Zeff et al. $(1992$, p.75) conclude that many companies used these reserves either to smooth or to understate their year-to-year profit.

\section{(3) Council of Dutch Employers' Federations Report}

At the same time as the report of the Wiardi Beckman Foundation, the Council of Dutch Employers' Federations decided to establish a follow-up to the Rujkens committee, the Hamburger Committee (1959). Its task was to investigate the desirability of developing new guidelines with respect to annual reporting of industrial public companies (Council of Dutch Employers Fedleration, 1959, p.7). The Federation's purpose was to respond to the study of the Wiardi Beckman Foundation and to influence the Verdam Committee, which had been appointed in 1960 (Zeff et al. 1992, p.127). The committee was in favour of general legal requirements rather than detailed legal prescriptions (Council of Dutch Employers Federation, 1959, p.25). To remove the existing public distrust, the committee recommended that management should pay considerable attention to the desirability of opening up "the affairs of business" (Council of Dutch Employers Federation, 1959, p.11; Zeff et al., 1992 , p. 130). In considering the role of financial statements, the committee followed its predecessor, the Rijkens Committee, by suggesting the required disclosure of valuation principles (for assets and liabilities) and income determination methods. It also suggested that accounting changes should be mentioned, along with comparative numbers (Council of Dutch Employers Federation, 1959, pp.30-31). Again, a strong

${ }^{10}$ Wiardi Beckman Foundation, Chapter 5, section 2. 
position was taken against secret and hidden reserves, which it regarded as no longer acceptable, because of their effect on the firm's capital and income (smoothing) position (Council of Dutch Employers Federation, 1959, pp.33-34). Other subjects addressed in the report related to the need for consolidated statements when investments are at stake, the disclosure of sales volumes and the cost of sales, and the audit of financial statements by an independent expert.

\section{(4) Telders Foundation Report}

Finally, the report of the Telders Foundation (1962) was the Liberals' reply to the Wiardi Beckman Foundation, advocating several amendments to the existing Article 42 in the Commercial Code. ${ }^{11}$ One of the central themes in the report (chapter 5) was interest groups" right to "information".." Several recommendations were also made with respect to financial reporting, to amend article 42 of the Code of Commerce. The proposed amendment is categorized into four elements, (a) legal requirements should not apply only to "Open" public companies ('Open' Naamloze Vennootschappen) but to all public companies, ${ }^{13}$ (b) a revision of the specification of the asset side of the balance sheet, (c) provisions for the liabilities side and (d) provisions regarding the profit and loss statement (Telders Foundation, 1962, pp. 323-324). The proposals for the contents of the financial statement resemble many of the ideas put forward in the Rijkens report. Their proposed revision of the requirements regarding financial reporting and prospectuses for securities contain detailed requirements regarding: the items on the asset and liability side of the balance sheet "...so as to require that they provide insight into solvency and liquidity"; disclosure of the valuation principles used to value assets and liabilities and determine profits; information on possible changes in these principles and their effects; and a specification of the company results which enables users to gain insight into its composition and the rate of return (Telders Foundation, 1962, pp. 325-326).

\section{Discussion of the desirability of more extensive legal requirements}

Apart from these reports, several other commentaries can be found in the

\footnotetext{
"Most of the information disclosure requirements were comparable to those of the Hamburger and Rijkens reports (Zeff et al. 1992, p.143).

${ }^{12}$ The interest groups were (1) shareholders, (2) potential shareholders, (3) the board of supervisors, (4) employees, and (5) creditors (Telders Foundation, 1962, pp.308-313).

${ }^{13}$ See section 2.2 for the specification of the criteria of "open" public companies (open NVs) under section $42 \mathrm{c}$ of the Code of Commerce.
} 
contemporary professional literature dealing with the reform question. ${ }^{14}$ These articles debate whether additional legal requirements are necessary. Burgert (1965), for instance, argues that in the evolution of the modern firm the position of the shareholders/owners, once invested with the highest power within the company, has become very vulnerable. There are several driving forces behind this:

a concentration tendency, especially within the industrial sector where the public company had replaced the traditional family company with its low separation of ownership and control;

- an increase in the numbers of large corporations and, as a result, concentration of power (in the hands of a small number of people: the firms' managers);

a large growth of the number of shareholders, which leads to increased dispersion of the shareholder ship;

a managerial revolution, which led to the displacement of the traditional manager who was also a shareholder of the firm (i.e. the separation of control and ownership). ${ }^{15}$

These forces had led, in a fairly unregulated market, to major changes in the disclosure policies of the majority of corporations:

(1) Those corporations subjected to Section 42 of the Code of Commerce, i.e. the public limited liability, who were obligated to disclose annual accounts, disclosed far more information than Section 42 required (Burgert 1965), ${ }^{16}$ Although there was no obligation to audit the annual report, practically all public companies listed on the Amsterdam Stock Exchange voluntarily had annual audits (Groeneveld 1965). ${ }^{17}$

${ }^{14}$ The literature review includes among others articles from non-economic journals by van Berckel (1965), Bouma (1971), Burgert (1965), Coeling (1965), Huizinga (1969a), Krens and Bulte (1972), and Pruijt (1966) (published in the Naamloze Vennootschap (NV) and Tijdscitrifti woor Vennootschappen Verenigingen en Stichtingen (TVVS)).

15 Management is regarded as a type of labour but with a special role: "coordinating the activities of inputs and carrying out the contracts agreed among inputs, all of which can be characterized as decision making" (Fama 1980, p.289).

${ }^{16}$ See also Zeff et al. 1992, pp.80-114, which documents several private-sector initiatives to improve financial reporting.

17 An investigation conducted by Lafeber showed that, in 1948 and 1951 , between 56 and $73 \%$ of the listed companies had an independent audit. It should also be noted that from 1958 on, the Regulation for Securities (Het fondsenreglement) of the Association of Security Brokers (Vereniging poor de Effectenhandel) required the auditing of annual accounts in prospectuses for securities (Zeff, et al. 1992, pp.79-81). 
Sanders et al. (1975, p.11) states that prior to the enactment a respectable number of companies already published 'acceptable' annual accounts. ${ }^{18}$ A number of firms published annual reports on a voluntary basis, and a significant proportion of these firms had audits. In addition to this, Zeff $e t$ al. (1992, pp. 107-109) present anecdotal evidence of companies 'improving' their financial statements, as a reaction to the previously presented reports. Several companies altered or extended their financial reporting as regards the use of: (a) comparative figures (and multi-year presentations), (b) current cost accounting numbers, (c) external auditing, (d) consolidated financial statements, (e) disclosure of sales and cost of sales. All in all, the issue regarding the need for financial accounting regulation still remained open.

However, the calls for more extensive (compulsory) regulation became stronger despite these changes. The Minister of Justice reported, in a statement of the Social and Economic Council (Sociaal Economische Raad, SER) on the report of the Verdam Committee that "... The government is convinced that the current regulations on this matter are deficient. The more extensive regulations proposed by the commission will be a substantial improvement" (Sociaal Economische Raad, 1965). At the same time, the revision of company law was on the political agenda in other member countries of the European Community. ${ }^{19}$

\section{The report of the Verdam committee ${ }^{20}$}

In consideration of the above-mentioned developments a committee, established in 1960 under chairmanship of Prof. Mr. P.J. Verdam, stated that "...the lack of legal prescriptions, adapted to modern insights regarding [measurement and disclosure requirements of] annual accounts, will slow down the process of adjustment." (Verdam Committee, p.34, 1965). The report of the Verdam Committee, which reviewed questions concerning the revision of legal form with respect to monitoring within large corporations as well as the question of accountability to the public,

\footnotetext{
${ }^{18} \mathrm{No}$ information is available as to the number of companies publishing annual reports.

"Germany replaced the "Aktiengesetz" of 1937 with a new "Aktiengesetz" of 1965. In France the new "Loi sur les sociétés commerciales" was implemented in 1966, and in England the proposed "Companies Bill of November 3 1966", based on the Jenkins report of 1962, led to the new "Companies Act 1967" (Huizinga 1969a).

${ }^{20}$ The committee had been established in 1960 by the Minister of Justice, Mr. A.C.W. Beerman. Its task was to propose revisions of Dutch Company law. The report was called: "Herziening van het ondernemingsrecht: Rapport van de Commissie ingesteld bij beschikking van de Minister van Justitie van 8 april 1960".
} 
contained proposals to improve annual reporting. ${ }^{21}$ The "annual reporting improvement proposal" consisted of issues concerning (1) the legal restructuring of the enterprise and its financial reporting, (2) the question of the installation of a Companies Commission $^{22}$, (3) the position and rights of employees and shareholders within the company (including the right of inquiry), and (4) the involvement of the employees in the affairs of the company (Verdam Committee, 1965, pp. 1-6; Zeff $e t$ al. 1992, p. 150$)$. With respect to the proposals for financial reporting, the commission emphasized the role of valuation principles:

... The use of unacceptable or unspecified valuation principles does not allow a judgment on the annual financial statement. Still, one can find examples of both practices. This is due to the tendency to form secret and hidden reserves. (Verdam Committee, 1965, pp.52-53)

As in the reports previously discussed, the Verdam Committee rejected secret and hidden reserves, because it was one of the main reasons why the picture that financial statements provided was troubled (Verdam Committee, 1965, p.53). Concerning the draft articles on this and other issues on financial reporting regulation the report discussed in three subsequent chapters items dealing with definitions, measurement and disclosure issues. The contents of the final draft articles as incorporated in the Act of 1970 will be discussed in the next section.

\section{Additional arguments in favour of regulation}

In the Verdam Committee report and the in political debates preliminary to the introduction of amendment of the Act on Annual Financial Statements, several additional arguments are used in favour of government regulation: ${ }^{23}$

(1) It was felt that management had too high a degree of discretion. As a result, inadequate control of management's activities led to their propensity for manipulation of accounting numbers, i.e. building up "silent and/or secret" reserves to smooth income as well as representing the firms' financial position other than (more favourably than) it actually was (Huizinga, 1969, p.11,

\footnotetext{
${ }^{21}$ The Verdam Commission differed from the Rijkens and the Hamburger committees in that it was governmental commission. It presented its findings in 1965 in the report called Herziening wan het Ondememingsrecht (Revision of Enterprise Law).

${ }^{22}$ A subcommittee was formed to deal with this item (Verdam Commission, 1965, p.6).

${ }^{23}$ See also Maijoor (1991, pp.29-31) for a discussion of the arguments used in favour of regulation.
} 
Sanders et al., 1975, p.5).2425

(2) The protection of the position and rights of employees, owners and debtholders can no longer be guaranteed with the existing inadequate disclosure practices (Wiardi Beckman Foundation, 1959, pp. 119-125).

(3) Arguments concerning the relation private versus public interest view financial disclosure regulation as desirable from a public interest point of view (Verdam Committee, 1965, p.31).

(4) Also, through national and international harmonisation of financial accounting legislation, competition between corporations will be more fair.

(5) Finally, better protection of stockholders and third parties is established through harmonisation (Verdam Committee, 1965, pp.34-35).

Other issues considered in the political debates and reports that came in to favour of regulation are:

(5) Dutch accounting regulation was less developed compared to other countries,

(6) Disclosure of financial information played a vital role in the process of democratization,

(7) Large firms should be open and therefore provide financial information, because of their importance in economic and social life.

Although economic consequences of accounting regulation received considerable attention (Maijoor, 1991, p.30) there has not been any empirical research underlying the arguments used in the debates by policy makers. For instance, Blom (1966, p.1) concluded that an empirical investigation of the question whether the legal form of the company requires reconsideration has not been conducted by the Committee.

With him several authors have argued the essence of an empirical survey of Dutch accounting practice. Vecht concluded this in consideration of the report presented by the Annual Reporting Committee (1955):

A report as this is especially important because modern tenninology and modern wiews on financial accounting should be presented in a pleasant, readable and sensible way to managers, financial press, shareholders, and other interested parties. Furthermore, the report is also in another respect of great importance, that is to provide a contribution to accounting practice. Concerning this issue, we believe that it gradually would be useful to investigate to what extent accounting practice has progressed since 1955, and subsequently

\footnotetext{
${ }^{24}$ It should be noted that building up secret or hidden reserves leads to the decrease of equity and/or profits.

${ }^{25}$ Which indicates that regulatory restrictions in financiall reporting are motivated by opporturistic behaviour assumptions.
} 
what the present shortcomings are, through means of an investigation of awnual reports of a representative sample of firns. (Vecht 1956, p.121)

\section{Arguments against regulation}

Despite the aforementioned arguments in favour of regulation there has been a major change in annual reporting in the absence of government regulation. ${ }^{26}$ Therefore, Burgert (1965, p.265) argues that it is a thin base for new legislation when its main purpose is to pull "... a few unwilling dogs" over the line. ${ }^{27}$

Bouma (1972) continues the criticism by arguing that the weakness of the investigations conducted by the Verdam Committee is that it completely lacks empirical research. Or, as Maijoor (1991, p.30) summarizes the political process

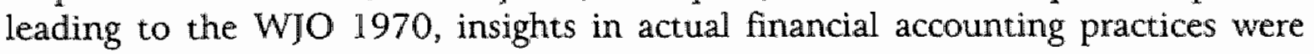
minimal.

\footnotetext{
${ }^{26}$ See also page $21-22$. Zeff (1992, pp.80-114) documents several private-sector initiatives that helped to improve the quallity of financial reporting. As for instance, the increased number of recommendations/ requirements of the Stock Exchange Association, comments in professional publications, and the installation of the Sijthoff Prize, reflecting the norms of "good" financial reporting.

${ }^{27}$ See also Van Berckel (1965). Blom (1966), Huizinga (1969b) and Bouma (1972) for comments on the report of the Verdam Committee.
} 


\section{Appendix 2.BI}

\section{Changes in financial reporting requirements as a consequence of the implementation of the Act on Annual Financial Statements (WJO) and an analysis of its contents}

The financial accounting environment in the Netherlands has been subject to several changes over time, with the most important modifications taking place during the last three decades. Countries such as the United States, United Kingdom, Australia and Germany preceded the Netherlands in regulating financial reporting. ${ }^{28}$ In the United States, where standard-setting has had a long history, regulation on the issue of financial accounting in the early 1930 s led to the establishment of the Securities and Exchange Commission. The 1933 Securities Act required firms listed on the stock exchange to provide financial information. In the UK, the 1948 Companies Act introduced many new disclosure requirements, although financial reporting standards had existed since the nineteenth century. ${ }^{29}$

In contrast, until 1971 the legal financial accounting prescriptions in the Netherlands consisted of just two sections governing the annual financial statements of "open" public companies (open Naamloze Vennootschappen) ${ }^{30}$ : sections 42 and $42 \mathrm{c}(3)$ of the Code of Commerce of 1929 (Wetboek van Koophandel, 1950).

\footnotetext{
${ }^{28}$ See Sanders et al. (1975, p.9) and Nobes and Parker (1991, p.139; p.200).

${ }^{29}$ Indeed earlier laws existed in the UK, dating back as far as 1844 (Parker, 1989, p.21).

${ }^{30}$ In the Dutch context the Naamloze Vennootschap (NV) refers to a public limited liability company that may have its shares traded on a stock exchange (Bollen, 1996, p.11). The NV, referred to in section $42 \mathrm{c}$, is regarded as "open" NV if:

- the articles of association of the public company permitted bearer shares totalling more than hfl 50.000 , or the public company had either bearer shares or bearer certificates totalling more than hfl 50.000 , or

- the public company had either bearer debentures outstanding or had bearer certificates of its issued registered debentures, or

- shares or debentures, or certificates of such securities of the public company were listed on the stock exchange, or

- it was wholly or partly the company"s business to draw money from third parties or to operate in the field of insurance (Maijoor, 1991 , p.100).
} 
The Act on Annual Financial Statements (Wet op de Jaarrekening van Ondernemingen, or WJO), approved on 10 September 1970 and implemented in May 1971, changed this situation. It contained legal requirements for the annual financial statements of firms. According to Sanders et al. (1975, p.9) this Act brought the Dutch regulatory system for financial reporting on comparable terms with the countries mentioned earlier.

At the same time, on an international level, the Council of the European Communities was pleading for harmonisation of the contents of annual accounts through European Directives. In 1965 they $^{31}$ expressed their wish that representatives of the accounting profession should work out proposals for harmonizing the legal accounting requirements in the Member States. But it was not until the late seventies and eighties that Dutch companies were influenced by these international harmonisation efforts, with the implementation of the Fourth and Seventh EC Directives.

Soon after the WJO had been introduced, the first draft of the Fourth Directive on companies' annual financial statements was published on November 1971. The Brussels exposure draft of the Fourth Directive differed from the WJO on a number of items. For example, the Fourth Directive introduced fixed formats regarding the balance sheet and profit and loss account. Also, it contained requirements as to publication. ${ }^{32}$ Its contents will be analysed in full in section 2.4 . After a second draft in 1974, the final version of the Directive was promulgated in 1978. Following a lengthy process of discussion and political debates in the second Chamber, starting in 1980 with the first draft amendment to the WJO, the Fourth Directive was incorporated in Dutch law in 1983, known as Title 8 (De Jaarrekening en het Jaanverslag), ${ }^{33}$ Book 2 of the Civil Code. And so, for the second time within a period of 13 years, there was another important shift in the legislation governing financial reporting.

\section{Dutch financial accounting practice prior to 1971}

The Commercial code of 1837 was the earliest Dutch law that contained sections that related to financial reporting. It obliged each merchant to draw up a daily journal, and set some specifications regarding a balance sheet (a draft inventory and balance

\footnotetext{
${ }^{31}$ In the literature and proposals referred to as the General Management of the Internal Market of the EEC (Elmendorff, 1967).

${ }^{32}$ Fourth Council Directive of July 251978 (Official Journal of the European Communities, $1978)$.

${ }^{33}$ In English: The Financial Statement and the Annual Report. For an extensive discussion of the adoption process, see Zeff et al. (1992), chapter 6 .
} 
sheet), but there was no obligation to publish this information (article 6 and 8). According to article 55 the directors of public companies were required to supply shareholders with a profit and loss statement (Buijink, 1992, p.94).

It was only after the work of the several commissions and Justice Ministers, and their reports and draft laws based on the 1837 Commercial Code, ${ }^{34}$ that the revised company law of 1928/1929 made the filing of annual balance sheets and profit and loss accounts with the Chambers of Commerce mandatory for some Dutch public companies. According to section 42, paragraph 3, "open" public companies had to specify the items on the asset side of the balance sheet, along with the valuation principles (in the explanatory notes):

The asset side comprises the following items: (a) short-term securities and cash, (b) investments in other companies, (c/d) securities listed/not listed on an exchange (not. qualified as an investment), (e) receivables, ( $\mathrm{f}$ ) inventories, ( $\mathrm{g}$ ) fixed assets, (h) intangible assets, (i) the value of revenues due in future years, (i) costs and losses to be carried forward in the following years, and ( $k$ ) the amount of share capital which has been issued, but not fully paid. ${ }^{35}$ Section $42 \mathrm{a}$ also mentioned the possibility of engaging an external auditor. ${ }^{36}$

In addition to these legal requirements, in 1909 the Amsterdam Stock Exchange (ASE) set requirements obliging new companies listing shares or bonds to provide a profit and loss statement, balance sheet, and directors' annual report to shareholders and/or public debtholders. However, until 1929, neither company law nor ASE rules set out any specific accounting measurement rules, and only a few disclosure rules. The financial reporting environment for Dutch companies did not change again between 1929 to 1971 , the year in which the WJO became operative.

In essence, financial reporting requirements for Dutch firms prior to 1971 were very small in number. That is, only a few disclosure rules existed and no measurement rules.

\footnotetext{
${ }^{34}$ Attempts to regulate public companies date back as far as 1871 , when the Jolles proposal, was rejected by parliament. A government commission, appointed in 1879 . prepared a draft law proposing companies' balance sheet disclosures on assets and liabilities sides. This was followed by the report of the Kist Commission (1890), a draft law prepared by Justice Minister Nelissen (1910), submission of a revised draft law (1925), enactment of the draft law by Parliament, and finally the revision of the recently enacted law by the Visser Commission as well as its acceptance of amendments regarding financial reporting. The final requirements of the Act which was adopted were far less extensive than the earlier proposal (Zeff et al., pp.3344).

${ }^{35}$ Handelingen der Staten Generaal. Bijlagen 283.1-8; "Wijzigingen van de artikelen $42 c$ (nieuw) en 42 (nieuw) wan het Wetbok van Koophandel (balans en winst- en verliesrekening)".
}

${ }^{36}$ Wetboek van Koophandel (1950, pp.28-29). 


\section{Prelude to the Act on Annual Financial Statements (WJO)}

The first major shift in Dutch accounting legislation occurred forty years after the company Act of 1929, with the implementation of the WJO in 1971. The contents of this Act will be discussed in section 2.3.

Calls for compulsory financial reporting regulation grew rapidly after 1950, and led to several reports and articles in the literature in which the supposed deficiencies in Dutch financial reporting are documented. The overall conclusion drawn from the political debates was that accounting practice was no longer adequate and that far more detailed financial accounting regulation was needed. One hot issue was the widespread use of secret and hidden reserves which enabled firms to smooth earnings and present the financial results, from the viewpoint of the management, in a more 'appropriate" light. ${ }^{37}$

Although most members of Dutch Parliament felt that financial reporting in the Netherlands was inadequate, there were also reactions that opposed to additional legal financial reporting requirements. According to these, additional financial reporting requirements were not required. For instance, Burgert (1965) has demonstrated that in the absence of such specific requirements there were major voluntary changes in firms' financial reporting policies. Companies disclosed far more information than what was required at the time and, although there was no obligation to audit the annual report, almost all public companies listed on the ASE had annual audits. Bouma (1972) has also criticized the underpinning of these parliamentary reports. The parliamentary debates and reports reveal that various economic and noneconomic arguments were used by policy makers, but none were based on empirical investigations.

As to what additional requirements for disclosure and accounting methods should be stipulated, several proposals were made before the preliminary draft of the "Companies Act on Annual Financial Statement" was tabled. Apart from a few amendments, the Act was based on the final report of the Verdam Committee. ${ }^{39}$ This appendix provides an extensive discussion of the parliamentary reports on existing disclosure practices and proposals for improvements, and reactions from proponents and adversaries to them.

\footnotetext{
${ }^{37}$ Which is consistent with the assumption put forward in Chapter one that government intervention was motivated by opportunistic behaviour on the part of firm's management.

${ }^{38}$ The most important changes relate to modifications to articles $5,13,14$, and 15 (see Zeff et al., 1992, pp. 171-172).
} 
III Changes in financial reporting requirements as a consequence of the implementation of the WJO

The regulation prior to 1971 was applicable only to a particular group of companies, the "open" public companies (open Naamloze Vennootschappen; open NVs). But the WJO covered not only NVs, but also private companies (Besloten Vennootschappen: BVs), ${ }^{39}$ mutual insurance companies, and co-operative societies which met any of the following criteria:

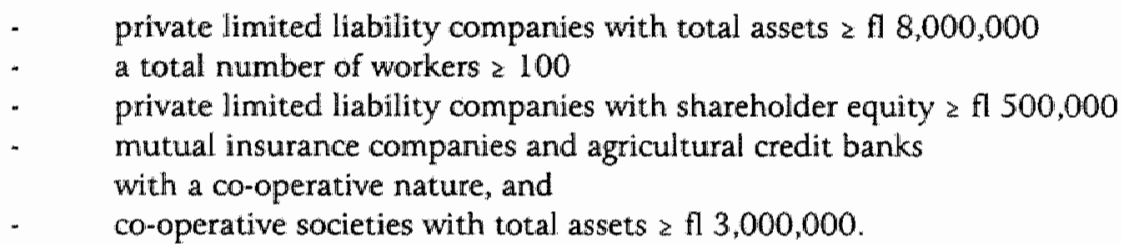

Public companies (NVs) and large co-operative societies were the first to be required to disclose and audit their financial statements, for the year 1971. For private companies (BVs) the first year of compliance was 1973. Maijoor (1991, p. 105) reports that $692 \mathrm{NVs}$ disclosed financial statements in 1971, and 2,539 in 1974. In 1974,674 BVs and 881 large cooperative societies disclosed financial statements (no data on 1971). ${ }^{40}$ The total number of financial statements disclosed by NVs, BVs and Co-operative societies was 1,573 in 1971 and 4,094 in $1974 .{ }^{41}$

The effects on banks, insurance companies and other financial institutions are not considered here because these companies have to meet specific financial reporting requirements, laid down in sections 14 and 15 of the former Title 6 , Title 8 and the

\footnotetext{
${ }^{39}$ The private company (BV) is a form established in 1971, (Wet op Besloten Vennootschappen, Staatsblad 286). In the Dutch context a private company refers to a private limited liability company whose shares cannot be freely transferred (Bollen, 1995, p. 11). All $\mathrm{BV}$ s were exempted from publication of the financial statements, except for those exceeding the threshold criteria.
}

${ }^{40}$ Bollen (1995, p.68) reported a much higher disclosure number for $\mathrm{BV}$, although this refers to the total number of disclosures on the (book)year 1974, whereas the number in Maijoor's study reports on the number of financial statements published in that year 1974. Another possible explanation for the differences between these number is the use of different databases: Bollen used the Chamber of Commerce database, which was not available at the time of Maijoor's study. Nevertheless, the data should be treated carefully.

"According to Maijoor (1991, p.101) the number of mutual insurance companies and agricultural credit banks is relatively small: approximately 100 financial reports were disclosed each year. 
presently effective Title 9 , Book 2 of the Civil Code. ${ }^{42}$ A discussion of the selection criteria applied in the empirical part of this dissertation is provided in chapter two.

The remainder of this section focuses on the contents of the main sections of the WJO which are relevant to listed NVs, excluding financial institutions. The most prominent changes resulting from the Act will be presented in a summary table.

\section{Contents of the WIO}

This section focuses on the contents of those sections of the Act on Annual Financial Statements of Enterprises (WJO) of May 7, 1970, which are relevant to listed NVs, excluding financial institutions. Since this study investigates the effects of legislation on managements' discretion regarding the choice between alternative financial accounting procedures, the analysis will focus on (I) the specific measurement rules regarding the valuation of assets and liabilities and (2) on disclosure rules relating to the detail and form of specific items in the balance sheet and profit and loss account. $^{43}$

The WJO contains five different sections:

(I) The first section deals with general principles relating to the composition and purpose of the financial report. Article 5 is perhaps the most profound of all; it introduces the so-called open formula, meaning that the principles underlying the valuation of assets and liabilities and the determination of results should be in accord with standards that are regarded as being acceptable in the economic and social climate (maatschappelijk verker);

(II) Section II stipulates provisions relating to the various asset and liability items of the balance sheet;

(III) The third part of the Act contains further provisions and disclosure regulations for the profit and loss account and explanatory notes;

(IV) The fourth section deals with the administration of justice concerning annual financial statements. All legal actions are within the jurisdiction of the Enterprise Chamber (see section 2.3.3);

(V) The last section contains provisions for different types of enterprises. Most insurance companies and banks have to meet requirements which differ from

\footnotetext{
${ }^{4}$ For instance, one of the sections prescribes specific formats of the balance sheet and profit and loss account.

${ }^{4}$ Whenever specific choices within the legal framework are ruled out or made mandatory by legally-prescribed financial reporting rules, this implies that the alternative set of available accounting procedures has been limited. Mandatory disclosure rules, on the other hand, do not influence the total set of financial accounting choices available.
} 
those applying to other companies, and are laid down in other Acts. ${ }^{44}$

\section{General Provisions ${ }^{43}$}

The first part of the Act lays down some general principles. Firms were required to include a balance sheet, a profit and loss account, and explanatory notes in their financial report.

Section 2 of the general provisions deal with the purpose of the financial report: it should allow a sound judgement to be made regarding the financial position and results of the company and, to the extent to which annual accounts permit, of its solvency and liquidity. Article 5 , in the first section, is undoubtedly the most characteristic part of the 1970 act: the principles underlying the valuation of assets and liabilities and the determination of results should be in accord with standards that are regarded as being acceptable in economic and social climate (the so called open formula). ${ }^{46}$

\section{Provisions relating to the Balance sheet}

The sections concerning provisions for the balance sheet (and profit and loss account) will be discussed in systematical order of appearance.

\section{Valuation principles}

No recommendations were made with respect to the use of the current cost accounting valuation principle, as was earlier proposed by the Rijkens and Hamburger committees. Assets and liabilities had to be valued according to norms acceptable in

\footnotetext{
${ }^{44}$ The financial reporting requirements for insurance companies are laid down in the Insurance Acts. They are supervised by the Insurance Chamber (Verzekeringskawer). Financial reporting regullations for banks are defined in the Bank Act.

${ }^{43}$ The discussion of the contents of the Articles in the Act is based on the English unofficial translation of NIVRA paper no. 6, "Act on Annual Accounts of Enterprises" (NIVRA, 1972).

${ }^{46}$ It is expected that ".companies and the organisations of accountants will consider it their duty to make an inventory of the standards used in economic and social life and to test these standards against what, in their opinion, may be deemed to be acceptable in the present social system. The publications about acceptable bases resulting from these activities will fill a real need experienced by the boards of enterprises and may also serve as a guide for the Enterprise Chamber of the Court of Justice of Amsterdam when a suit about this is submitted to its judgement" (NIVRA 1972, p.55).
} 
economic and social climate. ${ }^{47}$ So, both historical cost and current cost valuation were accepted.

\section{Fixed Assets}

In so far as intangible assets are included in the balance sheet they are valued at an amount not exceeding the amount actually expended by the enterprise, less accumulated amortization. As pointed out on page 20 , the words 'not exceeding' set a special rule for maximum valuation. ${ }^{48}$

Section 10 requires separation of the tangible fixed assets into: (a) the business plant and the premises, (b) machinery and fittings, (c) other durable business equipment, and (d) fixed assets not used for the business activities.

A sub-section of section 5 requires that the explanatory notes give an exposition of the valuation principles, that is, they must explain what bases have been chosen and what system of depreciation is being applied. If an alteration of the basis is of essential significance, such an alteration should be explicitly noted, showing its effects on the net result and equity. Compared to the existing legal requirements companies were no longer able to alter their valuation basis and/or depreciation system without explicitly mentioning the effects of the change on results and equity.

Concerning financial fixed assets information has to be provided regarding the value of the participation and possible changes therein during the year. The information about the change in the value has to be mentioned separately, along with the total amount receivable from the subsidiaries. Nor with respect to the valuation of financial fixed assets did the law require specific methods of accounting (section 12). As already mentioned, the only exception to this is the maximum valuation rule for intangibles. Financial information should be supplied in the annual financial statement concerning all majority holdings (section 13), by providing either an additional consolidated statement or individual accounts. ${ }^{49}$ The requirements of the Act are fully applicable to these holdings. Also, the disclosure of the names of companies in which a majority share is held, foreign subsidiaries and participation in partnerships and similar holdings should be provided (section 14). The parent company is free to choose separate, combined or consolidated financial statements.

${ }^{47}$ The minister and the Committee believed that the text of section 5, which stated that "...the principles used in valuing the assets and liabilities shall satisfy norms that are considered to acceptable in economic and social climate...", would ensure a valuation that was neither too low nor too optimistic (Zeff et al, 1992, p.153).

"The following classes of intangible assets are distinguished: (a) goodwill, (b) patents, (c) licences, (d) copyrights, (e) concessions and exploitation rights, and (f) initial and startingup expenses.

The same disclosure is made in respect of other firms in which is participated, if the value of the participation is at least $15 \%$ of the assets of the participating firm. 


\section{Current assets}

If the company has inventory/stocks of various kinds, then such categories have to be stated separately (section 16 ). Section 17 requires a subdivision of receivables/debtors. ${ }^{50}$ The amount of negotiated bills (wissels) in respect of which the firm is still at risk has to be stated (section 18).

The following items have to be categorized: (a) cash, bank, and giro balances, (b) the total value of securities listed on (Dutch or foreign) stock exchanges, and (c) all other securities. Also have to be disclosed information regarding the amount/extent to which balances or securities are not recoverable at call or at free disposal.

\section{Equity (Capital and reserves)}

Shareholders equity must be divided into issued share capital and reserves (section 20). Other stipulations require declarations of (a) the categories of shares, (b) amounts not fully paid up, (c) the value of repurchased but uncancelled shares at the amount at which such shares are included in the balance sheet, and (d) the names of the holders of shares or of other rights entitling such owners to speciall powers, other than those relating to the profit appropriation or to the balance upon winding up, as well as the number of shares or rights of this kind held by each of them.

\section{Secret reserves}

Section 6 requires reserves and reserve movements to be separately stated and explained in the annual accounts, in order to ensure a fair picture of the composition of the enterprise's financial position and result. The Act effectively rules out so called hidden and secret reserves, by preventing "unacceptable" valuation (section 5), since they influence the picture given by the annual accounts. ${ }^{51}$

\section{Provisions for liabilities and charges}

Section 23 states that provisions can be dealt with in the balance sheet in various ways. First, they may be deducted from the items to which they relate, on the assets side. This may be effected either by explicitly inserting a debit or by including it in the valuation of the asset, within the limits set by section 5 . Another method of dealing with provisions is by showing specific items on the liabilities side.

\section{Long-term liabilities}

${ }^{50}$ The following items are to be treated separately:

(a) cash, and bank balances, (b) the aggregate value of securities listed on a Dutch or foreign Stock Exchange, and (c) the aggregate value of other securities, in so far as such holdings do not. lead to participation.

${ }^{51}$ In the Verdam Committee draft law, section 20 explicitly refers to the distinction that has to be made between provisions on the one hand, relating to specific risks, and reserves on the other hand, as a part of shareholders equity. Therefore, provisions have to be separated. (Revision of the company law, 1965, p.57). 
Long-term liabilities are divided, in section 22, into (a) debenture loans and debentures issued by mortgage banks, (b) amounts due to creditors in whose capital the enterprise participates, (c) amounts due to creditors participating in the capital of the enterprise, (d) liabilities re pensions, and (e) other debts with a term of more than one year.

\section{Short-term liabilities}

Current accounts payable are to be divided into the amounts due to banks, the amounts due to suppliers and the trading credits received, and the amounts payable in respect of pensions and taxes.

\section{Provisions concerning the profit and loss account, and notes}

The third part of the Act gives disclosure regulations for the profit and loss account and the explanatory notes. Information must be provided on the size of the company's business during the financial year, compared also to the preceding financial year. Section 28 of the Act requires sales information, in either absolute or proportional numbers relating to the previous year, although the term sales or revenues is not explicitly mentioned. Instead, a general formulation of "the extent of affairs" of the firm during the financial year has to be shown by the usual measures of industry (section 28).

One important item of cost to be disclosed is the depreciation of fixed assets. Additionally, wage expenses and social security expense are also to be presented separately in the profit and loss statement or in the notes thereto. ${ }^{52}$

In addition to depreciation, the operating result, other gains and losses, the profit or loss before tax, and the estimated amount of taxes relating to the profit have to be shown. The figures are further specified by the usual measures of industry (section 29).

The following income items and charges must be stated separately (a) profits or losses on participations, (b) profits or losses on investments, (c) interests gains or losses, (d) extraordinary gains and losses. The profit and loss account or the explanatory notes should also declare the honorariums of the supervisory board (commissarissen).

\section{Appointment of an auditor}

Regarding the performance of an audit on the published financial statements, section 39 contains a subsection which states the obligation to have it audited by an auditor. This audit report must be published together with the financial statements.

\footnotetext{
${ }^{52}$ Only a few companies disclosed their total cost of sales in the early sixties (Zeff et. al, 1992, p. 155$)$.
} 


\section{Other Provisions}

\section{Establishment of the Enterprise Chamber}

Another important effect of the WJO was the establishment of the Enterprise Chamber (Ondememingskamer) in 1971. This is an accounting court (i.e., a special section of the Court of Justice of Amsterdam) which settles disputes between companies and the parties interested in their financial statements (Klaassen 1980, p.327). The Act contains rules concerning the Enterprise Chamber (sections 337 to 341). According to these, any person or institution with a direct interest in the financial statements of a firm which falls under the WJO regulations can bring its claims or charges of failure before this court. ${ }^{53}$ As pointed out by Klassen (1980, p.329) this Court is intended to improve financial reporting. ${ }^{54}$ For the purpose of this dissertation however, the rulings of this court are not relevant, since they did not lead to any change in the mandatory financial reporting requirements.

The relevant changes following from the implementation of Act on Financial Statements have been brought together in tables 2.1 and 2.2. The tables highlight the specific features of the change in the regulatory regime in 1970 by comparing the former Article 42(c) with the WJO.

\footnotetext{
${ }^{53}$ Interested parties include shareholders, employees, suppliers and creditors.

54The first decision on a court case, the Douwe Egberts arrest in 1977, came six years after the Act on Annual Financial Statements had become effective (Klaassen 1980, p.331). A total of 59 cases had been brought before the court by 1991 , of which 20 were filed in the first ten years and 39 in the next ten years (Nagtegaal, 1991).
} 
Table 2.1: Regulatory changes relating to the balance sheet and notes

\begin{tabular}{|c|c|c|}
\hline meM & 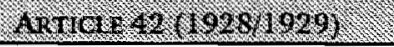 & Wor 1070 \\
\hline general provisions & $\begin{array}{l}\text { relate to ballance sheet and profit } \\
\text { and loss account }\end{array}$ & $\begin{array}{l}\text { relate to balance sheet and profit and } \\
\text { loss account }\end{array}$ \\
\hline application area & $\begin{array}{c}\text { (1) "open" public companies } \\
- \\
- \\
- \\
-\end{array}$ & $\begin{array}{l}\text { (1) all public companies } \\
\text { (2) categories of private } \\
\text { companies }^{53} \\
\text { (3) co-operative societies } \\
\text { (4) mutual insurance companies } \\
\text { (5) agricultural credit banks }\end{array}$ \\
\hline main valuation criteria & - & open formula \\
\hline basic concept & - & $\begin{array}{l}\text { (1) to provide insight } \\
\text { (2) principles that should be } \\
\text { acceptable in economic } \\
\text { and social climate }\end{array}$ \\
\hline intangible fixed assets & $\begin{array}{l}\text { disclosure of one single } \\
\text { amount }\end{array}$ & $\begin{array}{l}\text { separation of items }(\mathrm{d}) \\
\text { maximum valuation rule }(\mathrm{m})\end{array}$ \\
\hline tangible fixed assets & $\begin{array}{l}\text { disclosure of one single } \\
\text { amount; valuation principle } \\
- \\
-\end{array}$ & $\begin{array}{l}\text { separation of items (d) } \\
\text { valuation principle (d) } \\
\text { system of depreciation (d) } \\
\text { changes in valuation principle (d) }\end{array}$ \\
\hline financial fixed assets & $\begin{array}{l}\text { disclosure of investments } \\
\text { securities listed/not listed }\end{array}$ & $\begin{array}{l}\text { separation of items (d): } \\
\text { disclosure of major. holdings (d); } \\
\text { names of majority holdings, } \\
\text { foreign subsidiaries and } \\
\text { partnerships (d); } \\
\text { consolidated financial statements } \\
\text { or individual accounts (d) }\end{array}$ \\
\hline current assets & $\begin{array}{l}\text { disclosure of short-term } \\
\text { securities, cash, receivables, } \\
\text { and inventory; } \\
\text { costs and losses carried } \\
\text { forward to the next year }\end{array}$ & $\begin{array}{l}\text { separation of items (d) } \\
\text { separation of inventories (d) } \\
\text { separation of receivables (d) } \\
\text { negotiated bills (d) } \\
\text { securities unrecoverabie at call (d) }\end{array}$ \\
\hline
\end{tabular}

(d) disclosure rule

(m) measurement rulle

${ }^{55}$ See paragraph 2.3 .1 


\begin{tabular}{|c|c|c|}
\hline 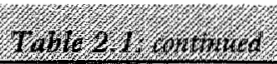 & 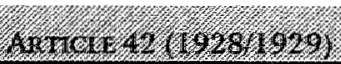 & 1010.747 \\
\hline $\begin{array}{l}\text { equity (capital and } \\
\text { reserves) }\end{array}$ & $\begin{array}{l}- \\
-\end{array}$ & $\begin{array}{l}\text { separation of issued share capital } \\
\text { (d) } \\
\text { separation of reserves (d) } \\
\text { veto on secret reserves (m) }\end{array}$ \\
\hline provisions & - & disclosure methods prescribed (d) \\
\hline long-term liabilities & - & $\begin{array}{l}\text { separation of items }(\mathrm{d}) \\
\text { disclosure of interest rate on } \\
\text { debt }>\mathbb{1} \text { year (d) }\end{array}$ \\
\hline short-term liabilities & - & separation of items (d) \\
\hline consolidation & - & $\begin{array}{l}\text { information required on majority } \\
\text { holdings in consolidated or } \\
\text { individual account(s) (d) }\end{array}$ \\
\hline
\end{tabular}

Table 2.2: Regulatory changes relating to the profit and loss account and notes

\begin{tabular}{|c|c|c|}
\hline (156) & (1) & Wro $(1970)$ \\
\hline $\begin{array}{l}\text { net turnover/salles } \\
\text { information }\end{array}$ & - & $\begin{array}{l}\text { absolute/or proportional } \\
\text { numbers(d) }\end{array}$ \\
\hline information on & - & separation of: (d) \\
\hline income & - & operating result \\
\hline & - & other gains and losses before tax \\
\hline & - & profit before tax \\
\hline & - & tax provision \\
\hline & - & profits or losses on participations \\
\hline & - & profits or losses on investments \\
\hline & - & interest gains or losses \\
\hline & - & extraordinary gains and losses \\
\hline charges/costs & . & $\begin{array}{l}\text { depreciation of fixed assets (d) } \\
\text { wages and salaries (d) } \\
\text { remuneration of supervisory } \\
\text { board (d) }\end{array}$ \\
\hline audit & - & abligatory audit of annual accounts \\
\hline
\end{tabular}

(d) disclosure rule

(m) measurement rule 


\section{Appendix $2 B .2$}

\section{Changes in financial reporting requirements as a consequence of the implementation of the Fourth European Economic Community Directive (Title 8) and an analysis of its contents}

This appendix provides an analysis of the contents of Title 8 , beginning with a brief historical outline of the circumstances prior to the enactment of the Act. Then the additional provisions laid down in Title 8 with respect to disclosure and measurement rules will be described. A tabular summary of the changes is provided at the end of this appendix.

History leading up to Title 8: adjustments to Dutch financial accounting law

After the enactment of the WJO, the Tripartiete Overleg (TO, the "three-party consultation') was established at the initiative of the Minister of Justice to stimulate cooperation between employers' and employees' representatives and auditors (through their professional body, NIVRA) in the field of financial accounting (Zeff $e t$ al. 1992, p.282). ${ }^{56}$ One of the parties playing an active role regarding accounting regulation issues was the NIVRA's newly established CAJ committee (Commissie van Advies inzake Jaarverslaggeving, the Financial Reporting Advisory Committee). It prepared drafts for consideration by the TO. ${ }^{57}$ In 1971 the TO issued its first exposure draft, called the "Provisional Draft of Considered Views as a Consequence of the Act on Annual Financial Statements" (Zeff et al., 1992, p.202). Between 1971 and 1979 a total number of 7 such drafts and three final statements of considered views (which were

\footnotetext{
${ }^{50}$ A Tripartite Study Group served as a study group to discuss issues in financial accounting, and to issue "Considered views", later known as "Nletherlands Accounting Guidelines", dealing. with the valuation of assets and liabilities and the determination of income in financial statements. It consisted of delegates from the employers' associations, auditors, and representatives of the employee federations. However the Group's exposure drafts were not binding, unlike American and British "standards".

${ }^{57}$ For a detailed discussion of the work of these bodies and institutions and their impact on financial reporting see Zeff et al. (1992, chapter 5).
} 
called 'guidelines' after 1980) were issued. ${ }^{58}$ After several years of restructuring, the three parties agreed to replace the TO with the Raad poor de Jaanverslaggeving (RJ, Financial Reporting Council) in order to create a more formal structured entity. Several of the NIVRA's annual studies have shown that there was "not much evidence of compliance" with the drafts, considered views and guidelines produced by these bodies. $^{59}$

Due to a recodification of the Dutch Civil Law, the WJO was replaced with Title 6, Book 2 of the new Dutch Civil Code on 26 July 1976. Apart from a few technical adjustments, such as the term enterprise being replaced by legal entity, the contents of Title 6 were identical to the former WJO (Burgert and Timmermans, 1989, p.23). There was one important additional requirement in the new Title 6 which required a segmentation of the operating income, the so called Wierenga-amendment (Article 335 , section 2). The WJO did not contain such a provision. ${ }^{60}$ For the purposes of this dissertation, other adjustments are not relevant.

Less than a year after the establishment of the WJO, the first draft of the Fourth EC Directive was published. The first draft could be characterized as detailed and exact, and based primarily on the German Aktiengesetz (Burgert, 1972, p.35; Krens, 1972, p.17; Zeff et al. 1992, p.294). The German (academic) accounting profession played a prominent role in the European harmonisation process that eventually led to the implementation of the Fourth EC Directive within the different member countries of the European community. ${ }^{61}$ In the second draft, published in 1974, there was a shift towards a more liberal British true and fair view. Between the first and second draft the United Kingdom, Ireland and Denmark had been admitted to the EC. As

${ }^{58} \mathrm{~A}$ book called Richtlijnen voor de Jaarrekening was published in 1981 , containing discussions on drafts of rewritten considered views (Raad voor de laarverslaggeving, 1981).

\footnotetext{
${ }^{59}$ Onderzock Jaarverslagen 1977, 1979, and 1981. NIVRA Geschriften Nummer 21, 22, and 29 (Amsterdam).
}

${ }^{60} \mathrm{~A}$ distinction should be made between the segmentation of operating income and a segmentation of sales. The Wierenga amendment referred to the segmentation of operating income, while the Fourth European Community Directive only required segmentation of sales. After the implementation of Title 8 the segmented operating income information was not longer required after the introduction of Title 8.

\footnotetext{
${ }^{61}$ See for instance several publications of Elmendorff $(1967,1971)$ and the Elmendorff committee (Commissie Elmendorff) on proposals for European harmonisation (1968), Kaminski (1970), Goerdeler (1973), and Busse von Colbe (1974). Also, we would like to refer to a congress proceeding called "Einzelabschluß und KonzernabschluB, Beiträge zum neuen Bilanzrecht" (Mellwig, et al., 1988). It contains several important contributions of German accounting researchers discussing the consequences of the implementation of European EECDirectives, including the fourth Directive, into the German 'Bilanzrecht'.
} 
a consequence, the draft was more in line with the contents of Title 6 . With the approval of the definitive version of the Fourth Directive in 1978, the Dutch government began the process of adopting the law (Title 6) ${ }^{62} \mathrm{~A}$ draft law was submitted to parliament on September 8 1980. After debates in the Second and First Chamber, it was given final approval on December 7 1983, as Title 8 , Book 2 of the Civil Code (Burgert and Timmermans, 1989, p.29).

II

\title{
Harmonization of accounting regulations in the European Community
}

The major impetus of European policy-makers was to establish more uniform financial reporting within the European countries for reasons of efficiency. Financial information must be reliable and comparable. Or as a member of the Institute of Chartered Accountants in England and Wales said in concluding his plea for harmonization:

.... standards and procedures in the different countries are uneven. As a result of the discrepancies in accounting standards and procedures in Europe, the need for increased uniformity within the member countries of the European Conmunity becomes more apparent. (Benson, 1972, p.758).

In the Official Journal of the European Communities, the Council states:

\begin{abstract}
... Whereas the coordination of national provisions concersing the presentation and contents of annual accounts and annual reports, the valuation methods used therein and their publication in respect of certain companies with limited liability is of special iniportance for the protection of members [of these companies] and third parties. (Journal of the European Communities, 1978$, p. 11$)^{63}$
\end{abstract}

The contents of the Fourth EEC Directive can be summarized as follows. Primarily, simultaneous coordination was necessary for companies, because, on the one hand, their activities extend across national territories and, on the other hand, they can offer no safeguards to third parties beyond the amounts of their net assets. The necessity for and the urgency of such coordination had been recognized and confirmed earlier (Journal of the European Communities, 1978, p.11). The Council thought it was essential to establish minimum equivalent legal requirements regarding the extent of the financial information that should be made available to the public by companies. Therefore, the financial statement should give $a$ true and fair view of a company"s assets and liabilities, financial position and profit or loss. In this respect,

${ }^{62}$ For a more extensive survey of the historical developments in accounting practice and the Dutch regulatory process, see Burgert and Timmermans (1989) and Zeff et al. (1992).

${ }^{63}$ Council of the European Communities 1978. Fourth Council Directive of July 251978 , treaty on the annual accounts of certain types of companies. Official Joumal of the European Communities (July): pp.11-31. 
a mandatory layout (prescribed scheme) was given for the balance sheet and the profit and loss account along with the notes to the accounts and the annual report.. Different methods for the valuation of assets and liabilities must be coordinated to ensure that annual accounts give comparable and equivalent information. Financial statements have to be audited by authorized persons, and only small companies may be relieved of this audit obligation. A company belonging to a group should present a true and fair wiew of the activities of the group as a whole.

As in the case of the WJO, dishonest management practices or malpractice was one of the arguments used in the Dutch parliamentary debates by those in favour of financial accounting regulation. ${ }^{64}$ Maijoor (1991, pp.30-32) summarized these arguments.

The financial reporting requirements prescribed by the Fourth EC Directive apply to the laws, regulations and administrative provisions of the Netherlands relating to a public limited liability company (NV), private limited liability company (BV), limited partnership (CV), cooperative society (Coop), and mutual guarantee association (OWM). ${ }^{65}$

\section{III}

\section{Contents of Title $8^{66}$}

The adaption of Title 6 to create Title 8 incorporated a number of significant changes. These changes will be summarized in the remainder of this section. As in the case of the WJO, the analysis focuses only on legal regulatory changes concerning non-financial NVs. ${ }^{67}$ The empirical tests of the effects of Title 8 presented in chapters three and four are based on data taken from these companies.

The Act is applicable to annual accounts, managerial directors' reports and supplementary information for financial years from 1 January 1984. For companies

\footnotetext{
${ }^{64} \mathrm{Again}$, this indicates that government perception of managements behaviour is consistent with the opportunist behaviour perspective.

${ }^{65}$ For additional information about the number of Dutch firms subjected to the regulations see Maijoor (1991, p.173). Maijoor estimates that $4204 \mathrm{NVs}, \mathrm{BVs}$ and co-operative societies in the Netherlands disclosed annual accounts in 1980. This figure decreased to 3575 in 1984. However, the number of annual accounts disclosed one year later increased to 13,293, and to 69,892 in 1987.

${ }^{66}$ The discussion of the contents of the articles in Title 8 is based on the report: New Dutch legislation on ammual reports; Act to adapt Dutch legislation to the Fourth EEC Directive regarding the anual accounts and the managing director's report, published by Moret \& Limperg in 1984.

${ }^{67}$ Banks and other financial institutions are subjected to their own financial reporting requirements (see paragraph 2.3.1).
} 
whose financial year coincides with the calender year, this means that the new regulations became effective for the first time in 1984. The requirements regarding drawing up and submitting annual accounts, a managing director's report and supplementary information were included in Title 8 of book 2 of the Civil Code, which then replaced the former Title $6 .^{68}$ Title 8 is broken down into 12 chapters. The sections of the new Title 8 and changes with respect to the former Title 6 have been analysed and the relevant changes are presented in tables 2.4 and 2.5 . The first. table contains provisions relating to the balance sheet, while the second comprises information on provisions relating to the profit and loss accounts as well as the notes.

\section{General Provisions}

Identical to the WJO the first part contains some general provisions (former Title 6 , chapter one). As stated before, the law is applicable to the NV, BV, CV, Coop, and OWM. The basic concept underlying the Fourth Directive is that the annual account, comprising the balance sheet, the profit and loss account and the notes, should give a true and fair view of the companies' assets, liabilities, financial position and profit or loss. The true and fair view now is applicable to the entire annual report, whereas in the WJO it related only to the valuation of assets and liabilities as well as the determination of the results. The size of the company can justify that not all the requirements of the Act need be met. Modifications, which entail simplification of the requirements as to layout as well as simplifications of or exemptions from the requirements as to filing, have been introduced for small and medium corporate bodies.

The general provisions of the Act gather stipulations consisting of three parts, namely managerial directors report, annual accounts and supplementing information. Section 2 of this part deals with the purpose of the financial report: "The annual account shall be in accordance with generally accepted principles and shall furnish such information as to enable a responsible opinion to be formed regarding the financial position and the profit or loss and, to the extent that the nature of annual accounts permits, regarding the solvency and liquidity of the corporate body" (section 362 (1)). The financial position and the profit and loss is to be presented in a fair, consistent and clear manner (section 362 (2) and (3)). Should the objects of annual accounts so require, it is the companies' duty to include additional information to that legally prescribed. Furthermore, if necessary for the information which annual accounts should provide, a company is further obliged to depart from the special requirements laid down in the Act. The reasons have to be stated as well as the impact on the financial position as well as the profit or loss.

\footnotetext{
${ }^{6}$ Since the new law contained more (sub) sections there was not enough room in the former Title 6 of Book 2 of the Civil Code. So the new Title 8 is positioned at the end of Book 2 of the Civill Code (Burgert and Timmermans, 1989, p.30).
} 
In the selection of policies for the valuation of assets and liabilities and for the determination of the profit or loss, companies shall follow the requirements as regards the object and nature of the annual accounts, as laid down in article 362 (1-4) (art. 384 (1) first sentence). The companies have to take account of a number of fundamental accounting policies which are stipulated in the Act: going concern (section 384 (3)), consistency (section 384 (6)), accrual (section 384 (5)), prudence (section $384(2)$ ), recognition (section 384 (2)), individual valuation (section 385 ), amortization, depreciation and diminution in value independent of the profit or loss (sections 386-387).

\section{Layout requirements and formats}

By Royal Administration Decree of December 23, 1983, dealing with the layout of accounts (Annual Accounts Format Decree), formats and further provisions have been enacted. The decree does not apply to insurance companies and credit institutions. The layout of annual accounts has to be consistent from year to year. The previous year's layout may not be departed from but for well-founded reasons. Departures have to be disclosed in the notes together with an explanation of the reasons for doing so. The material requirements with which the layout of annual accounts must comply, are laid down in parts 3 (balance sheet and notes), 4 (profit and loss and notes), and 5 (special requirements relating to the notes) of the law. At the same time, balance sheet and profit and loss account formats have been established for NVs and BVs. The two balance sheet formats incorporated in the Fourth Directive have been taken over by that decree. ${ }^{69}$ Apart from the main classification, laid down in section 364 , the act prescribes formats for the asset and liabilities side of the balance sheet (sections 365-372 relate to the asset side and sections 373-376 relate to liabilities side). Also new is the obligation to break down capital and reserves (section 373) into: (1) paid up and share capital, (2) share premium account, (3) revaluation reserve, (4) other statutory reserves, (5) reserves provided for in the articles of association, (6) other reserves, and (7) undistributed profits.

Provisions for liabilities and charges must in any case mention separately the provisions for pension liabilities and the provisions for deferred taxes (section 374).

\section{Valuation}

In the former title 6 no specific regulations were required with respect to valuation of assets and the determination of profit and loss. The new Act mentions the possibility of historical cost accounting or, for fixed assets and fixed assets investments and stocks, current cost accounting. The Act leaves open the question as to which accounting system to use for valuation. Final selection of historical or

\footnotetext{
${ }^{69}$ The two balance sheet formats are: a vertical balance sheet format (format A) and a horizontal balance sheet format (format B) (art. 364 (1)). Small and medium NVs and BVs are entitled to use abridged balance sheet and profit and loss accounts formats (articles 396 398).
} 
current cost policy is determined by the requirements conceming the object (providing information) and nature (fair, consistent and clear) of annual accounts.

\section{Accounting method changes}

Important in relation to the concept of consistency is the contents of section $362(6)$. It requires that accounting policies may differ from those applied in the previous financial year only for well-founded reasons. The reasons shall in that case be set out, while at the same time information is furnished concerning the significance for the financial position and the profit and loss in the light of adjusted figures for the financial year or preceding financial year.

\section{Provisions relating to the balance sheet}

\section{Fixed Assets}

Decisive for the distinction between fixed and current assets is whether or not the assets are intended for use on a continuing basis in the company's activities.

Fixed assets have to be divided into three categories, intangible and tangible fixed assets, and financial fixed assets. Intangible fixed assets have to be classified into: (a) share issues and expenses, (b) research and development, (c) concessions and licenses, (d) property rights, (e) goodwill, (f) payments of accounts. Expenses under (a) and (b) have to be explained. Concerning the treatment of goodwill there are three alternative procedures prescribed. Capitalization of intangible assets is allowed. With the exception of share issue expenses and those of research and development, capitalising is allowed only if the intangible assets are purchased. Therefore the legislation requires that these assets may be included only at most at acquisition cost, reduced by amortization (section 385 (4)). The amortization expense shall be determined in such a way that the share issue and research and development expenses referred to, have to be amortised over a period of at most five years. For the portion not yet amortised of these expenses, a statutory reserve has to be created in capital reserves (Burgert and Timmermans, 1985, p.401).

With respect to tangible fixed assets, an item not mentioned earlier "in the course of construction and payments on account", must be published in the balance sheet.

Section 367 mentions another new element, financial fixed assets, which has to be categorized into: (a) shares (or depositary receipts) and other participations in group companies, (b) other participating interests (related companies), (c) amounts owed by group companies, (d) amounts owed by related companies, (e) other investments, (f) other loans. Of all these items, the movements between opening and closing balances must be published.

For the first time rules were described for the valuation of investments, including the use of the net equity value method. Furthermore, it has been stipulated that if tangible fixed assets and financial fixed assets are valued at current cost, the amount of revaluation included thereof shall be disclosed separately in the notes (section 368 
(2)). The explanation of accounting policies with respect to valuation of assets (and liabilities) and determination of profit and loss shall be given for each item separately. A combined explanation is only allowed for items valued on the same basis.

Although a more detailed description of the consolidated financial statements has not been incorporated in Dutch law until the Seventh EEC Directive (1988), there were alterations in the new Title 8 . The Act lays down that the financial data, together or separate with those of the corporate body and other group companies, must be included in a consolidated financial statement, drawn up according to the consolidation method of accounting (section 379 and 404). This means that consolidation is compulsory, but, one is free to leave the parent company outside the group annual account or to include more than one set of group annual accounts. Names and domiciles of companies incorporated in consolidated financial statements have to be disclosed. Financial data of subsidiaries not being group companies have to be included under supplementary information. The layout requirements according to Title 8 also apply to corporate bodies belonging to a group (sections $362,379,402$ 404).

\section{Current assets}

The subdivision of current assets is to a large extent identical to the provisions that were laid down in the WJO. However, there are some additional information requirements, concerning payments on accounts (inventory, section 369), amounts owed by group companies, called up share capital not paid, and other debtors, in sofar as not belonging to investments included under current assets and to cash, bank, and giro (debtors, 370 ). Also, other items included under debtors with a remaining term in excess of one year have to be disclosed separately. Loans to holders of shares and to members need to be shown separately (in the notes to the item debtors).

Investments not included under financial fixed assets can include (a) shares of depositary receipts and other participations in group companies, and (b) other investments. The total of investments have to be stated.

\section{Equity (Capital and reserves)}

The existing requirements for the categorization of shareholders' equity have been further detailed (section 373). The separate amounts of paid up and called share capital have to be disclosed. If the company holds shares or depositary receipts of its own they may not be capitalized (section 385).

\section{Statutory/legal reserves}

The Act makes new provisions for several statutory/legal reserves: (a) statutory/legal reserve for intangible fixed assets, concerning unamortized share issue expenses and research and development, (b) statutory/legal reserve for participating interests, regarding the excess value from post-acquisition profit retentions or from profits retained after 
valuation for the first time, when valued according to the equity method of accounting, and (c) revaluation reserves (section 389 ). Statutory reserves may not be distributed to shareholders nor may they be released to reserves for as long as the reason for these reserves still exists. Furthermore, the Act stipulates that statutory reserves may be formed as a charge to the profit and loss account, or as a charge to free reserves, as long as they do not arise from an upward value adjustment of asset accounts.

Concerning current cost accounting, a company is allowed to value tangible fixed assets, financial fixed assets and stocks on the basis of current cost accounting. Increases in current cost have to be credited to a revaluation reserve (section 390 (1)). Reductions in value of the asset is charged to the profit and loss account to the extent that they cannot be withdrawn from the revaluation reserve (section 387 ). The revaluation reserve cannot be reduced further than to the sum of revaluation included in the book value of assets present at the balance sheet date. This minimum prevails as a legal reserve. In the notes to the revaluation reserve it shall be stated if and how an account is taken of the impact of taxes on the financial position and the profit or loss (section $390(5)$ ).

\section{Minority interests in group companies}

When the company holds less than the whole share capital, an item minority interests in group companies has to be included in the balance sheet. ${ }^{70}$

\section{Provisions for liabilities and charges}

Under provisions, which are formed to cover concrete or specific risks and obligations which actually exist on balance sheet date, separately provisions for pension liabilities and deferred taxes must be mentioned, either in the balance sheet or in the notes. According to the new Act (section 374), the provisions have to be split according to the nature of the obligation and, they also have to be described according to that nature. Downward valuation of assets cannot be shown as an provision on the liabilities side of the balance sheet, they have to be deducted directly from the asset account itself. Additionally, in the notes has to be stated whether provisions are regarded as long term ( $>1$ year).

\section{Long-term /short-term liabilities}

The specifications of creditors have not been altered significantly. The classification of items is to be disclosed according to Annual Accounts Formats Decree (section 375).

\section{Commitments by way of guarantee}

If the company has assumed a liability for the debt of others, the resulting guarantee commitments (to the extent that no provisions have been in the balance sheet) have

${ }^{70}$ This has been laid down in the Annual Accounts Formats Decree. 
to be disclosed and categorized in the notes. Guarantees given on behalf of group companies shall be disclosed separately (section 376 ).

\section{Provisions relating to the profit and loss account and notes}

As in the case of the balance sheet, the profit and loss account has to be made up according to the formats enacted by Royal Administration Decree. The categories distinguished in this section are far more detailed compared to Title 6 provisions. There are four possible formats. Companies have the choice between the four formats of the profit and loss accounts enacted by Royal Administration Decree. Section 377 contains the main classification of the required items: operating profit or loss before and after taxes, taxes on operating profit and loss, extraordinary profit or loss before and after taxes, taxes on extraordinary profit or loss, other taxes, and net profit or loss after taxes.

The breakdown of the operating loss or profit according to type should be: net turnover, change in stocks of finished goods and work in progress, own work capitalised, other operating income, wages and salaries, social security expenses and pension expenses, raw materials and consumables and other external expenses, amortization and depreciation of tangible and intangible fixed assets, exceptional diminution in value of current assets, and other operating expenses. Additionally, breakdown of the profit and loss account on the basis of function is: net turnover, cost of sales (excluding interest payable and depreciation), gross margin turnover, distribution expenses (including depreciation), and general administrative expenses, and other operating income.

The nature and extent of extraordinary income and expenses has to be disclosed (section 377) unless they are immaterial. Net-turnover has to be stated in absolute numbers. Diminution in value of intangible and tangible fixed assets must be disclosed in the profit and loss account or in the notes. Also in contrast to previous reporting practice, the balance of gross margin on turnover and total expenses is referred to as net margin on turnover. This amount together with operating income is the operating profit or loss. Furthermore, taxes have to be split up into taxes on operating profit and taxes on extraordinary profit or loss. Operating expenses have to be classified into far more items than required so far: (a) raw materials and consumables, (b) work contracted out and other external expenses, (c) wages and salaries, (d) social security expenses, (e) depreciation, amortization and diminution in value, subdivided into intangible and tangible fixed assets, (f) exceptional diminution in value of current assets, $(\mathrm{g})$ other operating expenses.

Apart from the section on accounting policies, as well as from the sections dealing with the layout of the balance sheet and the profit and loss account, there are additional special requirements related to the notes, included in chapter 5 of Title 8 . For instance, section 378 requires movements in capital and reserves to be shown in 
a summary. Section 379 deals with capital interests. The notes should include among other things the name, domicile, and the proportion of capital held. Section 380 requires an analysis of net twmover, i.e. the separation of classes of business contributing to net turnover and a division into geographical market areas. Further information provided in the notes should relate to profit appropriation/sharing, important longtem financial commitments (section 381), employee information (section 382) concerning the average number of employees classified according to the business organisation, supervising directors and managerial directors' remuneration (section $381(1))$ and loans (section 383(3)). Section 383 contains new and more detailed requirements with respect to supervising directors and managerial directors' remuneration. The amounts have be separately disclosed for both present and past supervision directors and managerial directors.

As the tables 2.3 and 2.4 show, the Fourth Directive entailed considerable changes to Title 6. As in the case of the WJO, there was a significant increase in disclosure rules concerning the amount and detail of disclosure. Prescribed schedules were introduced to be used for balance sheet and profit and loss statement. ${ }^{71}$ The Act also explicitly mentions the main valuation criteria for assets and the determination of profit, which may be based either on historical cost accounting or current cost accounting. However, it is not permitted to use current cost accounting for the balance sheet and historical cost accounting for the profit and loss account. The new Act also required specific rules for the valuation of investments, including the "net equity value method". Additional requirements include the disclosure of the revaluation of tangible and fixed assets investments if valued at current cost. Another novelty was the mandatory use of legal reserves in certain cases in combination with a maximum amortization period of five years (for costs related to the issue of shares and costs of research and development).

Provisions relating to the notes required among other things (a) information concerning the segmentation of sales by product-line and geographical market areas, (b) details concerning the contents of the directors' report, and (c) the remuneration of directors and (as in Title 6) the members of the supervisory board. The tables show all the relevant financial reporting changes enforced by law.

\footnotetext{
${ }^{7}$ These so called fixed formats were mandated by the Royal Decree on Standard Formats.
} 
Table 2.3: Regulatory changes relating to the balance sheet and notes

\begin{tabular}{|c|c|c|}
\hline m & mor. & 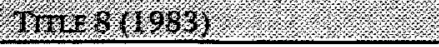 \\
\hline general provisions & $\begin{array}{l}\text { relate to balance sheet and profit and } \\
\text { lass account }\end{array}$ & $\begin{array}{l}\text { relate to annual account, } \\
\text { supplementary information and } \\
\text { managerial director's report }\end{array}$ \\
\hline application area & $\begin{array}{l}\text { (1) all public companies } \\
\text { (2) categories of private companies } \\
\text { (3) co-operative societies } \\
\text { (4) mutual insurance companies } \\
\text { (5) agricultural credit banks }\end{array}$ & $\begin{array}{l}\text { (1) all public companies } \\
\text { (2) (large) private companies } \\
\text { (3) limited partnerships } \\
\text { (4) mutual insurance companies } \\
\text { (5) agricultural credit banks }\end{array}$ \\
\hline $\begin{array}{l}\text { main valuation } \\
\text { criteria }\end{array}$ & open formula & $\begin{array}{l}\text { current cost or historical cost } \\
\text { accounting }(m)\end{array}$ \\
\hline basic concept & $\begin{array}{l}\text { (1) insight } \\
\text { (2) principles accepted in } \\
\text { economic and social climate }\end{array}$ & $\begin{array}{l}\text { additional: } \\
\text { going concern } \\
\text { prudence } \\
\text { recognition } \\
\text { individual valuation } \\
\text { amortization, depreciation and } \\
\text { diminution }\end{array}$ \\
\hline llayout requirements & - & $\begin{array}{l}\text { prescribed schedules (Royal } \\
\text { Decree on standard formats (d) }\end{array}$ \\
\hline tangible fixed assets & $\begin{array}{l}\text { separation of items } \\
\text { disclosure of waluation principle } \\
\text { system of depreciation } \\
\text { changes in waluation principles }\end{array}$ & $\begin{array}{l}\text { additional items: } \\
\text { in the course of construction and } \\
\text { payment on account (d); } \\
\text { revaluation sum must be } \\
\text { disclosed when valued at current } \\
\text { cost (d); } \\
\text { disclosure of valuation principle } \\
\text { for each separate asset item (d) }\end{array}$ \\
\hline $\begin{array}{l}\text { intangible fixed } \\
\text { assets }\end{array}$ & $\begin{array}{l}\text { separation of items } \\
\text { maximum valuation rule }(\mathrm{m})\end{array}$ & $\begin{array}{l}\text { current cost valuation } \\
\text { prohibited }(\mathrm{m}) \\
\text { required items: } \\
\text { share issues and expenses }(\mathrm{m}) \text {, } \\
\text { research and development }(\mathrm{m}) \text {, } \\
\text { concessions and licenses }(\mathrm{d}) \text {, } \\
\text { property rights (d), } \\
\text { goodwill (d); } \\
\text { maximum valuation rule (m) } \\
\text { if capitalized then legal reserve }\end{array}$ \\
\hline
\end{tabular}




\begin{tabular}{|c|c|c|}
\hline 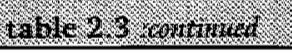 & 1400.1970 & 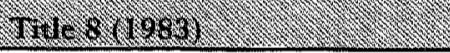 \\
\hline financial fixed assets & $\begin{array}{l}\text { separation of items } \\
\text { disclosure of all majority holdings } \\
\text { WJO requirements fully applicable } \\
\text { names of majority holdings, } \\
\text { foreign subsidiaries and } \\
\text { partnerships consolidated financial } \\
\text { statement or individual accounts. }\end{array}$ & $\begin{array}{l}\text { additional: } \\
\text { valuation rules described } \\
\text { including net equity valuation } \\
(\mathrm{m}) \text {; } \\
\text { introduction of legal reserves }(\mathrm{m})\end{array}$ \\
\hline current assets & $\begin{array}{l}\text { separation of items } \\
\text { separation of inventomies } \\
\text { separation of receivables } \\
\text { negotiated bills } \\
\text { securities not recoverable at call }\end{array}$ & $\begin{array}{l}\text { additional: } \\
\text { payments on accounts (d), } \\
\text { amounts owned by group } \\
\text { companies (d), called up share } \\
\text { capital not paid (d). } \\
\text { other debtors (d), } \\
\text { amount investments other than } \\
\text { financial fixed assets (d) }\end{array}$ \\
\hline minority interests & - & $\begin{array}{l}\text { disclosure of minority interests in } \\
\text { separate item (d) }\end{array}$ \\
\hline equity & $\begin{array}{l}\text { separation of issued share capital } \\
\text { separation of reserves } \\
\text { veto on secret and hidden reserves }\end{array}$ & $\begin{array}{l}\text { additional: } \\
\text { separation of paid up and } \\
\text { called shares (d) } \\
\text { shares/depositary receipts may } \\
\text { not be capitalized (m) } \\
\text { separation of statutory reserves } \\
\text { (d) }\end{array}$ \\
\hline provisions & methods of disclosure prescribed & $\begin{array}{l}\text { additional: } \\
\text { provisions split up by nature (d) } \\
\text { no provisions allowed for } \\
\text { devaluation of assets (m) } \\
\text { long term provisions (d) }\end{array}$ \\
\hline long-term liabilities & $\begin{array}{l}\text { separation of items } \\
\text { interest rate on debt }>1 \text { year }\end{array}$ & $\begin{array}{l}\text { additional: } \\
\text { disclosure of debt }>5 \text { years (d) }\end{array}$ \\
\hline short-term liabilities & separation of items & $\begin{array}{l}\text { disclosure of one amount for } \\
\text { taxation and social securities (d) }\end{array}$ \\
\hline $\begin{array}{l}\text { commitments by } \\
\text { way of guarantee }\end{array}$ & - & $\begin{array}{l}\text { disclosure and categorization of } \\
\text { commitments (d) } \\
\text { separate disclos. of commitments } \\
\text { on behalf of group (d) }\end{array}$ \\
\hline consolidation & $\begin{array}{l}\text { information required on majority } \\
\text { holdings in consolidated or } \\
\text { individual accounts }\end{array}$ & $\begin{array}{l}\text { consolidation of subsidiaries with } \\
\text { capital interest of } 25 \% \text { or more in } \\
\text { group account }(\mathrm{m})\end{array}$ \\
\hline
\end{tabular}

(m) measurement rule

(d) disclosure rule 
Table 2.4: Regulatory changes relating to the profit and lass account and notes

\begin{tabular}{|c|c|c|}
\hline 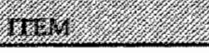 & $970 \times(1970)$ & Ther $8(1983)$ \\
\hline $\begin{array}{l}\text { layout } \\
\text { requirements }\end{array}$ & * & Royal Decree on standard formats \\
\hline net tumover & $\begin{array}{l}\text { absolute/or proportional } \\
\text { numbers }\end{array}$ & \\
\hline $\begin{array}{l}\text { information on } \\
\text { income }\end{array}$ & $\begin{array}{l}\text { separation of: } \\
\text { operating income } \\
\text { breakdown of operating } \\
\text { loss/profit(according to type or } \\
\text { function items }{ }^{72} \text { ), other gains } \\
\text { and losses before tax, } \\
\text { profit before tax, } \\
\text { tax provision, } \\
\text { profits or losses on } \\
\text { participations, } \\
\text { profits or losses on investments, } \\
\text { interest gains or losses, } \\
\text { extraordinary gains and losses }\end{array}$ & $\begin{array}{l}\text { additional: } \\
\text { more detailed items in main } \\
\text { classification (d), } \\
\text { net turn-over information } \\
\text { by business sectors and } \\
\text { geographical areas (d). } \\
\text { disclosure of nature and extent of } \\
\text { extraordinary income and expenses } \\
\text { (d) }\end{array}$ \\
\hline chargeg/costs & $\begin{array}{l}\text { depreciation of fixed assets } \\
\text { wages and salaries } \\
\text { remuneration of supervisory } \\
\text { board }\end{array}$ & $\begin{array}{l}\text { additional: } \\
\text { remuneration of directors (d) }\end{array}$ \\
\hline audit & $\begin{array}{l}\text { obligatory audit of annual } \\
\text { accounts }\end{array}$ & $\begin{array}{l}\text { additional: } \\
\text { audit of managing directors' report }\end{array}$ \\
\hline $\begin{array}{l}\text { supplementary } \\
\text { information } \\
\text { (notes) }\end{array}$ & - & $\begin{array}{l}\text { profit appropriation and sharing (d), } \\
\text { managing directors' report (d), } \\
\text { disclosure of movements in capital } \\
\text { and reserves (d), } \\
\text { disclosure of capital interests (d), } \\
\text { employee information (d) }\end{array}$ \\
\hline
\end{tabular}

(mi) measurement rule

(d) disclosure rule

\footnotetext{
${ }^{2}$ Only introduced with the implementation of Title 6 in 1976 (Wierenga amendment).
} 
Appendix 3A.1: $\quad$ Sample firms WJO (1965-1976)

(1) Ahold

(2) Batenburg Beheer

(3) Beer's Zonen

(4) Begemann

(5) Bergoss

(6) van Berkel's Patent

(7) Blijdenstein Willink

(8) De Boer Jr.

(9) Bols

(10) Bredero Verenigde Bedrijven

(11) Buhrmann-Tetterode

(12) Chamotte

(13) Crane

(14) CSM

(15) Desseaux

(16) Duiker Apparaten

(17) Emba

(18) Gero

(19) van der Giessen-de Noord

(20) Goudsmit

(21) Grasso

(22) Hagemeyer

(23) Heineken

(24) Hero

(25) Hoek's Machinefabriek

(26) Holec

(27) Hollandia Kloos

(28) Hoogovens

(29) IBB Kondor Groep

(30) Inventum

(31) Klene's Suikerfabriek

(32) KNP
(33) Koninklijke Ned. Springstoffen

(34) Kwatta

(35) Maastrichtse Zinkwit

(36) Macintosh

(37) van Melle

(38) Mulder Boskoop

(39) Naeff

(40) Nagron

(41) NEDAP

(42) van Nelle

(49) Nijuerdal ten Cate

(44) Norit

(45) Verenigde Bedrijven Nutricia

(46) Oce wan Grinten

(47) Orenstein en Koppel

(48) Palthe

(49) Philips

(50) Porceleyne Fles

(5I Prins Dokkum

(52) Reesink

(53) van Reeuwijk

(54) Sanders Behang

(55) Textielgroep Twente

(56) Ubbink

(57) Unikap

(58) Verenigde Glasfabrieken

(59) Verto

(60) Vihamij Buttinger

(61) VNU

(62) Gemeensch. Bezit V.R.G.

(63) Wegener's Couranten Concern

(64) Wijers Beheer 
Appendix 3A.2: Samplle firms Title 8 (1977-1986)

(1) Antilliaanse Verffabriek

(2) Amsterdam Rubber

(3) ACF Holding

(4) Ahold

(5) AKZO

(6) ARM.

(7) Audet

(8) A.I.R

(9) BAM Holding

(10) Batenburg Beheer

(11) A.L. van Beek

(12) Beer's Zonen

(13) Begemann

(14) van Berkel's Patent

(15) Blijenstein Willink

(16) De Boer Ir.

(17) Bols

(18) Kon. Borsumij Wehry

(19) Kon. Boskalis Westminster

(20) Braat Bouwstoffen

(21) Buhrmann-Tetterode

(22) T. Heybroek

(23) I.H.C. Calland

(24) CSM

(25) Ceteco

(26) Chamotte Unie

(27) Cindu Key Kramer

(28) Desseaux

(29) van Dorp Groep

(30) Econosto

(31) Elsevier

(32) Emba

(33) Fokker

(34) Furness

(35) Cramma Holding

(36) Gelatine Delf:

(37) van der Giessen-de Noord

(38) Gist Brocades

(39) Goudsmit

(40) Grasso

(41) Oce van der Grinten

(42) Hagemeyer

(43) HBG

(44) Heineken

(45) Hoek's Machinefabriek

(46) Holdoh Houtunie

(47) Holec

(48) Hollandia Kloos
(49) Hoogovens

(50) Hunter Douglas

(51) Kondor Groep

(52) Industrieele Maatschappij

(53) Internatio Muller

(54) Kempen \& Begeer

(55) Kluwer

(56) KNP

(57) KBB

(58) Krasnapolski

(59) Landre \& Glinderman

(60) Leidsche Wolspinnerij

(61) Macintosh

(62) Meneba

(63) Mulder Boskoop

(64) Naarden Chemie

(65) Naeff

(66) Verenigde NBM-bedrijven

(67) NEDAP

(68) Kon. Ned. Springstoffenfabriek

(69) Nijverdal ten Cate

(70) Norit

(71) Verenigde Bedrijven Nutricia

(72) Orenstein en Koppel

(73) Pakhoed

(74) ICA holding

(75) Palthe

(76) Philips

(77) Houthandel William Pont

(78) Porceleyne Fles

(79) Proost \& Brandt

(80) Reesink

(81) Riva

(82) Sanders Behang

(83) Schuitema

(84) Schuttersveld

(85) Holdingmij de Telegraaf

(86) Textielgroep Twente

(87) Otra

(88) Twentsche Kabel

(89) Ubbink

(90) Unilever

(91) Verenigde Glasfabrieken

(92) Verenigde Machinefabriek Stork

(93) Verto

(94) V.N.U.

(95) Kon. Volker Stevin

(96) Gemeensch. Bezit V.R.G. 
(97) Wegener's Couranten Concem

(98) Koninklijke Wessanen

(99) A'damse Droogdok Mij

(100) Wijers Beheer

(101) Wolters Samson

(102) Kon. Ned. Petroleum Mij (Shell)

(103) Holland America Line Trust

(104) K.L.M.

(105) Kan. Nedlloyd Groep

(106) van Ommeren

(107) Stoomvaartmij Zeeland

source: Hoogendoorn (1990) 
Appendix 3B.Il and 3B.2: Distribution of Accounting changes per category for WJO and Title 8 sample firms

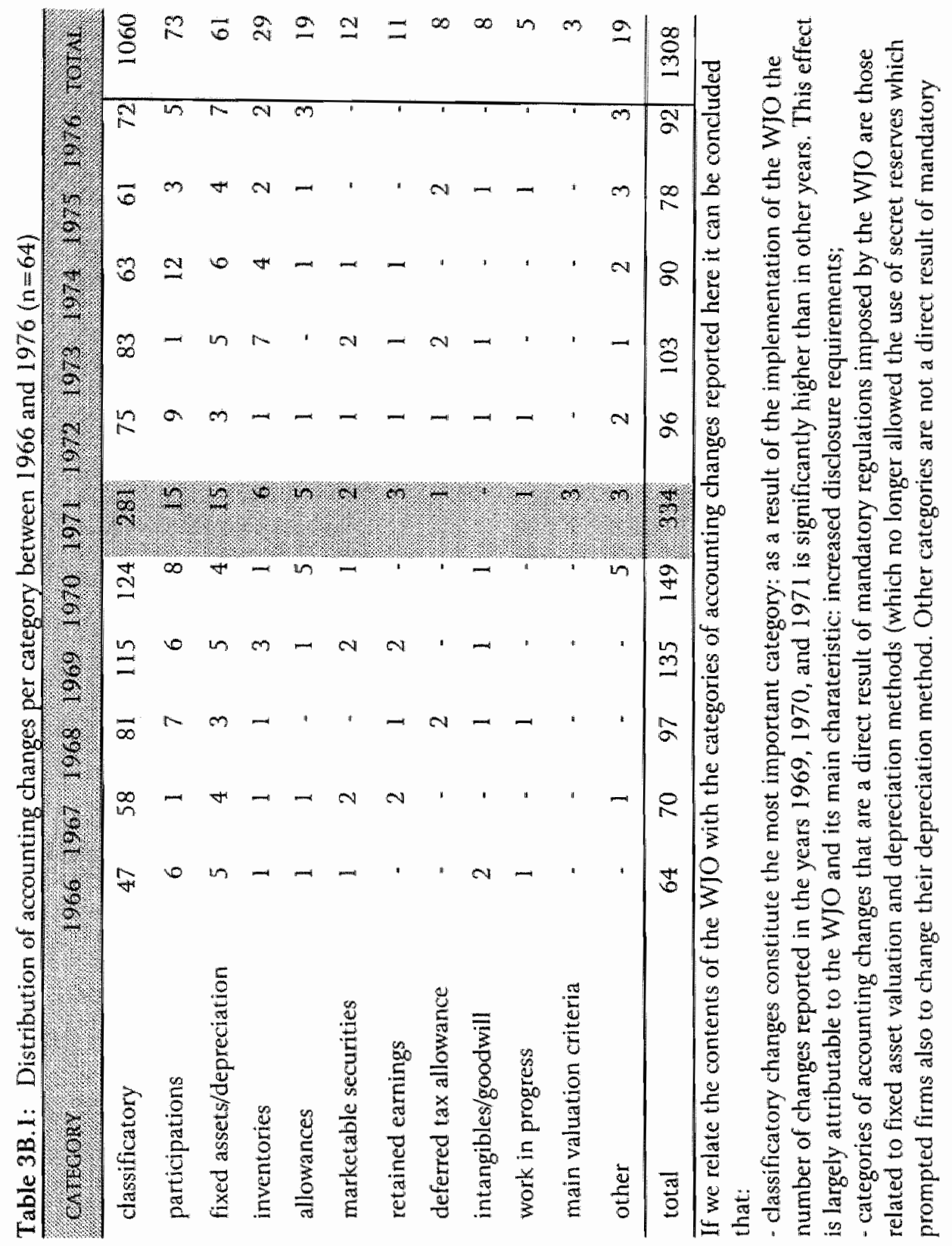




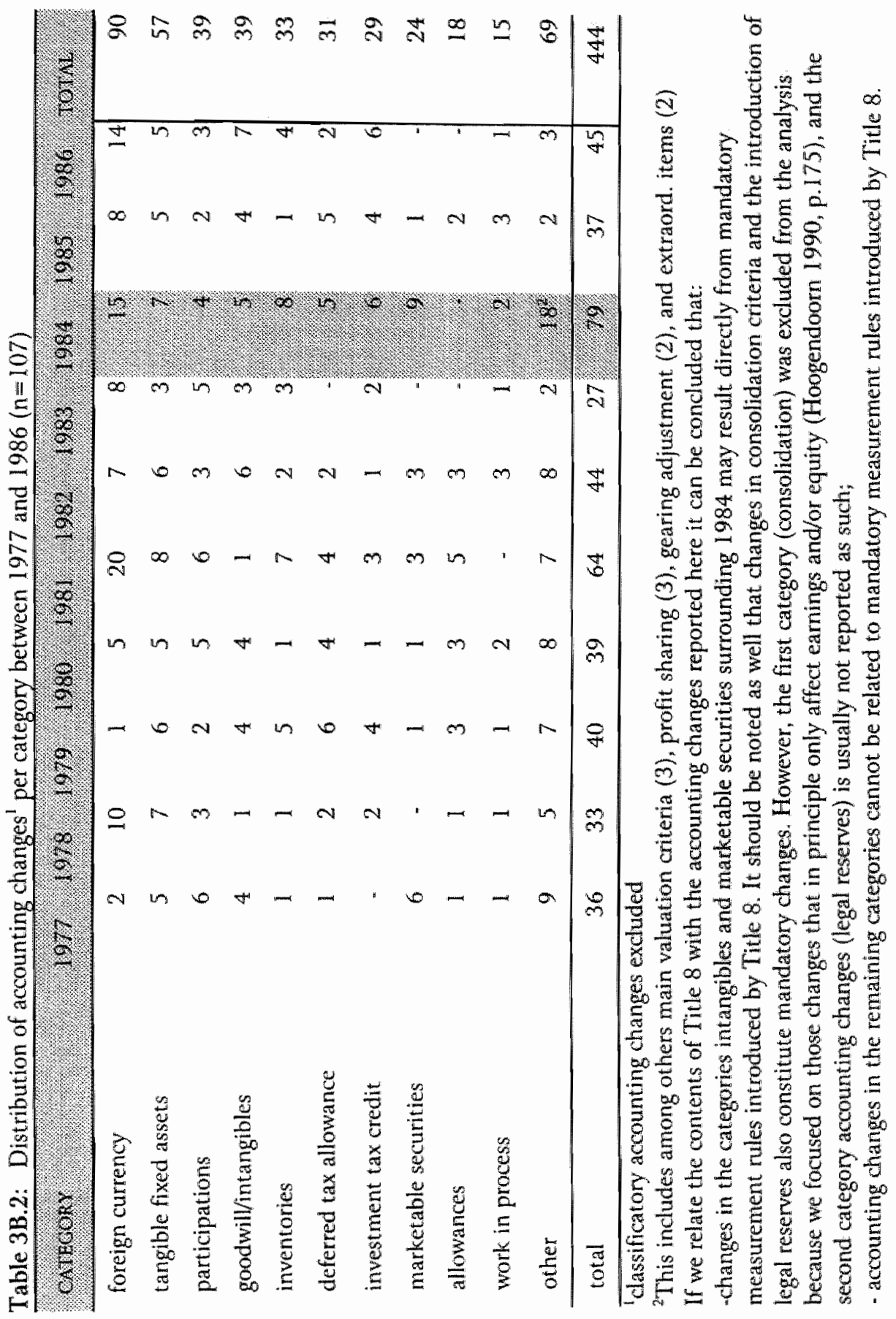


Appendix 3C. 1: Accourting method changes WTO sample firms (1)

Explanatory list of abbrewiations.

Nature of accounting changes:

(1) start-up costs/preoperational expenses

(2)assets not in use/idle porperty

(3)past service commitments

(4) main valuation criteriat

(5)extraondinary items

(6):subsidiarles

(7)provistions

(B):securities

(9):shares

(10)exploration casts

(11) goodwill

(12)lease/rental rights

(13)intagible assets

(14)interest costs

(15)plant and equipoment.

(16)lease contracts

(17)loans

(18)tangible fixed assets

(19)work in prooess

(20)disclosure/classification

(21)research and dewelopment

(22)tantiemes/bonuses

(23)holiday borius

(24)inventory

(25) deffered tax allowance
(26) foreign currencies

(27) tax credits

(28) furnuture and fixtures

(29) gearing adjustment

(30) taxes

(31) development credit

(32) early retirement plan

(33) receivables

(34) short-term liabilities

(35) subscriptions

(36) investments

(37) reorganisation costs

(38) bonds and debentures:

(39) unearned premium reserve

(40) conmission fees insurarices

(41) annuities

(42) dividend

(43) general expenses

(44) costs of share trading/deductible expenses

(45) reserves

(46) depreciation

(47) minority interest

(48) turmover

(49) capital surplus/share premium reserve

\section{- Number:}

The information provided here summarizes all classiffatory changes made in one year

\section{Explanatory list of adjustmemt methods:}

(1) cumulative effect in result (cumulatief effect in resultaan)

(2) curtent adjustment (actueel, aanpassing nieuwe activa en passiva)

(3) current and future adjustment (actued, aanpassing alle relevante activa en passiva)

(4) cumulative effect in equity (cumulatief effect in eigen vermogen)

(5) unknown

(6) methad $1+4$ combined

\section{*Earaingis/Equity and \%Earnings/\%quity}

The impact and relative impact of the accounting change on earnings/equity "the impact could not be determined

\section{*INFO}

Yes: information is provided in the annual financial statenent on the nature andior magnitude of the accounting change No: no information is included in the annual financial statement on the nature andior magnitude of the accounting change 


\begin{tabular}{|c|c|c|c|c|c|c|c|c|c|}
\hline FIRM & YEAR & NATURE & NUMBER & METHOD & EARN EFF & \%EARNINGS & EQUTTY EFF & * EQUITY & INFO \\
\hline  & 1965 & 20 & 1 & 3 & 0 & 0 & 0 & 0 & No \\
\hline  & 1967 & 20 & 2 & 3 & 0 & 0 & 0 & 0 & No \\
\hline 1 & 1970 & 20 & 3 & 3 & 0 & 0 & 0 & 0 & No \\
\hline 1 & 1971 & 8 & - & 2 & 0 & 0 & .6 & 0 & Yes \\
\hline 1 & 1971 & 20 & l & 3 & 0 & 0 & 0 & 0 & No \\
\hline 1 & 1972 & 20 & 2 & 3 & 0 & 0 & 0 & 0 & No \\
\hline 1 & 1973 & 20 & 7 & 3 & 0 & 0 & 0 & 0. & No \\
\hline 蒠 & 1974 & 20 & 2 & 3 & 0 & 0 & 0 & 0 & No \\
\hline 1 & 1975 & 20 & 1 & 3 & 0 & 0 & 0 & 0 & No \\
\hline 1 & 1976 & 18 & . & 2 & .885 & 0.11 & 18165 & 0.08 & Yes \\
\hline 1 & 1976 & 23 & - & 2 & $?$ & $?$ & & $?$ & Yes \\
\hline 2 & 1969 & 18 & - & 2 & $?$ & ? & $?$ & $?$ & No \\
\hline 2 & 1970 & 18 & - & 2 & 0 & 0 & 70 & 0.13 & Yes \\
\hline 2 & 1970 & 20 & 4 & 3 & 0 & 0 & 0 & 0 & No \\
\hline 2 & 1971 & 19 & . & 2 & 0 & 0 & 0 & 0 & Yes \\
\hline 2 & 1971 & 25 & - & 2 & 0 & 0 & -475 & .0 .09 & Yes \\
\hline 2 & 1971 & 20 & 7 & 3 & 0 & 0 & 0 & 0 & No \\
\hline 2 & 1973 & 20 & 1 & 3 & 0 & 0 & 0 & 0 & No \\
\hline 2 & 1974 & 20 & $x$ & 3 & 0 & 0 & 0 & 0 & No \\
\hline 2 & 1975 & 20 & 5 & 3 & 0 & 0 & 0 & 00 & No \\
\hline 2 & 1976 & 6 & - & 2 & $?$ & ? & $?$ & $?$ & No \\
\hline 2 & 1976 & 6 & - & 2 & $?$ & $?$ & $?$ & $?$ & No \\
\hline 2 & 1976 & 20 & 3 & 3 & 0 & 0 & 0 & 0 & No \\
\hline 3 & 1966 & 6 & - & 2 & 0 & 0 & 30 & 0.06 & No \\
\hline 3 & 1966 & 20 & 1 & 3 & 0 & 0 & 0 & 0 & No \\
\hline 3 & 1969 & 20 & 2 & 2 & 0 & 0 & 0 & $a$ & No \\
\hline 3 & 1970 & 20 & 1 & 3 & 0 & 0 & 0 & 0 & No \\
\hline 3 & 1971 & 6 & . & 5 & $?$ & $?$ & $?$ & $?$ & Yes \\
\hline 3 & 1971 & 20 & 11 & 3 & 0 & 0 & 0 & 0 & No \\
\hline 3 & 1972 & 20 & 4 & 3 & 0 & 0 & 0 & 0 & No \\
\hline 3 & 1973 & 20 & 3 & 3 & 0 & 0 & a & 0 & No \\
\hline 3 & 1974 & 20 & 3 & 3 & 0 & 0 & a & 0 & No \\
\hline 3 & 1976 & 18 & - & 2 & -314 & -0.05 & 7180 & 0.28 & Yes \\
\hline 4 & 1968 & 20 & 2 & 3 & 0 & 0 & 0 & 0 & No \\
\hline 4 & 1969 & 8 & 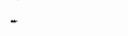 & 2 & 0 & 0 & 10 & 0.03 & Yes \\
\hline 4 & 1971 & 18 & - & 4 & -36 & -0.07 & 1542 & 0.31 & Yes \\
\hline 4 & 1971 & 8 & . & 2 & .50 & -0.10 & .50 & 0.01 & Yes \\
\hline 4 & 1972 & 20 & $\mathbb{1}$ & 3 & 0 & 0 & 0 & 0 & No \\
\hline 4 & 1973 & 20 & 1 & 3 & 0 & 0 & 0 & 0 & No \\
\hline 5 & 1968 & 20 & I & 3 & 0 & 0 & a & 0 & No \\
\hline 5 & 1969 & 6 & . & 4 & 0 & 0 & 202 & 0.02 & Yes \\
\hline 5 & 1969 & 20 & 4 & 3 & 0 & 0 & 0 & 0 & No \\
\hline 5 & 1.970 & 20 & 1 & 3 & 0 & 0 & 0 & 0 & No \\
\hline 5 & 1971 & 6 & & 2 & $?$ & ? & $?$ & $?$ & Yes. \\
\hline 5 & 1971 & 6 & . & 2 & $?$ & $?$ & $?$ & $?$ & Yes \\
\hline 5 & 1971 & 20 & 6 & 3 & 0 & 0 & 0 & 0 & No \\
\hline 5 & 1972 & 6 & & 2 & ? & ? & ? & $?$ & Yes \\
\hline 5 & 1973 & 20 & 1 & 3 & 0 & 0 & 0 & 0 & No \\
\hline 5 & 1974 & 24 & $\ldots$ & 2 & $?$ & $?$ & ? & $?$ & Yes \\
\hline 5 & 1974 & 20 & 2 & 3 & 0 & 0 & 0 & 0 & No \\
\hline 5 & 1975 & 20 & 2 & 3. & 0 & 0 & 0 & 0 & Na \\
\hline 5 & 1976 & 6 & . & 4 & 0 & 0 & 471 & 0.03 & Yes \\
\hline 6 & 1966 & 13 & . & 2 & 0 & 0 & $?$ & $?$ & No \\
\hline 6 & 1967 & 18 & . & 4 & 0 & 0 & 11205 & 0.22 & Yes \\
\hline 6 & 1967 & 8 & . & 2 & 0 & 0 & 500 & 0.09 & Yes \\
\hline
\end{tabular}




\begin{tabular}{|c|c|c|c|c|c|c|c|c|c|}
\hline FIRM & YEAR & NATURE & NUMBER & METHOD & EARN EFF & \%EARNINGS & EQUHTY EFF & \# EQUTTY & MNO \\
\hline 6 & 1968 & 20 & 2 & 3 & 0 & 0 & 0 & 0 & No \\
\hline 6 & 1969 & 6 & - & 2 & $?$ & $?$ & $?$ & $?$ & Yes \\
\hline 6 & 1969 & 20 & 5 & 3 & 0 & 0 & $\alpha$ & 0 & No \\
\hline 6 & 1971 & 20 & 6 & 3 & 0 & 0 & 0 & 0 & No \\
\hline 6 & 1972 & 20 & 2 & 3 & 0 & 0 & 0 & 0 & No \\
\hline 6 & 1975 & 49 & - & 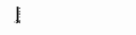 & $?$ & $?$ & $?$ & $?$ & Yes \\
\hline 6 & 1976 & 26 & . & 4 & 940 & 0.11 & 8357 & 0.07 & Yes \\
\hline 6 & 1976 & 20 & 1 & 3 & 0 & 0 & 0 & 0 & No \\
\hline 7 & 1966 & 20 & 1 & 3 & 0 & 0 & 0 & $a$ & No \\
\hline 7 & 1967 & 20 & 3 & 3 & 0 & 0 & 0 & 0 & Mo \\
\hline 7 & 1968 & 20 & 1 & 3 & 0 & 0 & 0 & 0 & No \\
\hline 7 & 1969 & 20 & 2 & 3 & 0 & $a$ & 0 & 0 & No \\
\hline 7 & 1971 & 4 & - & 2 & $?$ & $?$ & 2668 & 0.17 & les \\
\hline 7 & 1.971 & 8 & . & 2 & 0 & 0 & $?$ & $?$ & Y'es \\
\hline 7 & 1971 & 20 & 6 & 3 & 0 & 0 & 0 & 0 & No \\
\hline 7 & 1973 & 20 & 1 & 3 & 0 & 0 & 0 & 0 & No \\
\hline 7 & 1974 & 6 & a & 2 & $?$ & $?$ & 458 & 0.03 & Yes \\
\hline 7 & 1975 & 20 & 2 & 3 & 0 & 0 & 0 & 0 & No \\
\hline 8 & 1967 & 30 & . & 2 & -70 & -0.15 & 70 & 0.09 & No \\
\hline 8 & 1968 & 25 & - & 2 & 104 & 0.06 & 0 & 0 & No \\
\hline 8 & 1968 & 6 & - & 2 & 0 & 0 & 88 & 0.01 & No \\
\hline 8 & 1968 & 20 & 2 & 3 & 0 & 0 & 0 & 0 & No \\
\hline$B$ & 1970 & 20 & 2 & 3 & 0 & 0 & 0 & 0 & No \\
\hline 8 & $19 \mathrm{I}$ & 20 & 4 & 3 & 0 & 0 & 0 & 0 & No \\
\hline 8 & 1972 & 20 & I & 3 & 0 & 0 & 0 & 0 & No \\
\hline 8 & 1973 & 20 & 2 & 3 & 0 & 0 & 0 & 0 & No \\
\hline 9 & 1967 & 20 & 2 & 3 & 0 & 0 & 0 & 0 & No \\
\hline 9 & 1968 & 45 & . & 2 & 0 & 0 & $?$ & $?$ & $\mathrm{No}$ \\
\hline 9 & 1969 & 18 & - & 4 & 0 & 0 & 3742 & 0.05 & Yes \\
\hline 9 & 1970 & 8 & . & 5 & $?$ & $?$ & $?$ & $?$ & $\mathrm{No}$ \\
\hline 9 & 1970 & 34 & . & 5 & $?$ & $?$ & $?$ & $?$ & $\mathrm{No}$ \\
\hline 9 & 1970 & 50 & 。 & 4 & 0 & 0 & 8875 & 0.10 & No \\
\hline 9 & 1970 & 20 & 8 & 3 & 0 & 0 & 0 & 0 & No \\
\hline 9 & 1971 & 8 & - & 2 & 30 & 0.02 & -30 & -0.04 & Yes \\
\hline 9 & 1971 & 20 & 4 & 3 & 0 & 0 & 0 & 0 & No \\
\hline 9 & 1973 & 25 & - & 2 & 0 & 0 & -305 & .02 & $\mathrm{No}$ \\
\hline 9 & 1973 & 20 & 1 & 3 & 0 & 0 & 0 & 0 & No \\
\hline 9 & 1976 & 20 & 3 & 3 & 0 & 0 & 0 & 0 & $\mathrm{No}$ \\
\hline 10 & 1957 & 20 & 1 & 3 & $?$ & $?$ & $?$ & $?$ & No \\
\hline 10 & 1968 & 20 & 1 & 3 & $?$ & $?$ & $?$ & $?$ & $\mathrm{No}$ \\
\hline 10 & 1969 & 20 & 1 & 3 & $?$ & $?$ & $?$ & $?$ & $\mathrm{No}$ \\
\hline 10 & 1971 & 6 & - & 2 & 0 & 0 & -2935 & -0.04 & $\mathrm{No}$ \\
\hline 10 & 1971 & 20 & 9 & 3 & $?$ & $?$ & $?$ & $?$ & No \\
\hline 10 & 1973 & 20 & 1 & 3 & $?$ & $?$ & $?$ & $?$ & No \\
\hline 10 & 1976 & 20 & 2 & 3 & 0 & 10 & 0 & 0 & No \\
\hline 11 & 1969 & 8 & . & 2 & $?$ & $?$ & $?$ & $?$ & Yes \\
\hline $\mathbb{1}$ & 1969 & $B$ & . & 2 & $?$ & $?$ & $?$ & $?$ & No \\
\hline 11 & 1960 & 20 & 3 & 2 & 0 & 0 & 0 & 0 & No \\
\hline 11 & 1970 & 6 & $B$ & 2 & 0 & 0 & 0 & 0 & Yes \\
\hline 11 & 1970 & 20 & 2 & 3 & 0 & 0 & 0 & 0 & No \\
\hline 11 & 1971 & 6 & - & 2 & 0 & 0 & -1538 & 0 & Yes \\
\hline 11 & 1971 & 20 & 6 & 3 & 0 & 0 & 0 & 0 & No \\
\hline$\Downarrow 1$ & 1972 & 8 & . & 2 & $?$ & $?$ & $?$ & $?$ & Yes \\
\hline 11 & 1973 & 8 & - & 2 & $?$ & $?$ & $?$ & $?$ & Yes \\
\hline 11 & 1974 & 20 & 7 & 3 & 0 & 0 & 0 & 0 & No \\
\hline 11 & 1975 & 20 & 2 & 3 & 0 & 0 & 0 & 0 & Yes \\
\hline l. 1 & 1976 & 20 & 3 & 3 & $a$ & 0 & 0 & 0 & No \\
\hline 12 & 1967 & 8 & . & 2 & 0 & 0 & -2 & -01 & No \\
\hline 12 & 1968 & 19 & . & 2 & $?$ & $?$ & $?$ & $?$ & Y'es \\
\hline 12 & 1968 & 20 & 2 & 3 & $a$ & 0 & 0 & 0 & No \\
\hline 12 & 1969 & 20 & 3 & 3 & 0 & 0 & 0 & 0 & No \\
\hline 12 & 1970 & 6 & - & 2 & 0 & 0 & 983 & 0.18 & Yes \\
\hline
\end{tabular}




\begin{tabular}{|c|c|c|c|c|c|c|c|c|c|}
\hline FIRM: & YEAR & NATURE & NUMBER & METHOD & EARN.EFF & \%EARNINGS & EQUTTY EFF & Q⿻日禸 & $\mathrm{INFO}$ \\
\hline 12 & 1970 & 8 & - & 2 & 0 & 0 & 50 & $0 !$ & Yes \\
\hline 12 & 1971 & 20 & 7 & 3 & 0 & 0 & 0 & 0 & No \\
\hline 1.2 & 1972 & 20 & 3 & 3 & 0 & 0 & 0 & 0 & $\mathrm{No}$ \\
\hline 12 & 1973 & 18 & * & 2 & 0 & 0 & 4532 & 0.39 & Yes \\
\hline 12 & 1973 & 20 & 4 & 3 & 0 & 0 & 0 & 0 & No \\
\hline 12 & 1974 & 20 & 2 & 3 & 0 & 0 & 0 & 0 & No \\
\hline 12 & 1975 & 20 & 3 & 3 & 0 & 0 & 0 & 0 & No \\
\hline 12 & 1975 & 25 & . & 5 & 0 & 0 & -1152 & -0.08 & Yes \\
\hline 12 & 1976 & 20 & 2 & 3 & 0 & 0 & 0 & 0 & $\mathrm{No}$ \\
\hline 13 & 1966 & 18 & . & 2 & 0 & 0 & .291 & 0.02 & $Y_{e s}$ \\
\hline 13 & 1966 & 24 & - & 2 & $?$ & $?$ & $?$ & $?$ & Yes \\
\hline 13 & 1966 & 18 & - & 2 & -1150 & -0.09 & -150 & .0 .01 & $x$ \\
\hline 13 & 1967 & 20 & 2 & 3 & 0 & 0 & 0 & 0 & No \\
\hline 13 & 1967 & 18 & - & 2 & 0 & 0 & -88 & -06 & No \\
\hline 13 & 19618 & 20 & 3 & 3 & 0 & 0 & 0 & 0 & No \\
\hline 13 & 1969 & 20 & 1 & 3 & $a$ & 0 & 0 & 0 & No \\
\hline 13 & 1970 & 20 & 6 & 3 & 0 & 0 & 0 & 0 & No \\
\hline 13 & 1972 & 20 & 1 & 3 & 0 & 0 & 0 & 0 & No \\
\hline 13 & 1975 & 20 & 1 & 3 & 0 & 0 & 0 & 00 & No \\
\hline 13 & 1976 & 6 & - & 4 & 0 & 0 & .379 & .0 .03 & Yes. \\
\hline 14 & 1965 & 8 & . & 2 & 250 & 0.98 & 0 & 0 & Yes \\
\hline 14 & 1968 & 6 & - & 2 & 0 & 0 & 18257 & 0.39 & Yes \\
\hline 14 & 1968 & 20 & 18 & 3 & 0 & 0 & 0 & 0 & No \\
\hline 14 & 1968 & 18 & - & 5 & $?$ & $?$ & $?$ & $?$ & Xes \\
\hline 14 & 1969 & 20 & 8 & 3 & 0 & 0 & 0 & 0 & $\mathrm{No}$ \\
\hline 14 & 1971 & 18 & - & 2 & 319 & 0.03 & 319 & 05 & Yes \\
\hline 14 & 1971 & 20 & 4 & 3 & 0 & 0 & 0 & 0 & No \\
\hline 14 & 1972 & 20 & 1 & 3 & 0 & 0 & 0 & 0 & No \\
\hline 14 & 1973 & 24 & - & 2 & 835 & 0.08 & 835 & 0.01 & Yes \\
\hline 14 & 1913 & 8 & - & 2 & $?$ & $?$ & $?$ & 7 & Yes \\
\hline 14 & 1974 & 18 & - & 2 & 0 & 0 & 173.79 & 0.13 & Yes \\
\hline 14 & 1974 & 18 & - & 2 & 747 & 0.02 & 747 & 0.06 & Yes \\
\hline 14 & 1974 & 18 & - & 4 & 0 & 0 & 29104 & 0.22 & Yes \\
\hline 14 & 1974 & 20 & 4 & 3 & 0 & 0 & 0 & 0 & $\mathrm{Na}$ \\
\hline 14 & 1975 & 20 & 3 & 3 & 0 & 0 & 0 & 0 & $\mathrm{No}$ \\
\hline 14 & 1976 & 18 &  & 2 & 916 & 0.05 & 916 & 0.01 & Yes \\
\hline 15 & 1966 & 18 & * & 2 & 0 & 0 & 1656 & 0.31 & Yes \\
\hline 15 & 1966 & 20 & 1 & 3 & 0 & 0 & 0 & 0 & No \\
\hline 15 & 1967 & 24 & . & 2 & 0 & 0 & 0 & 0 & Yes \\
\hline 15 & 1968 & 24 & . & 2 & 0 & 0 & $?$ & ? & $Y$ \\
\hline 15 & 1969 & 20 & 4 & 3 & 0 & 0 & 0 & 0 & $\mathrm{No}$ \\
\hline 15 & 1969 & 20 & 3 & 3 & 0 & 0 & 0 & 0 & No \\
\hline 15 & 1971 & 20 & 7. & 3 & 0 & 0 & 0 & 0 & No \\
\hline 15 & 1972 & 18 & - & 2 & $?$ & $?$ & $?$ & ซ & Yes \\
\hline 15 & 1974 & 20 & 1 & 3 & 0 & 0 & 0 & 0 & No \\
\hline 15 & 1976 & 8 & - & 2 & .1100 & 0.17 & $a$ & 0 & Yes \\
\hline 15 & 1976 & 20 & 3 & 3 & 0 & $a$ & 0 & 0 & No \\
\hline 16 & 1966 & 20 & 2 & 3 & 0 & 0 & 0 & 0 & No \\
\hline 16 & 1971 & 6 & - & 2 & 0 & 0 & 0 & 0 & No \\
\hline 16 & 1972 & 20 & 1 & 3 & 0 & 0 & 0 & 0 & No \\
\hline 16 & 1974 & 6 & - & 2 & 0 & 0 & -130 & -0.02 & Yes: \\
\hline 16 & 1974 & 5 & * & 2 & -116 & 0.14 & 0 & 0 & Yes \\
\hline 16 & 1975 & 20 & 2 & 3 & 0 & 0 & 0 & 0 & Mo \\
\hline 16 & 1976 & 20 & 2 & 3 & 0 & 0 & 0 & 0 & No \\
\hline 17 & 1968 & 6 & . & 7 & 379 & 0.38 & 1313 & 0.08 & No \\
\hline 17 & 1968 & 20 & 4 & 3 & 0 & 0 & 0 & 0 & No \\
\hline 17 & 1971 & 20 & 3 & 3 & 0 & 0 & 0 & 0 & Ye: \\
\hline 17 & 1972 & 6 & . & 4 & 0 & 0 & 5505 & 0.29 & $\mathrm{No}$ \\
\hline 17 & 1972 & 20 & 1 & 3 & 0 & 0 & 0 & 0 & No \\
\hline 17 & 1974 & 24 & - & 2 & $?$ & $?$ & ? & $?$ & Yes \\
\hline 18 & 1966 & 20 & 2 & 3 & 0 & 0 & 0 & 0 & $\mathrm{No}$ \\
\hline 18 & 1970 & 51 & . & 4 & 0 & 0 & 540 & 0.04 & No \\
\hline
\end{tabular}




\begin{tabular}{|c|c|c|c|c|c|c|c|c|c|}
\hline FIRMI & YEAR & NATURE & NUMBER & METHOD & EARN EFF & \%EARNINGS & EQUITY EFF & \% EQUITY & INFO \\
\hline 18 & 1971 & 18 & - & 7 & 2360 & 0.51 & 2388 & 0.11 & Yes \\
\hline 18 & 1972 & 20 & 3 & 3 & 0 & 0 & 0 & 0 & No \\
\hline 18 & 1973 & 24 & . & 1 & .752 & -0.33 & 0 & 0 & Yes \\
\hline 18 & 1973 & 24 & - & 2 & $?$ & $?$ & $?$ & $?$ & Yes: \\
\hline 18 & 1973 & 18 &. & 2 & $?$ & $?$ & $?$ & $?$ & Yes \\
\hline 18 & 1973 & 20 & 2 & 3 & 0 & 0 & 0 & 0 & No \\
\hline 19 & 1966 & 6 & - & 2 & 0 & 0 & 0 & 0 & Ym.5. \\
\hline 19 & 1966 & 19 & - & 2 & 0 & 0 & $?$ & $?$ & No \\
\hline 19 & 1968 & 20 & 1 & 3 & 0 & 0 & 0 & 0 & No \\
\hline 19 & 1969 & 20 & 1 & 3 & 0 & 0 & 0 & 0 & No \\
\hline 19 & 1970 & 6 & - & 2 & -1273 & -1.28 & 1273 & 0.15 & No \\
\hline 19 & 1971 & 18 & - & 2 & $?$ & $?$ & $?$ & $?$ & Yes \\
\hline 19 & 1971 & 20 & 5 & 3 & 0 & 0 & 0 & 0 & $\mathrm{No}$ \\
\hline 19 & 1971 & 45 & - & 4 & 0 & 0 & 4427 & 0.31 & Yes \\
\hline 19 & 1972 & 20 & 2 & 3 & 0 & 0 & 0 & 0 & No \\
\hline 19 & 1973 & 18 & - & 1 & -60 & .10 & 27889 & 0.51 & Yes \\
\hline 19 & 1973 & 20 & 3 & 3 & 0 & 0 & 0 & 0 & No \\
\hline 20 & 1968 & 20 & 1 & 3 & 0 & 0 & 0 & 0 & No \\
\hline 20 & 1969 & 20 & 2 & 3 & 0 & 0 & 0 & 0 & No \\
\hline 20 & 1970 & 20 & 1 & 3 & 0 & 0 & 0 & 0 & No \\
\hline 20 & 1971 & 20 & 8 & 3 & 0 & 0 & 0 & 0 & No \\
\hline 20 & 1972 & 20 & 1 & 3 & 0 & 0 & 0 & 0 & No \\
\hline 20 & 1974 & 20 & 2 & 3 & 0 & 0 & 0 & 0 & $\mathrm{No}$ \\
\hline 20 & 1974 & 24 & " & 2 & -414 & -1.32 & 1226 & 0.23 & Yes \\
\hline 21 & 1966 & 20 & 3 & 3 & 0 & 0 & 0 & 0 & No \\
\hline 21 & 1967 & 20 & 3 & 3 & 0 & 0 & 0 & 0 & $\mathrm{No}$ \\
\hline 21 & 1969 & 20 & 4 & 3 & 0 & 0 & 0 & 0 & No \\
\hline 21 & 1970 & 20 & 2 & 3 & 0 & 0 & 0 & 0 & No \\
\hline 21 & 1971 & 6 & $\propto$ & 1 & $?$ & $?$ & 0 & 0 & Yes \\
\hline 21 & 1971 & 20 & 4 & 3 & 0 & 0 & 0 & 0 & No \\
\hline 21 & 1972 & 6 & - & 4 & $?$ & $?$ & 261 & 0.02 & Yes \\
\hline 21 & 1974 & 20 & 1 & 3 & 0 & 0 & 0 & 0 & Yes \\
\hline 21 & 1975 & 18 & * & 7 & .317 & 0.13 & 4932 & 0.20 & Yes \\
\hline 21 & 1975 & 20 & 1 & 3 & 0 & 0 & 0 & 0 & $\mathrm{No}$ \\
\hline 21 & 1976 & 20 & 3 & 3 & 0 & 0 & 0 & 0 & No \\
\hline 22 & 1966 & 20 & 1 & 3 & 0 & 0 & 0 & 0 & No \\
\hline 22 & 1967 & 18 & - & 2 & -420 & $\cdot .46$ & 420 & 0.09 & No \\
\hline 22 & 1967 & 20 & 3 & 3 & 0 & 0 & 0 & 0 & No \\
\hline 22 & 1967 & 18 & - & 2 & 0 & 0 & 0 & 0 & No \\
\hline 22 & 1968 & 20 & 1 & 3 & 0 & 0 & 0 & 0 & $\mathrm{No}$ \\
\hline 22 & 1969 & 20 & 2 & 3 & 0 & 0 & 0 & 0 & No \\
\hline 22 & 1970 & 8 & $=$ & 1 & .1586 & 0.16 & 0 & 0 & Yes \\
\hline 22 & 1970 & 20 & 9 & 3 & 0 & 0 & 0 & 0 & $\mathrm{Na}$ \\
\hline 22 & 1971 & 6 & - & 4 & 0 & 0 & 31957 & 0.66 & Yes \\
\hline 22 & 1971 & 20 & 3 & 3 & 0 & 0 & 0 & 0 & No \\
\hline 22 & 1974 & 20 & 3 & 3 & 0 & 0 & 0 & 0 & No \\
\hline 22 & 1974 & 6 & - & 4 & 0 & 0 & 254 & 0.02 & Yes \\
\hline 22 & 1975 & 11 & - & 2 & 1467 & 0.17 & -1467 & -0.02 & Yes \\
\hline 22 & 1975 & 24 & $=$ & 1 & 6153 & 1.53 & 0 & 0 & Yes \\
\hline 22 & 1976 & 18 & . & 3 & 2314 & 0.32 & 0 & 0 & Yes \\
\hline 23 & 1966 & 20 & 3 & 3 & 0 & 0 & 0 & 0 & No \\
\hline 23 & 1967 & 20 & 2 & 3 & 0 & 0 & 0 & 0 & No \\
\hline 23 & 1968 & 6 & - & 4 & 0 & 0 & 61216 & 0.25 & Yess \\
\hline 23 & 1969 & 20 & 2 & 3 & 0 & 0 & 0 & 0 & $\mathrm{No}$ \\
\hline 23 & 1970 & 20 & 5 & 3 & 0 & 0 & 0 & 0 & No \\
\hline 23 & 1971 & 20 & 2 & 3 & 0 & 0 & 0 & 0 & No \\
\hline 23 & 1972 & 26 & $\cdots$ & 2 & $?$ & $?$ & $?$ & $?$ & Yes \\
\hline 23. & 1973 & 20 & 2 & 3 & 0 & 0 & 0 & 0 & No \\
\hline 23 & 1974 & 20 & 3 & 3 & 0 & 0 & 0 & 0 & No \\
\hline 23 & 1975 & 20 & 3 & 3 & 0 & 0 & 0 & 0 & $\mathrm{No}$ \\
\hline 23 & 1975 & 25 & * & 2 & 0 & 0 & 0 & 0 & Yes \\
\hline 23 & 1976 & 20 & 4 & 3 & 0 & 0 & 0 & 0 & No \\
\hline
\end{tabular}




\begin{tabular}{|c|c|c|c|c|c|c|c|c|c|}
\hline FIRM & MEAR & NATURE & NUMBER & METHOD & EARN. EFF & \%EARNINGS & EQUTYYEFF & EQUITY & INFO \\
\hline 24 & 1970 & 20 & 110 & 3 & 0 & 0 & 0 & 0 & No \\
\hline 24 & 1973 & 20 & 1 & 3 & 0 & 0 & 0 & 0 & No \\
\hline 25 & 1966 & 18 & - & 2 & $?$ & $?$ & $?$ & $?$ & Yess \\
\hline 25 & 1967 & 20 & 3 & 3 & 0 & 0 & 0 & 0 & $\mathrm{No}$ \\
\hline 25 & 1968 & 20 & 4 & 3 & 0 & 0 & 0 & 0 & No \\
\hline 25 & 1970 & 20 & 4 & 3 & 0 & 0 & 0 & 0 & No \\
\hline 25 & 1971 & 6 & - & 2 & $?$ & $?$ & $?$ & $?$ & Yes \\
\hline 25 & 1971 & 20 & 8 & 3 & 0 & 0 & 0 & 0 & No \\
\hline 25 & 1972 & 6 & . & 2 & $?$ & $?$ & $?$ & $?$ & No \\
\hline 25 & 1972 & 20 & 2 & 3 & 0 & 0 & 0 & 0 & No \\
\hline 25 & 1973 & 20 & 2 & 3 & 0 & 0 & 0 & 0 & No \\
\hline 25 & 1975 & 19 & - & 3 & $?$ & $?$ & $?$ & $?$ & No \\
\hline 25 & 1976 & 20 & 2 & 3 & 0 & 0 & 0 & 0 & Nio \\
\hline 26 & 1965 & 20 & 2 & 3 & 0 & 0 & 0 & 0 & No \\
\hline 26 & 1966 & 20 & 1 & 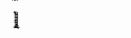 & 0 & 0 & 0 & 0 & No \\
\hline 26 & 1968 & 25 & - & 2 & 0 & 0 & 1748 & 0.02 & Yes \\
\hline 26 & 1969 & 20 & 3 & 3 & 0 & 0 & 0 & 0 & $\mathrm{No}$ \\
\hline 26 & 1971 & 24 & - & 2 & 0 & 0 & .14328 & $-0,08$ & Yes \\
\hline 26 & 1971 & 20 & 8 & 3 & 0 & 0 & 0 & 0 & Yes \\
\hline 26 & 1973 & 20 & 3 & 3 & 0 & 0 & 0 & 0 & No \\
\hline 26 & 1976 & 8 & . & 2 & 1652 & 0.06 & .1652 & -0.01 & Yes \\
\hline 27 & 1966 & 20 & 2 & 3 & 0 & 0 & 0 & 0 & No \\
\hline 27 & 1968 & 20 & 3 & 3 & 0 & 0 & 0 & 0 & No \\
\hline 27 & 1969 & 20 & 8 & 3 & 0 & 0 & 0 & 0 & $\mathrm{Na}$ \\
\hline 27 & 1969 & 18 & - & 2 & 0 & 0 & 6657 & 0.56 & Yes \\
\hline 27 & 1970 & 20 & 2 & 3 & 0 & 0 & 0 & 0 & No \\
\hline 27 & 1973 & 20 & 1 & 3 & 0 & 0 & 0 & 0 & No \\
\hline 27 & 1974 & 20 & 1 & 3 & 0 & 0 & 0 & 0 & No \\
\hline 27 & 1975 & 20 & 5 & 3 & 0 & 0 & $a$ & 0 & No \\
\hline 28 & 1966 & 20 & 4 & 3 & 0 & 0 & 0 & 0 & $\mathrm{No}$ \\
\hline 28 & 1967 & 20 & 1 & 3 & 0 & 0 & 0 & 0 & No \\
\hline 28 & 1968 & 20 & 3 & 3 & 0 & 0 & 0 & 0 & No \\
\hline 28 & 1969 & 20 & 1 & 3 & 0 & 0 & 0 & 0 & No \\
\hline 28 & $197 \mathrm{I}$ & 20 & 3 & 3 & 0 & 0 & 0 & 0 & No \\
\hline 28 & 1972 & 18 & - & 5 & $?$ & $?$ & $?$ & $?$ & Yes \\
\hline 28 & 1972 & 13 & - & 2 & -15235 & -0.21 & 15235 & 0.01 & Yes \\
\hline 28 & 1972 & 6 & . & 2 & 0 & 0 & -1353 & -0.05 & No \\
\hline 28 & 1972 & 24 & $=$ & 2 & $?$ & ? & $?$ & $?$ & No \\
\hline 28 & 1972 & 20 & 2 & 3 & 0 & 0 & 0 & 0 & Mo \\
\hline 28 & 1974 & 20 & 2 & 3 & 0 & 0 & 0 & 0 & No \\
\hline 28 & 1975 & 20 & 2 & 3 & 0 & 0 & 0 & 0 & No \\
\hline 29 & 1967 & 20 & 2 & 3 & 0 & 0 & 0 & 0 & $\mathrm{No}$ \\
\hline 29 & 1967 & 45 & . & 2 & .375 & 0.94 & 375 & 0.08 & Yes \\
\hline 29 & 1968 & 20 & 2 & 3 & 0 & 0 & 0 & 0 & No \\
\hline 29 & 1969 & 6 & 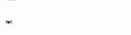 & 2 & $?$ & $?$ & $?$ & $?$ & Yes \\
\hline 29 & 1969 & 24 & . & 2 & $?$ & $?$ & ? & $?$ & Yes \\
\hline 29 & 1970 & 20 & 1 & 3 & 0 & 0 & 0 & 0 & No \\
\hline 29 & 1971 & 20 & 9 & 3 & 0 & 0 & 0 & 0 & $\mathrm{No}$ \\
\hline 29 & 1972 & 19 & - & 2 & 110 & 9.57 & .110 & 0.27 & Yes \\
\hline 29 & 1973 & 20 & 3. & 3 & 0 & 0 & 0 & 0 & No \\
\hline 29 & 1974 & 20 & 1 & 3 & 0 & 0 & 0 & 0 & No \\
\hline 30 & 1966 & 18 & - & 2 & $?$ & $?$ & 2329 & 0.29 & No \\
\hline 30 & 1967 & 20 & 2 & 3 & 0 & 0 & 0 & $a$ & No \\
\hline 30 & 1968 & 20 & 3 & 3 & 0 & 0 & 0 & 0 & No \\
\hline 30 & 1969 & 20 & i & 3 & 0 & 0 & 0 & 0 & $\mathrm{No}$ \\
\hline 30 & 1970 & 20 & i & 3 & 0 & 0 & 0 & 0 & $\mathrm{No}_{0}$ \\
\hline 30 & 1971 & 18 & - & 2 & 33 & 0.09 & .36 & -0.01 & Yes \\
\hline 30 & 1971 & 20 & 10 & 3 & 0 & 0 & 0 & 0 & No \\
\hline 30 & 1972 & 20 & ] & 3 & 0 & 0 & 0 & 0 & No \\
\hline 30 & 1973 & 20 & $\mathbb{1}$ & 3 & 0 & 0 & 0 & 0 & No \\
\hline 30 & 1974 & 20 & 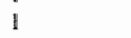 & 3 & 0 & 0 & 0 & 0 & No \\
\hline 31 & 1970 & 118 &. & 2 & 37 & 0.19 & .37 & 0.02 & Yes \\
\hline
\end{tabular}




\begin{tabular}{|c|c|c|c|c|c|c|c|c|c|}
\hline FIRM & YEAR & NATUEE & NUMBER & METHOD & EARN. EFF & $\%$ EARNINGS & EQUTIY EFF & \% EQUTTY & INFO \\
\hline $3 !$ & 1971 & 20 & 8 & 3 & 0 & 0 & 0 & 0 & No \\
\hline $3 \Perp$ & 1971 & 18 & - & 2 & $?$ & $?$ & $?$ & $?$ & Yies \\
\hline $3 \Perp$ & 1972 & 20 & 1 & 3 & 0 & a & 0 & 0 & No \\
\hline 31 & 1974 & 20 & 2 & 3 & 0 & a & 0 & 0 & No \\
\hline 31 & 1976 & 18 & ${ }^{\prime}$ & 4 & 0 & 0 & 48 & 0.02 & Yes \\
\hline 32 & 1966 & 6 & - & 4 & 0 & 0 & $?$ & 7 & Yes \\
\hline 32 & 1967 & 20 & 4 & 3 & 0 & 0 & 0 & 0 & No \\
\hline 32 & 1968 & 20 & 3 & 3 & 0 & $a$ & 0 & 0 & No \\
\hline 32 & 1969 & 24 & $=$ & 2 & 0 & a & $2 \pi 0$ & 0.02 & Yes \\
\hline 32 & 1971 & 22 & - & 2 & 22 & 0 & 0 & 0 & Yes \\
\hline 32 & 1971 & 20 & 5 & 3 & 0 & 0 & 0 & 0 & No \\
\hline 32 & 1972 & 6 & - & 5 & $?$ & $?$ & $?$ & $?$ & Yes \\
\hline 32 & 1972 & 25 & - & 2 & $?$ & $?$ & $?$ & $?$ & Yes \\
\hline 32 & 1973 & 24 & - & 4 & 0 & 0 & 3077 & 0.02 & Yes \\
\hline 32 & 1975 & 8 & - & 2 & .1918 & 0.18 & 0 & 0 & Yes \\
\hline 32 & 1976 & 20 & 2 & 0 & 0 & 0 & 0 & 0 & No \\
\hline 33 & 1966 & 8 & $=$ & 2 & $a$ & 0 & .34 & -0.06 & No \\
\hline 33 & 1966 & 20 & 2 & 3 & $a$ & 0 & 0 & 0 & No \\
\hline 33 & 1967 & 45 & - & 2 & 0 & 0 & 110 & 0.19 & No \\
\hline 33 & 1967 & 20 & 1 & 3 & 0 & 0 & 0 & 0 & No \\
\hline 33 & 1971 & 20 & 6 & 3 & 0 & 0 & 0 & 0 & No \\
\hline 33 & 1972 & 18 & - & 2 & 0 & 0 & 1139 & 0.15 & Yes \\
\hline 33 & 1972 & 8 & * & 2 & -250 & .0 .64 & 250 & 0.03 & $Y_{e s}$ \\
\hline 33 & 1973 & 20 & 1 & 3 & 0 & 0 & 0 & 0 & No \\
\hline 33 & 1974 & 20 & 1 & 3 & 0 & 0 & 0 & 0 & No \\
\hline 33 & 1975 & 20 & 3 & 3 & 0 & 0 & 0 & 0 & No \\
\hline 33 & 1976 & 20 & 3 & 3 & 0 & 0 & 0 & 0 & No \\
\hline 34 & 1966 & 20 & 2 & 3 & 0 & 0 & 0 & 0 & $\mathrm{No}$ \\
\hline 34 & 1966 & 8 & - & 2 & 0 & 0 & 2493 & 0.25 & Yes \\
\hline 34 & 1967 & 20 & 5 & 3 & 0 & 0 & 0 & 0 & No \\
\hline 34 & 1971 & 18 & - & 2 & 0 & 0 & 975 & 0.09 & Yes \\
\hline 34 & 1971 & 20 & 5 & 3 & 0 & 0 & 0 & 0 & No \\
\hline 34 & 1973 & 20 & 1 & 3 & 0 & 0 & 0 & 0 & No \\
\hline 34 & 1974 & 24 & . & 2 & $?$ & $?$ & 125 & 0.02 & Yes \\
\hline 34 & 1975 & 20 & 1 & 3 & 0 & 0 & 0 & 0 & No \\
\hline 35 & 1970 & 20 & 3 & 3 & 0 & 0 & 0 & 0 & $\mathrm{No}$ \\
\hline 35 & 1971 & 20 & 10 & 3 & 0 & 0 & 0 & 0 & No \\
\hline 35 & 1972 & 6 & . & 2 & 0 & 0 & 26478 & 0.59 & Yes: \\
\hline 35 & 1972 & 20 & 2 & 3 & 0 & 0 & 0 & 0 & No \\
\hline 35 & 1073 & 6 & . & 2 & 0 & 0 & 730 & 0.02 & Yes \\
\hline 35 & 1973 & 20 & 2 & 3 & 0 & 0 & 0 & 0 & No \\
\hline 35 & 1975 & 20 & 1 & 3 & 0 & 0 & 0 & 0 & No \\
\hline 35 & 1976 & 20 & 1 & 3 & 0 & 0 & 0 & 0 & No \\
\hline 36 & 1966 & 20 & 2 & 3 & 0 & 0 & 0 & 0 & No \\
\hline 36 & 1969 & 20 & 2 & 3 & 0 & 0 & 0 & 0 & No \\
\hline 36 & 1970 & 6 & . & 2 & -2620 & 0.46 & 2620 & 0.13 & Yes \\
\hline 36 & 1971 & 20 & 2 & 3 & 0 & 0 & 0 & 0 & $\mathrm{Mo}$ \\
\hline 36 & 1972 & 22 & . & 2 & -597 & $\times 0.12$ & 0 & 0 & Yes \\
\hline 36 & 1972 & 20 & 1 & 3 & 0 & $a$ & 0 & 0 & $\mathrm{No}$ \\
\hline 3.6 & 1973 & 48 & - & 2 & -30 & 0.03 & .91 & -0.02 & $\mathrm{Na}$ \\
\hline 3.6 & 1973 & 20 & 3 & 3 & 0 & 0 & 0 & 0 & No \\
\hline 36 & 1973 & 20 & 3 & 3 & 0 & 0 & 0 & 0 & No \\
\hline 36 & 1974 & 6 & . & 2 & -162 & -0.06 & -162 & -0.04 & Yes \\
\hline 3.6 & 1975 & 20 & I & 3 & 0 & 0 & 0 & 0 & No \\
\hline 36 & 1976 & 6 & . & 5 & $\eta$ & ? & $?$ & $?$ & No \\
\hline 37 & 1970 & 20 & 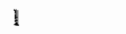 & 3 & 0 & 0 & 0 & 0 & Mo \\
\hline 37 & $197 \mathrm{I}$ & 6 & . & 4 & 0 & 0 & 704 & 0.05 & Yes \\
\hline 37 & 1972 & 20 & 3 & 3 & 0 & 0 & 0 & 0 & $\mathrm{No}$ \\
\hline 37 & 1972 & 6 & . & 2 & .240 & -0.13 & 240 & 0,02 & $\mathrm{No}$ \\
\hline 37 & 1974 & 6 & . & 1 & $?$ & $?$ & $?$ & $?$ & Yes \\
\hline 37 & 1975 & 20 & 2 & 3 & 0 & 0 & 0 & 0 & No \\
\hline 38 & 1966 & 20 & 3 & 3 & 0 & 0 & 0 & 0 & No \\
\hline
\end{tabular}




\begin{tabular}{|c|c|c|c|c|c|c|c|c|c|}
\hline FIRM & YEAR & NATURE & NUMBER & METHOD & EARN. EFF & \%EARNINGS & EQUTTY EFF & \% EQUTr & INFO \\
\hline 38 & $196 \pi$ & 20 & $\mathbb{1}$ & 3. & 0 & 0 & 0 & & No \\
\hline 38 & 1969 & 6 & - & 2 & 0 & 0 & 234 & 0.08 & Yes \\
\hline 38 & 1971 & 18 & : & 2 & .20 & .0 .03 & .20 & $a$ & No \\
\hline 38 & 1971 & 20 & 5 & 3 & 0 & 0 & 0 & 0 & No \\
\hline 38 & 1973 & 20 & 1 & 3 & 0 & 0 & 0 & 0 & No \\
\hline 38 & 1974 & 20 & 5 & 3 & 0 & 0 & 0 & 0 & No \\
\hline 38 & 1975 & 20 & 1 & 3 & 0 & 0 & 0 & 0 & No \\
\hline 39 & 1965 & 20 & 2 & 3 & 0 & 0 & 0 & 0 & No \\
\hline 39 & 1968 & 18 & & 2 & -75 & -0.25 & 0 & 0 & Yes \\
\hline 39 & 1968 & 20 & 4 & 3 & 0 & 0 & 0 & 0 & No \\
\hline 39 & 1969 & 20 & 3 & 3 & 0 & 0 & 0 & 0 & No \\
\hline 39 & 1970 & 20 & 2 & 3 & 0 & 0 & 0 & 0 & Mo \\
\hline 39 & 1971 & 18 & - & 4 & 0 & 0 & 125 & 0.09 & Yes \\
\hline 39 & 1971 & 8 & - & 2 & -40 & -0.24 & a & 0 & Yes \\
\hline 39 & 1971 & 24 & - & 2 & 0 & $a$ & 316 & 0.12 & Yes \\
\hline 39 & 1972 & 20 & 5 & 3 & 0 & $a$ & 0 & 0 & No \\
\hline 39 & 1975 & 20 & 1 & 3 & 0 & 0 & 0 & 0 & No \\
\hline 39 & 1976 & 20 & 2 & 3 & 0 & $a$ & 0 & 0 & No \\
\hline 40 & 1966 & 20 & 2 & 3 & 0 & 0 & 0 & 0 & No \\
\hline 40 & 1969 & 20 & 3 & 3 & 0 & 0 & 0 & 0 & No \\
\hline 40 & 1971 & 18 & " & 4 & 0 & 0 & -107 & -0.02 & Yes \\
\hline 40 & 1971 & 20 & 2 & 3 & 0 & 0 & 0 & 0 & No \\
\hline 40 & 1974 & 6 & - & 2 & 315 & 0.05 & 8125 & 0.12 & Yes \\
\hline 41 & 1965 & 4 & . & 2 & $?$ & $?$ & $?$ & $?$ & Yes \\
\hline 41 & 1966 & 20 & 1 & 3 & 0 & 0 & 0 & 0 & No \\
\hline 41 & 1969 & 20 & 7 & 3 & 0 & 0 & 0 & 0 & No \\
\hline 41 & 1970 & 20 & 1. & 3 & 0 & 0 & 0 & 0 & No \\
\hline 41 & 1971 & 20 & 2 & 3. & 0 & 0 & 0 & 0 & No \\
\hline 41 & 1972 & 20 & $\mathrm{l}$ & 3. & 0 & 0 & 0 & 0 & No \\
\hline 41 & 1973 & 25 & - & 2 & 40 & .05 & 0 & 0 & Yesi \\
\hline 41 & 1974 & 20 & $\Downarrow$ & 3 & 0 & 0 & a & 0 & No \\
\hline 41 & 1976 & 20 & 4 & 3 & 0 & 0 & 0 & 0 & No \\
\hline 42 & 1966 & 20 & 3. & 3 & 0 & 0 & 0 & 0 & No \\
\hline 42 & 1967 & 20 & 4 & 3 & 0 & 0 & $a$ & 0 & No \\
\hline 42 & 1968 & 20 & 2 & 3 & 0 & 0 & 0 & 0 & No \\
\hline 42 & 1969 & 20 & 3 & 3 & 0 & 0 & 0 & 0 & No \\
\hline 42 & 1970 & 20 & 3 & 3 & 0 & 0 & $a$ & 0 & No \\
\hline 42 & 1971 & 20 & 2 & 3 & 0 & 0 & 0 & 0 & No \\
\hline 42 & 1972 & 20 & 3 & 3 & 0 & 0 & 0 & 0 & No \\
\hline 42 & 1973 & 13 & $=$ & 2 & 0 & 0 & .3753 & .0 .08 & No \\
\hline 42 & 1973 & 20 & 7 & 3 & 0 & 0 & 0 & 0 & No \\
\hline 43 & 1966 & 6 & - & 2 & 0 & 0 & -464 & 0.03 & No \\
\hline 43 & 1967 & 20 & d & 3 & 0 & 0 & 0 & 0 & No \\
\hline 43 & 1969 & 20 & 3 & 3 & 0 & 0 & 0 & 0 & No \\
\hline 43 & 1970 & 6 & . & 7 & 975 & 0.12 & 9986 & 0.07 & Yes \\
\hline 43 & 1970 & 20 & 4 & 3 & 0 & 0 & 0 & 0 & No \\
\hline 43 & 1971 & 20 & 3 & 3 & $a$ & 0 & 0 & 0 & No \\
\hline 43 & 1972 & 20 & 1 & 3 & 0 & 0 & 0 & 0 & No \\
\hline 4.3 & 1973 & 20 & 5 & 3 & 0 & 0 & 0 & 0 & No \\
\hline 43 & 1974 & 20 & $i$ & 3 & 0 & 0 & 0 & 0 & No \\
\hline 43 & 1975 & 6 & - & 2 & 0 & 0 & 0 & 0 & Yes \\
\hline 43 & 1975 & 20 & 4 & 3 & 0 & 0 & 0 & 0 & No \\
\hline 43 & 1976 & 20 & 3 & 3 & 0 & 0 & 0 & 0 & No \\
\hline 44 & 1967 & 20 & 1 & 3 & 0 & 0 & 0 & 0 & No \\
\hline 44 & 1969 & 20 & 2 & 3 & 0 & 0 & 0 & 0 & No \\
\hline 44 & 1970 & 6 & - & 2 & 0 & 0 & $?$ & $?$ & Yes \\
\hline 44 & 1970 & 18. & . & 2 & 0 & 0 & 16858 & 0.44 & Yes \\
\hline 44 & 1970 & 13 & " & 2 & 0 & 0 & 596 & 0.02 & Yes \\
\hline 44 & 1970 & 20 & 4 & 3 & 0 & 0 & 0 & 0 & No \\
\hline 44 & $197 !$ & 20 & 4 & 3 & 0 & 0 & 0 & 0 & No \\
\hline 44 & 1973 & 20 & 1 & 3 & 0 & 0 & $a$ & 0 & No \\
\hline 45 & 1966 & 6 & - & 2 & $?$ & $?$ & $?$ & $?$ & Yes \\
\hline
\end{tabular}




\begin{tabular}{|c|c|c|c|c|c|c|c|c|c|}
\hline FIRM & YEAR & NATURE & NUMBER & METHOD & EARW EFF & WEARNINGS & EQUITY EFF & \% EQUITY & INEO \\
\hline 45 & 1967 & 20 & 2 & 3 & 0 & 0 & 0 & 0 & No \\
\hline 45 & 1968 & 20 & 1 & 3 & 0 & 0 & 0 & 0 & No \\
\hline 4.5 & 1971 & 18 & - & 4 & $?$ & $?$ & $?$ & $?$ & Yes \\
\hline 45 & 1971 & 20 & 1 & 3 & 0 & 0 & 0 & 0 & No \\
\hline 45 & 1971 & 18 & - & 2 & -281 & .0 .04 & 283 & 0.04 & No \\
\hline 45 & 1974 & 6 & - & 2 & 0 & 0 & 0 & 0 & Yes \\
\hline 45 & 1.975 & 3 & - & 2 & $?$ & $?$ & 7 & $?$ & Yes \\
\hline 45 & 1976 & 3 & . & 2 & $?$ & $?$ & 7 & $?$ & Yes \\
\hline 46 & 1966 & 20 & 5 & 3 & 0 & 0 & 0 & 0 & No \\
\hline 46 & 1967 & 20 & 2 & 3 & 0 & 0 & 0 & 0 & No \\
\hline 46 & 1968 & 20 & 4 & 3 & 0 & 0 & 0 & 0 & No \\
\hline 46 & 1969 & 11 & - & 2 & $?$ & $?$ & ? & $?$ & Yes \\
\hline 46 & 1969 & 20 & 4 & 3 & 0 & 0 & 0 & 0 & No \\
\hline 46 & 1970 & 47 & . & 2 & $?$ & $?$ & ? & $?$ & Yes \\
\hline 46 & 1970 & 20 & 3 & 3 & $a$ & 0 & 0 & 0 & No \\
\hline 46 & 1972 & 20 & 2 & 3 & 0 & 0 & 0 & 0 & No \\
\hline 46 & 1976 & 20 & 1 & 3 & $a$ & 0 & 0 & 0 & No \\
\hline 47 & 1970 & 20 & 12 & 3 & 0 & 0 & 0 & 0 & No \\
\hline 47 & 1970 & 8 & . & 2 & .50 & -0.06 & 0 & 0 & Yes \\
\hline 47 & 1971 & 20 & 3 & 3 & $a$ & 0 & 0 & 0 & No \\
\hline 47 & 1973 & 20 & 2 & 3 & 0 & 0 & 0 & 0 & No \\
\hline 47 & 1974 & 20 & 1 & 3 & 0 & 0 & 0 & 0 & $\mathrm{No}$ \\
\hline 47 & 1975 & 20 & 2 & 3 & 0 & 0 & 0 & 0 & No \\
\hline 48 & 1969 & 6 & - & 2 & 0 & 0 & 0 & 0 & Yes \\
\hline 48 & 1970 & 20 & 4 & 3 & 0 & 0 & 0 & 0 & No \\
\hline 48 & 1971 & 18 & . & 2 & 0 & 0 & 5136 & 0.36 & Yes \\
\hline 48 & 1971 & 20 & 8 & 3 & 0 & 0 & 0 & 0 & No \\
\hline 48 & 1972 & 20 & 2 & 3 & 0 & 0 & 0 & 0 & No \\
\hline 48 & 1973 & 20 & 2 & 3 & 0 & D & 0 & 0 & No \\
\hline 48 & 1974 & 33 & . & 2 & 0 & 0 & -58 & -0.04 & Yes \\
\hline 48 & 1975 & 33 & - & 2 & 0 & 0 & -124 & .0 .010 & Yes \\
\hline 48 & 1975 & 6 & . & 2 & $?$ & $?$ & $?$ & $?$ & Yes \\
\hline 48 & 1975 & 20 & 4 & 3 & $a$ & 0 & 0 & 0 & $\mathrm{No}$ \\
\hline 48 & 1976 & 20 & 4 & 3 & $a$ & 0 & 0 & 0 & No \\
\hline 49 & 1966 & 20 & 1 & 3 & 0 & 0 & 0 & 0 & No \\
\hline 49 & 1967 & 6 & . & 2 & $?$ & $?$ & $?$ & $?$ & No \\
\hline 49 & 1967 & 20 & 1 & 3 & 0 & 0 & 0 & 0 & No \\
\hline 49 & 1969 & 6 & . & 2 & $?$ & $?$ & $?$ & ? & Yes \\
\hline 49 & 1971 & 6 & . & 2 & $?$ & $?$ & ? & $?$ & Yes \\
\hline 49 & 1971 & 6 & . & 2 & $?$ & $?$ & $?$ & $?$ & Yes \\
\hline 49 & $197 \|$ & 24 & . & 2 & $?$ & $?$ & ? & $?$ & Yes \\
\hline 49 & 1971 & 4 & . & 2 & 72 & 8.21 & 72 & 0 & Yes \\
\hline 49 & 1972 & 20 & 2 & 3 & 0 & 0 & 0 & 0 & No \\
\hline 49 & 1974 & 6 & - & 2 & 24 & 0.03 & 24 & 0 & Yes \\
\hline 49 & 1974 & 6 & . & 2 & $?$ & $?$ & $?$ & $?$ & Yes \\
\hline 49 & 1975 & 20 & 2 & 3 & 0 & 0 & 0 & 0 & No \\
\hline 49 & 1976 & 20 & 3 & 3 & 0 & 0 & 0 & 0 & No \\
\hline 50 & 1966 & 6 & . & 2 & $?$ & $?$ & $?$ & $?$ & Yes \\
\hline 50 & 1968 & 20 & 1 & 3 & 0 & 0 & 0 & 0 & No \\
\hline 50 & 1968 & 6 & - & 2 & 0 & 0 & 33 & 08 & Yes \\
\hline 50 & 1.969 & 20 & 2 & 3 & 0 & 0 & 0 & 0 & No \\
\hline 50 & 1970 & 8 & . & 2 & 20 & 4.16 & -70 & 0.19 & Yes \\
\hline 50 & 1970 & 20 & 3 & 3 & 0 & 0 & 0 & 0 & No \\
\hline 50 & 1971 & 24 & . & 2 & $?$ & $?$ & $?$ & $?$ & Yes \\
\hline 50 & 1971 & 20 & 7 & 3 & 0 & 0 & 0 & 0 & No \\
\hline 50 & 1975 & 18 & . & 2 & 0 & 0 & 70 & 0.32 & Yes \\
\hline 50 & 1976 & 20 & 3 & 3 & 0 & a & 0 & 0 & No \\
\hline 51 & 1967 & 20 & 1 & 3 & 0 & 0 & 0 & 0 & No \\
\hline 51 & 1969 & 20 & 4 & 4 & 0 & 0 & 0 & 0 & No \\
\hline 51 & 1970 & 20 & 2 & 3 & 0 & 0 & 0 & 0 & No \\
\hline 51 & $197 \mathbb{1}$ & 6 & . & 4 & $=270$ & 0.47 & .254 & -0.06 & Yes: \\
\hline 51 & 1971 & 20 & 9 & 3 & 0 & 0 & 0 & 0 & No \\
\hline
\end{tabular}




\begin{tabular}{|c|c|c|c|c|c|c|c|c|c|}
\hline FHM & YEAR & NATURE & NUMBER & METHOD & EARN & \%EARNINGS & EQUTTY EFF & EQumY & INFO \\
\hline 51 & 1972 & 20 & 2 & 3 & 0 & 0 & $\mathfrak{0}$ & 0 & $\mathrm{No}$ \\
\hline 51 & 1973 & 20 & 2 & 3 & 0 & 0 & 0 & 0 & No \\
\hline 51 & 1974 & 8 & " & 2 & 0 & 0 & -86 & -0.04 & Yes \\
\hline 511 & 1974 & 20 & 4 & 3 & 0 & 0 & 0 & 0 & No \\
\hline $5 \|$ & 1975 & 20 & 2 & 3 & 0 & 0 & 0 & 0 & No \\
\hline 51 & 1976 & 8 & - & 2 & $a$ & 0 & -113 & -0.05 & Yes \\
\hline 51 & 1976 & 20 & 2 & 3 & 0 & 0 & 0 & 0 & No \\
\hline 52 & 1967 & 20 & 1 & 3 & 0 & 0 & 0 & 0 & No \\
\hline 52 & 1969 & 24 & - & 2 & 0 & 0 & 6664 & 0.17 & Yes \\
\hline 52 & 1970 & 20 & 1 & 3 & 0 & 0 & 0 & 0 & $\mathrm{No}$ \\
\hline 52 & 197 & 8 & " & 2 & 0 & 0 & -370 & -0.13 & Yes \\
\hline 52 & 1971 & 24 & - & 2 & 0 & 0 & $?$ & $?$ & Yes \\
\hline 52 & 1971 & 20 & 3 & 3 & 0 & 0 & 0 & 0 & $\mathrm{No}$ \\
\hline 52 & 1972 & 20 & 1 & 3 & 0 & 0 & 0 & 0 & No \\
\hline 52 & 1973 & 20 & 2 & 3 & 0 & 0 & 0 & 0 & No \\
\hline 52 & 1974 & 20 & 2 & 3 & 0 & 0 & 0 & 0 & No \\
\hline 52 & 1976 & 24 & . & 4 & 0 & 0 & -3972 & -0.11 & $X_{\mathrm{ess}}$ \\
\hline 53 & 1966 & 20 & 2 & 3 & 0 & 0 & 0 & 0 & No \\
\hline 53 & 1967 & 20 & 2 & 3 & 0 & 0 & 0 & 0 & No \\
\hline 53 & 1968 & 20 & 1 & 3 & 0 & 0 & 0 & 0 & No \\
\hline 53 & 1969 & 45 & - & 2 & -275 & -0.40 & 275 & 0.06 & Yes \\
\hline 53 & 1970 & 20 & 1 & 3 & 0 & 0 & 0 & 0 & No \\
\hline 53 & 1971 & 18 & . & 2 & 0 & 0 & 3856 & 0.44 & Yes \\
\hline 53 & 1971 & 18 & - & 2 & $?$ & $?$ & $?$ & $?$ & Yes \\
\hline 53 & 1971 & 45 & - & 2 & 482 & 0.32 & -482 & 0.15 & Yess \\
\hline 53 & 1972 & 45 & - & 2 & 324 & 0.39 & .324 & -0.03 & Yes \\
\hline 53 & 1973 & 45 & . & 2 & 324 & 0.32 & -324 & -0.03 & Yes \\
\hline 53 & 1974 & 45 & - & 2 & 284 & 0.25 & .284 & -0.04 & Yes \\
\hline 53 & 1974 & 6 & - & 2 & 0 & 0 & 397 & 0.04 & Yes \\
\hline 53 & 1975 & 6 & - & 2 & 239 & 0.37 & -239 & 0.02 & Yes \\
\hline 53 & 1976 & 20 & 2 & 3 & 0 & 0 & 0 & 0 & No \\
\hline 54 & 1966 & 11 & " & 4 & -25 & .02 & 325 & 0.08 & Yes \\
\hline 54 & 1969 & 18 & - & 2 & $?$ & $?$ & 760 & 0.14 & Yes: \\
\hline 54 & 1969 & 45 & " & 2 & 0 & 0 & -382 & -0.07 & No \\
\hline 54 & 1969 & 20 & 5 & 3 & 0 & 0 & 0 & 0 & No \\
\hline 54 & 1970 & 20 & I & 3 & 0 & 0 & 0 & 0 & No \\
\hline 54 & 1971 & 20 & 1 & 3 & 0 & 0 & 0 & 0 & No \\
\hline 54 & 1972 & 20 & 3 & 3 & 0 & 0 & 0 & 0 & No \\
\hline 55 & 1965 & 20 & 2 & 3 & 0 & 0 & 0 & 0 & No \\
\hline 55 & 1968 & 20 & 1 & 3 & 0 & 0 & 0 & 0 & No \\
\hline 55 & 1969 & 20 & 2 & 3 & 0 & 0 & 0 & 0 & No \\
\hline 55 & 1971 & 45 & - & 1 & -2799 & -35.88 & 0 & 0 & No \\
\hline 55 & 1971 & 24 & - & 2 & .1382 & -1.77 & 1382 & 0.13 & Yess \\
\hline 35 & 1973 & 24 & - & 4 & 50 & 016 & 2186 & 0.15 & Yess \\
\hline 55 & 1974 & 18 & 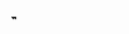 & 4 & 0 & 0 & 3597 & 0.18 & Yizes \\
\hline 55 & 1976 & 20 & 2 & 3. & 0 & 0 & 0 & 0 & No \\
\hline 56 & 1.965 & 20 & 2 & 3 & 0 & 0 & 0 & 0 & No \\
\hline 56 & 1967 & 20 & 2 & 3 & 0 & 0 & 0 & 0 & No \\
\hline 56 & 1969 & 20 & 3 & 3 & 0 & 0 & 0 & 0 & No \\
\hline 56 & 1970 & 20 & 1 & 3 & 0 & 0 & 0 & 0 & No \\
\hline 56 & 1970 & 6 & - & 2 & 0 & 0 & 792 & 0.31 & Yest \\
\hline 56 & 1971 & 20 & 4 & 3 & 0 & 0 & 0 & 0 & Nio \\
\hline 56 & 1974 & 18 & - & 2 & .253 & -0.22 & 456 & 0.05 & No \\
\hline 56 & 1975 & 18 & - & 2 & 72 & 0.06 & 0 & 0 & Yes \\
\hline 57 & 1967 & 20 & l & 3 & 0 & 0 & 0 & 0 & No \\
\hline 57 & 1968 & 20 & 3 & 3 & 0 & 0 & 0 & 0 & No \\
\hline 57 & 1971 & 6 & - & 2 & 71 & 0.29 & 140 & 0.02 & Ye:s \\
\hline 57 & 1971 & 20 & 3 & 3 & 0 & 0 & 0 & 0 & No \\
\hline $5 \pi$ & 1972 & 20 & 3 & 3 & 0 & a & 0 & 0 & No \\
\hline 57 & 1974 & 20 & 1 & 3 & 0 & 0 & 0 & 0 & $\mathrm{Na}$ \\
\hline 57 & 1976 & 20 & 2 & 3 & 0 & 0 & 0 & 0 & No \\
\hline 58 & 1966 & 20 & 1 & 3 & 0 & 0 & 0 & 0 & No \\
\hline
\end{tabular}




\begin{tabular}{|c|c|c|c|c|c|c|c|c|c|}
\hline FrMM & YEAR & NATURE & NUMBER & METHOD & EARN. EFF & $\%$ EARNINGS & EQUHTYEFF & $\% \mathbb{E Q U T T}$ & INFO \\
\hline$\$ 8$ & 1968 & 20 & 1 & 3 & 0 & 0 & 0 & 0 & No \\
\hline 58 & 1969 & 20 & 4 & 3 & 0 & 0 & 0 & 0 & No \\
\hline 58 & 1971 & 20 & 10 & 3 & 0 & 0 & 0 & 0 & Mo \\
\hline 38 & 1972 & 20 & 2 & 3 & 0 & 0 & 0 & 0 & No \\
\hline$\$ 8$ & 1973 & 20 & 4 & 3 & 0 & 0 & 0 & 0 & No \\
\hline 58 & 1974 & 20 & 2 & 3 & 0 & 0 & 0 & 0 & No \\
\hline 58 & 1974 & 8 & - & 2 & 0 & 0 & -43 & -01 & Yes \\
\hline 59 & 1966 & 20 & 2 & 3 & 0 & 0 & 0 & 0 & No \\
\hline 59 & 1969 & 18 & - & 2 & 100 & 0.24 & -100 & -0.03 & Yes \\
\hline$\$ 9$ & 1970 & 24 & - & 2 & $?$ & $?$ & $?$ & $?$ & Yes \\
\hline 59 & 1970 & 20 & 4 & 3 & 0 & 0 & 0 & 0 & No \\
\hline 59 & 1971 & 8 & . & 2 & 0 & 0 & 0 & 0 & Yess \\
\hline 59 & 1971 & 4 & - & 2 & 0 & 0 & 794 & 0.02 & Yes \\
\hline 59 & 1971 & 6 & - & 4 & 190 & 0.01 & 877 & 0.02 & Yes \\
\hline 59 & 974 & 18 & . & 4 & 0 & 0 & 10784 & 0.19 & Yes \\
\hline 60 & 1965 & 20 & 2 & 3 & 0 & 0 & 0 & 0 & No \\
\hline 60 & 1968 & 20 & 3 & 3 & 0 & 0 & 0 & 0 & No \\
\hline 60 & 1.970 & 15 & . & 2 & $?$ & $?$ & $\llbracket 386$ & 0.05 & Yess \\
\hline 60 & 1971 & 15 & - & 2 & $?$ & $?$ & $?$ & $?$ & Yes \\
\hline 60 & 1971 & 20 & 4 & 3 & 0 & 0 & 0 & 0 & No \\
\hline 60 & 1.973 & 18 & - & 4 & $?$ & $?$ & $?$ & $?$ & Yes \\
\hline 60 & 1973 & 24 & . & 2 & $?$ & $?$ & $?$ & $?$ & Yes \\
\hline 61 & 1968 & 18 & - & 4 & 0 & 0 & 27761 & 0.22 & Yes \\
\hline 61 & 1968 & 13 & . & 2 & 0 & 0 & -7855 & -0.07 & Yes \\
\hline 61 & 1968 & 6 & " & 2 & $?$ & $?$ & 3714 & 0.03 & Yos \\
\hline 61 & 1969 & 20 & 1 & 3 & 0 & 0 & 0 & 0 & $\mathrm{No}$ \\
\hline 61 & 1970 & 18 & - & 2 & 0 & 0 & 2484 & 0.01 & Yes \\
\hline 61 & 1970 & 6 & . & 2 & $?$ & $?$ & $?$ & $?$ & Yes \\
\hline 61 & 1971 & 20 & 9 & 3 & 0 & 0 & 0 & 0 & No \\
\hline 61 & 1973 & 20 & 5 & 3 & 0 & 0 & 0 & 0 & No \\
\hline 61 & 1974 & 20 & 2 & 3 & 0 & 0 & 0 & 0 & No \\
\hline 61 & 1976 & 20 & 2 & 3 & 0 & 0 & 0 & 0 & No \\
\hline 62 & 1967 & 8 & - & 2 & 0 & 0 & $?$ & $?$ & Yes \\
\hline 62 & 1968 & 6 & 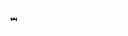 & 2 & 0 & 0 & $?$ & $?$ & Yes \\
\hline 62 & 1970 & 20 & 1 & 3 & 0 & 0 & 0 & 0 & No \\
\hline 62 & 1971 & 20 & 6 & 3 & 0 & 0 & 0 & 0 & No \\
\hline 62 & 1972 & 20 & 8 & 3 & 0 & 0 & 0 & 0 & No \\
\hline 62 & 1973 & 24 &. & 2 & 0 & 0 & -4211 & -0.11 & No \\
\hline 62 & 1973 & 18 & 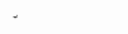 & 2 & 418 & $-0,06$ & 418 & 0.01 & Yea \\
\hline 62 & 1974 & 6 & - & 2 & 0 & 0 & 0 & 0 & No \\
\hline 62 & 1974 & 6 & . & 2 & 0 & 0 & 0 & 0 & No \\
\hline 62 & 1974 & 20 & 3 & 3 & 0 & $a$ & 0 & 0 & No \\
\hline 62 & 1975 & 24 & - & 2 & 1062 & 0.19 & 1790 & 0.03 & Yres \\
\hline 62 & 1976 & 24 & . & 2 & 1046 & 0.13 & 1475 & 0.01 & Yes \\
\hline 62 & 1976 & 20 & 2 & 3 & 0 & 0 & 0 & 0 & No \\
\hline 63 & 1967 & 20 & 3 & 3 & 0 & 0 & 0 & 0 & Mio \\
\hline 63 & 1968 & 20 & 3 & 3 & 0 & 0 & 0 & 0 & No \\
\hline 63 & 1969 & 20 & 4 & 3 & 0 & 0 & 0 & 0 & No \\
\hline 63 & 1970 & 20 & l & 3 & 0 & 0 & 0 & 0 & No \\
\hline 63 & 1971 & 20 & 9 & 3 & 0 & 0 & 0 & 0 & No \\
\hline 63 & 1972 & 6 & . & 2 & 0 & 0 & 0 & 0 & No \\
\hline 63 & 1972 & 20 & 5 & 3 & 0 & 0 & 0 & 0 & No \\
\hline 63 & 1973 & 20 & 2 & 3 & 0 & 0 & 0 & 0 & No \\
\hline 63 & 1974 & 20 & 2 & 3 & 0 & 0 & 0 & 0 & No \\
\hline 63 & 1975 & 46 & - & 2 & 312 & 0.49 & 0 & 0 & Yes \\
\hline 63 & 1975 & 20 & 3 & 3 & 0 & 0 & 0 & 0 & No \\
\hline 63 & 1976 & 46 & - & 2 & 256 & 0.24 & 0 & 0 & Yes: \\
\hline 63 & 1976 & 20 & 2 & 3 & 0 & 0 & 0 & 0 & No \\
\hline 64 & 1969 & 20 & 3 & 3 & 0 & 0 & 0 & 0 & No \\
\hline 64 & 1970 & 8 & . & 2 & 0 & 0 & 0 & 0 & No \\
\hline 64 & 1970 & 20 & 4 & 3 & 0 & 0 & 0 & 0 & No \\
\hline 64 & 1971 & 20 & 9 & 3 & 10 & 0 & 0 & 0 & No \\
\hline
\end{tabular}




\begin{tabular}{|c|c|c|c|c|c|c|c|c|c|}
\hline FIRM & YEAR & NATURE & NUMBER & METHOD & EARN, EFF & GEARNINGS & EQUTTY EFF & EQUITY & INFO \\
\hline 64 & 1975 & 20 & 2 & 3 & 0 & 0 & 0 & 0 & No \\
\hline 64 & 1976 & 18 & . & 2 & -310 & -0.70 & 8396 & 0.26 & yes \\
\hline 64 & 1976 & 20 & 4 & 3 & 0 & 0 & 0 & 0 & No \\
\hline
\end{tabular}

cotal number of accounting changes: 1308 
Appendix $3 \mathrm{C} .2$ : Accounting changes Title 8 sample firms (2)

\section{Explamatory list of abbreviations}

\section{"Nature of accounting changes:}
(1) startup costs/preoperational expenses
(2) assetsin not in usefidle porperty
(26) foreign currencies
(3) past service commitments
(27) tax credits
(4) majiry valuation criteria
(5) extraordinary items
(G)subsidiaries
(7)prowisions
(8) securities
(28) furniture and inxtures
(29) gearing adjustment
(30) taxes
(9)shares
(31) development credit
(32) early retirement plan
(33) receivables
(34) short-term liabilities

(10)exploration costs

(11)goodwill

(12) lease/rental rights

(35) subscriptions

(13)intagible assets)

(36) investments

(37) reorganisation costs

(38) bonds and debentures

(14)interest costs

(15) plant and equipment.

(39) unearned premium reserve

(16) lease contracts

(17) lioans

(18)tangible fixed assets

(19)work in process

(20)disclosure/classification ito

(21) research and dewelopment

(40) commission tees insurances.

(41) anntities

(42) dividend

(43) general expenses

(44) costs of share trading/deductible expenses

(45) reserves

(46) depreciation

(47) minority interest

(23)holiday bonus

(24)inventory

(48) turnower

25)deffered tax allowance

(49) capital surplusishare premium reserve

Number:

GTe information provided here summarizes all classificatory changes made in one year

\section{"Explanatory list of adjustment methods:}

(1) cumulative effect in result (cumulatief effect in resultadt)

(2). currem adjustment (actued, aarpassing nteuwe activa en passiva)

(3) current and future adjustment (actueel, ampassing alle relevante activa en passiva)

(4) cumulative elfect in equity (cumulatief effect in eigen vermogen)

(5) unknown

(6) method 1 \& 4 combined

\section{* Earnings/Equity and \%Earnings/\% Equity}

The impact and relative inpact of the accounting change on earnings/equity

$?$ the impact could not be dietermined

\section{*INFO}

Yes: infortmation is prowided in the annual financial statement on the nature and/or magniotude of the accounting change No: no information is included in the annual financial statement on the nature andior magnitude of the accounting change 


\begin{tabular}{|c|c|c|c|c|c|c|c|c|}
\hline FIRM & YEAR & NATURE* & METHHOD & EARN EFF & \%EARNINGS & EQUTIY EFF. & \& ECUMTI & MNFO \\
\hline 1 & 1986 & 6 & $\mathbb{1}$ & -56 & $-0: 1$ & 0 & 0 & Yes \\
\hline 2 & 1979 & 6 & 2 & 648 & 1.71 & 0 & 0 & Yes \\
\hline 2 & 1984 & 11 & 4 & 1462 & 0.16 & -3502 & -0.17 & Yest \\
\hline 2 & 1984 & 26 & 2 & -1690 & -0.18 & 1690 & 0.08 & Yes \\
\hline 3 & 1977 & 22 & 3 & -645 & -0.05 & 0 & 0 & No \\
\hline 3 & 1978 & 25 & 4 & $?$ & $?$ & $?$ & $?$ & Yes \\
\hline 3 & 1984 & 24 & 4 & -100 & .0 .01 & 1682 & 0.01 & Yes \\
\hline 3 & 1984 & 22 & 3 & 73 & $0.0:$ & 0 & 0 & No \\
\hline 4 & $197 t$ & 12 & 2 & $?$ & $?$ & 0 & 0 & No \\
\hline 4 & 1977 & 11 & 2 & 4302 & 0.13 & 0 & 0 & No \\
\hline 4 & 1982 & 6 & 3 & $?$ & $?$ & 6661 & 0.01 & yes \\
\hline 4 & 1982 & 18 & 3 & 1266 & 0.02 & -1266 & 0 & yes \\
\hline 4 & 1983 & 26 & 2 & $?$ & $?$ & $?$ & $?$ & Yes \\
\hline 4 & 1984 & 16 & 3 & $?$ & $?$ & -4407 & .0 .01 & Yes \\
\hline 5 & 1977 & 1 & 4 & 15000 & 0.09 & 22000 & 0.01 & Yess \\
\hline 5 & 1980 & 14 & 2 & 19000 & 0.21 & 0 & 0 & Yes \\
\hline 5 & 1984 & 26 & 5 & 0 & 0 & 0 & 0 & Yes \\
\hline 6 & 1977 & 18 & 2 & 49 & 0.01 & -49 & 0 & No \\
\hline 6 & 1983 & 6 & 1 & 368 & 0.1 & 0 & 0 & Yes \\
\hline 7 & 1980 & 4 & 3 & 0 & 0 & 12689 & 0.15 & Yes \\
\hline 7 & 1984 & 13 & 4 & 400 & 0.03 & -1144 & -0.01 & Yes \\
\hline 8 & 1977 & 25 & 4 & $?$ & $?$ & -446 & .0 .05 & Yes \\
\hline 8 & 1977 & 6 & 3 & $?$ & $?$ & 1249 & 0.14 & Yes \\
\hline 8 & 1978 & 7 & 4 & 39 & 0.04 & -385 & -0.04 & Yes \\
\hline a & 1979 & 20 & 3 & $?$ & $?$ & -486 & -0.05 & Yes \\
\hline 8 & 1980 & 7 & 1 & 1243 & 113 & 0 & 0 & Yes \\
\hline$\$$ & 1985 & 25 & 1 & 99 & 0.18 & 0 & 0 & No \\
\hline 9 & 1980 & 14 & 2 & $?$ & $?$ & 0 & 0 & Yes: \\
\hline 9 & 1982 & 19 & 5 & -1100 & -0.27 & $a$ & 0 & $Y^{\prime \prime e s}$ \\
\hline 9 & 11983 & 6 & 4 & 0 & 0 & 1049 & 0.03 & Yes \\
\hline 9 & 1984 & 24 & 5 & $?$ & $?$ & 0 & 0 & No \\
\hline 9 & 1986 & 19 & 2 & 0 & 0 & 0 & 0 & Yes \\
\hline 10 & 1985 & 19 & 5 & 0 & 0 & 0 & 0 & Yes \\
\hline 11 & 1978 & 18 & 4 & 33 & 0 & 3160 & 0.24 & Yes \\
\hline 11 & 1980 & 6 & 5 & $?$ & $?$ & ? & $?$ & No \\
\hline 11 & 1981 & 26 & 2 & 0 & 0 & 0 & 0 & Yes \\
\hline 11 & 1985 & 7 & 4 & 0 & 0 & 5500 & 0.3 & Yes \\
\hline 12 & 1980 & 25 & 4 & 0 & 0 & -1922 & $-0,03$ & Yes \\
\hline 13 & 1978 & 20 & 3 & 0 & 0 & .1 & 0 & No \\
\hline 13 & 1979 & 20 & 3 & 0 & 0 & .8508 & -8.12 & Yes \\
\hline 13 & .. 979 & 25 & 5 & -25 & 0 & 0 & 0 & Yes \\
\hline 13 & 1979 & 7 & 5 & .85 & .0 .01 & 0 & 0 & Yes \\
\hline 13 & 1980 & 7 & 5 & $?$ & $?$ & 0 & 0 & No \\
\hline 13 & 1982 & 25 & 4 & $?$ & $?$ & 800 & 1.26 & Yest \\
\hline 13 & 1986 & 18 & 2 & $?$ & $?$ & $p$ & $?$ & $\mathrm{Mo}$ \\
\hline 14 & 1979 & 21 & 3 & $?$ & $?$ & .1302 & -0.0 & $\mathrm{Yes}$ \\
\hline 15 & 1978 & 2 & 2 & $?$ & $?$ & $?$ & $?$ & Mo \\
\hline 15 & 1980 & $\mathbb{1}$ & 2 & -22 & -0.09 & 0 & 0 & No \\
\hline 15 & 1983 & 26 & 5 & $?$ & $?$ & 0 & 0 & No \\
\hline 15 & 1986 & 26 & 2 & 2481 & 1.22 & -2481 & 0.06 & Yess \\
\hline 15 & 1986 & 26 & 3 & $?$ & $?$ & 0 & 0 & No \\
\hline 16 & 1981 & 25 & 1 & .400 & -0.25 & 0 & 0 & No \\
\hline 17 & 1977 & 18 & 3 & 0 & 0 & 27411 & 0.19 & Yes \\
\hline 17 & 1982 & 26 & 2 & 2000 & 0.05 & .2000 & .0 .01 & Yes \\
\hline 17 & 1985 & 26 & 2 & .2300 & 0.04 & 2300 & 0.01 & Yes \\
\hline 18 & 1978 & 15 & 4 & .290 & -0.02 & 9972 & 0.13 & Yes \\
\hline 18 & 1980 & 11 & 2 & 14424 & 2.82 & 0 & 0 & $\mathrm{No}$ \\
\hline 18 & 1983 & 11 & 2 & 7 & $?$ & -2617 & .0 .02 & Yes \\
\hline 18 & 1984 & 11 & 2 & $?$ & $?$ & 0 & 0 & Yes \\
\hline 19 & 1980 & 19 & $\mathbb{j}$ & 15000 & 0.41 & 0 & 0 & Yes \\
\hline 19 & 1.980 & 11 & 2 & $?$ & $?$ & .394 & 0 & No \\
\hline 19 & 1980 & 14 & 5 & ? & $?$ & 0 & 0 & No \\
\hline
\end{tabular}




\begin{tabular}{|c|c|c|c|c|c|c|c|c|}
\hline FIRM & YEAR & NATURE & METHOD & EARN EFF. & \%EARNINGS & EQUTTY EFE. & \% EQUTY & MNFO \\
\hline 19 & 1981 & 26 & 5 & $?$ & $?$ & 0 & 0 & No \\
\hline 19 & 1981 & 25 & 5 & $?$ & $?$ & 0 & 0 & No \\
\hline 19 & 1984 & 26 & 5 & $?$ & $?$ & 0 & 0 & No \\
\hline 19 & 1984 & 25 & 5 & $?$ & $?$ & 0 & 0 & No \\
\hline 19 & 1986 & 24 & 5 & $?$ & $?$ & 0 & 0 & $\mathrm{No}$ \\
\hline 20 & 1978 & 6 & 1 & 106 & 0.19 & 0 & 0 & Yes \\
\hline 20 & 1979 & 19 & 5 & $?$ & $?$ & 0 & 0 & $\mathrm{No}$ \\
\hline 20 & 1982 & 18 & 4 & .75 & -0. & 1820 & 0.18 & Yes \\
\hline 21 & 1978 & 27 & 2 & 2243 & 0.06 & -5381 & -0.01 & Yes \\
\hline 21 & 1983 & 26 & 2 & 1900 & 0.1 & -1900 & 0 & Yes \\
\hline 21 & 1984 & 26 & 4 & 0 & 0 & -5675 & -0.01 & Yes \\
\hline 21 & 1984 & 6 & 4 & 0 & 0 & 20010 & 0.04 & Yes \\
\hline 22 & 1981 & 3 & 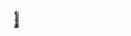 & $?$ & $?$ & 0 & 0 & Yes \\
\hline 23 & 1980 & 2 & 1 & 4250 & 0.32 & 0 & 0 & res \\
\hline 23 & 1981 & 8 & 2 & $?$ & $?$ & 0 & 0 & $\mathrm{No}$ \\
\hline 23 & 1981 & 26 & 2 & .11047 & .0 .33 & 11047 & 0.08 & Yes. \\
\hline 23 & 1981 & 6 & 1 & -2755 & 0.088 & 0 & 0 & $\mathrm{Na}$ \\
\hline 23 & 1982 & 7 & 1 & 5000 & 0.28 & 0 & 0 & Yes: \\
\hline 23 & 1982 & 3 & 5 & -1900 & -0.11 & 0 & 0 & $\mathrm{No}$ \\
\hline 23 & 1983 & 6 & 2 & 780 & 0.04 & -1895 & -0.1 & Yes: \\
\hline 23 & 1984 & 8 & 5 & 7 & $?$ & 0 & 0 & $\mathrm{No}$ \\
\hline 23 & 1984 & 26 & 2 & $?$ & $?$ & $?$ & $?$ & No \\
\hline 24 & 1979 & 25 & 4 & 0 & 0 & .9504 & -0.03 & Yes \\
\hline 24 & 1984 & 11 & 2 & 7 & $?$ & $?$ & $?$ & No \\
\hline 24 & 1985 & 26 & 2 & 2272 & 0.05 & -2272 & 0 & Mo \\
\hline 25 & 1978 & 26 & 5 & $?$ & $?$ & $?$ & $?$ & No \\
\hline 25 & 1982 & 26 & 4 & 0 & 0 & 700 & 0 & Y'es \\
\hline 26 & 1981 & 7 & 2 & -126 & 0.6 & 0 & 0 & Yes \\
\hline 26 & 1986 & 6 & 2 & 9726 & 10.1 & 45300 & 1.08 & No \\
\hline 27 & 1979 & 28 & 2 & $?$ & $?$ & 0 & 0 & No \\
\hline 27 & 1981 & 26 & 2 & 1366 & 0.22 & .1366 & .0 .02 & Yes \\
\hline 27 & 1984 & 26 & 2 & $?$ & ? & $?$ & $?$ & No \\
\hline 27 & $\$ 984$ & 18 & 2 & $?$ & $?$ & 0 & 0 & No \\
\hline 27 & 1986 & 26 & 4 & 0 & 0 & .506 & $-0,01$ & Yes. \\
\hline 28 & 1978 & 18 & 2 & $?$ & $?$ & 0 & 0 & Yes: \\
\hline 28 & 1981 & 5 & 2 & 135 & 0.03 & .135 & 0 & Yes \\
\hline 28 & 1981 & 7 & 2 & .83 & .0 .02 & 0 & 0 & Yes \\
\hline 29 & 1984 & 19 & 5 & 0 & 0 & 0 & 0 & Yes: \\
\hline 29 & 1984 & 25 & 4 & 0 & 0 & 776 & 0.04 & Yes \\
\hline 30 & 1984 & 3 & 2 & .39 & .0 .01 & 0 & 0 & No \\
\hline 30 & 19186 & 24 & 4 & 0 & 0 & 2392 & 0.05 & yes \\
\hline 31 & 1977 & 22 & 3 & -216 & .0 .01 & 0 & 0 & Yes \\
\hline 31 & 1979 & 28 & 5 & 0 & 0 & 0 & 0 & No \\
\hline 31 & 1979 & 13 & 2 & -873 & .0 .02 & 13968 & 0.08 & Mo \\
\hline 31 & 1,982 & 13 & 2 & $?$ & $?$ & 0 & 0 & ves \\
\hline 31 & 1982 & 26 & 3 & 11467 & 0.31 & -11467 & -0.04 & Yes \\
\hline 31 & 1982 & 24 & 4 & -3000 & -0.09 & 0 & 0 & Yes \\
\hline 31 & 1982 & 18 & 5 & $?$ & $i$ & $?$ & $?$ & No \\
\hline $3 \mathrm{I}$ & 1984 & 27 & 5 & $?$ & $?$ & 0 & 0 & $\mathrm{MO}$ \\
\hline $3 \|$ & 1985 & 24 & 4 & 1000 & 0.01 & 2033 & 0 & yes \\
\hline 31 & 1985 & 13 & 2 & -399 & 0 & 0 & 0 & No \\
\hline 31 & 1985 & 13 & 2 & -508 & 0 & 64025 & 0.25 & Yes \\
\hline 32 & 1981 & 26 & 5 & $?$ & $?$ & 0 & 0 & No \\
\hline 32 & 1981 & 18 & 2 & 379 & 0.05 & -379 & -0.03 & Yes \\
\hline 32 & 1986 & 25 & 5 & $?$ & $?$ & 0 & 0 & No \\
\hline 33 & 1983 & 6 & 4 & 0 & 0 & 19067 & 0.16 & Yes \\
\hline 33 & 1985 & 7 & 1 & -8000 & -0.2 & 0 & 0 & Yes \\
\hline 33 & 1985 & 26 & 5 & 1774 & 0.05 & -1774 & -0.01 & No \\
\hline 33 & 986 & 27 & 5 & $?$ & $?$ & 0 & 0 & No \\
\hline 34 & 1977 & 16 & 4 & 0 & 0 & -775 & 0.01 & Yes \\
\hline 34 & 1977 & 8 & 5 & $?$ & $?$ & 0 & 0 & No \\
\hline 34 & 1980 & 6 & 2 & 790 & 0.31 & .790 & -0.01 & No \\
\hline
\end{tabular}




\begin{tabular}{|c|c|c|c|c|c|c|c|c|}
\hline FIRM! & YEAR & NATURE & METHOD & EARN EFF. & \%EARNINGS & EOUITY EFF. & SQUTI & INFO \\
\hline 34 & 1982 & 22 & 3 & .164 & -0.03 & 0 & 0 & No \\
\hline 34 & 1984 & 26 & 2 & .1875 & -0.24 & 1875 & 0.02 & Yes \\
\hline 35 & 1979 & 18 & 5 & $?$ & $?$ & $?$ & $?$ & No \\
\hline 35 & 1982 & 18 & 5 & $?$ & $?$ & $?$ & ? & No \\
\hline 35 & 1982 & 24 & 5 & $?$ & $?$ & $?$ & $?$ & No \\
\hline 36 & 1982 & 26 & 5 & $?$ & $?$ & $?$ & $?$ & No \\
\hline 36 & 1982 & 23 & 2 & $?$ & $?$ & 0 & 0 & res \\
\hline 36 & 1984 & 20 & 3 & 0 & 0 & .107 & 0.02 & Yex \\
\hline 316 & 1986 & 4 & 3 & -832 & -0.24 & 5241 & 0.43 & Yes \\
\hline 36 & 1986 & 18 & 5 & 99 & 0.03 & 0 & 0 & No \\
\hline 37 & 1977 & 3 & 4 & 0 & 0 & -4892 & -0.09 & Yes \\
\hline 37 & 1983 & 14 & 5 & 0 & 0 & 0 & 0 & $Y e s$ \\
\hline 38 & 1981 & 15 & 3 & 0 & 0 & 106163 & 0.28 & Yes \\
\hline 38 & 1984 & 25 & 5 & $?$ & $?$ & $?$ & $?$ & Yes \\
\hline 39 & 1977 & 6 & 3 & 0 & 0 & 2857 & 0.69 & Yes \\
\hline 39 & 1979 & 24 & 5 & $?$ & $?$ & $?$ & ?" & Yes \\
\hline 39 & 1984 & 24 & 3 & 0 & 0 & 1071 & 0.15 & Yes \\
\hline 40 & 1983 & 6 & 4 & $?$ & $?$ & 1166 & 0.03 & Yes \\
\hline 41 & 1978 & 20 & 2 & $?$ & $?$ & $?$ & $?$ & No \\
\hline 41 & 1980 & 26 & 5 & $?$ & $?$ & $?$ & $?$ & No \\
\hline 41 & 1980 & 25 & 4 & 0 & 0 & -5155 & $.0,01$ & Yes \\
\hline 41 & 1985 & 26 & 5 & 0 & 0 & 0 & 0 & Yes \\
\hline 42 & 1978 & 26 & 2 & -4979 & -0.5 & 4979 & 0.05 & Yes \\
\hline 42 & 1979 & 25 & 5 & $?$ & $?$ & 0 & 0 & No \\
\hline 42 & 1981 & 26 & 2 & 2184 & 0.45 & 2184 & -0.02 & Yes \\
\hline 42 & 1982 & 26 & 5 & $?$ & $?$ & $?$ & $?$ & Yes. \\
\hline 42 & 1984 & 8 & 5 & $?$ & $?$ & 0 & 0 & No \\
\hline 42 & 1984 & 8 & 2 & $?$ & $?$ & 0 & 0 & Yes \\
\hline 42 & 1986 & 11 & 2 & 0 & 0 & 0 & 0 & Yes \\
\hline 42 & 1986 & 13 & 2 & 24850 & 11.04 & 0 & 0 & No \\
\hline 43 & 1977 & 19 & 5 & 35000 & 2.57 & 0 & 0 & Tres \\
\hline 43 & 1982 & 11 & 2 & -20016 & -0.25 & 60048 & 0.14 & No \\
\hline 43 & 1984 & 26 & 2 & -1251 & -0.02 & 1.251 & 0 & Yes \\
\hline 44 & 1977 & $T$ & 2 & $?$ & $?$ & 7 & $?$ & No \\
\hline 44 & 1979 & 7 & 3 & 0 & 0 & 156700 & 0.13 & Yes \\
\hline 44 & 1979 & 6 & 2 & 0 & 0 & .7895 & .0 .01 & Yes \\
\hline 44 & 1979 & 25 & 3 & $?$ & $?$ & .31000 & -0.03 & Yes \\
\hline 44 & 1979 & 27 & 3 & 0 & 0 & .48841 & -0.04 & Yes \\
\hline 44 & 1985 & 8 & 5 & $?$ & $?$ & 0 & 0 & $\mathrm{No}$ \\
\hline 4 & 1986 & 26 & 2 & $?$ & $?$ & $?$ & $?$ & No \\
\hline 45 & 1980 & 26 & 2 & -1110 & -0.07 & 1110 & 0.01 & res: \\
\hline 45 & 1980 & 26 & 5 & 0 & 0 & $?$ & 7 & $\mathrm{No}$ \\
\hline 45 & 1981 & 24 & 5 & -200 & $.0,02$ & 0 & 0 & Yes \\
\hline 46 & 1977 & 18 & 4 & -36 & .0 .02 & 946 & 0,09 & Yes \\
\hline 47 & 1978 & 26 & 2 & $?$ & $?$ & 0 & $a$ & Yes \\
\hline 47 & 1979 & 8 & 5 & $?$ & $?$ & 0 & 0 & No \\
\hline 47 & 1982 & 7 & 4 & 0 & 0 & 19.456 & 0.16 & Yes \\
\hline 47 & 1984 & 26 & 4 & $?$ & $?$ & $?$ & ? & No \\
\hline 47 & 1984 & 24 & $\mathbb{1}$ & 7276 & 0.88 & 0 & 0 & Yes \\
\hline 47 & 1984 & 26 & 2 & 14 & 0 & .14 & 0 & Wes \\
\hline 47 & 1984 & 29 & 2. & 2900 & 0.35 & 0 & 0 & Yes \\
\hline 47 & 1985 & 25 & 5 & 1300 & 0.19 & 0 & 0 & No \\
\hline 47 & 1985 & 19 & 5 & $?$ & $?$ & 0 & 0 & No \\
\hline 48 & 1980 & 19 & 5 & $?$ & $?$ & 0 & 0 & No \\
\hline 48 & 1981 & 26 & 5 & $?$ & $?$ & 0 & 0 & Wo \\
\hline 48 & 1986 & 26 & 2 & 521 & 0.16 & -521 & 0.02 & No \\
\hline 49 & 1979 & 27 & 2 & $?$ & $?$ & 0 & 0 & Yes \\
\hline 49 & 1981 & 26 & 2 & .1050 & 0 & 1050 & 0 & Yes \\
\hline 49 & 1981 & 17 & 1 & 4000 & 0.01 & 0 & 0 & Yes \\
\hline 49 & 1982 & 8 & 1 & $?$ & $?$ & 0 & 0 & Yes \\
\hline 49 & 1982 & 6 & 4 & 11000 & 0.09 & 19000 & 0.02 & Yes \\
\hline 49 & 1982 & 10 & 1 & 11800 & 0.09 & 0 & 0 & Yex \\
\hline
\end{tabular}




\begin{tabular}{|c|c|c|c|c|c|c|c|c|}
\hline FIRM & YEAR & NATURE & METHOD & EARN EFF. & GEARNINGS & EQUITY EFF. & $\%$ EQUTTY & $\mathrm{MNOC}$ \\
\hline 49 & 1982 & 18 & 1 & $?$ & $?$ & 0 & 0 & Yes \\
\hline 49 & 1984 & 26 & 2 & 9900 & 0.05 & $?$ & $?$ & Yes: \\
\hline 49 & 1984 & 8 & 2 & .500 & 0 & 0 & 0 & Yes: \\
\hline 49 & 1986 & 24 & 3 & 0 & 0 & 160200 & 0.1 & Yes \\
\hline 50 & 1983 & 26 & 5 & .95 & -0.01 & .1914 & -0.16 & Yes \\
\hline 50 & 1985 & 19 & 5 & 0 & 0 & 0 & 0 & Yes \\
\hline 51 & 1982 & 3 & 5 & $?$ & $?$ & 0 & 0 & No \\
\hline$\$ 1$ & 19.82 & 19 & 2 & $?$ & $?$ & 0 & 0 & Yes \\
\hline 52 & 1977 & 9 & 3 & 0 & 0 & .34 & -0.01 & No \\
\hline 52 & 19480 & 18 & 4 & 0 & 0 & 2644 & 0.25 & Mo \\
\hline 52 & 1980 & 9 & 4 & 0 & 0 & 33 & 0 & Yest \\
\hline 52 & 1986 & 21 & 2 & 415 & 0.06 & 0 & 0 & No \\
\hline 53 & 1977 & 9 & 1 & $?$ & $?$ & $?$ & $?$ & Yes \\
\hline 53 & 1977 & 9 & 4 & $?$ & $?$ & -6679 & -0.02 & Yes \\
\hline 53 & 1977 & 9 & 2 & .891 & -0.03 & 891 & 0 & Yes \\
\hline 53 & 1978 & 26 & 4 & 5497 & 0.21 & .5497 & -0.01 & Yes: \\
\hline 53 & 1979 & 25 & 5 & $?$ & $?$ & 0 & 0 & No \\
\hline 53 & 1981 & 6 & 4 & 4900 & 0.59 & 18505 & 0.05 & Yes \\
\hline 53 & 1981 & 26 & 2 & 500 & 0.06 & .500 & 0 & Yes \\
\hline 53 & 1981 & 11 & 2 & 1800 & 0.22 & 0 & 0 & Yes \\
\hline 53 & 1981 & 7 & 1 & 3000 & 0.36 & 0 & 0 & Yes \\
\hline 53 & 1984 & 6 & 4 & 3300 & 0.23 & 8275 & 0.03 & Yes \\
\hline 53 & 1986 & 11 & 4 & 1100 & 0.03 & .8686 & -0.02 & Yes \\
\hline 53 & 1986 & 26 & 5 & $?$ & $?$ & $?$ & $?$ & No \\
\hline 54 & 1986 & 27 & 2 & $?$ & $?$ & $a$ & 0 & Yes \\
\hline 54 & 1978 & 18 & 4 & 0 & 0 & 2420 & 0.21 & Yes \\
\hline 54 & 1979 & 24 & 3 & 0 & 0 & 3352 & 0.25 & Yes \\
\hline 54 & 1986 & 27 & 1 & 411 & 0.63 & 0 & 0 & Yes \\
\hline 55 & 1981 & 26 & 3 & 2200 & 0.07 & -2200 & -0.01 & Yes \\
\hline 55 & 1981 & 26 & 5 & 0 & 0 & 0 & 0 & Yes \\
\hline 55 & 1984 & 19 & 5 & 0 & 0 & 0 & 0 & Yes \\
\hline 55 & 1985 & 13 & 2 & 500 & 0.02 & 0 & 0 & Yes \\
\hline 56 & 1978 & 27 & 2 & 66 & 0.02 & -3538 & -0.0 & Yes \\
\hline 56 & 1981 & 26 & 2 & .140 & -0.02 & 0 & 0 & $\mathrm{No}$ \\
\hline 56 & 1983 & 24 & 1 & -4600 & 0.11 & 0 & 0 & Yes \\
\hline 56 & 1984 & 24 & 1 & .14300 & -0.18 & 0 & 0 & Yes \\
\hline 56 & 1984 & 26 & 4 & 0 & 0 & -41.03 & -0.01 & Yes \\
\hline 56 & 1985 & 27 & 2 & -6500 & -0.05 & 0 & 0 & Yes \\
\hline 56 & 1985 & 18 & 2 & $?$ & $?$ & 0 & 0 & Yes \\
\hline 57 & 1980 & 18 & 2 & 7400 & 0.35 & 0 & 0 & Yex \\
\hline 57 & 1982 & 9 & 3 & -1659 & .0 .05 & -39255 & -0.2 & Yes \\
\hline 57 & 1985 & 26 & 2 & .936 & -0.03 & 936 & 0 & No \\
\hline 58 & 1977 & 30 & 5 & ? & $?$ & 0 & 0 & Yes \\
\hline 58 & 1980 & 25 & 4 & $?$ & $?$ & -1100 & 0.07 & Yes \\
\hline 58 & 1980 & 18 & 4 & 0 & 0 & 1524 & 0.1 & No \\
\hline 58 & 1985 & 18 & 4 & -220 & -0.11 & 9029 & 0.45 & Yes \\
\hline 59 & 1978 & 3 & 4 & .56 & -0.03 & -1068 & -0.09 & Yes \\
\hline 59 & 1982 & 22 & 3 & $?$ & $?$ & 0 & 0 & Yes \\
\hline 59 & 1986 & 18 & 4 & 0 & 0 & 0 & 0 & $\mathrm{No}$ \\
\hline 59 & 1986 & 25 & 5 & $?$ & $?$ & 0 & 0 & No \\
\hline 59 & 1986 & 27 & 5 & $?$ & $?$ & 0 & 0 & No \\
\hline 60 & 1979 & 20 & 3 & 0 & 0 & 3 & 0 & Yes \\
\hline 60 & 1979 & 26 & 2 & $?$ & $?$ & $?$ & $?$ & No \\
\hline 60 & 1980 & 24 & 5 & $?$ & $?$ & 0 & 0 & No \\
\hline 60 & 1.981 & 26 & 2 & 101 & 4.81 & .101 & 0 & $\mathrm{No}$ \\
\hline 60 & 1984 & 25 & 4 & 0 & 0 & $350^{\circ}$ & 0.03 & Yes \\
\hline 60 & 1986 & 26 & 2 & $?$ & $?$ & $?$ & $?$ & No \\
\hline 60 & 1986 & 18 & 2 & 400 & 0.47 & 0 & 0 & Yes \\
\hline 61 & 1977 & 26 & 2 & 807 & 0.19 & -807 & -0.02 & Yes \\
\hline 61 & 1990 & 18 & 4 & $?$ & $?$ & 2450 & 0,07 & Yes \\
\hline 61 & 1984 & 27 & 5 & $?$ & $?$ & 0 & 0 & No \\
\hline 62 & 1979 & 7 & 4 & 2800 & -0.47 & -2200 & -0.02 & Yes \\
\hline
\end{tabular}




\begin{tabular}{|c|c|c|c|c|c|c|c|c|}
\hline FIMM & YEAR & NATURE & METHOD & EARN. EEF. & QEARNINGS & EQUITY EFF. & \% EQUTT & $\mathrm{NFO}$ \\
\hline 62 & 1984 & 4 & 3 & 1827 & -0.27 & -45856 & $-0,36$ & Yes \\
\hline 62 & 1.984 & 6 & 3 & $?$ & $?$ & $?$ & $?$ & No \\
\hline 62 & 1984 & 8 & 5 & $?$ & $?$ & $?$ & $?$ & No \\
\hline 62 & 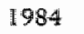 & 5 & 3 & $?$ & $?$ & $?$ & $?$ & No \\
\hline 62 & 1985 & 11 & 2 & -18 & -0.01 & 1126 & 0.01 & No \\
\hline 62 & 1986 & 6 & 1 & 6430 & 0.37 & 0 & $a$ & Yes \\
\hline 63 & 1981 & 24 & 5 & $?$ & $?$ & 0 & 0 & No \\
\hline 63 & 1981 & 18 & 4 & 0 & 0 & 1919 & 0.74 & Yes \\
\hline 64 & 1983 & 26 & 2 & .519 & -0.03 & 519 & 0 & Yes \\
\hline 64 & 1983 & 24 & 4 & $?$ & $?$ & $-\$ 546$ & -0.03 & Yes \\
\hline 64 & 1983 & 27 & 5 & $?$ & $?$ & 0 & 0 & No \\
\hline 65 & 1983 & 18 & 2 & 30 & 0.07 & -30 & -0.01 & Yes: \\
\hline 66 & 1977 & 11 & 4 & $?$ & $?$ & .876 & -0.02 & Yes: \\
\hline 66 & 1978 & 26 & 5 & $?$ & $?$ & $?$ & $?$ & $\mathrm{Na}$ \\
\hline 66 & 1978 & 19 & 5 & $?$ & $?$ & 0 & 0 & $\mathrm{No}$ \\
\hline 66 & 1981 & 26 & 4 & $?$ & $?$ & $?$ & $?$ & Yes \\
\hline 66 & 1993 & 11 & 2 & -140 & -0.03 & 700 & 0.03 & No \\
\hline 6.6 & 1985 & 18 & 2 & $?$ & $?$ & $?$ & $?$ & No \\
\hline 67 & 1979 & 31 & 3 & 1100 & 5.77 & 0 & 0 & Yes \\
\hline 68 & 1977 & 6 & 4 & 0 & 0 & 2008 & 0.24 & Yes \\
\hline 68 & 1980 & 6 & 3 & 0 & 0 & .49 & 0 & Yies \\
\hline 68 & 1981 & 6 & 2 & 132 & 0.22 & .132 & $=0.01$ & Yes \\
\hline 68 & 1984 & 20 & 4 & 0 & 0 & 2710 & 0.2 & Yes \\
\hline 68 & 1985 & 6 & 3 & -478 & -0.32 & 0 & 0 & Yes \\
\hline 69 & 1978 & 24 & 5 & 0 & 0 & 0 & 0 & $\mathrm{No}$ \\
\hline 69 & 1980 & 25 & 1 & 1145 & 0.07 & a & 0 & No \\
\hline 69 & 1982 & 6 & 2 & $?$ & $?$ & $?$ & 7 & Yes \\
\hline 69 & 1984 & 20 & 3 & 0 & 0 & 318 & 0 & Yes \\
\hline 69 & 1986 & 11 & 4 & 1616 & 0.04 & -4787 & -0.02 & Yes \\
\hline 69 & 1986 & 13 & 目 & -249 & 0.01 & 0 & 0 & Yes \\
\hline 70 & 1979 & 18 & 2 & $?$ & $?$ & $?$ & $?$ & Yes \\
\hline 70 & 1980 & 26 & 2 & -1613 & -0.3 & 1613 & 0.02 & Yes \\
\hline 70 & 1983 & 26 & 4 & 0 & 0 & 0 & 0 & Yes \\
\hline 70 & 1984 & 8 & 5 & 0 & 0 & 0 & 0 & Yes \\
\hline 70 & 1985 & 32 & 5 & $?$ & $?$ & 0 & 0 & Yes \\
\hline 71 & 1981 & 24 & 4 & $?$ & ? & 4682 & 0.04 & Yes \\
\hline 71 & 1981 & 3 & 4 & $?$ & $?$ & $?$ & $?$ & Yes \\
\hline$T 1$ & 1986 & 26 & 2 & $\Downarrow 6,00$ & 0.04 & 0 & 0 & Yes \\
\hline 72 & 1980 & 7 & I & 190 & 0.18 & 0 & 0 & Yes \\
\hline 72 & 1983 & 27 & 5 & $?$ & $?$ & 0 & 0 & No \\
\hline 72 & 1984 & 22 & 3 & -185 & -0.11 & 0 & 0 & No \\
\hline 72 & 1984 & 6 & 6 & 150 & 0.09 & 300 & 0.02 & Yes \\
\hline 72 & 1984 & 18 & 4 & $?$ & $?$ & 2162 & 0.18 & Yes \\
\hline 72 & 1985 & 27 & 5 & $?$ & $?$ & 0 & 0 & No \\
\hline 73 & 1982 & 11 & 4 & 0 & 0 & 390 & 0 & Yes \\
\hline 73 & 1982 & 11 & 4 & 0 & 0 & -2710 & -0.01 & Yes \\
\hline 73 & 1982 & 26 & 2 & 8988 & 0.37 & -8988 & .0 .02 & Yes \\
\hline 74 & 1983 & 18 & 4 & 0 & 0 & 249 & 0.48 & Yes \\
\hline 74 & 1984 & 27 & 5 & $?$ & $?$ & 0 & 0 & No \\
\hline 74 & 1985 & 18 & 4 & $?$ & $?$ & 125 & 0.07 & No \\
\hline 74 & 1985 & 25 & 5 & $?$ & $?$ & $?$ & $?$ & No \\
\hline 74 & 1985 & 25 & 4 & 0 & 0 & -310 & -0.18 & No \\
\hline 75 & 1984 & 18 & 4 & -120 & -0.15 & 4197 & 0.72 & Yes \\
\hline 76 & 1978 & 11 & 2 & 26800 & 0.04 & 0 & 0 & No \\
\hline 76 & 1979 & 13 & 2 & 22000 & 0.04 & 0 & 0 & Yes \\
\hline 76 & 1980 & 22 & 3 & $?$ & $?$ & 0 & 0 & Yes \\
\hline 76 & 1981 & 25 & 3 & -393000 & -1.14 & 393000 & 0.03 & Yes \\
\hline 76 & 1981 & 29 & 3 & 615000 & 1.78 & -1566000 & 0.11 & Yes \\
\hline 76 & 1981 & 26 & 5 & $?$ & $?$ & $?$ & $?$ & $Y e s$ \\
\hline 76 & 1981 & 7 & 1 & 200000 & 0.58 & 0 & 0 & Yess \\
\hline 76 & 1981 & 7 & 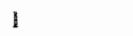 & 281000 & 0.18 & 0 & 0 & Yes \\
\hline 76 & 1981 & 9 & 3 & 0 & 0 & -10000 & 0 & Yes \\
\hline
\end{tabular}




\begin{tabular}{|c|c|c|c|c|c|c|c|c|}
\hline FIRM & YEAR & NATURE & METHOD & EARN, EFF & \%EARNIWGS & EQUTTY EFF & $\%$ EQUITH & INFO \\
\hline 76 & 1984 & 11 & 3 & 32000 & 0.04 & .160000 & -0.01 & Yes: \\
\hline 76 & 1984 & 28 & 1 & 352000 & 0.48 & 0 & 0 & yes \\
\hline 76 & 19.84 & 29 & 3 & 0 & 0 & 1553000 & 0.1 & Yes \\
\hline 76 & 986 & 13 & 5 & $?$ & $?$ & 0 & 0 & No \\
\hline 76 & 1986 & 27 & 1 & 122000 & 0.14 & 0 & 0 & Yes \\
\hline 77 & 1979 & 24 & 5 & 0 & 0 & 0 & 0 & Yes \\
\hline 77 & 1981 & 30 & 2 & 0 & 0 & 0 & 0 & Yes \\
\hline 77 & $\| 981$ & 24 & 4 & 0 & 0 & 23554 & 0.63 & Yes \\
\hline 77 & 1984 & 24 & 1 & 25992 & 3.04 & -25992 & -0.68 & Yes \\
\hline 77 & 1984 & 1.8 & 4 & 0 & 0 & 36660 & 0.97 & Yes \\
\hline 78 & $\llbracket 981$ & 24 & 1 & 552 & 2.82 & 0 & 0 & Yes \\
\hline 78 & 1982 & 27 & 5 & $?$ & $?^{2}$ & 0 & 0 & No \\
\hline 78 & 1984 & 2 & 4 & 0 & 0 & 1756 & 1.79 & Yes \\
\hline 79 & 1977 & 6 & $\|$ & 158 & 0.01 & 0 & 0 & Yes \\
\hline 79 & 1979 & 25 & 2 & 300 & 0.18 & 0 & 0 & Yers \\
\hline 79 & 1981 & 6 & 2 & .500 & -0.18 & 0 & 0 & Yes \\
\hline 79 & 1984 & 27 & 5 & $?$ & $?$ & $?$ & $?$ & No \\
\hline 80 & 1979 & 24 & 4 & $?$ & $?$ & 3669 & 0.1 & Yes \\
\hline 80 & 1979 & 18 & 5 & 0 & 0 & 0 & 0 & Yes \\
\hline 80 & 1979 & 3 & 4 & $?$ & $?$ & -965 & -0.03 & Yes \\
\hline 81 & 1981 & 18 & 2 & 264 & 0,06 & -264 & .0 .01 & Yes \\
\hline 82 & 1981 & 24 & 3 & 0 & 0 & 440 & 0.03 & Yes \\
\hline 82 & 1981 & 26 & 3 & 0 & 0 & 103 & 0.01 & Yes \\
\hline 82 & 1981 & 25 & 3 & -31 & -0.04 & .794 & -0.05 & Yes \\
\hline 83 & 1984 & 5 & 5 & $?$ & $?$ & 0 & 0 & Yes \\
\hline 83 & 1984 & 16 & 3 & $?$ & ? & 0 & 0 & Yes \\
\hline 83 & 1986 & 18 & 3 & $?$ & $?$ & 2756 & 0.03 & Yes \\
\hline 83 & 1986 & 11 & 2 & 3116 & 0.21 & $-31 \rrbracket 6$ & -0.03 & $\mathrm{No}$ \\
\hline 84 & 1979 & 20 & 3 & $?$ & $?$ & -17 & 0 & res \\
\hline 84 & 1981 & 2 & 6 & 2025 & 0.14 & 3325 & 0.12 & Yes \\
\hline 84 & 1985 & 18 & 5 & $?$ & $?$ & $?$ & $?$ & No \\
\hline 85 & 1980 & 6 & 4 & 0 & $a$ & 4230 & 0.03 & No \\
\hline 85 & 1984 & 18 & 2 & $?$ & $?$ & $?$ & 7 & No \\
\hline 85 & 1986 & 26 & 5 & $?$ & $?$ & 0 & 0 & No \\
\hline 86 & 1980 & 18 & 2 & 300 & 0.45 & -300 & -0.01 & Yes \\
\hline 86 & 1981 & 27 & 5 & $?$ & $?$ & 0 & 0 & No \\
\hline 86 & 1984 & 27 & 1 & 1700 & 1.47 & 0 & 0 & Yes \\
\hline 86 & 1984 & 24 & 2 & 654 & 0.56 & $?$ & $?$ & res. \\
\hline 87 & 1978 & 26 & 2 & 2600 & 0.37 & -2600 & -0.01 & Yes: \\
\hline 87 & 1979 & 27 & 5 & $?$ & $?$ & 0 & 0 & Mo \\
\hline 87 & 1979 & 11 & 5 & $?$ & $?$ & 0 & 0 & Yes \\
\hline 87 & 1983 & 18 & 5 & $?$ & $?$ & 0 & 0 & Yes \\
\hline 87 & 1984 & 8 & 5 & $?$ & $?$ & 0 & 0 & Yes \\
\hline 87 & 1984 & 22 & 3 & $?$ & $?$ & 0 & 0 & $\mathrm{Na}$ \\
\hline 88 & 1984 & 4 & 3 & $?$ & $?$ & 68413 & 1.45 & Yes \\
\hline 88 & 1986 & 24 & 2 & $?$ & $?$ & 0 & 0 & $\mathrm{No}$ \\
\hline 89 & 1982 & 19 & 5 & ? & $?$ & 0 & 0 & No \\
\hline 89 & 198,4 & 18 & 2 & 350 & 1.27 & -350 & -0.02 & $Y_{e s}$ \\
\hline 89 & 1985 & 26 & 2 & $?$ & $?$ & 0 & 0 & No \\
\hline 89 & 1986 & 26 & 2 & 186 & 0.13 & -186 & -0.01 & Yes \\
\hline 90 & 1977 & 6 & 3 & $?$ & $?$ & 32 & 0.01 & Yes \\
\hline 91 & 1980 & 25 & 1 & $-1,704$ & -0.21 & 0 & 0 & Y"es \\
\hline 91 & 1985 & 6 & 3 & 9959 & 1.88 & 88146 & 4.34 & yes \\
\hline 92 & 1981 & 26 & 2 & 8336 & 1.27 & -8336 & .0 .04 & Yes \\
\hline 92 & 1984 & 4 & 3 & 13911 & 0.82 & -2169 & -0.01 & Yes \\
\hline 92 & 1984 & 8 & 5 & ?" & $?$ & $?$ & $?$ & No \\
\hline 92 & 1986 & 27 & 2 & $?$ & $?$ & 0 & 0 & Yes \\
\hline 93 & 1977 & 13 & 5 & 628 & 0.06 & 0 & 0 & No \\
\hline 93 & 1978 & 18 & 2 & 2815 & 0.79 & 0 & 0 & Yes \\
\hline 93 & 1981 & 26 & 4 & 0 & 0 & -970 & -0.02 & Yess \\
\hline 93 & 1986 & 26 & 2 & $?$ & $?$ & $?$ & $?$ & $\mathrm{No}$ \\
\hline 94 & 1977 & 24 & l & .11034 & -0.24 & 0 & 0 & Yes \\
\hline
\end{tabular}




\begin{tabular}{|c|c|c|c|c|c|c|c|c|}
\hline FIRM & MEAR & NATURE & METHOD & EARN EFF. & WEARNINGS & EQUTTY EFF. & 野 EQUTY & INFO \\
\hline 94 & 1977 & 33 & $\mathbb{1}$ & -3238 & .0 .07 & 0 & 0 & Yes \\
\hline $9 \frac{4}{2}$ & 1977 & 34 & $\mathbb{1}$ & -1122 & -0.02 & 0 & 0 & les \\
\hline 94 & 1980 & 11 & 2 & $?$ & $?$ & $?$ & ? & No \\
\hline 94 & 1981 & 18 & $\mathbb{1}$ & -2704 & -0.08 & 0 & 0 & Yes \\
\hline 94 & 1981 & 18 & 2 & 2808 & 0.08 & .2808 & .0 .01 & Yes \\
\hline 94 & 1981 & 27 & 5 & $?$ & $?$ & 0) & 0 & $\mathrm{No}$ \\
\hline 94 & 1981 & 26 & 2 & 837 & 0.03 & .837 & 0 & Yes \\
\hline 94 & 1984 & 27 & 1 & 2600 & 0.06 & 0 & 0 & Yes \\
\hline 94 & 1984 & 26 & 2 & $?$ & $?$ & $?$ & $?$ & No \\
\hline 94 & 1984 & 24 & 1 & 3068 & 0.07 & 0 & 0 & Yess \\
\hline 95 & 1978 & 18 & 4 & -1126 & .0 .01 & 25687 & 0.04 & Yes \\
\hline 95 & 1978 & 6 & 1 & 2476 & 0.03 & 0 & 0 & Yes \\
\hline 95 & 1980 & 27 & 5 & $?$ & $?$ & 0 & 0 & No \\
\hline 95 & 1985 & 26 & 2 & 9615 & 2.69 & .9615 & -0.02 & Yes \\
\hline 95 & 1986 & 26 & 2 & 2000 & -0.12 & .7000 & $-0,01$ & Yes \\
\hline 96 & 1979 & 27 & 2 & $?$ & $?$ & 0 & 0 & Yes \\
\hline 96 & 1980 & 26 & 2 & .905 & 0.12 & 905 & 0.01 & Yes \\
\hline 96 & 1982 & 11 & 2 & $2\} 6\rfloor$ & 0.53 & -2161 & .0 .03 & No \\
\hline 96 & 1984 & 26 & 2 & $?$ & $?$ & $?$ & $?$ & No \\
\hline 96 & 1984 & 26 & 4 & 0 & 0 & -2800 & .0 .03 & Yes \\
\hline 96 & 1984 & 25 & 5 & $?$ & $?$ & 7 & $?$ & $\mathrm{No}$ \\
\hline 96 & 1985 & 27 & 5 & $?$ & $?$ & 0 & 0 & No \\
\hline 97 & 1980 & 18 & 3 & 0 & 0 & 6859 & 0.3 & Yes \\
\hline 97 & 1981 & 27 & 5 & $?$ & $?$ & 0 & 0 & No \\
\hline 97 & 1982 & 18 & 2 & .611 & -115.28 & 611 & 0.01 & $\mathrm{No}$ \\
\hline 97 & 1983 & 11 & 2 & 115 & 0.04 & 196 & 0 & Yes \\
\hline 97 & 1984 & 18 & 2 & 625 & 0.16 & -625 & -0.01 & Yes \\
\hline 98 & 1979 & 24 & 3 & 0 & 0 & 6772 & 0.03 & Yes \\
\hline 98 & 1981 & 26 & 2 & $?$ & $?$ & 7 & $?$ & No \\
\hline 99 & 1979 & 18 & 5 & $?$ & $?$ & 0 & 0 & No \\
\hline 100 & 1981 & 6 & 2 & $?$ & $?$ & 0 & 0 & No \\
\hline 100 & 1982 & 25 & 1 & 1308 & 7.7 & 0 & 0 & Yes \\
\hline 100 & 1984 & 2 & 5 & $?$ & $?$ & $?$ & $?$ & No \\
\hline 100 & 1985 & 25 & 4 & $?$ & $?$ & 431 & 0.05 & Yes \\
\hline 100 & 1985 & 18 & 1 & $?$ & $?$ & $?$ & $?$ & Yes \\
\hline 100 & 1985 & 27 & 1 & 512 & 10.1 & 0 & 0 & Yes \\
\hline $\mathbb{1 0 1}$ & 1982 & 11 & 3 & 0 & 0 & -10462 & -0.12 & Yes \\
\hline 101 & 1983 & 24 & 5 & 1200 & 0.09 & 0 & 0 & Yes \\
\hline 101 & 1983 & 35 & 2 & 1900 & .0 .14 & 0 & 0 & Yes \\
\hline 102 & 1978 & 10 & 3 & 76000 & 0.03 & 239000 & 0.0 & Yes \\
\hline 102 & 1978 & 16 & 3 & 20000 & 0.01 & -201000 & $.0,01$ & Yes \\
\hline 102 & 1980 & 14 & 2 & 297000 & 0,05 & 0 & 0 & Yes \\
\hline 102 & 1982 & 26 & 3 & $?$ & $?$ & 2985000 & 0.07 & Yes \\
\hline 102 & 1982 & 14 & 2 & 39000 & 0.01 & 0 & 0 & Y'es \\
\hline 102 & 1984 & 9 & 4 & 0 & 0 & 22000 & 0 & Yes \\
\hline 103 & 1977 & 18 & 5 & 990 & 0.04 & 0 & 0 & Yes \\
\hline 103 & 1977 & 11 & 2 & -270 & -0.01 & 8675 & 0.05 & Yes \\
\hline 103 & 1978 & 18 & 3 & 2639 & 0.17 & -2639 & 0 & Yes \\
\hline 103 & 1978 & 26 & 3 & 1763 & 0.25 & 3 & 0 & Yes \\
\hline 103 & 1980 & 6 & 5 & $?$ & $?$ & 0 & 0 & No \\
\hline 103 & 1981 & 18 & 5 & $?$ & $?$ & 0 & 0 & Yes. \\
\hline 104 & 1977 & 16 & 2 & $?$ & $?$ & 0 & 0 & Yes. \\
\hline 104 & 1978 & 26 & 4 & 0 & 0 & 30300 & 0.03 & Yes \\
\hline 104 & 1981 & 24 & 2 & 0 & 0 & 0 & 0 & Yes \\
\hline 104 & 1982 & 20 & 3 & 0 & 0 & -100000 & .0 .09 & Yes \\
\hline 104 & 1985 & 38 & 4 & -6969 & .0 .02 & 59125 & 0.03 & Yes \\
\hline 105 & 1977 & 26 & 3 & 0 & 0 & 23139 & 0.01 & Yes \\
\hline 105 & 1978 & 26 & 3 & 0 & 0 & -36083 & .0 .02 & Yes \\
\hline 105 & 1982 & 7 & 1 & 21198 & 0.56 & 0 & 0 & Yes \\
\hline 105 & 1983 & 19 & 1 & 46684 & 0.33 & 0 & 0 & Yes \\
\hline 105 & 1985 & 26 & 5 & $?$ & $?$ & $?$ & $?$ & No \\
\hline 105 & 1985 & 26 & 2 & 0 & 0 & -17010 & .001 & No \\
\hline
\end{tabular}




\begin{tabular}{|c|c|c|c|c|c|c|c|c|}
\hline $\mathrm{FIRM}$ & YEAR & NATURE & METHOD & EARN EFF. & \%EARMNGS & EQUTTY EFF. & \% EQUTTY & MFO \\
\hline 105 & 1986 & 26 & 5 & $?$ & $?$ & 0 & 0 & No \\
\hline 105 & 1986 & 26 & 3 & $?$ & $?$ & $?$ & $?$ & No \\
\hline 105 & 1986 & 10 & 2 & 9800 & 0.16 & 0 & 0 & Yes \\
\hline 105 & 1986 & 26 & 5 & $?$ & $?$ & $?$ & $?$ & $\mathrm{No}$ \\
\hline 106 & 1977 & 6 & 2 & 5097 & 2.24 & 0 & 0 & Yes \\
\hline 106 & 1978 & 6 & 4 & $?$ & $?$ & 16001 & 0.03 & Yes \\
\hline 106 & 1978 & 25 & 4 & $?$ & $?$ & -8114 & -0.02 & Yes \\
\hline 106 & 1979 & II & 5 & $?$ & $?$ & -3464 & -0.01 & Yes \\
\hline 106 & 1981 & 6 & 5 & $?$ & $?$ & a & 0 & No \\
\hline 106 & 1982 & 9 & 3 & 0 & 0 & -23 & 0 & Yes: \\
\hline 106 & 1983 & 26 & 5 & 315,68 & 1.36 & 0 & 0 & Yes: \\
\hline 106 & 1983 & 26 & 2 & 2189 & 0.21 & -2189 & 0 & Yes: \\
\hline 107 & 1977 & 18 & 5 & -40 & -0.03 & 40 & 0 & Yes: \\
\hline 107 & 1981 & 18 & 2 & 3622 & 2 & -3662 & -0.06 & Yes \\
\hline
\end{tabular}

total number of accounting changes: 444 
Appendix 4A: The accruals approach: definition, methodology and areas of application

Because the accrual approach has not been applied in previous Dutch empirical research, this appendix briefly summarizes the basic concept of the methodology, the definition of accruals, including the choice of accrual components, and potential problems related to the accrual concept.

There is a growing body of empirical research which investigates managers' use of accounting discretion to manage earnings by analysing firms ${ }^{4}$ accounting accruals, starting with Healy (1985). A recent example in this tradition is Dechow et al. (1995). These studies deal with the question of what factors determine the variations in earnings management, by adjustments of accounting procedures, in various contractual settings. The idea is that a manager chooses from the available set of accounting procedures to adjust accruals in response to explicit and implicit contractual. arrangements. Studies that use the accrual approach have been conducted in various different contractual settings, such as management compensation contracts, labour contracts, management buy-outs, import relief restrictions and tax rate changes. Recall that accounting accruals were defined as the difference between earnings and cash flow from operations: ${ }^{1}$

TOTAL ACCRUALS = EARNINGS - CASH FLOW FROM OPERATIONS (CFO)

The accrual approach is based on the idea that information on operational cash flows represent a more objective measure (i.e. one which is less susceptible to manipulation) of the real economic performance of the firm. Cash flow from operations reflects the net cash flows generated by the firms operating activities (Dechow, 1994, 5). Accruals are defined as the difference between the firm's reported earnings and its cash flow from operations. The accrual process can be seen as the visible result of the discretionary (voluntary) and non-discretionary (mandatory) accounting procedures and methods used by the company's management. Reported earnings reflect the cumulative effects of these choices.

The starting point for most studies is total accruals. Because the actual cash flow from operations is usually not available, it must be estimated indirectly (see also Mertens and Hassink, 1992). The most widely used definitions of cash flows are based on the calculation presented by Drtina and Largay (1985). More recent work has advocated alternative measures of cash flows as presented by Livnat and Zarowin (1990).

\footnotetext{
"See Healy (1985, p.86), Liberty and Zimmerman (1986, p.701), DeAngelo (1986, p.408), Rayburn (1986, p.119), Wilson (1986, p.294).
} 
Cash flow from operations consist of the components (Livnat and Zarowin, 1990, p.27):

- cash collection from customers

- cash payments to suppliers, employees, etc.

- cash payments to tax authorities

- net interest paid

- other operating cash flows

Because these components are not reported by firms they must be estimated from the data reported in the balance sheet and profit and loss account. The three basic components of the accrual definition of Rayburn (1986, p.155) are the change in working capital components during the year, the depreciation expenses, and the changes in income tax payable. The working capital elements consist of current assets and current liabilities. ${ }^{2}$ Changes in income tax payable are included in the changes in current liabilities. Finally current assets, are corrected for changes in cash and current liabilities are corrected for changes in maturities of long term debt. In definition:

[ $\Delta$ Current Assets $-\Delta$ Current Cash $\left._{t}\right]$

- $\left[\Delta\right.$ Current Liabilities $_{t}-\Delta$ Current Maturities of Long Term Debt $\left.t_{t}\right]$

- [Depreciation Expense ]

We added balance sheet and profit and loss account data from the 1993 financial statement of Royal Sphinx NV to calculate totals accruals over that year $\left({ }^{*} 1.000\right.$ Dutch Guilders).

Total accruals $=\left(\Delta\right.$ Current Assets $_{t} \quad \% \Delta$ Current Cash $\left._{t}\right)$

$[209.988 \% 188.303] \quad \%[11.387 \% 9.830]$

$\% \quad\left(\Delta\right.$ Current Liabilities,$\quad \% \Delta$ Current Maturities of Long Term Debt $\left.t_{t}\right)$

$\% \quad[[123.609 \% 149.576] \quad \%[11.039 \% 11.769]]$

\% (Depreciation Expense)

$\% \quad[21.989]$

$=23.376$

$\mathrm{CFO}=30.807 \quad \% \quad 23.376=7.431$

\footnotetext{
${ }^{2}$ Recall section 4.2.2, were we discussed the 'provisions' account as an additional working. capital component, within Dutch GAAP. However, based on the arguments presented in that section the changes in this account were not included in the definition used in this dissertation.
} 
Summary of the Consolidated balance sheet Royal Sphinx NV, March 31, 1993

\begin{tabular}{|c|c|c|c|c|c|}
\hline ASSETS & 1993 & 1992 & LIABIIITIES & 1993 & 1992 \\
\hline fixed assets & 240.611 & 241.656 & owners equity & 157.024 & 129.129 \\
\hline $\begin{array}{l}\text { current assets } \\
\text { (excl. cash) }\end{array}$ & 198.601 & 178.473 & provisions & 25.365 & 38.848 \\
\hline \multirow[t]{4}{*}{ cash } & 11.387 & 9.830 & long term debt & 144.601 & 112.406 \\
\hline & & & $\begin{array}{l}\text { maturities of } \\
\text { long term debt }\end{array}$ & 11.039 & 11.769 \\
\hline & & & short term debt & 112.570 & 137.807 \\
\hline & 450.599 & 429.959 & & 450.599 & 429.959 \\
\hline
\end{tabular}

Summary of the consolidated Profit and loss statement of Royal Sphinx NV, March 31, 1993

\begin{tabular}{lrrr} 
& 1993 & 1992 \\
\cline { 2 - 2 } turnover & 422.640 & & 416.663 \\
cost of sales (excl. deprec.) & $(351.521)$ & $(346.450)$ \\
depreciation & $(21.989)$ & $(21.322)$ \\
interest income and expenses & $(9.002)$ & $(10.828)$ \\
pre-tax operating income & 40.128 & 38.063 \\
taxes & $(12.239)$ & $(12.156)$ \\
income from subsidiaries & 2.918 & 2.546 \\
after tax-operating income & 30.807 & 28.453 \\
extraordinary gains/losses & 0 & 2.071 \\
net income & 30.807 & 30.524
\end{tabular}

Once cash flows from operations and total accruals are determined, the next step is to separate total accruals into non-discretionary and discretionary components. This is of major importance because not all accruals are at the discretion of management. Part of the total accruals are constrained by rules and institurions, and also by economic circumstances. Therefore, they are not susceptible to management, i.e. non-discretionary. The remainder is at the discretion of management, i.e. discretionary. In this dissertation two methods have been employed to determine non-discretionary and discretionary accruals. Chapter 4 discusses method I and method II. 
A manager has several mechanisms to influence eamings, including choosing accounting methods or accruals that defer income to later periods. There are, for instance, choices available between alternative ways of accounting for depreciation, between LIFO and FIFO valuation systems, whether costs should be treated as expenses or investments, and various accounting estimates and changes in those estimates. ${ }^{3}$ There are numerous examples of accruals that require estimation: e.g., the uncollectibility of accounts receivable, obsolete inventory, pension costs, and income from prepaid revenues. These more subtle techniques, which can be used to manage earnings, are less subject to detection by outside parties. The advantage of the accrual approach, as compared to other accounting method choice studies which focus on one or more specific accounting methods or procedures, is that it can reveal the effects of these subtle accounting techniques used to determine or manage earnings.

One important area in which the accrual technique has been applied is the income smoothing hypothesis. The income smoothing hypothesis assumes that because of existing contracts between managers and other parties, managers have, ceteris paribus, an incentive to smooth reported earnings. Managers may use discretionary accounting techniques to shift earnings from peak periods to less successful ones because of shareholders' expectations of earnings behaviour.

So, the major strength of the accruals concept is that it can detect more subtle earnings management activities compared to an analysis of accounting method choice. However, we should be aware of at least two potential problem areas related to the accrual methodology. The first is represented by the potential problems related to the definition of accruals and cash flow from operations. As discussed in sections 4.2 .2 , cash flow from operations is at best a proxy, because no information is provided on the actual cash flow figures. Remember that these cash flow from operations numbers are used to represent a more objective performance measure of the firm, with which reported earnings (representing the more subjective performance measure) can be compared. If the definition of accruals should contain any errors or omissions, this might lead to incorrect inferences about firms' accounting accruals and the evaluation of earnings management behaviour. A second potential problem area is related to the question: what are the true managed (discretionary) and unmanaged (non-discretionary) accruals for a firm. The (regression) models used in the literature are based on certain assumptions to predict the unmanaged accruals components: they assume a relationship between nondiscretionary accruals and certain (accounting) variables.

\footnotetext{
${ }^{3}$ We stipulated that as opposed to the method of accounting changes used in chapter 3 , the accounting accruals method does include accounting estimates and change in those estimates.
} 
To illustrate this, in the model applied in this dissertation non-discretionary accruals are a function of the firm's sales activity, its (non-financial) fixed assets and the institutional setting (financial accounting regulations). As a result of this, the remaining variability in accruals is assumed to reflect the accruals part that is manageable. However, whether this reflects actual earnings management behaviour or merely represents the consequences of this firm's business policy or its economic circumstances is not always easy to determine. In fact, each firm can have its own firm-specific accruals, while some of these might appear to be more or less manageable. Some studies therefore focus on specific types of accruals (bad debt allowance; see McNichols and Wilson, 1988) in order to enhance precision. But the problem is then that other accrual accounts are left out. But, if we choose to capture all potential accruals, we should be aware of potential misspecification of these regression models because it is not possible to observe all (accounting) variables necessary to distinguish between discretionary and non-discretionary. ${ }^{*}$ In addition to this, the accruals are also affected by consolidation changes because we used consolidated financial statements. The time-series of accruals in this dissertation covers more than 20 years and so the majority of the sample firms showed an increase in the number of investments in subsidiaries during this period. Consolidation of financial data (and the consolidation criteria) will have an impact on accruals; assets, liabilities and earnings will most likely be affected. Blommaert (1995) examined 71 Dutch companies, who first reported consolidated financial statements. In the period 1925 to 1964 , almost $65 \%$ of the sample firms provided consolidated financial statement for the first time. Sixteen years later (1980), all firms (7I) provided consolidated financial statements. After analysing these firm's financial characteristics he also found that (owner's) equity and net earnings in the consolidated financial statement were higher compared to the non-consolidated financial statement in the first year of consolidation. According to Blommaert this suggested opportunistic behaviour. It is therefore important to recognize that consolidated financial statements contain important accruals.

In sum, the 'accrual process' is the result of discretionary (voluntary) and nondiscretionary (mandatory) accounting procedures and methods used by the firm's management. Earnings represent the outcome of the firm's economic performance and the application of accounting procedures and methods in a specific period. Because it is difficult to compare earnings across firms, as a result of the variety of methods used to calculate accrual items (i.e., accounting procedures), the firm can. manage accruals to alter reported earnings to a certain extent.

\footnotetext{
${ }^{4}$ Recently, Kang and Sivaramaknishnan (1995) introduced techniques to improve the accruals model specifications, while they also advocated the use of additional regression variables.
} 
The analysis presented in chapter four uses the accrual approach to examine whether firms' financial reporting discretion has been affected by the introduction of mandatory financial reporting regulation in the Netherlands. The specific context in which the technique is used here is unique in that not only changes in discretionary accruals are expected, but also in non-discretionary accruals. 
Appendix 4B.1: Sample firms WJO

(1) Ahold

(2) Batenburg Beheer

(3) Beers Zonen

(4) Begemann

(5) Bergoss

(6) van Berkel's Patent

(7) Blijdenstein Willink

(8) De Boer Jr.

(9) Bols

(10) Bredero Verenigde Bedrijiven

(11) Buhrmann-Tetterode:

(12) Chamotte

(13) Crane

(14) CSM

(15) Desseaux

(16) Duiker Apparaten

(17) Emba

(18) Gero

(19) van der Giessen-de Noord

(20) Goudsmit

(21) Grasso

(22) Hagemeyer

(23) Heineken

(24) Hero

(25) Hoek's Machinefabriek

(26) Holec

(27) Hollandia Kloos

(28) Hoogovens

(29) IBB Kondor Groep

(30) Inventum

(31) Klene's Suikerfabriek

(32) KNP
(33) Koninklijke Nederl. Springstoffen

(34) Krwatta

(35) Maastrichtse Zinkwit

(36) Macintosh

(37) van Melle

(38) Mulder Boskoop

(39) Naeff

(40) Nagron

(41) NEDAP

(42) van Nelle

(49) Nijverdal ten Cate

(44) Norit

(45) Verertigde Bedrijven Nutricia

(46) Oce van Grinten

(47) Orenstein en Koppel

(48) Palthe

(49) Philips

(50) Porceleyne Fles

(51) Prins Dokkum

(52) Reesink

(53) van Reeuwijk

(54) Sanders Behang

(55) Textielgroep Twente

(56) Ubbink

(57) Unikap

(58) Verenigde Glasfabrieken

(59) Verto

(60) Vihamij Buttinger

(61) VNU

(62) Gemeensch. Bezit V.R.G.

(63) Wegener's Couranten Concern

(64) Wijers Beheer 
Appendix 4B.2: Sample firms Tite 8

\begin{tabular}{|c|c|c|c|}
\hline (1) & ACF Holling & (39) & KLM \\
\hline (2) & Ahold & $(40)$ & KNP \\
\hline (3) & AKZO & (41) & KBB \\
\hline (4) & A.I.R & $(42)$ & Krasnapoiski \\
\hline$(5)$ & BAM Holding & (43) & Landre \& Glinderman \\
\hline$(6)$ & Batenburg Beheer & (44) & Macintosh \\
\hline$(7)$ & Beer's Zonen & $(45)$ & Mulder Boskoop \\
\hline (8) & Begemann & (46) & Naeff \\
\hline$(9)$ & van Berkel's Patent & $(47)$ & Nagron \\
\hline (10) & Blijdenstein Willink & (48) & Verenigde NBM-bedrijven \\
\hline (11) & De Boer It. & (49) & NEDAP \\
\hline (12) & Biols & (50) & Nijverdal ten Cate \\
\hline (13) & Kon. Borsumij Wehry & (51) & Norit \\
\hline (14) & Kon. Boskalis Westminster & (52) & Verenigde Bedrijven Nutricia \\
\hline (15) & Braat Bouwstoffen & (53) & Pakhoed. \\
\hline (16) & Buhrmann-Tetterode & (54) & Palthe \\
\hline (17) & I.H.C. Calland & $(55)$ & Philips \\
\hline (18) & $\operatorname{CSM}$ & (56) & Porceleyre Fles \\
\hline (19) & Cindu Key Kramer & $(57)$ & Reesink \\
\hline$(20)$ & Desseaux & $(58)$ & Riva \\
\hline (21) & van Dorp Groep & (59) & Schuitema \\
\hline$(22)$ & Econosto & (60) & Holdingmij de Telegraaf \\
\hline$(23)$ & Elsevier & (61) & Textielgroep Twente \\
\hline$(24)$ & Folkker & (62) & Twentsche Kabel \\
\hline$(25)$ & Gamma Holding & $(63)$ & Ubbink \\
\hline$(26)$ & van der Giessen-de Noord & (64) & Unilever \\
\hline$(27)$ & Gist Brocades & (65) & Verenigde Glasfabrieken \\
\hline$(28)$ & Goudsmit & (66) & Verenigde Machinefabriek Stork \\
\hline$(29)$ & Grasso & (67) & Verto \\
\hline (30) & Oce van der Grinten & (68) & V.N.U. \\
\hline (3i) & Hagemeyer & (69) & Kon. Volker Stevin \\
\hline (32) & $\mathrm{HBG}$ & $(70)$ & Gemeensch. Bezit V.R.G. \\
\hline$(33)$ & Heineken & (71) & Wegener's Couranten Concern \\
\hline$(34)$ & Hoek's Machinefabriek & $(72)$ & Koninklijke Wessanen \\
\hline$(35)$ & Hollandia Kloos & (73) & Wijers Beheer \\
\hline$(36)$ & Hoogovens & $(74)$ & Wolters Kluwer \\
\hline$(37)$ & IBB Kondor Groep & $(75)$ & Kon. Med. Petroleum Mij (Shell) \\
\hline$(38)$ & Internatio Muller & (76) & van Ommeren Ceteco \\
\hline
\end{tabular}




\section{References}

Archibald, T.R., 1976. Some facts related to the depreciation switchback. Joumal of Finance, pp.67-73.

Archibald, T.R., 1968. The return to straight-line depreciation: an analysis of a change in accounting method. Empirical research in accounting: selected studies. Joumal of Accounting Research, vol. 6, (Supplement): pp. 164-180.

Ayres, F.L., 1986. Characteristics of firms electing early adoption of SFAS 52. Joumal of Accounting and Economics, Vol. 8, no.2, pp.143-158.

Ball, R. and G. Foster, 1982. Corporate Financial Reporting: A methodological review of empirical research, Journal of Accounting Research, Vol. 20, (Supplement): pp. 161-234.

Ball, R., 1989. The firm as a specialist contracting intermediary: Application to accounting and auditing, Working Paper, University of Rochester.

Ball, R. and C.W. Smith, 1992. The Economics of Accounting Policy Choice, McGrawHill, New York.

Barkema, H., 1991. Are agents indeed motivated by their bonuses? Paper presented at the 14th annual congress of the European Accounting Association in Maastricht.

Barnea, A., J. Ronen, and S. Sadan, 1975. The implementation of accounting objectives- an application to extraordinary items. The Accounting Review, vol. 50, (January): pp.35-46.

Barnea, A., J. Ronen, and S. Sadan, 1976. Classificatory smoothing of income with extraordinary items. The Accounting Review, vol. 51, (January): pp.21-34.

Beatty, R.P. and R.E. Verrechia, 1989. The effect of a mandated accounting change on the capitalization process. Contemporary Accounting Research, vol. 5, (Spring): pp.472-493.

Beaver, W.H., 1968. The information content of annual earnings announcements. Empirical research in accounting: Selected studies, Journal of Accounting Research, vol. 6, (Supplement): pp.67-92. 
Beaver, W.H., 1970. The time-series behavior of earnings. Empinical research in accounting: Selected studies, Joumal of Accounting Research, vol. 8, (Supplement): pp.6299.

Beaver, W.H. and J.S. Demski, 1974. The nature of financial accounting objectives: a summary and synthesis. Studies on financial accounting objectives: 1974, Joumal of Accounting Research, vol. 12. (Supplement): pp.170-187.

Beaver, W.H., P.A. Griffen, and W.R. Landsman, 1982. The incremental information content of replacement cost earnings. Journal of Accounting and Economics, vol. 4, no. 1, pp.15-40.

Beaver. W.H., 1989. Financial Reporting: An Accounting Revolution, Prentice Hall, Englewood Cliffs, New Jersey.

Belkaoui, A.R., 1992. Accounting Theory, Academic Press, London.

Benson, H. 1972. Harmonization of Accountancy practice. The Accountant, (December): pp. 756-758.

Benston, G.J., 1969. The value of the SEC's accounting disclosure requirements. The Accounting Review, vol. 44, (July): pp.515-532.

Benston, G.J., 1973. Required disclosure and the stock market: An evaluation of the Securities Exchange Act of 1934. American Economic Review, vol.63, (March): pp.132-155.

Benston, G.J., 1976. Corporate financial disclosure in the UK and the USA, Famborough, Hants, Saxon House.

Benston, G.J., 1984. The cost of complying with a Government Data Collection Program: the FTC's Line of Business Report, Joumal of Accounting and Public Policy, vol.3, no.2, pp.123-137.

Benston, G.J., 1985. The market for public accounting services: demand, supply, regulation. Jounal of Accounting and Public Policy, vol.4, no.1, pp.33-80.

Benston, G.J., 1986. The benefits and costs of voluntary accounting disclosure- $A$ discussion of: "Current cost disclosures and nondisclosures: theory and Canadian evidence. Contemporary Accounting Research, vol. 2, (January): pp.35-44. 
Berkel, J.J.L. van, 1965. Verslaggeving en publiciteit van vennootschappen. Tijdschrift voor Venootschappen, Verenigingen en Stichtingen, (November): pp. 173-178.

Bernard, V.L., 1989. Capitall markets research in accounting during the 1980's: A critical review, in: Frecka, T. (ed), 1989, The state of accounting research as we enter the 1990's, University of Illinois, pp.72-120.

Bernard, V.L. and T.L. Stober, 1989. The nature and amount of Information in Cash Flows and Accruals. The Accounting Review, vol. 64, no. 3, pp.624-652.

Blom, F.W.C., 1966. Wat heeft de commissie Verdam eigenlijk gedaan? Intermediair, (no.9): pp.1-7.

Blommaert, J.M.J., 1995. Consolideren en informeren. Een onderzoek naar de informatiewaarde van de geconsolideerde jaarrekening. Stenfert Kroese/Educatieve Partners Nederland, Houten.

Bollen, L.H.H., 1996. Financial Reporting Regulation for Small and Medium Sized Private Firms. Dissertation no. 96-34, University of Limburg, Maastricht.

Booth, P. and N. Cocks, 1990. Critical research issues in accounting standard setting. Journal of Business, Finance and Accounting, vol.17 (Autumn): pp.511-529.

Boukema, C.A., 1974. De werking van de nieuwe vennootschapswetgeving. Maandblad voor Accountancy en Bedriffshishoudkunde,(November): pp.476-483.

Bouma, J.L., 1972. Het rapport van de commissie jaarverslaggeving. De Naamloze Vennootschap. (September): pp.102-104.

Bowen, R.M., 1981. Valuation of earnings components in the electrical utility industry, The Accounting Review, vol.56, no.1, pp.1-22.

Bowen, R.M., E. Noreen, and J. Lacey, 1981. Determinanants of the corporate decision to capitalize interest. Journal of Accounting and Economics, vol.3, no.2, pp.151-179.

Bowen, R.M., D. Burgstahler, and L.A. Daley, 1986. Evidence on the relationship between earnings and various measures of cash flow. The Accounting Review, vol. 61 , (October): pp.713-725. 
Bowen, R.M., L. DuCharme, and D. Shores, 1992. Stakeholders' implicit claims and accounting method choice. Working Paper, University of Washington, Seattle.

Brayshaw, R.E., and A.E.R. Eldin, 1989. Smoothing hypothesis and the role of exchange differences. Journal of Business, Finance, and Accounting, vol.16, no.2, pp.621-633.

Bremser, W.G., 1975. The earnings characteristics of firms reporting discretionary accounting changes. The Accounting Review, vol. 50, (October): pp.563-573.

Brink, H.L., 1989. Actuele en internationale ontwikkelingen in de wet- en regelgeving in het bijzonder die met betrekking tot het verwerken van belastingen in de jaarrekening. De Naamloze Vennootschap. (November): pp.219-223.

Bruinessen, W., van 1975. Accounting standards and rules - Voluntary or regulatory determination? Maandblad voor Accountancy en Bedrijfshishoudkunde. (Januari): pp.3-15.

Buijink, W.F.J., 1992. Empirical Financial Accounting Research. Dissertation, no. 925, University of Limburg, Maastricht.

Burgert, R. 1965. Het voorontwerp van wet op de jaarekening van ondernemingen van de commissie Verdam op de keper beschouwd. Economisch Statistische Berichten. (8 November): pp.737-741.

Burgert, R, 1972. De vierde richtlijn der EEG-commisssie amtrent de jaarrekening. Maandblad voor Accountancy on Bedriffhuishoudkunde, (Februari): pp.184-201.

Burgert, R, 1967. Bedrijfseconomisch aanvaardbare gxondslagen voor de gepubliceerde jaarverslagen. De Accountant, (September): pp.153-192.

Burgert, R., 1981. Current accounting practice in the Netherlands. Maandblad voor Accountancy en Bedriifshuishoudkunde, (Februari/Maart): pp.52-64.

Burgert, R. en C.W.A. Timmermans, 1985. De jaarrekening niewwe stijl, Deel 2. Samson H.D. Tjeenk Willink, Alphen aan de Rijn, vierde druk.

Burgert, R. en C.W.A. Timmermans, 1989. De jaarrekening nieuwe stijl, Deel 2. Samson H.D. Tjeenk Willink, Alphen aan de Rijn, zesde druk. 
Busse von Colbe, W, 1974. Harmonisierung der Rechnungslegungsvorschriften für Kapitalgesellschaften in der Europäischen Gemeinschaft durch die vierte Richtlinie des Rates. Zeitschrift fü betriebswirtschaftliche Forschung, vol. 26, (no.10): pp.236646.

Cahan, S.F., 1992. The effect of antitrust investigations on discretionary accruals: a refined test of the political-cost hypothesis. The Accounting Review, vol. 67, (January): pp.77-95.

Chow, C.W., 1982. The demand for external auditing: size, debt and ownership influences. The Accounting Review, vol. 57, No.2, 272-291.

Chow, C.W., 1983. Empirical studies of the economic impact of accounting regulations: findings, problems and prospects. Journal of Accounting Literature, vol. 20, (Spring): pp.73-109.

Chow, C.W. and A. Wong Boren, 1987. Voluntary financial disclosure by Mexican corporations. The Accounting Review, vol. 62, (July), pp.533-541.

Christie, A.A., 1990. Aggregation of test statistics: An evaluation of the evidence on contracting and size hypothesis. Journal of Accounting and Economics, vol.12: pp.15-36.

Christie, A.A. and J.L. Zimmerman, 1994. Efficient and opportunistic choices of accounting procedures: Corporate control contests. The Accounting Review, vol.69, (October), pp.539-566.

Coelingh, J.P., 1965. De jaarverslaggeving uit het gezichtspunt van een ondernemer. De Naamloze Vennootschap, (Januari/Febuari): pp.5-6.

Commissie Elmendorff, 1968. Voorontwerp van een richtlijn: toelichting ontwerprichtlijn. Commissie van de Europese Gemeenschap, Brussel.

Commissie jaarverslaggeving (Annual Reporting Committee), 1955. Het jaarverslag, rapport van de Cornmissie Jaarverslaggeving van het verbond van Nederlandse werkgevers, het Centraal Saciaal Werkgevers Verbond, het Katholiek Verbond van Werkgeversverenigingen en het Verbond van Protestants-Christelijke Werkgevers in Nederland, Den Haag. 
Commissie Verdam, 1965. Herziening van het ondernemingsrecht, rapport wan de commissie ingesteld bij beschikking van de Minister van Justitie van 8 april 1960. Staatsuitgeverij, Den Haag.

Cooke, T.E. and R.S.O. Wallace, 1990. Financial disclosure regulation and its environment: a review and further analysis. Joumal of Accounting and Public Policy, vol. 9, no.2, pp.79-110.

Cooper, K and M.J. Sherer, 1984. The value of Corporate Accounting Reports: Arguments for a Political Economy of Accounting. Accounting, Organisations and Society, vol.9, no.4, pp.207-232.

Copeland, R.M., 1968. Income Smoothing. Empirical Research in Accounting: Selected Studies. Journal of Accounting Research. vol.6, (Supplement): pp.101-116.

Copeland, R.M. and R.D. Licastro, 1968. A note on income smoothing. The Accounting Review, vol. 43, no.3, pp.540-545.

Craig, R. and P. Walsh, 1989. Adjustments for extraordinary items in smoothing reported profits of listed australian companies: Some empirical evidence. Joumal of Business and Finance, vol.16, (Spring): pp.229-245.

Daley, L.A. and R.L. Vigeland, 1983. The effects of debt covenants and political costs on the choice of accounting methods: The case of accounting for R\&D costs. Journal of Accounting and Economics, vol.5, no.3, pp.195-212.

DeAngelo, L.E., 1986. Accounting numbers as market valuation substitution: A study of management buyouts of public stockholders. The Accounting Review, vol.61, (July): pp.400-420.

DeAngelo. L.E., 1988. Managerial competition, information costs, and corporate governance: The use of accounting performance measures in proxy contests. Joumal of Accounting and Economics, vol. 10, no. 1, pp.3-36.

DeAngelo, L.E., 1990. Equity valuation and corporate control. The Accounting Review, vol.65, (January), pp.93-112.

DeChow, P.M., 1994. Accounting earnings and cash flows as measures of firm performance: The role of accounting accruals, Joumal of Accounting and Economics, vol.17, no.2, pp.3-43. 
DeChow, P.M., R.G. Sloan, and A.P. Sweeney, 1995. Detecting earnings management. The Accounting Rewiew, vol.70, no. 2, pp.193-225.

Demski, J.S., 1994. Managerial uses of accounting infornation, Kuwer Academic Publishers, Boston.

Dhaliwal, D.S., 1980. The effect of the firm's capital structure on the choice of accounting methods. The Accounting Review, vol.55, no. 1, pp.78-94.

Dopuch, N., and R.L. Watts, 1972. Using time-series models to assess the significance of accounting changes. Journal of Accounting Research, vol.10, no.1, pp.180-199.

Drtina, R.E. and J.A. Largay, 1985. Pitfalls in calculating cash flow from operations. The Accounting Review, vol. 60, (April): pp.314-327.

Duke, J.C. and H.G. Hunt, 1990. An empirical examination of debt covenant restrictions and accounting related debt proxies. Journal of Accounting and Economics, vol. 12, no.l, pp.45-63.

Dye, R.A., 1988. Earnings management in an overlapping generations model. Joumal of Accounting Research, vol. 26, no.1, pp.195-235.

El-Gazzar, S., S. Lilien, and V. Pastena, 1986. Accounting for leases by lessees. Joumal of Accounting and Economics, vol. 8, no. 2, pp. 217-237.

Elmendorff, W., 1967. Harmonisierung der einzelstaatlichen Rechnungslegungsvorschriften in der Europaischen Wirtschaftsgemeinschaft. Joumal UEC: European Joumal of Accountancy, no. 4, pp. 217-239.

Elmendorff, W., 1971. Harmonisierung der einzelstaatlichen Rechnungslegungsvorschriften. Joumal UEC: European Joumal of Accountancy, no. 1, pp. 1-6.

Emenyonu, E.N. and S.J. Gray, 1992. EC Accounting Harmonisation: An empirical study of measurement practices in France, Germany and the UK. Accounting and Business Research, vol.23, no.89, pp.49-58.

Fama, E.F., 1980. Agency problems and the theory of the firm. Joumal of Political Economy, (April): pp.288-307. 
Federatie Nederlandse Vakbeweging, 1976. Open Boek, een nota over de behoefte van werknemers aan informatie over hun onderneming, FNV, Amsterdam.

Foppe, H.H.M., 1956. De verslaglegging door naamloze vennootschappen. Maandblad voor Accountancy en Bedriffshuishoudkunde, (Maart): pp.136-138.

Foppe, H.H.M., 1965. Het getrouwe beeld in de gepubliceerde jaarrekening. Economisch Statistische Berichten, (27 Oktober): pp.991-993.

Foster, G., 1986. Fivancial Statement Analysis. Prentice Hall, Englewood Cliffs, New Jersey.

Gaeremynk, A. 1994. The use of depreciation in accounting as a signalling device. Dissertatie no. 96, Katholieke Universiteit Leuven.

Goerdeler, R. 1973. A true and fair view - or compliance with the law and the company statutes. Die Wirtschaftsprüfung, vol. 26, no. 19, pp.517-525.

Gonedus, N.J. Dopuch and S.H. Penman 1974. Disclosure rules, informationproduction, and capital market equilibrium: The case of forecast disclosure rules. Journal of Accounting Research, vol. 12, (Supplement): pp.89-137.

Gordon, M.J., 1964. Postulates, Principles and Research in Accounting. The Accounting Review, vol.39, no.2, pp.251-263.

Gordon, M.J., B.N. Horwitz, and P.T. Meyers, 1966. Accounting measurement and normal growth of the firm. R.K. Jeadicke, Y. Ijiri, and O. Nielsen, eds. In: Research in Accounting Measurement. Chicago: America Accounting Association 1966, pp.221-231.

Grinten, W.C.L., van der, 1983. Voorwoord bij de Tweede Golf. Tijdschrift voor Vennootschappen, Verenigingen en Stichtingen, (nr, 83/6): p. 133-134.

Groeneveld, G.L., 1972. Het voorontwerp van beschouwingen naar aanleiding van de Wet op de Jaarrekening van Ondernemingen 1. Maandblad poor Accountancy en Bedriffshuishoudkunde, (Augustus): pp.365-367.

Guenther, D.A., 1994. Earnings management in response to corporate tax rate changes: evidence from the 1986 Tax Reform Act. The Accounting Review, vol.69, no.1, pp. $231-243$. 
Hand, J., 1989. Did firms undertake debt-equity swaps for accounting paper profit or true financial gain? The Accounting Review, vol. 64 , no.4, pp.587-623.

Hassink, H.F.D. en G.M.H. Mertens, 1990. Keuze van verslaggevingsregels: terminologie en registratie. Working Paper 90017, Rijksuniversiteit Limburg, Maastricht.

Hassink, H.F.D. en G.M.H. Mertens, 1992a. Keuze van verslaggevingsregels: een agency theoretische benadering. Maandblad voor Bedriffadministratie en Organisatie, (Maart): pp.42-49.

Hassink, H.F.D. en G.M.H. Mertens, 1992b. Drie decennia onderzoek naar de keuze van verslaggevingsregels: een tussentijdse evaluatie. FMA-kroniek 1992, pp.49-67. Samson, Den Haag.

Healy, P., 1985. The effect of bonus schemes on accounting decisions. Jowrnal of Accounting and Economics. vol.7, no.2, pp.85-107.

Hendriksen, E.S. and M. van Breda, 1992. Accounting theory. Richard D. Irwin, Homewood llinois.

Holthausen, R., 1981. Evidence on the effects of bond covenants and management compensation contracts on choice of accounting techniques: the case of depreciation switch-back. Jounnal of Accounting and Economics, vol.3, no. 1, pp.73109.

Holthausen, R, and R. Leftwich, 1983. The economic consequences of accounting choice: Implications of costly contracting and monitoring. Joumal of Accounting and Economics, vol.5, (August): pp.77-117.

Holthausen, R., 1990. Accounting method choice: Opportunistic behavior, efficient contracting, and information perspectives. Journal of Accounting and Economics, vol.12, no.1, pp.207-218.

Hoogendoorn, M.N., 1990. Stelselwijzigingen in de jaarrekening. Wolters-Noordhoff, Groningen.

Huizinga, P.W., 1969a. De jaarrekening van ondernemingen. Kluwer. Deventer.

Huizinga, P.W., 1969b. Jaarverslaggeving op de helling. Intermediair, no. 16, pp.1013 . 
Hunt, H.G., 1985. Potential determinants of corporate inventory accounting decisions. Joumal of Accownting Research, vol.23, no.2, pp.448-467.

Imhoff, E. and J.K. Thomas, 1988. Economic consequences of accounting standards: The lease disclosure rule change. Joumal of Accounting and Economics, vol. 10 , no. 4 , pp. $277-310$.

Jensen, M. and W. Meckling, 1976. Theory of the firm: Managerial behavior, agency costs, and ownership structure. Joumal of Financial Ecomomics, vol.3, (July): pp. $305-360$.

Jensen, M, 1983. Organization, theory and methodology. The Accounting Review, vol.58, no.2, pp.319.339.

Joos, P. and M. Lang, 1994. The effects of Accounting Diversity: Evidence from the European Union. Journal of Accounting Research, vol. 32, (Supplement): pp. 141168.

Johnson, W.B. and R. Ramanan, 1988. Discretionary accounting changes from successful efforts to full cost method: 1970-1976. The Accounting Review, vol. 63, (January): pp.96-1 10.

Jones, J.J., 1991. The effect of foreign trade regulation on accounting choices. Joumal of Accounting Literature. vol.29, (Autumn): pp. 193-228.

Kaminski, H., 1970. Stellungname der Groupe d'Etudes des Experts Comptables de la CEE zum Vorschlag einer vierten Richtlinie zur Harmonisierung der Rechnungslegungsvorschriften in der Europäischen Gemeinschaft. Die Wirtschaftsprifung, vol. 26, no. 9, pp.229-237.

Kaplan, R.S., 1985. Comments on Paul Healy: evidence of the effect of bonus schemes on accounting procedures and accrual decision. Joumal of Accounting and Economics. vol.7, no.2, pp.109-113.

Kang, S.H. and K. Sivaramakrishinan, 1995. Issues in testing earnings management and an instrumental variable approach. Joumal of Accounting Research, vol.33, no. 2 , pp.353-367.

Kelly, L. 1983. The development of a positive theory of corporate managements' role in external financial reporting. Joumal of Accounting Literature, vol.21, no.2, pp. $111-150$. 
Kestel, J.A., M. Smith, K. Houghton, and P. Robinson, 1991. An examination of the characteristics of those companies choosing to adopt income increasing accounting strategies: a West Australian study. Paper presented at the 14th annual congress of the European Accounting Association in Maastricht.

Klaassen, J., 1980. An accounting court: The impact of the enterprise chamber on financial reporting in the Netherlands. The Accounting Review, vol.55, (April): pp.327-341.

Klynveld Kraayenhof \& Co, 1983. De niewwe wet voor de jaareperslaggeving. Kleynveld Kraayenhof \& Co, Amsterdam.

Krens, F., 1972. De vierde EEG ontwerp-richtlijn ter harmonisatie van het vennootschapsrecht en de wet op de jaarrekening van ondernemingen (I). Maandblad Bedrijfskunde, (Februari): pp.17-23.

Krens, F. en J. Bulte, 1972a. Beschouwingen beschouwd 1. Tijdschrift voor Vennootschappen, Verenigingen en Stichtingen, no.7/8, pp.197-203.

Krens, F. en J. Bulte, 1972b. Beschouwingen beschouwd 2. Tijdschrift voor Vennootschappen, Verenigingen en Stichtingen, no.9, pp.218-225.

Lambert, R.A., 1984. Income smoothing as rational equilibrium behavior. The Accounting Review, vol.59, no.4, pp.604-618.

Leftwich, R., 1980. Market failure fallacies and accounting information. Joumal of Accounting and Economics, vol.2, no.3, pp.193-212.

Leftwich, R. R. Watts, and J.L. Zimmerman, 1981. Voluntary corporate disclosure: The case of interim reporting. Joumal of Accounting Literature, (Supplement.) voll.19, pp.50-77.

Leftwich, R., 1981. Evidence on the Impact of Mandatory Changes in Accounting Principles on Corporate Loan Agreements. Journal of Accounting and Economics, Vol.3, No.1, pp.3-36.

Leftwich, R., 1983. Accounting Information in Private Markets: Evidence from Private Lending Agreements. The Accounting Review, Vol.58, No.2. pp.23-42.

Lev, B., 1988. Toward a theory of equitable and efficient accounting policy. The Accounting Review, Vol.63, No.1, pp.1-22. 
Lev, B., 1989. On the usefulness of earnings and earnings research: Lessons and directions from two decades of empirical research. Joumal of Accounting Research, vol. 27, (Supplement): pp. 153-201.

Liberty, S.E., and J.L. Zimmerman, 1986. Labor union contract negotiations and accounting choices. The Accounting Review, vol.61, (July): pp.692-712.

Lilien, S. and V. Pastena, 1982. Determinants of intra-method choice in the oil and gas industry. Journal of Accounting and Economics, vol.4, no.3, pp.145-170.

Lilien, S., M. Mellman, and V. Pastena, 1988. Accounting changes: successful versus unsuccessful firms. The Accounting Review, vol.63, (October):pp.642-656.

Livnat, J. and P. Zarowin, 1990. The incremental information content of cashflow components. Journal of Accounting and Economics, vol. 12, no.1, pp.25-46.

Lys, T., 1984. Mandated accounting changes and debt covenants: the case of oil and gas accounting. Journal of Accounting and Economics, vol.6, no. 1, pp.39-66.

Maher, M.W., 1981. The impact of regulation on controls: Firms' response to the foreign corrupt practices act. The Accounting Review. vol.56, (October): pp.751-770.

Maijoor, S.J., 1991, The Economics of Accounting Regulation: Effects of Dutch Accounting Regulation for Public Accountants and Firns, PhD Dissertation, Faculty of Economics and Business Administration, University of Limburg, Maastricht.

Maijoor, S.J., 1994, Cost-benefit analysis and accounting regulation. Research in Accounting Regulation, vol. 8, pp. 59-70.

Maijoor, S.J., 1994. Economic effects of accounting regulation for public accountants: evidence from the Netherlands. Accounting and Business Research, vol.24, (summer): pp. 267-276.

Maijoor, S.J., 1996. Dutch accounting legislation and changes of organisational form: an efficient contracting perspective. Joumal of Accounting and Public Policy, vol. 15, no. 2, pp. 137-160.

Malmquist, D. 1990. Efficient contracting and the choice of accounting method in the oil and gas industry. Journal of Accounting and Economics, vol.12, no.1, pp.173205. 
Mazay, V., T. Wilkins, and I. Zimmer, 1990. Determinants of the choice of accounting for investments in associates. Paper presented at the 13th annual congress of the European Accounting Association in Budapest.

McNichols, M. and G.P. Wilson (1988). Evidence of eamings management from the provision for bad debts. Joumal of Accounting Research. vol. 26, (Supplement): pp.1-31.

Mellwig, W., A. Moxter, and D. Ordelheide, 1988. Einzelabschluß und Konzernabschluß, Beiträge zum neuen Bilanzrecht. Gabler, Wiesbaden.

Mertens, G.M.H., 1991. Accounting choice: Preliminary evidence on the effects of the introduction of accounting regulation in the Netherlands in 1971. European Accounting, vol. 3, no. 1, pp. 44-55.

Mertens, G.M.H. and H.F.D. Hassink, 1992. Using accounting accruals to assess the impact of earnings management. Paper presented at the 15th annual congress of the European Accounting Association in Madrid.

Mertens, G.M.H., 1995. The effect of two major financial accounting regulations on accounting method choice: the implementation of the Act on Annual Financial Statements in 1971 and the Fourth EC Directive in 1984 in the Netherlands. Paper presented at the 18 th annual congress of the European Accounting Association in Birmingham.

Mian, S.L. and C.W. Smith, 1990. Incentives for unconsolidated financial reporting. Joumal of Accounting and Economics, vol. 12, no.1, pp.141-171.

Moret en Limperg, 1984. New Dutch Legislation on Annual Reports. Moret \& Limperg Registeraccountants, Rotterdam.

Morse, D. and G. Richardson, 1983. The LIFO/FIFO decision. Journal of Accounting Research, vol.21, no. 1, pp.106-127.

Moyer, S.E., 1990. Capital adequacy ratio regulations and accounting choices in commercial banks. Joumal of Accounting and Economics, vol.12, no.2, pp.123-154.

Nagtegaal, J., 1991. Rechtspraak omtrent jaarrekeningen van ondernemingen in Nederland: 1971-1991, Doctoraalscriptie, Rijksuniversiteit Limburg, Maastricht.

Nobes, C. and R. Parker, 199l. Comparative International Accounting. Prentice Hall, Englewood Cliffs, New Jersey, Third edition. 
Parker, R. 1989. Importing and exporting accounting: the British Experience. In: International Pressures for Accounting Change (ed: A. Hopwood), pp. 7-31, Prentice Hall, Hertfordshire.

Philips, S., J. Zecher, 1981. The SEC and the Public Interest. MIT Press, Cambridge, Massachusetts.

Pincus, M. and C. Wasley, 1994. The incidence of accounting changes and characteristics of firms making accounting changes. Accounting Horizons, vol.8, no.2, pp.1-24.

Pourciau, S., 1993. Earnings Management and nonroutine executive changes. Journal of Accounting and Economics, vol. 18, no.3, pp. 317-336.

Press, E.G. and J.B. Weintrop, 1990. Accounting based constraints in public and private debt agreements: their association with leverage and impact on accounting choice. Yournal of Accounting and Economics, vol. 12, no.1, pp.65-95.

Pruijt, B., 1966. Het advies van de sociaal economische raad inzake de wetgeving over de jaarrekeningen van ondernemingen, Naamloze Vennootschap, no.6, pp.113118.

Puxty, A.G., H.C. Willmott, D.J. Cooper and T. Lowe 1987. Modes of regulation in advanced capitalism: locating accountancy in four countries. Accounting, Organisations and Society, vol.12, no.3, pp.273-191.

Raad van Nederlandse Werkgeversbonden (Counsil of Employers Federation), 1962. Verslaggeving, verantwoording en poorlichting door de besturen van Naamloze Vennootschappen. Raad van Nederlandse Werkgeversverbonden, Den Haag.

Raad voor de Jaarverslaggeving, 1981. Richtlijnen woor de Jaarrekening. Kluwer, Deventer.

Raad voor de Jaarverslaggeving, 1995. Richtlijnen voor de Jaarrekening. Kluwer, Deventer.

Rayburn, J., 1986. The association of operating cash flow and accruals with security returns. Journal of Accounting Research, vol. 24, (Supplement): pp.112-133. 
Rayburn, J. and S. Lenway, 1992. An investigation of the behavior of accruals in the semiconductor industry: 1985. Contemporary Accounting Research, vol. 8, no.l, pp. $237-251$.

Reglement, 1909. Reglement voor het opnemen van fondsen in de Prijscourant (Juni 1905). Vereeniging voor den Effectenhandel, Amsterdam.

Ronen, J. and S. Sadan, 1981. Smoothing income numbers; objectives means and implications. Addison-Wesley.

Ryan, B., R.W. Scapens, and M. Theobald, 1992. Research method and methodology in Finance and Accounting. Academic Press, London.

Samuelson, P.A. and W.D. Nordhaus, 1989. Economics. McGraw-Hill International, New York.

Sanders, P., G.L. Groeneveld en R. Burgert, 1975. De jaarrekening nieuwe stijl, commentaar op de Wet op de Jaarrekening. Samson Uitgeverij, Alphen aan de Rijn.

Schipper, K., 1989. Commentary on earnings management. Accounting Horizons, (December): pp.91-102.

Smith, C.W and R.L. Watts, 1982. Incentive Tax effects of US executive compensation plans. Australian Journal of Management, vol. 7, no.4, pp.39-157.

Sociaal Economische Raad, 1966. Advies inzake de wetgeving over de jaarrekening van ondemueming. Staatsuitgeverij, Den Haag.

Taylor, S.L., and R.B. Tress, 1988. The time series properties of Australian accounting data. Accounting and Finance, (May): pp. 17-28.

Prof. 'Telderstichting, 1962. Open ondememerschap, de groei van de onderneming en het vennootschapsrecht. Martinus Nijhoff, Den Haag.

Tempelaar, A.F., 1966. De jaarverslaggeving van Naamloze Vennootschappen. De Accountant, (Januari): pp.271-92.

Trueman, B. and S. Titman, 1988. An explanation for accounting income smoothing. Journal of Accounting Research, vol. 26, (Supplement): pp.127-139. 
Vecht, I.M., 1956. Jaarverslaggeving: een nieuw rapport. Maandblad voor Accountancy en Bedrijfshuishoudkunde, (Maart): pp.117-121.

Veld, C.H., 1989. Het gebruik van anti-verwateringsclausules in warrantovereenkomsten Maandblad voor Accountacy en Bedrijfseconomie. (Juli/Augustus): pp.284-291.

Watts, R.L., 1977, Corporate financial statements, A product of the market and political processes. Australian Joumal of Management. vol. 2, no. 2, pp.53-77.

Watts, R.L. and J.L.Zimmerman, 1978. Towards a Positive Theory of the Determination of Accounting Standards. The Accounting Review. vol. 53, no. 1, pp. 112-134.

Watts, R.L. and J.L. Zimmerman, 1986. Positive accounting theory. Prentice Hall, Englewood Cliffs, New Jersey.

Watts, R.L. and J.L. Zimmerman, 1987. Agency Theory Research in Accounting. In: Usefulness to Investors and Creditors of Information Provided by Financial Reporting, P.A. Griffin (ed.), FASB, Stamford, Connecticut, pp. 193-212.

Watts, R.L. and J.L. Zimmerman, 1990. Positive accounting theory: a ten year perspective. The Accouning Review, vol. 65, no. 1, pp. 131-156.

Wel, F. Van der, 1987. De motivering van stelselwijzigingen in de jaarrekening. Maandblad voor Accountancy en Bedrijfhuishoudkunde, (Mei): pp. 193-207.

Dr. Wiardi Beckman Stichting, 1959. De hervorming van de onderneming. Herziening van het vennootschapsrecht i.p.m. medezeggenschap in en toezicht op de onderneming. N.V. de Arbeiderspers, Amsterdam.

Wilson, G.P., 1986. The relative information content of accruals and cash flows: Combined evidence at the earnings announcement and annual report release date. Joumal of Accounting Research, no.24 (Supplement): pp.165-200.

Wilson, G.P., 1987. The incremental information content of the accrual and funds components of earnings after controlling for earnings. The Accounting Review, vol.62, no.2, pp.293-322.

Wolk, H., J. Francis, and M. Tearney, 1989. Accounting Theory: a conceptual and institutional approach. PWS Kent Publishers, Boston, Second edition. 
Wong, J., 1988. Economic incentives for the voluntary disclosure of current cost financial statements. Journal of Accounting and Economics, vol.10, no.2, pp.151-167. Zeff, S. A., 1978, The Rise of 'Economic Consequences'. Journal of Accountang, (December): pp. 56-63.

Zeff, S.A., F. v.d. Wel en C. Camfferman 1992. Company Financial Reporting: A historical and comparative study of the Dutch regulatory process. Elsevier Science Publishers, Amsterdam.

Zmijewski, M. and R. Hagerman, 1981. An income strategy approach to the positive theory of accounting standard setting choice. Joumal of Accounting and Economics, vol.3, no.2, pp.129-150. 


\section{Dutch Summary (samenvatting)}

Wet- en regelgeving zijn in Nederland in de afgelopen decennia fors uitgebreid en beinvloeden thans in sterke mate de praktijk van externe verslaggeving. Zo is wettelijk bepaald welke ondernemingen financiële informatie openbaar dienen te maken, welke informatie moet worden verstrekt en met welke frequentie. In deze dissertatie is getracht de invloed van een tweetal specifieke wetten op de praktijk van externe verslaggeving in Nederland empirisch te bepalen, te weten (1) de Wet op de Jaarrekening van Onderneming (1971) en (2) de vierde EEG-Richtlijn (geincorporeerd in Titel 8, 1984). Het onderzoeksthema van deze dissertatie is of en in welke mate de keuze van verslaggevingsregels door ondernemingen is beïnvloed door de implementatie van deze twee wetten op het terrein van de externe verslaggeving. De keuze van verslaggevingsregels behelst de selectie van waarderings- en presentatiegrondslagen door een onderneming uit de voor externe verslaggeving beschikbare totale verzameling van waarderings- en presentatiegrondslagen. Op drieërlei wijzen is getracht een bijdrage te leveren aan de bestaande economische literatuur op het gebied van externe verslaggeving. In de eerste plaats door middel van een empirische analyse en evaluatie van de regulering van externe verslaggeving. In de tweede plaats door het toetsen van een tweetal alternatieve (economische) theorieën met als doel een bijdrage te leveren aan de verdere ontwikkeling van een positieve (verklarende) theorie voor de keuze van verslaggevingsregels. In de derde plaats door gebruik te maken van twee verschillende onderzoeksmethoden teneinde hetzelfde fenomeen empirisch te toetsen en inzicht te krijgen in de gevolgde methoden.

Deze dissertatie hanteert een tweetal reeds gememoreerde onderzoeksmethoden die in de empirische literatuur wordt gesuggereerd om veranderingen in de externe financiële verslaggeving van ondernemingen vast te stellen:

(1) De eerste methode omvat het direct observeren van veranderingen in toegepaste waarderings- en presentatiegrondslagen (stelselwijzigingen): het opsporen en/of registreren van het aantal, de aard en de invloed van de wijzigingen op het vermogen en/of het resultaat.

(2) De tweede methode betreft het observeren van tijdreeksen van accounting accruals': het meten van de veranderingen in omvang en variabiliteit van accruals.

Door het toepassen van twee alternatieve onderzoeksmethoden is het mogelijk zowel de resultaten als ook de methoden te evalueren.

In hoofdstuk $l$ is een economische theorie geintroduceerd die het gedrag van ondernemingen op het terrein van de externe financiële verslaggeving verklaart. Het onderzoek naar de effecten van regulering richt zich op de aanbodzijde van de markt voor financiële informatie. Relevante economische theorieën bestuderen de 
rol van financiële informatie in economische verbanden en contracten, met name die tussen agenten (de ondernemingsleiding) en thun principalen (de aandeelhouders). Daarbij wordt tevens aandacht besteed aan de 'contracting cost' theorie. Deze theorie tracht bestaande (impliciete en expliciete) contracten en de hierop gebaseerde keuze van verslaggevingsregels mede te verklaren. Financiële informatie wordt hierbij beschouwd als een economisch goed. Het verstrekken hiervan gaat gepaard met kosten. Daarbij wordt een onderscheid gemaakt tussen een tweetal perspectieven, te weten "efficient contracting" en "opportunistic behaviowr". In het eerste geval kiest de ondermemingsleiding zodanig uit de tot haar beschikking staande verzameling van verslaggevingsregels ("accepted set") dat daarmee de welvaart van alle contractpartijen (en dus de waarde van de onderneming) wordt gemaximaliseerd. Wijzigingen binnen deze accepted set van verslaggevingsregels vormen aldus de weerslag van aanpassingen aan veranderende externe omstandigheden van de onderneming, die hiermee tracht haar maximale waarde te waarborgen. In het tweede geval wordt er expliciet van uitgegaan dat de ondememingsleiding eigen belang nastreeft. Hier wordt verondersteld dat de ondernemingsleiding aanpassingen binnen de accepted set van verslaggevingsregels doorvoert om zodoende haar eigen welvaart te vergroten. Dit kan maar hoeft niet altijd ten koste te gaan van de welvaart van de andere contractpartijen. Beide theoretische perspectieven zijn in het empirische deel van deze studie nader uitgewerkt en getoetst. (Additionele) wet- en regelgeving kunnen leiden tot aanpassingen van reeds bestaande en tevens toekomstige contracten, onder andere omdat zij restricties van de accepted set van verslaggevingsregels tot gevolg kunnen hebben. De mate van restrictie hangt af van de inhoud van de wet- en regelgeving, maar is tevens afhankelijk van ondernemingsspecifieke kenmerken en omstandigheden. Vanuit het perspectief van efficient contracting kan dit tot suboptimale contracten leiden, met als gevolg verminderde efficiency. Daar staat tegenover dat wet- en regelgevende instanties bestaande of nieuw te implementeren wet- en regelgeving rechtvaardigen vanuit de gedachte dat de bestaande wrijheid binnen de accepted set van verslaggevingsregels te groot is. Het reeds gememoreerde opportunistic behaviour perspectief sluit hierbij aan. (Additionele) wet- en regelgeving kunnen alleen dan effectief zijin als dergelijk opportunistisch gedrag kan worden ingeperkt. In deze dissertatie worden de effecten van wetgeving geanalyseerd in het kader van deze beide perspectieven.

Reeds eerder is in de Nederlandse literatuur aandacht besteed aan de inhoud van de (destijds) nieuwe wettelijke bepalingen. Onder meer werden de politieke en maatschappelijke achtergronden beschreven van met name de invoering van de WIO in 1971 en de vermeende effecten, voor zover die al verondersteld werden. Echter, nauwelijks is aandacht besteed aan onderzoek naar de werkelijke effecten op externe financiële verslaggeving van ondernemingen welke teweeg zijn gebracht 
door deze wetgeving. De steeds weer terugkerende suggestie dat de WJO slechts een codificatie was van de reeds door ondernemingen toegepaste exteme verslaggeving is nooit empirisch getoetst. Hoofdstuk 2 en de daarbij behorende appendices vormen de basis voor zowell de conceptuele als empirische analyse van deze dissertatie. Ten gevolge van de invoering van de WJO werden jaarrekeningen van de ondernemingen, welke onder het toenmalige regime van deze wet vielen, met ingang van het boekjaar 1971 voor het eerst onderworpen aan de nieuwe wettelijke vereisten. Alhoewel reeds sinds 1928 een artikel van kracht was voor de opstelling en publikatie van de jaarrekening (artikel $42 \mathrm{c}$ wetboek van Koophandel), kan worden gesteld dat de introductie van de WJO een belangrijke verandering teweeg heeft gebracht in het regulerende kader van de externe verslaggeving van ondernemingen in ons land. Dertien jaar later werden ondernemingen andermaal geconfronteerd met veranderende wettelijke bepalingen. Het betrof dit maal de implementatie van de vierde EEG-richtlijn in de Nederlandse wetgeving (Titel 8). De eisen met betrekking tot inhoud en opstelling van het jaarverslag werden verder aangescherpt met als doel Europese harmonisatie op het terrein van externe financiële verslaggeving te bewerkstelligen. In het tweede deel van hoofdstuk 2 worden de onderzoeksvragen ('research questions') gepresenteerd, welke zijn gebaseerd op de analyse van de inhoud van beide wetten. Deze vormen de basis voor het empirische deel van deze dissertatie, te weten hoofdstuk 3 en 4 . Voor de feitelijke toetsing van de hypothesen is gebruik gemaakt van een drietal verschillende datasets. Het betreft in alle gevallen jaarrekeninginformatie van Nederlandse naamloze vennootschappen, die gedurende de onderzochte periode genoteerd waren aan de Amsterdamse effectenbeurs. Uitgezonderd zijn banken en financiële instellingen omdat zij onder een afwijkend wettelijk regime vallen. De eerste set, bestaande uit de jaarrekeninginformatie van $64 \mathrm{NV}$ 's over de periode 1965 tot 1976 , is gebruikt om hypothesen te toetsen betreffende de invloed van de WJO. Deze set bevat zowel tijdreeksen van stelselwijzingen (wijzigingen in waarderings- en presentatiegrondslagen) als tijdreeksen van accruals, winsten en kasstromen. Voor de toetsing van hypothesen die betrekking hebben op de implementatie van de vierde EEG-richtlijn is gebruik gemaakt van een tweetal verschillende datasets. Een set bestaat uit alle stelselwijzingen van 107 beursgenoteerde NV's in de periode 1977-1986. Deze dataset is afkomstig van Hoogendoorn (1990). De andere set bevat informatie over actruals van 1975 tot 1990 en is afkomstig van de CBS NVbeursstatistieken.

In hoofdstuk drie worden de resultaten gepresenteerd van de empirische analyse gebaseerd op de eerste onderzoeksmethode; de observatie van wijzigingen in de toegepaste waarderings- en presentatiegrondslagen (stelselwijzigingen). De analyse omvat informatie over het aantal, de aard en de invloed van wijzigingen in de 
toegepaste waarderings- en presentatiegrondslagen van ondernemingen, welke zijn doorgevoerd in periode voor en na de implementatie van de WJO en Titel 8. De resultaten wijzen uit dat in 1971 en 1984 een significante toename van het aantal wijzigingen heeft plaatsgevonden. Het merendeel van deze wijzigingen heeft betrekking op wijzigingen in presentatiegrondslagen (disclosure rules). Het aantal wijzigingen dat invloed heeft op vermogen en/of resultaat is in de perioden na 1971 en 1984 niet significant toegenomen in vergelijking met de beide perioden hieraan voorafgaand. De algemene conclusie is dat ondememingen met name tijdens de implementatie van beide wetgevingen intensiever gebruik hebben gemaakt van stellselwijzigingen. Bij de analyse van de WJO blijkt evenwel dat het aantal en de invloed van wijzigingen met een invloed op het vermogen en/of resultaat na 1971 well significant is toegenomen. Verder zijn er meer wijzigingen met een positief effect op het vermogen en resultaat waargenomen dan wijzigingen met een negatief effect op het vermogen en/of resultaat. De resultaten in het geval van Titel 8 wijzen uit dat het effect van de wetgeving op de omvang en de invloed van stelselwijzigingen minder is in vergelijking tot de WJO. Het aantal en de invloed van de wijzigingen na 1984 is niet toegenomen vergeleken met de periode ervoor. Ook de richting van de invloed op het vermogen en/of resultat (positief/negatief) veranderde niet significant. Significante resultaten leveren de analyse van ondernemingskenmerken op. Hieruit blijkt dat: (1) grote ondernemingen relatief meer wijzigingen doorvoerden die invloed hebben op het vermogen en/of resultaat dan middelgrote of kleine ondernemingen, maar dat de effecten van de implementatie van de wetgeving op het externe verslaggevingsgedrag van kleine en middelgrote ondernemingen groter zijn (sterkere toename van het totale aantal wijzigingen na 1971 en 1984); (2) de effecten van implementatie van de wetgeving op het externe verslaggevingsgedrag van ondernemingen met een hogere vreemd/eigen vermogen ratio groter zijn (significante toename van het aantal wijzigingen met invloed op het vermogen en/of resultaat na implementatie) in vergelijking met ondememingen met een lagere vreemd/eigen vermogen ratio; (3) de effecten van implementatie van de wetgeving op het externe verslaggevingsgedrag van ondememingen blijken te verschillen per bedrijfstak.

In hoofdstuk vier wordt de empirische analyse voortgezet door gebruik te maken van de tweede onderzoeksmethode: observatie van de tijdreeksen van accruals, waarbij de winsten en kasstromen nader worden bestudeerd. Hierbij zijn met name wijzigingen in het niveau (level) als veranderingen in de variabiliteit van accruals van belang. Accruals zijn gedefinieerd als het verschil tussen de winst van een onderneming en de kasstroom uit operationele activiteiten. Anders gezegd, accruals vormen het resultaat van de boekhoudkundige vertaalslag van kasstromen (uit. operationele activiteiten) naar de uiteindelijk gerapporteerde nettowinst. Een 
belangrijk onderscheid dient te worden gemaakt tussen 'nondiscretionary' (niet discretionaire) en "discretionary" (discretionaire) accruals. De eerste categorie omvat accruals die niet of slechts op lange termijn beïnvloedbaar zijn door de ondernemingsleiding. De tweede categorie omvat accruals die well beïnvloedbaar zijn door de ondernemingsleiding. $\mathrm{Zij}$ worden mede bepaald door de mate van vrijheid (discretie) die de ondernemingsleiding heeft bij het bepalen van het financiële resultaat. Deze discretie kan door de ondernemingsleiding worden aangewend om de te rapporteren winst te werhogen c.q. te verlagen. Indien dit bewust gebeurt is er sprake van 'earnings management'. Verwacht wordt dat de invoering van additionele wetgeving zal leiden tot een toename van de nondiscretionary accnials. Dit zal leiden tot een hoger niveau alsmede een lagere variabiliteit van de totale accruals en dientengevolge een hogere variabiliteit van de winsten. Aldus kan worden verwacht dat winstegalisatie ('income smoothing'), als een specieke vorm van earnings management, wordt bemoeilijkt door additionele wetgeving. Teneinde accruals vast te stellen zijn een tweetal methoden gebruikt. Bij de eerste methode wordt uitgegaan van de totale accruals. Een wijziging van de totale accruals in 1971 en 1984 vergeleken met de voorgaande jaren is toe te schrijven aan een verandering in de nondiscretionary accruals. De resultaten wijzen uit dat (1) het niveau van de totale accruals significant toenam (met name in 1971 en 1984), (2) de variabiliteit van de totale accruals na 1971 wel, maar na 1984 niet afnam en (3) de variabiliteit van winsten is toegenomen. Bij de tweede methode om het effect van wetgeving op de accruals te bepalen is gebruik gemaakt van een regressiemodel. Hierbij worden de totale aconals opgesplitst in discretionary en nondiscretionary accruals, waardoor het effect van de wetgeving beter is te bepalen. De dummy-variabele 'wetgeving', die de effecten van de WJO en Titel 8 in het regressiemodel vertegenwoordigt, is in beide gevallen significant en negatief. Dit laatste duidt ex op dat nondiscretionary accruals na 1971 en 1984 zijn toegenomen. Tevens blijkt uit de resultaten dat de variabiliteit van discretionary accruals toeneemt na de implementatie van de beide wetten, hetgeen duidt op een inperking van de keuzemogelijkheden c.q. wijzigingsmogelijkheden van de toe te passen waarderings- en presentatie-grondslagen door ondememingen. De analyse levert ook verschillen op tussen de effecten van de WJO en Titel 8 . Ten eerste is de toename van het niveau van de totale accruals in het geval van Titel 8 alleen significant in 1984, maar niet in de jaren daama. Ten tweede is de toename van de variabiliteit van discretionary accruals alleen significant in het geval van de WJO. Tenslotte is ook bij de tweede onderzoeksmethode nagegaan of de invloed van de wetgeving mede afhankelijk is van ondernemingskenmerken. Hieruit bleek evenals in hoofdstuk drie, dat de ondernemingsomvang, de verhouding vreemd/eigen vermogen en de bedrijfstak van invloed zijn op het niveau en de variabiliteit van discretionary en nondiscretionary accruals alsmede de variabiliteit van gerapporteerde winsten. 


\section{Curriculum Vitae}

Gerard Mertens werd geboren op 4 juni 1964 in Heerlen. In 1982 slaagde hij voor zijn eindexamen Atheneum aan de Scholengemeenschap Sintermeerten te Heerlen. Hij studeerde tussen 1983 en 1988 toegepaste economische wetenschappen en behaalde september 1988 zijn doctoraalexamen economische geografie aan Katholieke Universiteit Nijmegen.

In oktober 1988 trad hij in dienst als assistent in opleiding bij de sectie Berichtgeving en Accountancy van de Universiteit Maastricht. Van 1992 tot en met 1995 was hij als universitair docent verbonden aan deze sectie. Sinds 1990 is hij als secretaris en onderzoeker verbonden aan de Stichting Academic Research, te Maastricht.

Met ingang van 1996 is hij verbonden als research fellow aan de sectie Kosten, Waarden en Winst van de Katholieke Universiteit Brabant. Tevens is hij sinds 1996 als projectleider werkzaam voor het Limperg Instituut te Amsterdam in het kader van het onderzoeksproject "Kwaliteit van de Externe Verslaggeving in Nederland". 